

\section{Desarrollo de microdispositivos}

para análisis de células y biomoléculas

\section{Gustavo Iván Rosero Yánez}

Tesis presentada para aspirar al grado

de:

Doctor en Ingeniería, mención

Materiales

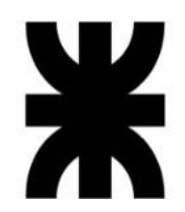

Facultad

Regional La

Plata

Universidad

Tecnológica

Nacional

2021 
Este trabajo se llevó a cabo en la Universidad Tecnológica Nacional, Facultad regional Haedo Centro de Ingeniería de Recubrimientos Especiales y Nanoestructuras (IREN) bajo la dirección del Dr. Carlos Lasorsa, la codirección de la Dr. Maximiliano Pérez y Dra. Maria Jose Diueguez.

* Se presenta a la consideración de las autoridades de la Universidad Tecnológica Nacional para aspirar al grado académico de Doctor en Ingeniería, mención Materiales. 


\section{Agradecimientos}

Quiero agradecer y dedicar este trabajo a mis padres Iván y Mónica, porque cuando anuncie qué quería hacer cuando termine el colegio, recibí su apoyo incondicional y categórico, a pesar de que ellos (como yo) sólo tenían una idea vaga de lo que es ser un científico. Nunca, recibí de su parte una negativa a pesar de los fracasos en el camino. A mi hermana Jessica y su familia por el todo cariño y apoyo emocional en todo momento.

A mi mejor amiga y esposa Ana por acompañarme incondicionalmente por este camino, nunca me alcanzaran las palabras ni cien vidas para agradecerte por todo tu apoyo y ayuda.

A mis tíos Lucía, Alfonso y Verónica por ser como mis segundos padres. Gracias por sus consejos y por su apoyo incondicional.

A mi familia política (Elizabeth, Julio, Michelle) por todas sus charlas y consejos.

A mi familia en Alemania: Juan Pablo Yánez, Hans y familia por el apoyo en la villa de Gottenheim.

A Mario y Mauricio mis amigos de toda la vida.

A mis amigos: Yessi y Cristian, Marina Sierra, Natalia Buorguiñon, Anahí San Luis, Carol Olmos, Igor Sá, Tamara Fernández y Jorge, Andrea Vaca, Johannes Burger, Pamela Schriber, Julia Pinter, Juan Mahecha y Paola Pineda, Luis Alfredo Martínez, Darío Ruarte, Gisela Pattarone. Alberto Roura, Wilson Tapia, Sofía Moya, Janeth Barahona.

A mis amigos de laboratorio: Geovanni, Camilo, Daniel, Israel, Tania, Andrea, Inmanol, Marisol Davobe, Felicita Pilz,

A los Dres. Carlos Lasorsa, Maximiliano Pérez y las Dras. Betiana Lerner, María José Diéguez, por todo el apoyo, consejos y aún más importante por compartir su conociendo, experiencias, anécdotas para finalizar el presente trabajo de tesis. 
A los Dres.: Alexis Debut, Luis Cumbal, Roland Mertelsmann y la Dra. Marie Follo, por todo el apoyo científico, técnico y humano brindado durante las estancias internacionales.

Mi agradecimiento al Consejo Nacional de Investigaciones Científicas y Técnicas (CONICET) por la beca que me permitió realizar el doctorado.

Agradezco al Instituto Nacional de Tecnológica Agropecuaria y al Instituto de Genética y al Dr. Francisco Sacco por permitirme desarrollar el proyecto aquí propuesto. Así como al grupo de trabajo Fernanda, Lorena, Martín, Romina.

Finalmente, a todos los que hizo falta mencionar muchas gracias por su apoyo. 


\section{Publicaciones}

A continuación, se detallan los trabajos publicados en revistas internacionales con referato y presentaciones a congresos realizadas durante esta tesis.

1. Gustavo Rosero, Gisela Pattarone, Ana Peňaherrera, Julia Felicitas Pilz, Joschka Bödecker, Betiana Lerner, Roland Mertelsmann, Maximiliano Perez, and Marie Follo. (2020), Metronomic doses and drug schematic combination response tested within microfluidic models for the treatment of breast cancer cells (JIMT1). Preprint article. Submit bioRxiv. https://www.biorxiv.org/content/10.1101/2020.07.16.188748v1

2. Camilo Perez, Anahi Sanluis-Verdes, Ariel Waisman, Antonella Lombardi , Gustavo Rosero , Alejandro La Greca, Shekhar Bhansali , Natalia Bourguignon , Carlos Luzzani, Maximiliano Perez, Santiago Miriuka, and Betiana Lerner. (2020). Single cell transfection of human induced pluripotent stem cells using a droplet-based microfluidic system. Preprint article. Submit bioRxiv. https://www.biorxiv.org/content/10.1101/2020.06.09.143214v1

3. Gustavo Rosero, Dario Duarte, Ana Peňaherrera, Dennise Raith, Julia Pinter, Joschka Bödecker, Betiana Lerner, Roland Mertelsmann, Maximiliano Perez, and Marie Follo. (2020), Evaluating Primary T-cell proliferation in microfluidic devices through machine learning image analysis. 2020 Submitted: Rsc Advances

3. Gustavo Rosero, Carol M. Olmos, Tamara Fernandez Cabada, Ross Booth, Manuel Der, Juan M. Cabaleiro, Alexis Debut, Luis Cumbal, Maximiliano S. Perez and Betiana Lerner. (2020), Hybrid microchannel-solid state micropore device for fast and optical cell detection. RSC Adv. 10, 5361-5370 (2020). DOI: 10.1039/c9ra09939. https://pubs.rsc.org/en/content/articlelanding/2020/ra/c9ra09939e\#!divAbstract

4. Rosero Gustavo, Carol M Olmos, Ana Peñaherrera, Karla Vizuete, Darío Ruarte, Marie Follo, Andrea Vaca, Carlos R Arroyo, Alexis Debut, Luis Cumbal, 
Maximiliano S Pérez, Betiana Lerner, Roland Mertelsmann. (2019), Costeffective fabrication of photopolymer molds with multi-level microstructures for PDMS microfluidic device manufacture. RSC Adv. 10, 4071-4079. DOI: 10.1039/c9ra07955f.

https://pubs.rsc.org/en/content/articlelanding/2020/ra/c9ra07955f\#!divAbstract.

5. Rosero Gustavo, Olmos, Carol M., Peñaherrera, Ana, Vaca Andrea, Vizuete, Karla, Debut Alexis Cumbal Luis, Masiero Diana, Hernandez Maria I., Lasorsa Carlos, Pérez Maximiliano S., Lerner Betiana. (2019), Influence of thermal treatment and aging time on the stability and swelling properties of nano/micronsized polymeric spheres for improved oil recovery application. Journal of applied polymer science. vol.136 n41. 0021-8995. DOI: 10.1002/app.48030. https://onlinelibrary.wiley.com/doi/abs/10.1002/app.48030.

6. Bourguignon N., Olmos C.M., Sierra Rodero, M., Peñaherrera A., Rosero Gustavo, Pineda P., Vizuete K., Arroyo C.R., Cumbal L., Lasorsa C., Perez M.S. and Lerner B. (2018), Accessible and Cost-Effective Method of PDMS Microdevices Fabrication Using a Reusable Photopolymer Mold. J. Polym. Sci. Part B: Polym. Phys., 56: 1433-1442. doi:10.1002/polb.24726. DOI: 10.1002/polb.24726.

https://onlinelibrary.wiley.com/doi/abs/10.1002/polb.24726

7. Olmos Carol M., Vaca Andrea, Rosero Gustavo, Peñaherrera Ana, Perez Camilo, De Sá Carneiro Igor, Vizuete Karla, Arroyo Carlos R., Debut Alexis, Pérez Maximiliano S., Cumbal Luis, Lerner Betiana. (2019), Epoxy resin mold and PDMS microfluidic devices through photopolymer flexographic printing plate. Sensors and Actuators Biochemical. Elsevier Science Sa. vol.288 n . p742 - 748. issn 0925-4005. DOI: 10.1016/j.snb.2019.03.062.

https://www.sciencedirect.com/science/article/abs/pii/S0925400519304198

8. Der Manuel; Olmos Carol, Rosero Gustavo, Santizo Itzel, Fernandez Tamara, Dieguez Maria, Sacco Francisco, Granell Pablo, Golmar Federico, Lerner Betiana, Lasorsa Carlos, Perez Maximiliano. (2018), Caracterización del proceso de fabricación de macroporos sobre sustrato de silicio por método 
electroquímico. Revista Materia.: Univfed Rio De Janeiro. vol.23 n².15177076. DOI: 10.1590/s1517-707620180002.046.

https://www.scielo.br/scielo.php?pid=S1517-

$\underline{70762018000200536 \& \text { script=sci_abstract } \& \text { tlng=es }}$

9. Diéguez María José, Petignat Camila, Ferella Luciana, Fiorentino Gabriela, Silva Martha, Dabove Marisol Alicia, Rosero Gustavo, López Micaela, Pergolesi María Fernanda, Ingala Lorena, Cuyeu Alba Romina, Sacco Francisco. (2018), Mapping a gene on wheat chromosome 4BL involved in a complementary interaction with adult plant leaf rust resistance gene LrSV2. Theoretical And Applied Genetics. Springer. vol.131 n 11. p2333 - 2344. issn 0040-5752. https://link.springer.com/article/10.1007/s00122-018-3155-X

10. Rosero Gustavo, Peñaherrera Ana, Olmos Carol, Boschan Alejandro, Granel Pablo, Golmar Federico, Lasorsa Carlos, Lerner Betiana, Perez Maximiliano. (2018), Design and analysis of different models of microfluidic devices evaluated in enhanced oil recovery (EOR) assays. Revista Materia.: Univfed Rio De Janeiro.vol.23 $n^{\circ} 2 . p$ issn 1517-7076.

https://www.scielo.br/scielo.php?pid=S1517$\underline{70762018000200538 \& \text { script }=\text { sci_abstract }}$

11. Peñaherrera A., Payés C., Sierra Rodero M., Vega M., Rosero Gustavo., Lerner B., Helguera G., Pérez M.S. (2016), Evaluation of cell culture in microfluidic chips for application in monoclonal antibody production. Microelectronic Engineering. Elsevier Science Bv. vol.158 nº p126 - 129. issn 0167-9317. https://www.sciencedirect.com/science/article/abs/pii/S0167931716301861

Durante este trabajo de tesis se realizaron 11 presentaciones a congresos, de los cuales 5 fueron congresos internacionales. 


\section{Objetivos}

En el presente trabajo de tesis se desarrollarán microcanales basados en canales de microfluídica, utilizando la ingeniera de materiales para prescindir de una sala limpia. El novedoso procedimiento utilizará un fotopolímero y una resina para la fabricación de microcanales. Los microdispositivos fabricados serán empleados para el sensado de células y biomoléculas.

Para el desarrollo de este objetivo general, se plantearon los siguientes objetivos específicos:

1. Fabricar dispositivos de microfluídica de polidimetilsiloxano (PDMS), empleando una resina epóxica.

2. Fabricar microporos mediante el método químico utilizando obleas de silicio cristalino.

3. Sensar ópticamente líneas celulares utilizando dispositivos de microfluídica fabricados con polidimetilsiloxano (PDMS) en los cuales se incluirá un microporo.

4. Analizar la muerte celular de células cancerígenas expuestas a quimioterapéuticos a través del sensado de biomoléculas en dispositivos de microfluídica.

5. Desarrollar un dispositivo de microfluídica para electroforesis de marcadores moleculares de $\mathrm{ADN}$ asociados a la resistencia de la roya de la hoja en trigo. 


\section{Resumen}

En la última década, los dispositivos de microfluídica han desempeñado un papel importante en muchos procesos biológicos, químicos, y aplicaciones de ingeniería ${ }^{1}$. Con esta consigna, en este trabajo de tesis se han desarrollado exitosamente dispositivos de microfluídica, los cuales fueron empleados para el sensado óptico de células con un microporo inmerso en estado sólido fabricado por un método químico. Además, se estudió la muerte celular con medicamentos quimioterapéuticos a través de la fluorescencia de las biomoléculas celulares para identificar tipos de muerte celular.

Es destacable que en este trabajo de tesis se desarrolló un método de fabricación de dispositivos de microfluídica, prescindiendo del acceso a un cuarto limpio (cleanroom), de tal manera que se posibilita la inclusión de la microfluídica prácticamente en cualquier laboratorio.

Varios diseños fueron fabricados e investigados para evaluar la capacidad de la resina epóxica para para obtener réplicas en polidimetilsiloxano (PDMS) para ensamblar los dispositivos de microfluídica. Esta capacidad para transferir el diseño desde la resina epóxica hacia el PDMS fue verificada mediante la caracterización con microscopia electrónica.

Además, se logró fabricar un microporo de estado sólido e integrarlo en un dispositivo multicapa de microfluídica. Este dispositivo fue utilizado para sensar ópticamente las células mediante la adquisición y análisis de imágenes, demostrando ser un método muy bueno y asequible para la detección y el conteo de células.

Los dispositivos de microfluídica también permitieron identificar tipos de apoptosis celular ocasionado por la exposición a la quimioterapia utilizada comúnmente en células del cáncer mama. Alrededor de 7000 imágenes fueron analizadas, lográndose identificar biomoléculas implicadas en la autofagia, vialidad celular, apoptosis programada y no programada.

\footnotetext{
${ }^{1}$ Kong, T., Shum, H. C. \& Weitz, D. A. The Fourth Decade of Microfluidics. Small 16, 2000070 (2020).
} 
Por otro lado, se desarrollaron varios microcanales que fueron diseñados, contrastados y estudiados para realizar electroforesis de marcadores moleculares de ADN para estudiar genes de resistencia a la roya de la hoja del trigo. 


\section{Abreviaturas}

ADN: $\quad$ Ácido Desoxirribonucleico

AFM: $\quad$ Microscopio de fuerza atómica

AG: $\quad$ Autofagia

AP: $\quad$ Apoptosis programada caspasa

ARN: $\quad$ Ácido Ribonucleico

ASR: $\quad$ Resstencia en todos los estadíos

BC: $\quad$ Cáncer de mama humano

BCC: Células de cáncer de mama

CE: Electroforesis Capilar

CTAB: Bromuro de cetiltrimetilamonio

CVD: Deposición de vapor químico

DEP: Dielectroforesis

DI: $\quad$ Agua desionizada

DLD: Desplazamiento lateral determinista

DMEN: Medio de águila modificado

DOX: Doxorrubicina

E: $\quad$ Campo eléctrico

ED: Diodo, electroquímico

EOF: Flujo electroosmótico

ERmold: Resina epóxica reutilizable

FIB: $\quad$ Haz de iones enfocado

Fmold: Fotopolímero flexográfico

GFP: $\quad$ Proteína fluorescente verde

HVPS: Fuentes de alto voltaje

HEK: Células embrionarias de riñón humano

HR: Respuesta Hipersensible

LC: $\quad$ Viabilidad celular

PACVD: Deposición química por vapor asistida por plasma

PC: $\quad$ Policarbonato

PCR: Reacción en cadena de la polimerasa

PFF: $\quad$ Fraccionamiento de Flujo de cizalla

PI: $\quad$ Yoduro de Propidio

PMMA: Polimetilmetacrilato

PTX: Paclitaxel

SD: Desviación estándar

SDS: Dodecilsulfato sódico

SEM Microscopía electrónica de barrido

TIL: $\quad$ Capa térmica de imágenes

VIS-UV: Visible-ultravioleta

D: $\quad$ Coeficiente de difusión

LDM: Quimioterapia dosis bajas

LOC: Lab-on-a-Chip

MEMS: Sistemas microelectromecánicos

PDMS: Poli-dimetilsiloxano

Pe: $\quad$ Número de Péclet

PEG: $\quad$ Polietilengrlicol

PET: Polietilentereftalato

$\boldsymbol{\mu T A S :} \quad$ Microsistemas de análisis 


\section{Índice de Contenidos}

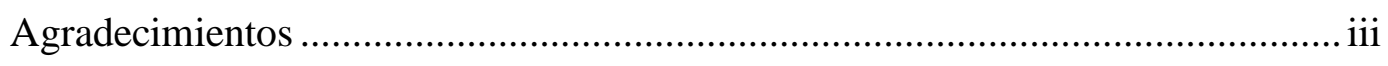

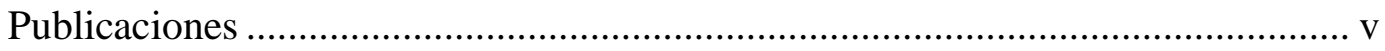

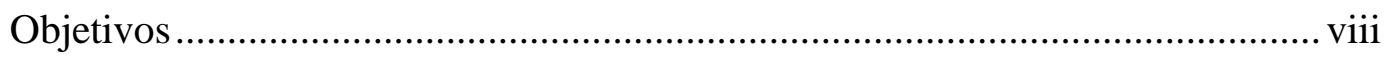

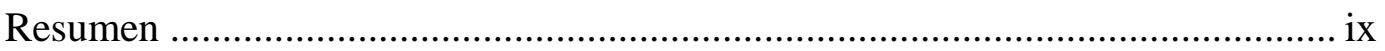

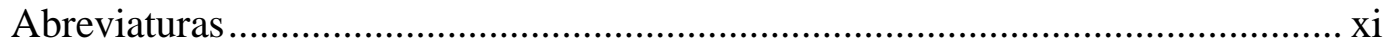

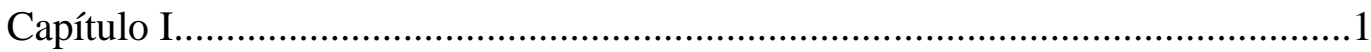

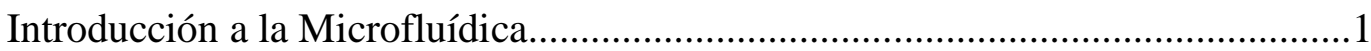

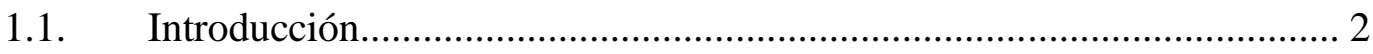

1.2. Beneficios de la miniaturización............................................................... 3

1.3. Beneficios de la automatización e integración............................................. 4

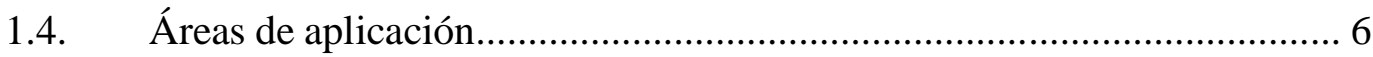

1.5. Conceptos Fundamentales y Física de la microfluídica en estudios

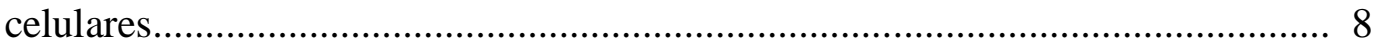

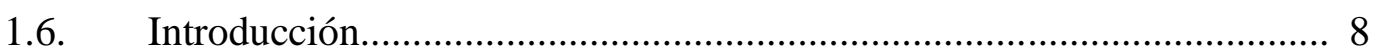

1.7. Viscosidad en los fluidos y en las células................................................ 9

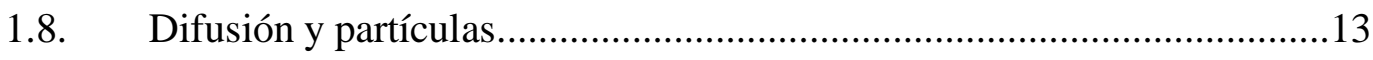

1.9. Efectos Hidrodinámicos en los microcanales....................................... 15

1.10. Momentum y limite de la trasferencia de masa entre las capas de un fluido. .15

1.11. Ley de Pascal y ley de Laplace............................................................ 17

1.12. Conservación de energía (ecuación de Bernoulli).................................. 18

1.13. Efecto de las fuerzas hidrodinámicas sobre la Cinética de unión de

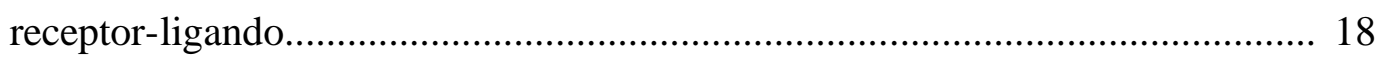

1.14. Fabricación de dispositivos de microfluidíca........................................ 19

1.15. Referencias................................................................................ 21

1.16. Suplementario S1 ..................................................................... 27 
Capítulo II.

Molde de resina epóxica y dispositivos de microfluídica de PDMS mediante una placa de un fotopolímero de impresión flexográfica......................................... 28

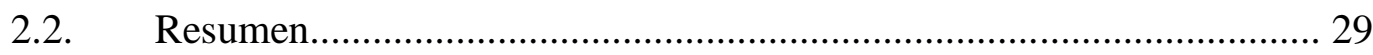

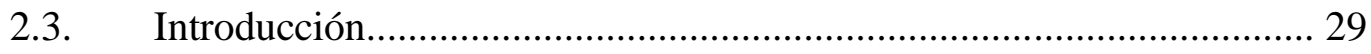

2.4. Materiales y métodos...................................................................... 30

2.4.1 Fabricación de dispositivos de microfluidos PDMS.............................. 30

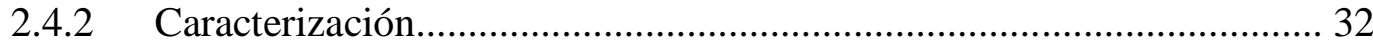

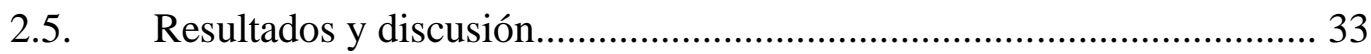

2.5.1 Replicación de características........................................................... 33

2.5.2 Fidelidad de la replicación de Fmold/ERmold y durabilidad de Fmold.

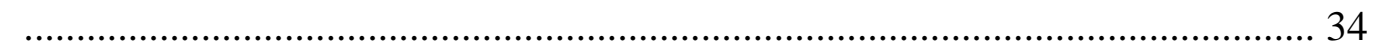

2.5.3 Fidelidad de replicación ERmold / PDMS y durabilidad Ermold.......... 36

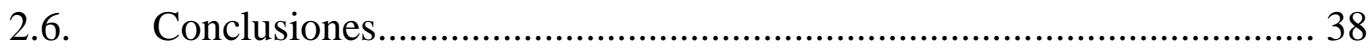

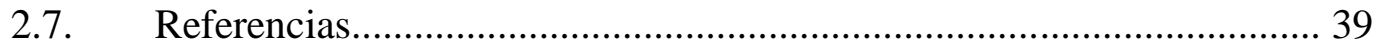

Capítulo III.

Caracterización del proceso de fabricación de microporos sobre sustrato de silicio por método electroquímico ........................................................................... 42

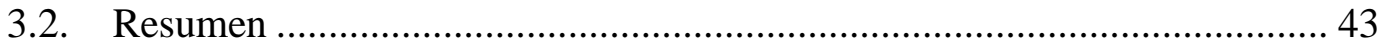

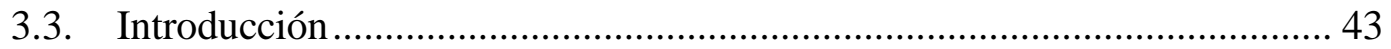

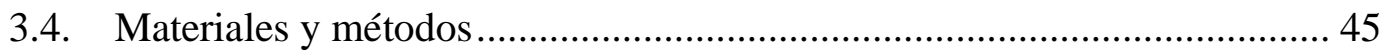

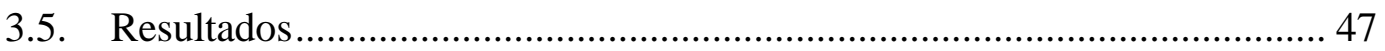

3.5.1 Caracterización del proceso de fabricación de poros: $\mathrm{HCl}, \mathrm{KOH} 4 \mathrm{M}, 84$

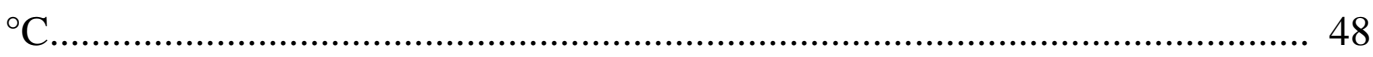

3.5.2 Caracterización del proceso de fabricación de poros: $\mathrm{HCOOH}, \mathrm{KOH} 4 \mathrm{M}$,

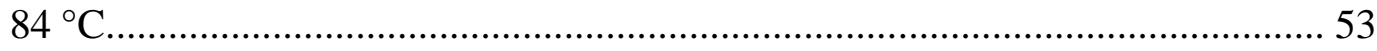

3.5.3 Caracterización del proceso de fabricación de poros: $\mathrm{HCOOH}, \mathrm{HCl}, \mathrm{KOH}$

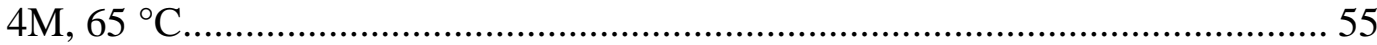

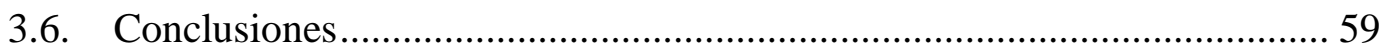

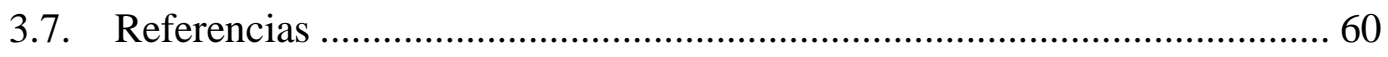


Dispositivo híbrido de microfluídica de estado sólido para la detección rápida y óptica de células

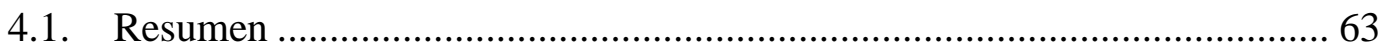

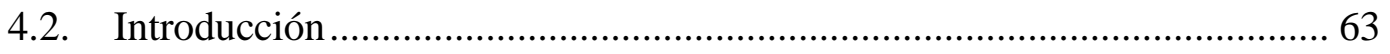

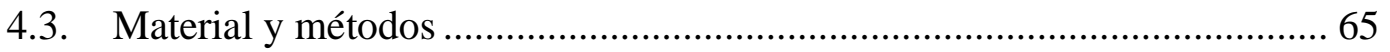

4.3.1. Fabricación y caracterización de microporos ....................................... 65

4.4. Fabricación del dispositivo de microfluíca la para detección visual de células y el conteo celular

4.4.1. Fabricación de microcanales de PDMS e integración del microporo. ... 67

4.4.2. Línea celular, cultivo celular y transfección transitoria. ..........................6 68

4.5. Montaje de configuración y detección/cuantificación visual. .................... 69

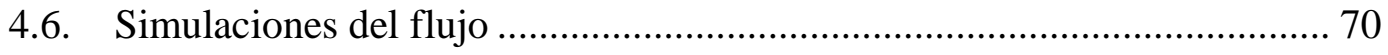

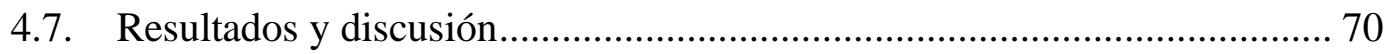

4.7.1. Fabricación de microporos: influencia de las variables de control ........ 70

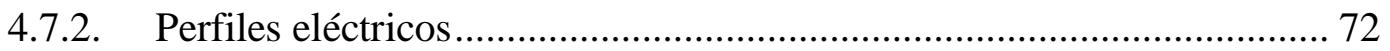

4.7.1. Aplicación: detección y conteo de células............................................ 75

4.7.2. Simulación: determinación de zonas objetivo de enfoque .................... 77

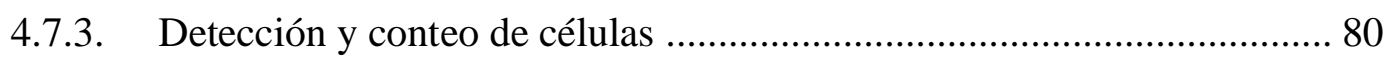

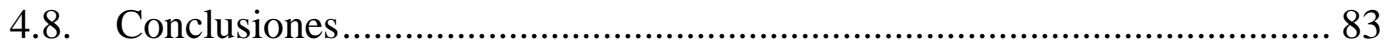

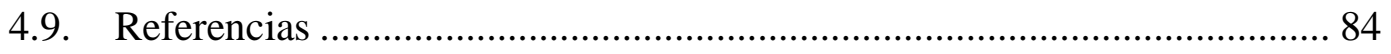

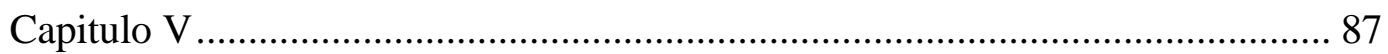

Dosis metronómicas y respuesta a la combinación esquemática de fármacos probadas en modelos de microfluídica para el tratamiento de células de cáncer de

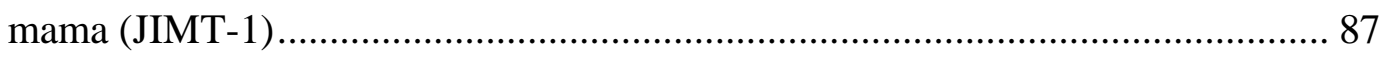

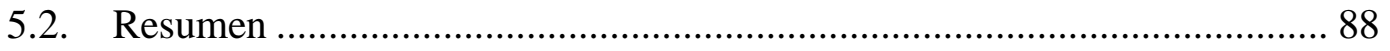

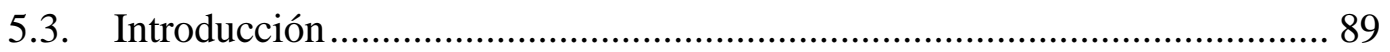

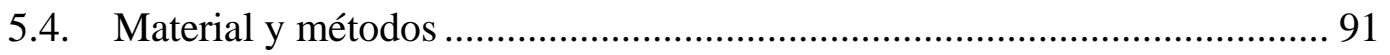

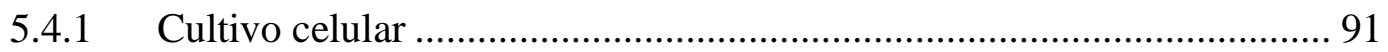

5.4.2 Modos de muerte celular y caracterización .......................................... 91

5.4.3 Tratamiento combinado de células con paclitaxel, doxorrubicina y

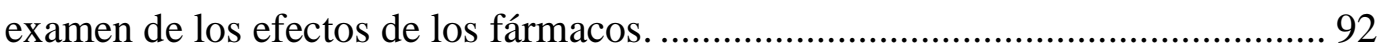


5.4.4 Tratamiento con paclitaxel metronómico y evaluación de los efectos de

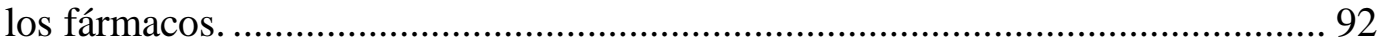

5.4.5 Procesamiento y cuantificación de imágenes ....................................... 92

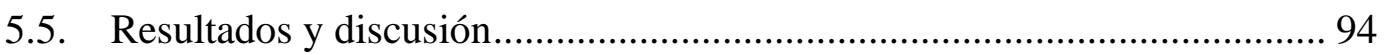

5.5.1 Seguimiento del crecimiento de las células de cáncer de mama dentro de las cámaras de cultivo celular. 94

5.5.2 Efecto de los esquemas de fármacos de paclitaxel, doxorrubicina y la

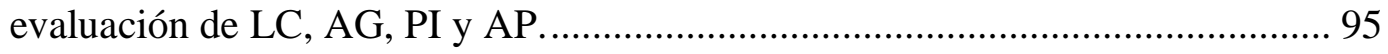

5.5.3 Efecto del tratamiento metronómico con paclitaxel. ............................. 97

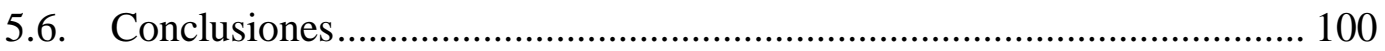

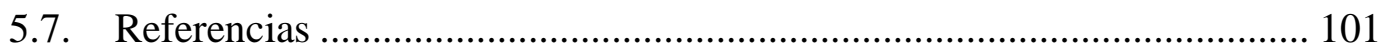

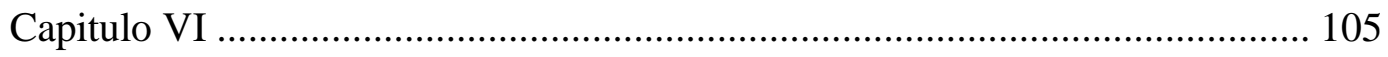

Desarrollo de microcanales para electroforesis de ADN, aplicación al estudio de genes de resistencia a roya de la hoja de trigo utilizando marcadores moleculares

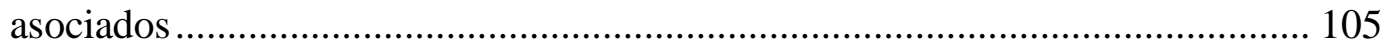

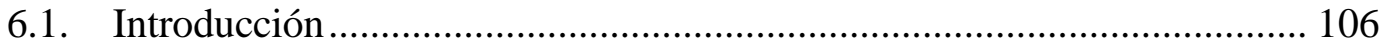

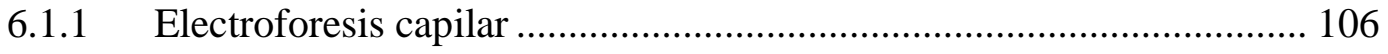

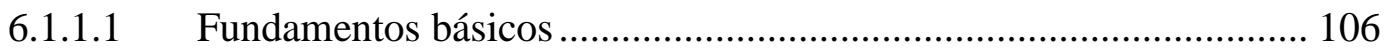

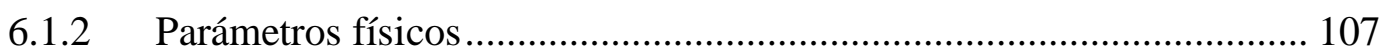

6.1.2.1 Parámetros que afectan a la separación. ......................................... 109

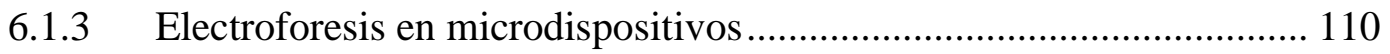

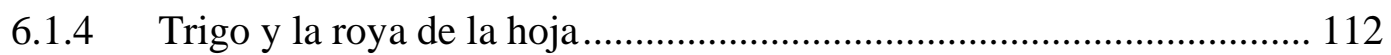

6.1.5 Mecanismos genéticos de resistencia de la planta ............................. 113

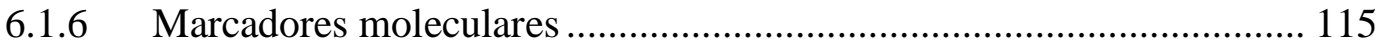

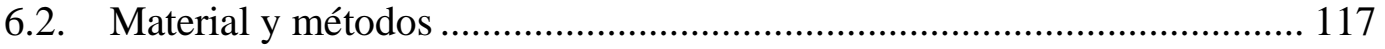

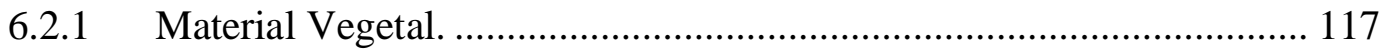

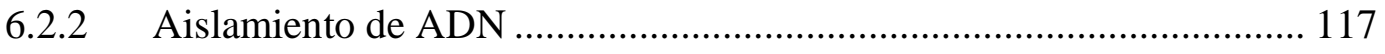

6.2.3 Amplificación de marcadores de ADN por PCR................................. 118

6.2.4 Diseño de los microdispositivos para la electroforesis ....................... 118 
6.2.5 Fabricación de los dispositivos en PDMS ........................................ 119

6.2.6 i) Ensamblaje del dispositivo en PDMS en forma de cruz .................. 121

6.2.7 ii) Ensamblaje del dispositivo en vidrios ........................................ 122

6.2.8 Visualización de productos de PCR …................................................ 123

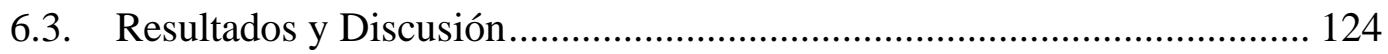

6.3.1 Fabricación de los dispositivos para electroforesis. ........................... 124

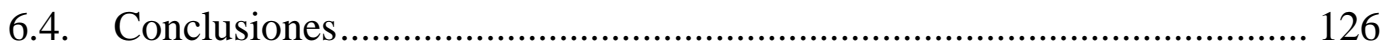

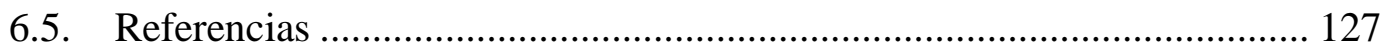

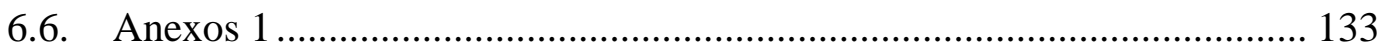

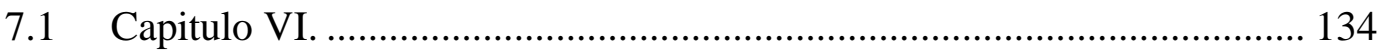

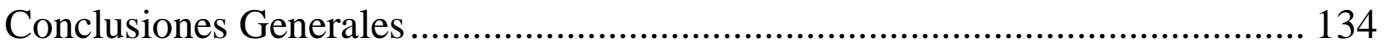




\section{Índice de Figuras}

Figura. 2.1. Dispositivo de microfluídica, que se utiliza para estudiar el crecimiento de poblaciones microbianas, se observan canales complejos. Este dispositivo incluye una alta densidad de válvulas neumáticas. Los colores son tintes introducidos para trazar los canales 4

Figura. 2.2. Dispositivo de microfluídica, que realiza pruebas de inmunoensayos que se utilizan ampliamente en medicina e investigación biológica. Los tornillos en este sistema (marcado con círculos punteados) actúa como válvulas simples operadas manualmente.El agua teñida de verde marca los canales. De bajo costo, portátil, fácil de operar

Figura. 2.3. Flujo laminar de cizalla laminar entre dos platos. La fricción entre el fluido y los límites en movimiento ocasiona que el fluido cizalle debido a la tensión $(\tau)$ causado por la velocidad de gradiente $(\partial \mathrm{u} / \partial \mathrm{y})$ en una velocidad de flujo relativo (u). La fuerza requerida para esta acción es una medida del valor numérico de la viscosidad del fluido. 11

Figura. 2.1. Fabricación del microdispositivo PDMS. (a) Molde maestro DEL fotopolimérico flexográfico (Fmold). (b, c) La resina epóxica se cuela sobre el molde F y se cura a $25^{\circ} \mathrm{C}(\mathrm{d}$, e) Después de $72 \mathrm{~h}$, se despega el molde ER para formar el molde macho. (f, g) El PDMS se cuela en el ERmold y se cura a $40^{\circ} \mathrm{C}$ durante la noche. (h) Se despega la réplica de PDMS. (i) Se perforaron los puertos de entra y salida para las conexiónes y luego la réplica se une irreversiblemente a un portaobjetos de vidrio por exposición al plasma....... 31

Figura. 2.2 Imágenes SEM de topologías de microfluidos PDMS moldeadas a partir de ERmold. Replicas de topologías microfluídicas que van desde patrones lineales y curvos: A: circular, B: serpentina, C: diagonal, D: curvo, E: cuadrado, F: intersección lineal. (barra de escala: $100 \mu \mathrm{m}$ ). 33

Figura. 2.3. Precisión en las características de Fmold a ERmold. (a) Imágenes SEM de secciones seleccionadas del Fmold fabricado (fila azul), ERmold-1 (fila verde), ERmold-2 (fila verde) y ERmold-3 (fila verde). Sección A: Unión en T, sección B: curva, sección C: segmentos la intersección del canal lineal. (b) 
Enfoque en el diseño de dispositivo microfluídico donde se generan las gotas de emulsión doble. (Barra de escala: $200 \mu \mathrm{m}$ ) 35

Figura. 2.4. Precisión en la copia de características de ERmold a réplica de PDMS.

(a) Imágenes SEM de secciones seleccionadas de las réplicas de PDMS. (b) Enfoque en el sitio de emulsión del dispositivo microfluídico generador de gotas. (Barra de escala: $1000 \mu \mathrm{m}$ ).

Figura. 3.1. Ilustración esquemática de las etapas iniciales del proceso de formación de poros. 1.1) Oblea de silicio, 1.2) Oblea de silicio con deposición de nitruro de silicio, 1.3) Remoción localizada de nitruro de silicio y 1.4) grabado húmedo con $\mathrm{KOH} 7 \mathrm{M}$.

Figura. 3.2. Ilustración esquemática: segunda etapa de grabado químico. a) Celda con dos compartimientos para solución de grabado $\mathrm{KOH} 4 \mathrm{M}$ y solución de frenado (HCL 12 M o HCOOH 30M), b) Conexión de electrodos de platino conectados con un dispositivo Keithley $2612 b$. 45

Figura. 3.3. Evolución de la corriente para la condición C-84-1I. T1, T2 y T3 corresponden con los tiempos característicos del proceso.

Figura. 3.4. Descripción de las etapas del proceso de fabricación de poros. a) Comportamiento inicial correspondiente al ataque químico, b) Dependencia exponencial luego de apertura de poro, c) Trasformación exponencial del grafico 4b, d) Etapa de neutralización. 48

Figura. 3.5. Comparación de las curvas de evolución de la corriente, condiciones: $\mathrm{HCl}, 84{ }^{\circ} \mathrm{C}$. a) Línea negra: condición $1 \mathrm{~V}$, Línea roja: condición 0,5 V y Línea azul: condición $0,1 \mathrm{~V}$, b) Imágenes de los microporos obtenidos...... 49

Figura. 3.6. Comparación de las curvas de evolución de la corriente, condiciones: $\mathrm{HCl}, 84{ }^{\circ} \mathrm{C}$. Línea negra: 0,5 V-replica 1, Línea roja: 0,5 V-replica 2........ 50

Figura. 3.7. Comparación de las curvas de evolución de la corriente, condiciones: $\mathrm{HCOOH}, 84^{\circ} \mathrm{C}$. a) Línea negra: condición $1 \mathrm{~V}$, Línea roja: condición 0,5 V y Línea azul: condición $0,1 \mathrm{~V}$. 52

Figura. 3.8. Imágenes de poros obtenidas mediante microscopia electrónica de barrido. a y b) microporos formados en la parte lateral de la ventana, c y d) 
microporos formados dentro de la ventana. Condiciones a: $\mathrm{HCOOH}, 84{ }^{\circ} \mathrm{C}, 1$

V. 53

Figura. 3.9. Superficie obtenida posterior al proceso electroquímico de formación de poros. Condiciones: $\mathrm{KOH} 4 \mathrm{M}$, $\mathrm{HCOOH} 30 \mathrm{M}$, Temperatura: $65^{\circ} \mathrm{C}$. 54

Figura. 4.1. Fabricación de microporos de silicio por el método electroquímico. Imagen esquemática de la configuración de grabado.

Figura.4.2. Fabricación y configuración para el conteo de células (a) diseño de microcanales y unión de réplica de PDMS en un portaobjetos de vidrio, (b) el microporo está unido y alineado con bloque PDMS (5 mm de espesor), (c) Esquema del dispositivo microfluídico y el montaje de la configuración.... 65

Figura. 4.3. Imágenes de SEM de los microporos. (a) KOH20-HCl-80-1 (anverso), (b) KOH50-HCl-80-1 (anverso), (c) KOH50-HCOOH-80-0.1 (anverso), (d) KOH50- HCOOH-80-0.1 (reverso). Los códigos de los microporos corresponden con la concentración de $\mathrm{KOH}$, seguido del ácido, la temperatura y el voltaje aplicados durante el grabado electroquímico.

Figura. 4.4. Imáges de SEM de la superficie del silicio; (a) 50 wt\% KOH, 1 V a 40 ${ }^{\circ} \mathrm{C}$, (b) $20 \mathrm{wt} \% \mathrm{KOH}, 1 \mathrm{~V}$ a $60{ }^{\circ} \mathrm{C}$, (c) $20 \mathrm{wt} \% \mathrm{KOH}, 1 \mathrm{~V}$ a $60{ }^{\circ} \mathrm{C}$, (d) $20 \mathrm{wt} \%$ $\mathrm{KOH}, 1 \mathrm{~V}$ a $80{ }^{\circ} \mathrm{C}$, (e) $20 \mathrm{wt} \% \mathrm{KOH}, 1 \mathrm{~V}$ a $80^{\circ} \mathrm{C}$ (f) $20 \mathrm{wt} \% \mathrm{KOH}, 1 \mathrm{~V}$ a 80 ${ }^{\circ} \mathrm{C}$.

Figura. 4.5. Gráficos de I - t registrados durante el grabado electroquímico en $\mathrm{KOH}$ al $50 \%$ en peso para obleas de silicio sometidas a diferentes condiciones: (a) $\mathrm{HCl} 12 \mathrm{M} \mathrm{a} 80{ }^{\circ} \mathrm{C}$; (b) $\mathrm{HCl} 12 \mathrm{M}$ a $60{ }^{\circ} \mathrm{C}$; (c) $\mathrm{HCl} 12 \mathrm{M} \mathrm{a} 40{ }^{\circ} \mathrm{C}$; (d) $\mathrm{HCOOH}$ $12 \mathrm{M}$ a $80{ }^{\circ} \mathrm{C}$; (e) $\mathrm{HCOOH} 12 \mathrm{M}$ a $60{ }^{\circ} \mathrm{C}$; (f) $\mathrm{HCOOH} 12 \mathrm{M}$ a $40{ }^{\circ} \mathrm{C}$. $\mathrm{Se}$ aplicaron tensiones de $1000 \mathrm{~V}, 500 \mathrm{~V}$ y $100 \mathrm{~V}$ durante el proceso de grabado. Las flechas rojas indican el tiempo de apertura de los poros. 73

Figura. 4.6. Distribución del esfuerzo cortante en el microcanal de microporo y PDMS. Condiciones: viscosidad de 1,5 cP y caudal de $16,6 \mathrm{ml} \mathrm{min}^{-1}$ 75

Figura. 4.7. (a) Caída de presión y (b) esfuerzo cortante calculado a diferentes velocidades de flujo y viscosidades. 76

Figura. 4.8. Perfiles de velocidad en la sección transversal del microporo. Condiciones: viscosidad de $1,5 \mathrm{cP}$ y caudal de $16,6 \mathrm{ml} \mathrm{min}^{-1}$ 77 
Figura. 4.9. Identificación de células completas bajo un campo claro del microscopio. (a) Imagen de la célula, (b) imagen del núcleo de la célula, (c) imagen del procesamiento por ImageJ-FIJI de una célula, (d) imagen del procesamiento del núcleo de la célula por ImageJ-FIJI. Dimensiones del microporo: $\sim 150 \mathrm{~mm} \times 150 \mathrm{~mm}$. 78

Figura. 4.10. Células HEK-293 medidas a diferentes velocidades de flujo. 79

Figura. 5.1. Imágenes de microscopía representativas de autofagia y marcaje con PI en células de cáncer de mama después de tres días de crecimiento en dos pocillos diferentes en los microdispositivos. $(\mathrm{a}, \mathrm{d})$ Imágenes en campo claro del cultivo. (b,e) Imágenes de fluorescencia de células después del tratamiento con el kit de autofagia que etiqueta preferencialmente vacuolas autofágicas, mostradas en verde (c,f) Imágenes de fluorescencia después del marcaje con PI. Las células muertas están mostradas en rojo.

Figura. 5.2. Distribución celular después de la caracterización con marcadores de fluorescencia por 5 días. A la derecha se presenta un gráfico de barras que ilustra la composición de la fracción celular por día durante el período de tiempo de 5 días. A la izquierda, la superficie del área cubierta por células vivas (LC) aumentó mientras los niveles del proceso de autofagia (AG) disminuyó significativamente. $(*)$ y $(* *)$ indican la diferencia significativa de cada día entre los subgrupos $(\mathrm{p}<0.05)$. 88

Figura. 5.3. Efecto de la doxorrubicina en las células después de 4 horas. A la izquierda, el proceso de apoptosis (AP) aumentó significativamente con respecto al control. El área cubierta por las células vivas (LC) no disminuyó significativamente en comparación con el control. A la derecha, el gráfico de barras muestra los valores de los resultados en la composición de la fracción celular. (*) indica la diferencia significativa de cada día entre los subgrupos $(\mathrm{p}<0.05)$. 90

Figura. 5.4. Doxorrubicina combinada con paclitaxel. La gráfica de barras denota el efecto de PTX después de 24 horas sobre los modos de muerte celular. El marcaje con ioduro de propidio (PI) incrementó significativamente con respecto al control. El área cubierta por las células vivas (LC) no disminuyó significativamente en comparación con el control. A la derecha se muestra un 
gráfico de barras con la composición de la fracción celular por día durante 4 horas. (*) indica la diferencia significativa de cada día entre subgrupos $(\mathrm{p}<0.05)$.

Figura. 5.5. Efecto de paclitaxel (PTX) comparado con el control (B) durante 5 días a concentración baja de PTX. El gráfico de barras denota el valor del porcentaje de área cubierto por células para cada modo de muerte celular estudiado. A la izquierda, el proceso de apoptosis (AP) incrementó significativamente en comparación al control, y el área cubierta por las células vivas (LC) disminuyó significativamente con respecto al control. A la derecha se muestra un gráfico de barras que describe los resultados de la composición de la fracción celular por día durante un perío de 5 días. (**) y (*) indica las diferencias significativas de cada día entre los subgrupos $(\mathrm{p}<0.05)$. 93

Figura. 6.1. Formación de la doble capa eléctrica y generación del flujo electro osmótico. 100

Figura. 6.2. Perfiles de los flujos (A) y electro-osmótico (B) por presión. 101

Figura. 6.3. Esquema del diseño típico de un microchip de electroforesis capilar.

Figura. 6.4. Roya de la hoja - Puccinia recondita. Daño en hoja de trigo (Louisiana State University AgCenter Archive, Louisiana State University AgCenter, Bugwood.org) 104

Figura. 6.5. Escala de Mains \& Jackson, donde se describen los grados de resistencia o susceptibilidad de acuerdo al tipo de respuesta del huésped. R: Resistente; MR: Moderadamente Resistente; MS: Moderadamente Suceptible; S: Suceptible. Fuente: McIntosh et al., 1995. 106

Figura. 6.6. Dispositivos utilizados para la electroforesis. i). Diseño en forma de cruz donde A es la entrada de las muestras, B y C sitios donde se colocan los electrodos para introducir las muestras en los canales y $\mathrm{C}$ es la salida o el desecho. (Los electrodos también son colocados en A y D para poder aplicar un diferencial de potencial dependiendo el caso). ii) Dispositivo ensamblando con vidrios cubre objetos donde el gel de acrilamida queda contenido. iii) 
Diseño del dispositivo de los nueve microcanales con dimensiones escaladas y con pocillos para las muestras.

Figura. 6.7. Esquema de electroforesis en el i dispositivo de microfluídica en forma de cruz.

Figura. 6.8. Esquema de electroforesis en el dispositivo de microfluídica utilizando el ensamblaje de vidrios porta objetos (ii).

Figura. 6.9. Visualización del polimorfismo del marcador gpw4388 por electroforesis en gel de poliacrilamida desnaturalizante 5\%, en las líneas parentales SV (Sinvalocho) y P (Purplestraw).

Figura. 6.10. Esquema propuesto para electroforesis en el dispositivo (iii) con canales de microfluídica y el ensamblaje de vidrios con gel de acrilamida independiente. 
Tesis doctoral Gustavo Iván Rosero Yánez. Capítulo 1

\section{Capítulo I}

\section{Introducción a la Microfluídica.}




\subsection{Introducción.}

La microfluídica es la ciencia que se ocupa de estudiar el comportamiento, control preciso y la manipulación de fluidos y partículas en la escala de decenas a cientos de micrómetros ${ }^{1}$. La microfluídica se considera como una plataforma para aplicaciones biomédicas y químicas, llamado Lab-on-a-Chip (LOC) o micro sistemas de análisis total ( $\mu \mathrm{TAS})^{2}$. En la historia los primeros dispositivos de microfluídica demostraron que los mecanismos podían ser miniaturizados e integrarse entre sí, lo que llevó a la idea de que se podría fabricar un "laboratorio en un chip". Desde entonces, ha habido un gran interés en aprovechar todo el potencial de este enfoque y en consecuencia se han desarrollado innumerables dispositivos de microfluidos, así como métodos de fabricación. Materiales como el poli-dimetilsiloxano (PDMS), y otros elastómeros han surgido recientemente como excelentes alternativas al silicio y el vidrio utilizados en los primeros dispositivos fabricados mediante procesos MEMS (sistemas microelectromecánicos) $)^{3,4}$. La fabricación simplificada de dispositivos utilizando resinas poliméricas como moldes maestros permiten fabricar una amplia gama diseños. Además, poseen extensas arquitecturas y dimensiones en la escala micrométrica que son comparables con las últimas tecnologías dependientes de cuartos limpios 5 . Permitiendo que la microfluídica se convierta en una tecnología ubicua y con aplicaciones en muchos campos diversos. 


\subsection{Beneficios de la miniaturización.}

Una de las ventajas, de los componentes y procesos miniaturizados es la utilización de volúmenes pequeños, lo que lleva a la reducción en el consumo de reactivos. Todo esto disminuye los costos y permite utilizar pequeñas cantidades de muestras ${ }^{6}$. También se reducen las cantidades de productos de desecho. Adicionalmente, la relación superficie/volumen de los componentes pequeños facilita la transferencia de calor, lo que permite realizar cambios rápidos de temperatura y un control preciso de la misma. En reacciones exotérmicas, esta característica puede ayudar a eliminar la acumulación de calor que podrían provocar reacciones secundarias no deseadas ${ }^{7}$.

A pequeña escala y con el tamaño de los dispositivos de microfluídica, la mezcla por difusión es rápida, a menudo aumenta la velocidad y precisión de las reacciones. En algunos trabajos las mejoras son notables en los tiempos de medición, sensibilidad mejorada, mayor selectividad y repetitividad, por citar los más comunes. Por ejemplo, la dispersión se reduce en las separaciones electroforéticas por la rápida disipación del calor. En algunas separaciones, la sensibilidad mejora porque el tiempo de medición reducido conduce a un grado menor de ensanchamiento de picos ${ }^{8}$.

Los dispositivos de microfluídica a veces permiten realizar procesos de formas completamente nuevas. Por ejemplo, la temperatura del fluido se puede variar rápidamente moviendo el fluido entre las regiones del chip con diferentes temperaturas en lugar de calentar y enfriar el fluido. En un dispositivo para detectar proteínas en las condiciones de cristalización se aprovecha la difusión de interfaz libre, un proceso que es práctico solo en el microescala ${ }^{9}$. La naturaleza del flujo de un fluido en microcanales permite nuevos métodos para realizar intercambio de solventes, filtrado y reacciones en dos fases ${ }^{10}$. 


\subsection{Beneficios de la automatización e integración.}

Los beneficios de la microfluídica incluyen, (i) volúmenes reducidos de muestra y reactivo, (ii) procesamiento rápido de la muestra, (iii) alta sensibilidad, (iv) bajo costo, (v) mejor portabilidad, y (vi) el potencial de estar altamente integrado y automatizado para reducir la intervención humana y el error ${ }^{11}$.

La manipulación precisa, la separación y el fraccionamiento de biopartículas es una capacidad indispensable de la microfluídica. Por ejemplo, en el procesamiento de micropartículas dispuestas en sola línea permite la detección y análisis que es un componente importante de la citometría de flujo en un chip. Además, la separación de micropartículas/células de acuerdo con sus formas biofísicas únicas, como; el tamaño, la densidad, la forma, la deformabilidad y las proteínas de superficie permiten una amplia gama de aplicaciones ${ }^{12,13}$.

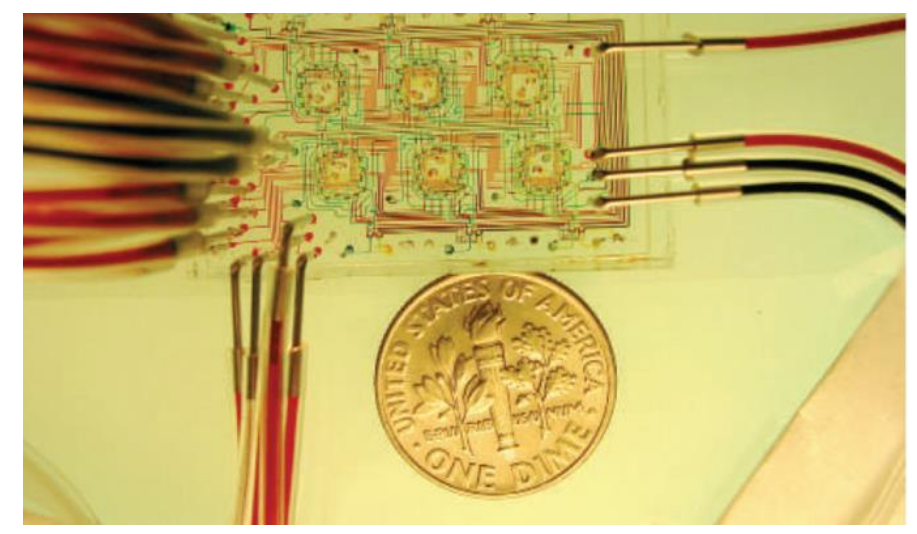

Figura.1.1. Dispositivo de microfluídica que se utiliza para estudiar el crecimiento de poblaciones microbianas, se observan canales complejos. Este dispositivo incluye una alta densidad de válvulas neumáticas. Los colores son tintes introducidos para trazar los canales ${ }^{14}$.

Realizar todas las operaciones de manipulación de fluidos en un solo chip ahorra tiempo, reduce el riesgo de pérdida o contaminación de la muestra y puede eliminar la necesidad de un laboratorio voluminoso y costoso usando robots. Además, el funcionamiento de los dispositivos de microfluídica se puede automatizar, aumentando así el rendimiento, mejorando la facilidad de uso, 
mejorando la repetitividad y reduciendo el elemento de error humano. La automatización también es útil en aplicaciones que requieren operación remota, como dispositivos que realizan seguimiento continuo de procesos químicos o ambientales en lugares inaccesibles ${ }^{15}$.

Otra forma de aumentar el rendimiento es aprovechar el paralelismo. Se han demostrado chips individuales que realizan cientos de ensayos o reacciones idénticas ${ }^{16,17,18}$. Poseen una distribución en el chip con una sola entrada para la muestra donde es conducida a microrreactores, una solución interesante para el problema de la interfaz de micro-a-macro ${ }^{19,17}$. Este problema se refiere al desajuste entre los tamaños de muestra que pueden se difíciles de manipularse en el laboratorio $(\mu \mathrm{L}-\mathrm{mL})$ versus el volumen de microrreactores $(\mathrm{pL}-\mathrm{nL})$.

Una de las ventajas de la automatización es poder manipular partículas, las tecnologías se pueden clasificar en dos tipos activos y pasivos. Tecnología activa como la dielectroforesis (DEP) ${ }^{20}$, que dependen de campos de fuerza externos, mientras que las tecnologías pasivas dependen completamente de la geometría del canal o fuerzas hidrodinámicas intrínsecas, como el fraccionamiento de flujo de cizalla (PFF) ${ }^{21}$ desplazamiento lateral determinista (DLD).

Los pequeños dispositivos de microfluídica también pueden ofrecer la característica de portabilidad, lo que permite aplicaciones en análisis químico, medicina en el punto de atención o medicina forense. La capacidad de realizar pruebas integradas para diagnóstico en lugar de en un laboratorio centralizado podría reducir los costos, mejorar el tiempo de respuesta y reducir el riesgo de confusión de muestras. Si se fabrican a bajo precio, los dispositivos podrían ser desechables, eliminando la contaminación cruzada entre pruebas. 


\section{4. Áreas de aplicación.}

En la literatura se han reportado varias reacciones y ensayos que se han realizado en los dispositivos de microfluídica ${ }^{22,23,24,25,26}$. Algunos han mostrado importantes mejoras en el rendimiento en comparación con sus homólogos de macroescala y ofrecen una prometedora comercialización. En algunos casos, las implementaciones a microescala han transformado completamente la forma en que cierto tipo de experimentos se realizan o han permitido la paralelización de experimentos que antes ni siquiera se podían contemplar.

Entre los numerosos procesos biológicos y bioquímicos demostrados se encuentra la reacción en cadena de la polimerasa $(\mathrm{PCR})^{17}$, inmunoensayos ${ }^{27}$, detección de fármacos, recuento y clasificación de células ${ }^{28}$, electroforésis, extracción de ácido nucleico ${ }^{16}$, análisis de muestras de sangre sin purificar $^{27}$, secuenciación de $\mathrm{ADN}^{29}$, exámenes de detección de condiciones de cristalización de proteínas $^{9}$, estudios de cultivo celular ${ }^{14}$ y manipulación unicelular ${ }^{30}$.

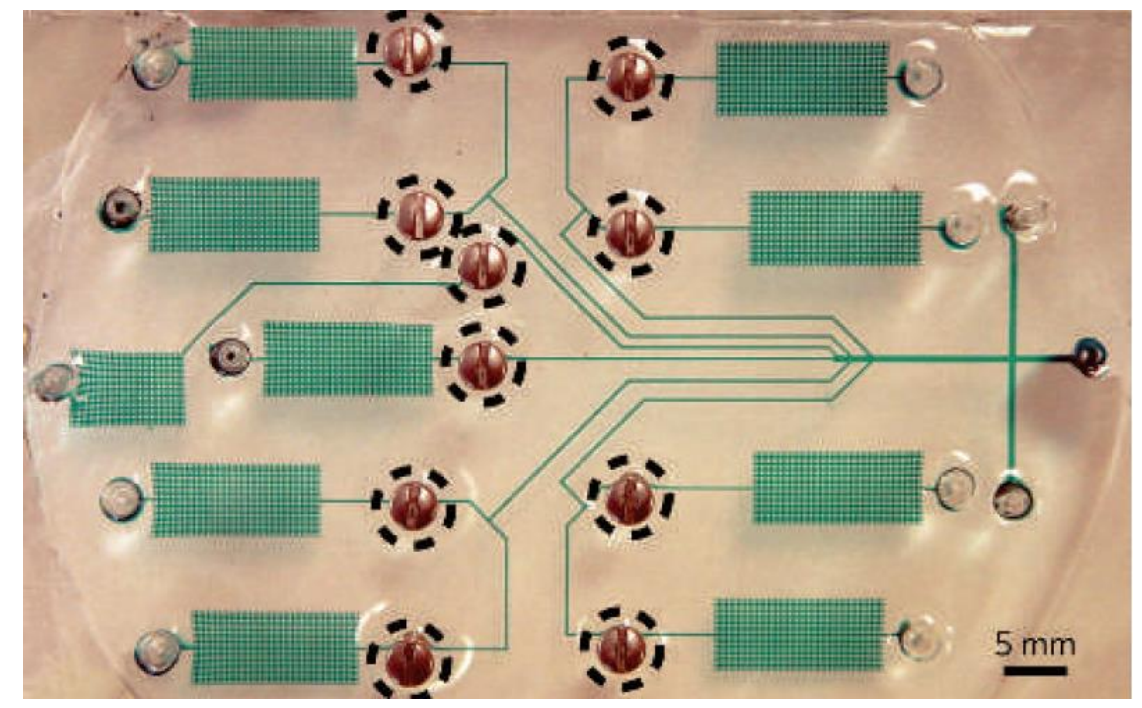

Figura.1.2. Dispositivo de microfluídica, que realiza pruebas de inmunoensayos que se utilizan ampliamente en medicina e investigación biológica. Los tornillos en este sistema (marcados con círculos punteados) actúan como válvulas simples operadas manualmente le otorgan la característica de bajo costo, portátil y fácil de operar. El agua teñida de verde marca los canales ${ }^{31}$. 
Otros procesos biológicos y bioquímicos dentro de las aplicaciones de la química, han producido mejoras significativas en rendimientos sintéticos y de selectividades ${ }^{32,7}$. Además, los dispositivos de microfluídica posibilitan nuevas reacciones o procesos mediante un control sin precedentes sobre la química de la superficie, el calor local y la transferencia de masa $a^{33,34,23,35}$. Un mayor grado de control puede ayudar a diseñar experimentos para aumentar el conocimiento sobre el proceso de muchas sustancias química ${ }^{36}$.

Varios investigadores también han argumentado que los microrreactores podrían usarse en productos químicos industriales, plantas de producción o tratamiento de residuos si los requisitos de procesamiento volumétrico son bajos ${ }^{37,7,34}$. La capacidad de configurar la producción cuando y donde sea necesario podría disminuir la necesidad de almacenamiento y transporte de productos químicos peligrosos o de productos de corta duración. Además, los microrreactores tienen el potencial de aumentar la seguridad de procesos peligrosos. Por ejemplo la fluoración de compuestos aromáticos se puede lograr con una prevención de la fuga térmica ${ }^{23}$. En caso de falla del microrreactor, las consecuencias serán relativamente menores debido a la pequeña masa de material presente en el reactor en un momento dado.

Aparte de los ensayos y reacciones, la microfluídica ha jugado un papel interesante en muchas otras áreas. Los ejemplos incluyen fotomáscaras en escala de grises que consta de canales llenos de diferentes concentraciones de colorante $^{38}$, cámaras elastoméricas presurizadas ${ }^{39}$, circuitos fluídicos para implementar en computación del ADN y microcanales para enfriar circuitos microelectrónicos ${ }^{40}$. 


\subsection{Conceptos Fundamentales y Física de la microfluídica en estudios celulares.}

\subsubsection{Introducción.}

El manipular pequeñas cantidades de fluidos (gases y/o líquidos) para efectuar reacciones, hacer análisis, o investigaciones fundamentales, energía, medio ambiente, la medicina, la biología, la física y la química son de gran interés en el campo científico y aplicaciones industriales. Si se fabrican a bajo precio, los dispositivos podrían ser desechables, eliminando la contaminación cruzada entre pruebas $^{41,42,43,1,44,45,46,47,48,49}$. La microfluídica es la ciencia y tecnología que puede manipular pequeñas cantidades de fluidos $\left(10^{-6}\right.$ a $10^{-15} \mathrm{~L}$.), donde las estructuras o canales tienen dimensiones en escala micrométrica ${ }^{44,45,50,51}$. La microfluídica se han convertido rápidamente en una herramienta importante en varios campos de investigación básica ${ }^{46-49,52,53,54,55}$. Varios materiales e instrumentos como: tubos, nebulizadores y aspersores hoy en día están basados en sistemas de microfluídica especialmente en síntesis química ${ }^{46-48,54,55}$. Una razón de su rápido desarrollo es por la predicción de los flujos en una escala micrométrica permitiendo un control exquisito de las interfaces en los microcanales. Hoy en día la microfluídica se ha utilizado en muchos campos científicos e industriales como una herramienta para el desarrollo de diversos temas relacionados con la química, materiales, biología o física.

En esta sección se enfoca en los fundamentos físicos sobre los que esta disciplina ha formados sus pilares y como estos fundamentos tienen efectos directos sobre las células. Las características espaciales de la microfluídica se centran entre la macroescala y nanoescala, lo que le confiere una dualidad en el comportamiento del fluido. Sin embargo, la microescala es mucho más grande que la trayectoria libre media $(\lambda)$ del movimiento de las moléculas. Por lo tanto, el fluido en el espacio de la microescala obedece a la ley del medio continuo, que puede tratarse mediante la ecuación de la continuidad ${ }^{52}$. Generalmente, la mayoría de los mecanismos básicos que gobiernan a los fluidos, también se puede utilizar para la microfluídica como; la ley de Pascal, la ley de Laplace, la de Bernoulli y las 
leyes de Poiseuille, y los modelos de dinámica de fluidos de Navier-StokesFourier. Sin embargo, a medida que se reduce la escala, el efecto de las fuerzas viscosas se vuelve dominante en la microfluídica, diferente de la macroescala en la que el efecto de la fuerza de inercia domina el comportamiento del fluido y en la microescala con un número de Reynolds bajo el flujo laminar se vuelve dominante. Por lo tanto, el tipo de transporte de masa dominante cambia de convección a difusión. Además, la movilidad electroforética es independiente de la escala, está relacionada con los campos eléctricos que conduce a características de flujo únicas en microfluídica ${ }^{53,56,57}$. El transporte por difusión, efectos capilares, así como los relacionados con la viscosidad, tensión superficial y efectos de superficie e interfaz, resultan ser dominantes en sistemas microfluídicos ${ }^{53-56}$. A continuación, se describirá el mecanismo de fluido básico de la ley del medio continuo y algunas características mesoscópicas únicas en los microcanales. Luego, brevemente la fabricación de los dispositivos microfluídicos será descrita y analizada.

\subsubsection{Viscosidad en los fluidos y en las células.}

A diferencia del estado sólido donde las moléculas suelen vibrar en el estado fijo, las moléculas en los líquidos son libres de moverse y solo están limitadas por la cohesión, fuerzas que dan lugar a efectos viscosos, que se ven afectados en su mayor parte por la temperatura y ligeramente por presión. Por lo tanto, al igual que los sólidos, los líquidos generalmente se tratan como no compresivos.

Entonces, la viscosidad $(\mu)$ es muy importante para las moléculas en estado líquido, particularmente en el análisis de transporte de masa y calor en las interfaces de líquido-líquido y gas-líquido ${ }^{58}$. Por otro lado, la viscosidad celular se ve afectada por una multitud de parámetros y cada célula tiene una viscosidad específica y, por lo tanto, deformabilidad. Por ejemplo, la deformabilidad de las células sanguíneas disminuye cuando se infectan con Plasmodium falciparum. Por el contrario, las células cancerosas tienden a ser más deformables que las células sanas de su entorno ${ }^{59}$. En consecuencia, los estudios deformaciones 
celulares tienen un gran potencial en el desarrollo de métodos novedosos para clasificar y aislar células o incluso en estudiar procesos biológicos.

Tradicionalmente, los estudios de deformación celular se realizan con una sonda de un microscopio de fuerza atómica (AFM) que está en contacto directo con la célula ${ }^{60}$. Sin embargo, implican un contacto directo con la célula que puede dañar o alterar su estructura. Para evitar el contacto directo con las células y prevenir daños no deseados y/o alteraciones de la estructura celular, se han realizado varios estudios utilizando hidrodinámica manipulación en sistemas microfluídicos ${ }^{61,62,63,64,65,66,67,68,69}$ por ejemplo; estudiando la deformabilidad de poblaciones de leucocitos sanos y malignos se logró predecir el estado de enfermedad en pacientes con cáncer con activación inmunitaria obteniendo una sensibilidad de $91 \%$ y una especificidad del $86 \%^{12}$.

Por lo tanto, para las células la viscosidad esta muy ligada con la deformabilidad celular, mientras que la viscosidad $(\mu)$ o la viscosidad dinámica de un fluido es una medida de su resistencia a la deformación gradual por el esfuerzo cortante o el esfuerzo de tracción. Si se visualiza más detenidamente un fluido como se observa en la figura 2.3 se puede apreciar que el mismo se encuentra contenido entre dos placas con límites paralelos, donde una placa es estacionaria y la otra placa está en movimiento, con una velocidad horizontal constante u. Donde la magnitud de la fuerza $F$ es proporcional a la rapidez $u$ y al área $A$ de cada placa es inversamente proporcional a su separación $y$ :

Ecuación.1.1

$$
F=\mu A \frac{u}{y}
$$




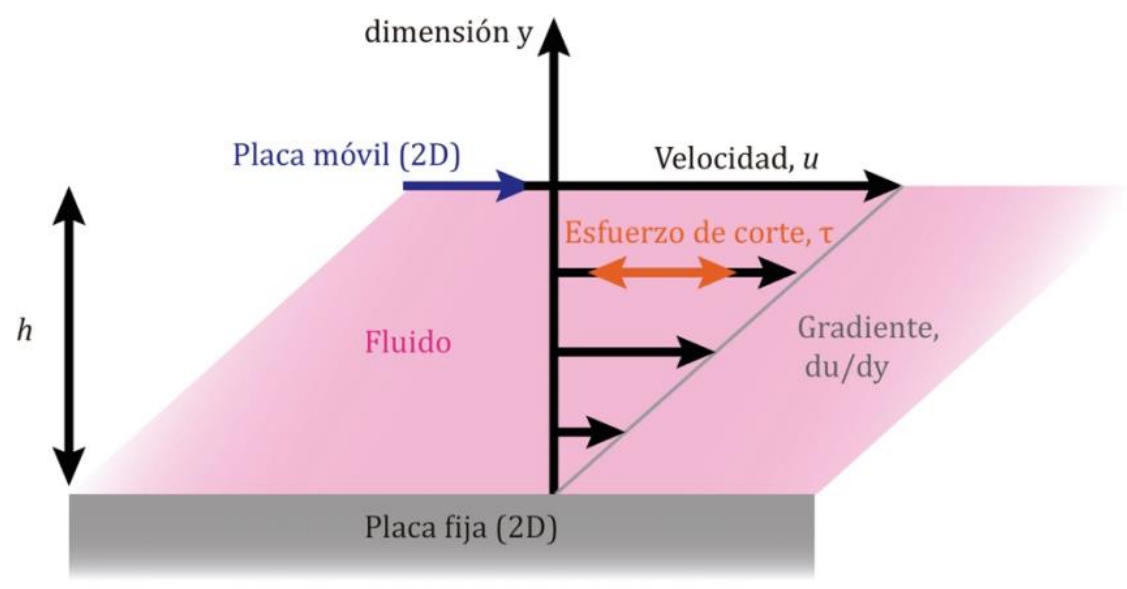

Figura.1.3. Flujo laminar de cizalla entre dos placas. La fricción entre el fluido y los límites en movimiento ocasiona que el fluido cizalla debido a la tensión $(\tau)$ causado por la velocidad de gradiente $(\partial \mathrm{u} / \partial \mathrm{y})$ en una velocidad de flujo relativo (u). La fuerza requerida para esta acción es una medida del valor numérico de la viscosidad del fluido ${ }^{58}$.

El factor de proporcionalidad $\mu$ en esta fórmula es la viscosidad (específicamente, la viscosidad dinámica) del fluido ${ }^{58}$. Además, la velocidad del fluido cambiará suavemente desde cero en la superficie estacionaria hasta la velocidad de la superficie en movimiento, o formando un gradiente espacial. La velocidad del fluido $d u / d y$ ocasionado por esfuerzo cortante es linealmente proporcional a la tasa de deformación en fluidos Newtonianos que es una constante de proporcionalidad. La cual se la denomina convencionalmente como viscosidad del fluido $\mu$ Ecuación 1.1 (que es única e independiente para cada fluido). Por otro lado, muchos de los fluidos biológicos pertenecen a una clasificación conocida como fluidos no-Newtonianos como por ejemplo; la sangre ${ }^{70}$, donde la relación entre el esfuerzo cortante y la velocidad de deformación no es lineal y además resulta variable, lo que resulta en diferentes patrones de comportamiento en el flujo. Por lo tanto, es importante que se tenga en cuenta cualquier no linealidad en el comportamiento de los fluidos cuando se estudia células o partículas en un flujo ${ }^{71}$. La relación $u / y$ se conocida como tasa de deformación o velocidad de cizalla y es la derivada de la velocidad del fluido en la dirección perpendicular a las placas. Isaac Newton expresó las fuerzas viscosas mediante la ecuación diferencial: 
Ecuación.1.2

$$
\tau=\mu \frac{d u}{d x}
$$

donde $\tau=F / A$ y $\partial \mathrm{u} / \partial \mathrm{y}$ es la velocidad de corte local. Esta fórmula asume que el flujo se mueve a lo largo de dos líneas paralelas al eje y, el cual es perpendicular al flujo. Esta ecuación se puede utilizar cuando la velocidad no varía linealmente mientras el fluido pase a través de la tubería. En un flujo paralelo en general (como podría ocurrir en una tubería recta), el esfuerzo cortante es proporcional al gradiente de la velocidad, como en una sección transversal de un canal de microfluídica ${ }^{58}$. El perfil de velocidad a través de la sección transversal de un canal de microfluídica se puede determinar a partir de la solución de las ecuaciones de movimiento de fluidos, Navier-Stokes y las ecuaciones de conservación de masa (o continuidad) ${ }^{72}$. Sin embargo, para una sección circular transversal canal de diámetro d, el perfil de velocidad está dado por la siguiente relación $(\mathrm{r}, \theta, \mathrm{z})$ :

\section{Ecuación.1.3}

$$
\mu_{z}(r)=\frac{8 Q}{\pi d^{2}}\left(1-\left(\frac{2 r}{d}\right)^{2}\right)
$$

donde Q es el caudal volumétrico y r es la distancia radial desde la línea central del canal. La ecuación 2.3 describe una función parabólica en la dirección radial y, por lo tanto, el perfil de velocidad dentro de un canal o tubería circular se denomina "parabólico", con una velocidad máxima que ocurre en la línea central del canal. Sin embargo, la distribución de velocidad en un canal cuadrado o rectangular es más complejo, la ecuación de la velocidad y su distribución en un canal rectangular se proporciona en la sección S1 para el lector interesado. Este perfil de velocidad particular (en un canal rectangular) es el producto de las interacciones de la capa límite entre las paredes laterales y las paredes superior e inferior y la diferencia en sus dimensiones. Al introducir simetría dimensional, por ejemplo, adoptando un canal con idéntica altura y ancho, los perfiles de velocidad a lo largo del ancho y la altura de el canal se vuelven idénticos. Por otro lado, en fluidos no-Newtonianos, la relación entre el esfuerzo cortante o corte de cizalla y la velocidad de deformación no es lineal. Por lo tanto, el 
esfuerzo cortante en las paredes de los microcanales resulta ser crítico para las células. Las fuerzas de corte pueden alterar el comportamiento o incluso dañar la estructura del citoesqueleto de la célula si ésta fuerza es excesivamente grande. Para obtener la distribución del esfuerzo cortante en la pared del canal, el gradiente de velocidad (es decir, la tasa de deformación) en la pared debe ser determinado utilizando la ecuación 2.3 para un canal circular, con respecto a r, lo que produce:

Ecuación.1.4.

$$
\tau_{\text {pared }}=\mu \gamma_{\text {pared }}=-\left.\mu \frac{d u_{z}}{d r}\right|_{r=\frac{d}{2}}=\frac{32 \mu Q}{\pi d^{3}}
$$

En la ecuación 2.4 se el esfuerzo cortante de pared en un canal circular o tubo es constante a través de las paredes del canal. La viscosidad y del diámetro del canal son una función del caudal. El mayor flujo en el canal ocurre cuando el diámetro del canal es menor, la viscosidad se vuelve constante cuando se alcanzan valores grandes del esfuerzo cortante de la pared. Por el contrario, el esfuerzo cortante de la pared en un canal rectangular no es constante y varía a lo largo de las paredes superior, inferior y laterales del canal.

\subsubsection{Difusión y partículas.}

La mezcla en fluidos no solo depende de la viscosidad de los fluidos sino también del coeficiente de difusión de masa o la difusividad de masa (D) ${ }^{58}$. El movimiento browniano es el movimiento aleatorio de partículas en suspensión sumergidas en un fluido (líquido o gas), que es el resultado de su frecuente colisión con los átomos o moléculas en el gas o líquido. Según la teoría de Einstein-Smoluchowski, la distancia cuadrática media a la que se difunde una partícula en el tiempo t se expresa como ${ }^{58,73}$ :

Ecuación.1.5

$$
<r^{2}>=6 D t
$$

donde D es el coeficiente de difusión. Según la relación de Stokes-Einstein, el coeficiente de difusión se expresa como: 


$$
D=\frac{k T}{3 \pi \mu a}
$$

Donde k es la constante de Boltzmann, que es aproximadamente $1.3806488 \times 10^{-}$ ${ }^{23} \mathrm{~J} / \mathrm{K}$. T es la temperatura absoluta ${ }^{73}$. De la ecuación anterior, podemos ver que cuanto mayor es la temperatura T, mayor es el coeficiente de difusión D. Por el contrario, cuanto mayor es el tamaño de partícula o mayor es su viscosidad media $\mu$, menor es el coeficiente de difusión. Un sistema de microfluidos típico normalmente opera a una temperatura ambiente de $25^{\circ} \mathrm{C}$. El coeficiente de difusión D para una partícula de $1 \mu \mathrm{m}$ en agua es teóricamente aproximadamente $4 \times 10^{-13} \mathrm{~m} / \mathrm{s}$. Cuando el sistema partículas-fluido no es estático, sino que se mueve a lo largo del microcanal, el número de Péclet se puede emplear para evaluar la importancia relativa de la convección a la difusión ${ }^{74}$.

\section{Ecuación.2.7 Pe $=\frac{L U}{D}$}

donde L es la dimensión característica del canal y U es la velocidad característica del fluido. Un número de Péclet grande indica que la convección domina el transporte de partículas en el flujo, mientras que un número de Péclet pequeño significa que la difusión juega un papel principal en el transporte.

En la microfluídica inercial, la velocidad lineal característica del fluido está en la escala de $\sim \mathrm{m} / \mathrm{s}$, y las dimensiones características de los microcanales está en el orden de $\sim 100 \mu \mathrm{m}$. El número de Péclet para partículas de $1 \mu \mathrm{m}$ en microfluidos inerciales es $\sim 2.5 \times 10^{8}$, lo que indica que la convección domina el transporte de partículas en lugar de la difusión. Por lo tanto, la difusión normalmente se ignorará en el análisis del movimiento de partículas a microescala en microfluidos inerciales.

La difusión de la señalización moléculas se ha estudiado ampliamente en la perfusión de sistemas microfluídicos ${ }^{75}$. Por ejemplo; utilizando un dispositivo de microfluídica junto con modelos numéricos para movimiento browniano. Determinaron el impacto local endógenamente de ligandos secretados para la activación de la glucoproteína 130 (gp130) y su activación del transductor de 
señal y activador de la transcripción 3 (STAT3) en células madre embrionarias de ratón (mESC). Lograron demostrar tanto experimental como numéricamente que los niveles de activación de STAT3 disminuyen al aumentar el caudal (es decir, con el número de Péclet), lo que resulta en una mayor diferenciación de $\mathrm{mESC}^{75}$.

\subsubsection{Efectos Hidrodinámicos en los microcanales.}

El flujo de un fluido se caracteriza comúnmente por números adimensionales, como el número de Reynolds Re, que es la relación entre las fuerzas inerciales y las fuerzas viscosas:

Ecuación. 1.8

$$
R e=\frac{\rho U d_{H}}{\mu}, d_{H}=\frac{4 A}{P}
$$

donde $\rho$ es la densidad del fluido, $\mathrm{U}$ es la velocidad característica del flujo, $\mathrm{dH}$ es el diámetro hidráulico del canal, $\mu$ es la viscosidad dinámica del fluido, A y P son el área de la sección transversal y el perímetro del canal, respectivamente. El flujo de un fluido en los canales de microfluídica está descrito por el desplazamiento en canales con pequeñas dimensiones $(\mathrm{dH})$, velocidades $(\mathrm{U}) \mathrm{y}$, por lo tanto, en la mayoría de los casos, se caracteriza por un número bajo de Reynolds, donde el flujo es laminar y los elementos de fluidos se mueven en líneas paralelas ordenadas. Números bajos de Reynolds también indican que las fuerzas viscosas dominan a las fuerzas de inercia en la microescala. En pocas palabras, las fuerzas viscosas surgen cuando el fluido se ralentiza debido a la fricción, por ejemplo, cerca de la pared de un canal $^{71}$.

\subsubsection{Momentum y limite de la trasferencia de masa entre las capas de un fluido.}

Cuando un fluido es confinado en un microcanal, las paredes del canal ralentizan a los fluidos. Formándose capas, adyacentes a la pared que fluye lento, en comparación con el flujo de campo lejano (fluido que fluye a una distancia muy 
alejada de la pared). Entre estas dos capas (capa límite) crece según la relación obtenida de la solución de Blasius para una capa límite laminar ${ }^{76,77}$ :

Ecuación.1.9

$$
\delta=\frac{5 x}{\sqrt{R e_{x}}}
$$

donde $\delta$ es el espesor de la capa límite y x es la distancia desde el borde de la pared $^{72}$. Más allá de la longitud de la entrada (Le), las distribuciones de velocidades a través de la sección transversal del canal no evolucionan durante más tiempo, pero se mantienen estables a lo largo del canal. La longitud de entrada para un canal con una sección transversal arbitraria y de diámetro hidráulico, dh, y el número de flujo de Re esta dado por $^{76}$ :

Ecuación.1.10

$$
\frac{L e}{d_{h}} \approx 0.05 R e
$$

De la ecuación 2.10, es notable que para un número de Reynolds bajo $(\operatorname{Re} \sim 1)$, la longitud de entrada es sólo una fracción del diámetro hidráulico y por lo tanto es insignificante en la mayoría de las aplicaciones de microfluídica.

La concentración de analitos dentro del flujo entrante también se ve afectada por la distribución del momentum (velocidad). Como el analito es consumido o producido por las células adheridas a la pared, será transportado a través de la sección transversal del canal por una combinación de difusión de masa y convección, lo que resulta en una capa límite de transferencia de masa. La capa límite de transferencia de masa el espesor $(\delta c)$ está relacionado con la capa límite de momento $(\delta)$ de acuerdo $\operatorname{con}^{78}$ :

Ecuación.1.11

$$
\frac{\delta_{c}}{\delta}=S c^{-\frac{1}{3}}, S c=\frac{v}{D}
$$

donde Sc es el número de Schmidt (que define la relación entre la difusión del momento en el fluido y la difusión del analito dentro del fluido), D es el coeficiente de difusión del analito y v la viscosidad cinemática. El momentum de la capa límite es a menudo más gruesa que la capa límite de transferencia masa 
porque el coeficiente de la difusión del momentm (también conocido como viscosidad cinemática) es a menudo varios órdenes de magnitud mayor que la difusión del coeficiente del analito ${ }^{78}$.

Similar a la caracterización de flujo y del transporte, a través del número de Reynolds, el transporte de masa en canales y capilares se caracteriza por ser adimensional Número de Péclet. El número de Péclet es la relación entre el transporte de masa convectiva (es decir, transporte debido al flujo) y el transporte de masa difusiva, cuanto mayor es la velocidad en un capilar, mayor es el número de Péclet y entonces está asociado al transporte convectivo. Además una característica importante del trasporte de masa del flujo de un fluido en entornos microfluídicos es la dispersión de Taylor, que describe una mejor propagación axial de los analitos debido que estudia la distribución de velocidades en la pared del canal a lo largo de la sección transversal. Donde el coeficiente de difusión "efectivo" (De) se puede determinar a partir de la siguiente relación ${ }^{79}$ :

Ecuación.1.12

$$
D_{e}=D\left(1+\frac{1}{192} P e^{2}\right)
$$

Donde la ecuación 2.12 sugiere que, a números bajos de Pe, el coeficiente de difusión es igual al coeficiente molecular de difusión y a medida que aumenta la velocidad del flujo mejora la difusión efectiva ${ }^{80,81}$.

\subsubsection{Ley de Pascal.}

La presión ejercida en fluido incompresible, estático en cualquier lugar cerrado se transmite por igual en todas las direcciones a través del fluido (Ley de Pascal). La presión ejercida por un fluido estático se denomina presión de fluido estático, que surge del peso de ese fluido y por lo tanto depende solo de la profundidad del fluido h, su densidad $\rho$, y la aceleración de la gravedad g:

Ecuación.1.13

$$
P_{\text {fluido estático }}=\rho g h
$$


Se puede interpretar de la ley de Pascal, que cualquier cambio en la presión aplicada en cualquier punto del fluido se transmite de forma igual a través del fluido $^{58}$.

\subsubsection{Conservación de energía (ecuación de Bernoulli)}

La ecuación puede ser derivada del principio de la conservación de la energía donde, la suma de todas las formas de energía mecánica permanecen constantes a lo largo de la línea de flujo. El fluido posee energía cinética por su movimiento, y también tiene energía potencial. Además, si se realiza un trabajo sobre el fluido debido a la presión estática. Si no hay pérdidas por fricción, se aplica la ley de conservación de energía y la ecuación de Bernoulli es la siguiente:

Ecuación.1.14

$$
P+\rho g h+\frac{1}{2} \rho u^{2}=\text { constante }
$$

Donde $\mathrm{P}$ es la presión hidrostática, h es la altura sobre el nivel de referencia, $\mathrm{u}$ es la velocidad, $\rho$ es la densidad y g es la aceleración de la gravedad en cualquier elemento de volumen en la línea de flujo del fluido. El término $\rho$ gh se conoce con el nombre de presión hidráulica y la expresión $1 / 2 \rho \mathrm{u}^{2}$ se denomina presión dinámica $^{58}$.

\subsubsection{Efecto de las fuerzas hidrodinámicas sobre la cinética de unión de receptor-ligando.}

La adhesión celular a menudo está mediada por un pequeño número de enlaces receptor-ligando, a veces incluso por un solo enlace. Como resultado de estos pequeños números de enlaces, los eventos de unión celular se vuelven estocásticos. La presencia de fuerzas externas (como fuerzas hidrodinámicas) durante la reacción de unión complica aún más la unión (en términos de estocasticidad). Esta naturaleza probabilística multifacética de la unión receptorligando ha estimulado las maneras de dilucidar estos efectos estocásticos a través de modelos matemáticos y de la experimentación ${ }^{82}$. Bells ${ }^{83}$ ugirió una relación 
entre la tasa de disociación de la unión y la reacción de la fuerza de desalojo como se muestra a continiación:

Ecuación.1.15

$$
K_{d}(f)=K_{d}^{o} \exp \left[\left(a f / K_{b} T\right)^{b}\right]
$$

donde $K_{b}^{0}$ es la tasa de disociación en ausencia de una fuerza externa, a define el estado de enlace, $\mathrm{f}$ es la fuerza de desalojo, y $K_{b}$ y $\mathrm{T}$ son la constante de Boltzmann y la temperatura, respectivamente. Se han dedicado muchos estudios experimentales a probar la validez del modelo de Bell y una variedad de investigaciones numéricas han implementado el modelo en sus soluciones ${ }^{84}$. Por ejemplo, utilizando una bicapa lipídica en un canal confinado, utilizando un fluido que contenía neutrófilos ${ }^{85}$. La bicapa estaba formada por lípidos y enlazados con P-selectina (a una densidad de 1 a 15 por $\mu \mathrm{m}^{2}$ ). Lograron validar las tasas de disociación a varias fuerzas de tracción para comprender mejor la biofísica del rodamiento celular e investigar el desprendimiento de neutrófilos en flujo cortante $\left(3,5 \mathrm{~s}^{-1}\right)$ y sin esfuerzo de tracción $\left(1 \mathrm{~s}^{-1}\right)$ para definir parámetros cinéticos. Sus datos experimentales coincidieron con la ecuación propuesto por el modelo de Bell, y pudieron calcular la distancia del enlace de $0,05 \mathrm{~nm}$.

\subsection{Fabricación de dispositivos de microfluidíca}

Hoy en día, la microfluídica y las microtecnologías han surgido como poderosas herramientas para recrear los microambientes para el desarrollo y análisis celular. Hay diferentes técnicas de fabricación para generar los dispositivos de microfluídica, y cada técnica ofrece diferentes ventajas y desventajas. Históricamente, la técnica más utilizada para fabricar microdispositivos en aplicaciones celulares ha sido la litografía ${ }^{86}$. Dado que esta técnica se ha utilizado para fabricar los microdispositivos utilizados en esta tesis, la técnica será explicada brevemente. Una fotoresina se expone a una longitud de onda específica (por ejemplo, luz ultravioleta) siguiendo un patrón espacial definido por una máscara. En fotoresinas negativas (por ejemplo, SU-8), la luz expuesta regiones polimerizan, mientras que las regiones no expuestas se eliminan utilizando diferentes disolventes. En fotoresinas positivas, las regiones no 
expuestas polimerizan, mientras que las expuestas se eliminan. La utilización de fotoresinas, demanda la utilización de salas limpias, impidiendo la accesibilidad a está tecnología. Por otro lado, En el capitulo 2 se detalla el protocolo utilizado de un fotopolímero que es utilizado ampliamente en esta tesis. Tradicionalmente, la estructura de la fotorresina se utiliza como plantilla o moldes para fabricar los microdispositivos, basados en PDMS. El PDMS se vierte sobre la fotorresina y después de la polimerización del PDMS las estructuras se desprenden. La estructura final basada en PDMS se adhiere a un cubreobjetos de vidrio por medio de un tratamiento de plasma (los detalles del protocolo utilizado en esta tesis se muestran en el capítulo 2). El PDMS exhibe varias ventajas para las aplicaciones de cultivo celular: 1) es biocompatible; 2) alta permeabilidad permite el intercambio de gas oxígeno/CO2 en incubadoras; 3) su comportamiento elástico permite deformaciones mecánicas; y 4) su costo relativamente bajo permite la producción de microdispositivos ${ }^{87}$. 


\subsection{Referencias}

1. Whitesides, G. M. The origins and the future of microfluidics. Nature $\mathbf{4 4 2 ,}$ 368-373 (2006).

2. Sackmann, E. K., Fulton, A. L. \& Beebe, D. J. The present and future role of microfluidics in biomedical research. Nature 507, 181-189 (2014).

3. Ashraf, M. W., Tayyaba, S. \& Afzulpurkar, N. Micro Electromechanical Systems (MEMS) Based Microfluidic Devices for Biomedical Applications. Int. J. Mol. Sci. 12, 3648-3704 (2011).

4. Nazmul Islam and Saief Sayed. Microfluidics for Lab-on-a-Chip Applications, Microelectromechanical Systems and Devices,. in MEMS Microfluidics for Lab-on-a-Chip Applications, Microelectromechanical Systems and Devices (2012).

5. Olmos, C. M. et al. Epoxy resin mold and PDMS microfluidic devices through photopolymer flexographic printing plate. Sens. Actuators B Chem. 288, 742748 (2019).

6. Peer Reviewed: Plastic Advances Microfluidic Devices. Anal. Chem. 74, 78 A-86 A (2002).

7. DeWitt, S. H. Micro reactors for chemical synthesis. Curr. Opin. Chem. Biol. 3, 350-356 (1999).

8. Sanders, G. H. W. \& Manz, A. Chip-based microsystems for genomic and proteomic analysis. TrAC Trends Anal. Chem. 19, 364-378 (2000).

9. Hansen, C. L., Skordalakes, E., Berger, J. M. \& Quake, S. R. A robust and scalable microfluidic metering method that allows protein crystal growth by free interface diffusion. Proc. Natl. Acad. Sci. 99, 16531 (2002).

10. Tokeshi, M. et al. Chemical processing on microchips for analysis, synthesis, and bioassay. ELECTROPHORESIS 24, 3583-3594 (2003).

11. Hale, C. \& Darabi, J. Magnetophoretic-based microfluidic device for DNA isolation. Biomicrofluidics 8, 044118 (2014).

12. Di Carlo, D. Inertial microfluidics. Lab. Chip 9, 3038-3046 (2009).

13. Mach, A. J., Adeyiga, O. B. \& Di Carlo, D. Microfluidic sample preparation for diagnostic cytopathology. Lab. Chip 13, 1011-1026 (2013).

14. Balagaddé, F. K., You, L., Hansen, C. L., Arnold, F. H. \& Quake, S. R. Long-Term Monitoring of Bacteria Undergoing Programmed Population Control in a Microchemostat. Science 309, 137 (2005).

15. Crouch, R. D. Molecular Diversity and Combinatorial Chemistry: Principles and Applications (Tetrahedron Organic Chemistry Series) (Pirrung, Michael C.). 


\section{J. Chem. Educ. 82, 1154 (2005).}

16. Hong, J. W., Studer, V., Hang, G., Anderson, W. F. \& Quake, S. R. A nanoliter-scale nucleic acid processor with parallel architecture. Nat. Biotechnol. 22, 435-439 (2004).

17. Liu, J., Hansen, C. \& Quake, S. R. Solving the "World-to-Chip" Interface Problem with a Microfluidic Matrix. Anal. Chem. 75, 4718-4723 (2003).

18. Pieprzyk, M. \& High, H. Fluidigm Dynamic Arrays provide a platform for single-cell gene expression analysis. Nat. Methods 6, iii-iv (2009).

19. Fredrickson, C. K. \& Fan, Z. H. Macro-to-micro interfaces for microfluidic devices. Lab. Chip 4, 526-533 (2004).

20. Cetin, B. \& Li, D. Dielectrophoresis in microfluidics technology. Electrophoresis 32, 2410-2427 (2011).

21. Yamada, M., Nakashima, M. \& Seki, M. Pinched Flow Fractionation: Continuous Size Separation of Particles Utilizing a Laminar Flow Profile in a Pinched Microchannel. Anal. Chem. 76, 5465-5471 (2004).

22. Auroux, P.-A., Iossifidis, D., Reyes, D. R. \& Manz, A. Micro total analysis systems. 2. Analytical standard operations and applications. Anal. Chem. 74, 2637-2652 (2002).

23. Jensen, K. F. Microreaction engineering - is small better? 16th Int. Conf. Chem. React. Eng. 56, 293-303 (2001).

24. Hong, J. W. \& Quake, S. R. Integrated nanoliter systems. Nat. Biotechnol. 21, 1179-1183 (2003).

25. McDonald, J. C. \& Whitesides, G. M. Poly(dimethylsiloxane) as a Material for Fabricating Microfluidic Devices. Acc. Chem. Res. 35, 491-499 (2002).

26. Šalić, A. \& Zelić, B. Synergy of Microtechnology and Biotechnology: Microreactors as an Effective Tool for Biotransformation Processes $(\S)$ : (§)The paper was presented at European Biotechnology Congress, 25-27 May 2017, Dubrovnik, Croatia. Food Technol. Biotechnol. 56, 464-479 (2018).

27. Dutse, S. W. \& Yusof, N. A. Microfluidics-based lab-on-chip systems in DNA-based biosensing: an overview. Sensors 11, 5754-5768 (2011).

28. Fu, A. Y., Chou, H.-P., Spence, C., Arnold, F. H. \& Quake, S. R. An Integrated Microfabricated Cell Sorter. Anal. Chem. 74, 2451-2457 (2002).

29. Kartalov, E. P. \& Quake, S. R. Microfluidic device reads up to four consecutive base pairs in DNA sequencing-by-synthesis. Nucleic Acids Res. 32, 2873-2879 (2004).

30. Wheeler, A. R. et al. Microfluidic Device for Single-Cell Analysis. Anal. Chem. 75, 3581-3586 (2003). 
31. Weibel, D. B. et al. Torque-Actuated Valves for Microfluidics. Anal. Chem. 77, 4726-4733 (2005).

32. Thorsen, T., Maerkl, S. J. \& Quake, S. R. Microfluidic Large-Scale Integration. Science 298, 580 (2002).

33. Chow, A. W. Lab-on-a-chip: Opportunities for chemical engineering. AIChE J. 48, 1590-1595 (2002).

34. Jensen, K. F. Microchemical systems: Status, challenges, and opportunities. AIChE J. 45, 2051-2054 (1999).

35. Jansen, D. J. \& Shenvi, R. A. Synthesis of medicinally relevant terpenes: reducing the cost and time of drug discovery. Future Med. Chem. 6, 1127-1148 (2014).

36. Fletcher, P. D. et al. Micro reactors: principles and applications in organic synthesis. Tetrahedron 58, 4735-4757 (2002).

37. MARTIN, P. M., MATSON, D. W. \& BENNETT, W. D. MICROFABRICATION METHODS FOR MICROCHANNEL REACTORS AND SEPARATIONS SYSTEMS. Chem. Eng. Commun. 173, 245-254 (1999).

38. Chen, C., Hirdes, D. \& Folch, A. Gray-scale photolithography using microfluidic photomasks. Proc. Natl. Acad. Sci. 100, 1499 (2003).

39. Chronis, N., Liu, G. L., Jeong, K.-H. \& Lee, L. P. Tunable liquid-filled microlens array integrated with microfluidic network. Opt Express 11, 23702378 (2003).

40. Bing Dang et al. Wafer-level microfluidic cooling interconnects for GSI. in Proceedings of the IEEE 2005 International Interconnect Technology Conference, 2005. 180-182 (2005). doi:10.1109/IITC.2005.1499971.

41. deMello, A. J. Control and detection of chemical reactions in microfluidic systems. Nature 442, 394-402 (2006).

42. Nightingale, A. M. et al. Large-scale synthesis of nanocrystals in a multichannel droplet reactor. J. Mater. Chem. A 1, 4067-4076 (2013).

43. Lv, J.-A. et al. Photocontrol of fluid slugs in liquid crystal polymer microactuators. Nature 537, 179-184 (2016).

44. Psaltis, D., Quake, S. R. \& Yang, C. Developing optofluidic technology through the fusion of microfluidics and optics. Nature 442, 381-386 (2006).

45. Craighead, H. Future lab-on-a-chip technologies for interrogating individual molecules. Nature 442, 387-393 (2006).

46. Amstad, E. et al. Production of amorphous nanoparticles by supersonic spray-drying with a microfluidic nebulator. Science 349, 956 (2015). 
47. Adamo, A. et al. On-demand continuous-flow production of pharmaceuticals in a compact, reconfigurable system. Science 352, 61 (2016).

48. Baah, D. \& Floyd-Smith, T. Microfluidics for particle synthesis from photocrosslinkable materials. Microfluid. Nanofluidics 17, 431-455 (2014).

49. Kim, H. et al. Submillisecond organic synthesis: Outpacing Fries rearrangement through microfluidic rapid mixing. Science 352, 691 (2016).

50. Fan, X. \& Yun, S.-H. The potential of optofluidic biolasers. Nat. Methods 11, 141-147 (2014).

51. Ren, K., Zhou, J. \& Wu, H. Materials for microfluidic chip fabrication. Acc. Chem. Res. 46, 2396-2406 (2013).

52. Squires, T. M. \& Quake, S. R. Microfluidics: Fluid physics at the nanoliter scale. Rev. Mod. Phys. 77, 977-1026 (2005).

53. Seemann, R., Brinkmann, M., Pfohl, T. \& Herminghaus, S. Droplet based microfluidics. Rep. Prog. Phys. Phys. Soc. G. B. 75, 016601 (2012).

54. Wang, R. et al. A General Strategy for Nanohybrids Synthesis via Coupled Competitive Reactions Controlled in a Hybrid Process. Sci. Rep. 5, 9189 (2015).

55. Wang, J., Wang, Z., Li, S., Wang, R. \& Song, Y. Surface and interface engineering of $\mathrm{FePt} / \mathrm{C}$ nanocatalysts for electro-catalytic methanol oxidation: enhanced activity and durability. Nanoscale 9, 4066-4075 (2017).

56. Harnett, C. K., Templeton, J., Dunphy-Guzman, K. A., Senousy, Y. M. \& Kanouff, M. P. Model based design of a microfluidic mixer driven by induced charge electroosmosis. Lab. Chip 8, 565-572 (2008).

57. Zhang, F. Induced-Charge Electrokinetic Flow. in Encyclopedia of Microfluidics and Nanofluidics (ed. Li, D.) 1383-1387 (Springer New York, 2015). doi:10.1007/978-1-4614-5491-5_1704.

58. Nguyen, N. T., Wereley, S. T. \& Shaegh, S. A. M. Fundamentals and Applications of Microfluidics, Third Edition. (Artech House, 2019).

59. Alibert, C., Goud, B. \& Manneville, J.-B. Are cancer cells really softer than normal cells? Biol. Cell 109, 167-189 (2017).

60. Lekka, M. et al. Elasticity of normal and cancerous human bladder cells studied by scanning force microscopy. Eur. Biophys. J. EBJ 28, 312-316 (1999).

61. Deng, Y. et al. Inertial Microfluidic Cell Stretcher (iMCS): Fully Automated, High-Throughput, and Near Real-Time Cell Mechanotyping. Small Weinh. Bergstr. Ger. 13, (2017).

62. Chen, Q., Schlichtherle, M. \& Wahlgren, M. Molecular aspects of severe malaria. Clin. Microbiol. Rev. 13, 439-450 (2000). 
63. Holmes, D. et al. Separation of blood cells with differing deformability using deterministic lateral displacement $(\dagger)$. Interface Focus 4, 20140011 (2014).

64. Luo, Z. et al. Deformation of a single mouse oocyte in a constricted microfluidic channel. Microfluid. Nanofluidics 19, 883-890 (2015).

65. Hou, H. et al. Deformability study of breast cancer cells using microfluidics. Biomed. Microdevices 11, 557-564 (2009).

66. Wang, K. et al. Specific membrane capacitance, cytoplasm conductivity and instantaneous Young's modulus of single tumour cells. Sci. Data 4, 170015 (2017).

67. Hodgson, A. C. et al. A microfluidic device for characterizing nuclear deformations. Lab Chip 17, 805-813 (2017).

68. Guo, Q., Reiling, S. J., Rohrbach, P. \& Ma, H. Microfluidic biomechanical assay for red blood cells parasitized by Plasmodium falciparum. Lab Chip 12, 1143-1150 (2012).

69. Shelby, J. P., White, J., Ganesan, K., Rathod, P. K. \& Chiu, D. T. A microfluidic model for single-cell capillary obstruction by Plasmodium falciparum-infected erythrocytes. Proc. Natl. Acad. Sci. U. S. A. 100, 1461814622 (2003).

70. Bodnár, T., Sequeira, A. \& Prosi, M. On the shear-thinning and viscoelastic effects of blood flow under various flow rates. Numer. Anal. Fluid Flow Heat Transf. 217, 5055-5067 (2011).

71. Huber, D., Oskooei, A., Casadevall I Solvas, X., deMello, A. \& Kaigala, G. V. Hydrodynamics in Cell Studies. Chem. Rev. 118, 2042-2079 (2018).

72. Fluid Mechanics. in Engineering Thermofluids: Thermodynamics, Fluid Mechanics, and Heat Transfer (ed. Massoud, M.) 223-430 (Springer Berlin Heidelberg, 2005). doi:10.1007/3-540-27280-1_3.

73. Kartashov, Y. V., Vysloukh, V. A. \& Torner, L. Brownian soliton motion. Phys. Rev. A 77, 051802 (2008).

74. Clift, R., Grace, J. \& Weber, M. Bubbles, Drops, and Particles. in (1978).

75. Moledina, F. et al. Predictive microfluidic control of regulatory ligand trajectories in individual pluripotent cells. Proc. Natl. Acad. Sci. U. S. A. 109, 3264-3269 (2012).

76. Schlichting (Deceased), Hermann. author. (role)aut (role)http://id. loc. gov/vocabulary/relators/aut \& Gersten, Klaus. author. (role)aut (role)http://id. loc. gov/vocabulary/relators/aut. Boundary-Layer Theory. (2017).

77. White, F. M. Viscous fluid flow [by] Frank M. White. (McGraw-Hill, 1974).

78. Welty, J. R., Wicks, C. E. \& Wilson, R. E. Fundamentals of momentum, 
heat, and mass transfer. in (1969).

79. Solutions of Uncharged Molecules. in Physicochemical Hydrodynamics 53107 (John Wiley \& Sons, Ltd, 1994). doi:10.1002/0471725137.ch4.

80. Rajamanickam, P. Dispersion of solute in straining flows and boundary layers. Phys. Fluids 32, 051703 (2020).

81. Levenspiel, O. \& Smith, W. K. Notes on the diffusion-type model for the longitudinal mixing of fluids in flow. Front. Chem. Eng. Sci. 50, 3891-3896 (1995).

82. Zhu, C. Kinetics and mechanics of cell adhesion. J. Biomech. 33, 23-33 (2000).

83. Bell, G. Models for the specific adhesion of cells to cells. Science 200, 618 (1978).

84. Kaplanski, G. et al. Granulocyte-endothelium initial adhesion. Analysis of transient binding events mediated by E-selectin in a laminar shear flow. Biophys. J. 64, 1922-1933 (1993).

85. Alon, R., Hammer, D. A. \& Springer, T. A. Lifetime of the P-selectincarbohydrate bond and its response to tensile force in hydrodynamic flow. Nature 374, 539-542 (1995).

86. Shin, Y. et al. Microfluidic assay for simultaneous culture of multiple cell types on surfaces or within hydrogels. Nat. Protoc. 7, 1247-1259 (2012).

87. Duffy, D. C., McDonald, J. C., Schueller, O. J. A. \& Whitesides, G. M. Rapid Prototyping of Microfluidic Systems in Poly(dimethylsiloxane). Anal. Chem. 70, 4974-4984 (1998). 


\subsection{Suplementario $S 1$}

Resolviendo Navier-Stokes para un microcanal cuadrado sin condiciones de borde por la fuerza de cizalla en las paredes, donde se describe el perfil de velocidad:

$$
U_{x}(Y, Z)=\frac{48 Q}{\pi^{3} h w} \frac{\sum_{n}^{\infty}=1,3, \ldots \ldots \frac{1}{n^{3}}\left[1-\frac{\cosh \left(n \pi \frac{y}{n}\right)}{\cosh \left(n \pi \frac{w}{2 h}\right)}\right] \sin \left(n \pi \frac{z}{h}\right)}{1-\sum_{n}^{\infty}=1,3, \ldots \frac{192 h}{n^{5} \pi^{5} w} \tanh \left(n \pi \frac{w}{2 h}\right)}
$$

Donde Q es el caudal volumétrico, h y w son la altura y el ancho del canal. 


\section{Capítulo II}

\section{Molde de resina epóxica y dispositivos} de microfluídica de PDMS mediante una placa de un fotopolímero de impresión flexográfica. 


\subsection{Resumen.}

La placa de impresión de fotopolímero flexográfico es un material fotopolimérico nuevo utilizado para la fabricación de microdispositivos. Este trabajo demuestra que el molde maestro de fotopolímero flexográfico puede ser utilizado para la fabricación de microdispositivos de PDMS a través de un proceso de manufactura multipasos. Esta metodología abarca tres pasos principales de fabricación: (1) se genera un molde de placa de impresión de fotopolímero flexográfico (Fmold) mediante exposición a luz UV a través de una filmina transparente, (2) las estructuras del molde de fotopolímero se transfieren al molde de resina epóxica y (3) se fabrica el microdispositivo a partir del molde de resina epóxica. La caracterización de los microdispositivos de PDMS fabricados fue realizada mediante microscopía electrónica de barrido (SEM) y perfilometría. Los resultados mostraron alta precisión en la replicación de los perfiles. La metodología descrita en este trabajo provee una estrategia fácil, robusta y de bajo costo que facilita el escalamiento de los dispositivos de microfluídica sin requerir equipo sofisticado.

\subsection{Introducción.}

La técnica de flexografía es un proceso de impresión muy extendido que se ha utilizado en varios sustratos como paquetes de alimentos, periódicos, insertos, papel de regalo, papel tapiz, catálogos, entre otros ${ }^{1,2}$. En los últimos años, esta técnica se ha empleado para producir varias estructuras en relieve para sistemas de fluidos en papel $^{3}$, dispositivos electrónicos como electrodos ${ }^{4}$, condensadores ${ }^{5}$, sensores $^{6}$ y transistores ${ }^{7}$. Los procesos involucrados son; el uso de impresión gráfica convencional, tintas funcionales, sustratos como vidrio, papel, película PET, placa de impresión flexográfica de fotopolímero entre otros ${ }^{3,8}$. Como resultado, una variedad de patrones con escala micrométrica se puede obtener con una resolución y espesor uniforme. Las mejoras logradas con esta técnica han llevado a un alto rendimiento y a un diseño de dispositivos complejos con una amplia variedad de aplicaciones en diferentes campos ${ }^{1,9}$. La metodología de uso de la tecnología flexográfica para la fabricación de los dispositivos de microfluídica la metodología se ha desarrollado y caracterizado recientemente previamente por los autores ${ }^{10}$. Tiene muchas ventajas sobre métodos no tradicionales como la 
ablación con láser de $\mathrm{CO}_{2}{ }^{11}$, estampado en caliente ${ }^{12}$, sello de acero inoxidable ${ }^{13}$, tóner ${ }^{14}$, moldeado líquido ${ }^{15,16}$, bloques de construcción ${ }^{17}$, ablación láser ${ }^{18}$, hinchamiento láser ${ }^{19}$, semicontacto escritura ${ }^{20}$, impresión $3 \mathrm{D}^{21,22}$ y molde de cera $^{23}$. Las principales ventajas de los moldes flexográficos son: (i) fabricación de moldes en poco tiempo, (ii) el fenómeno de laminación debido a las estructuras del molde de fotopolímero forma un solo elemento que está ausente, (iii) bajo costo, (iv) moldes múltiples con una variedad de dimensiones (altura, ancho, largo) podrían fabricarse, (v) replicación de alto rendimiento, (vi) ancho mínimo del canal de $10 \mu \mathrm{m}$ y (vii) baja rugosidad superficial de las estructuras ${ }^{10}$. En los trabajos anteriores, a pesar de todas las ventajas mencionadas del Pliegues, su vida útil se limitaba al desprendimiento de la capa de $\mathrm{SiO}_{2}$ causado por el proceso de replicación. Adicionalmente, para la fabricación es necesario un equipo de deposición de vapor químico (CVD) para los moldes. En este trabajo, una metodología alternativa para fabricar microdispositivos PDMS fue desarrollado, combinando la técnica Fmold con el método ERmold. La nueva metodología ofrece moldes duraderos que no requieren la deposición de $\mathrm{SiO}_{2}$ como la metodología informada anteriormente y, por tanto, su durabilidad es mucho mayor. Además, la fabricación ERmold no requiere equipo CVD, por lo que este molde se puede utilizar ampliamente en cualquier laboratorio sin necesidad de adquirir costosos equipos. Finalmente, los moldes resultantes y las réplicas de PDMS fueron caracterizados mediante microscopía electrónica de barrido (SEM) y técnicas de perfilometría.

\subsection{Materiales y métodos.}

\subsubsection{Fabricación de dispositivos de microfluídica PDMS.}

El proceso de fabricación de los dispositivos de microfluídica de PDMS consta de tres pasos principales: (1) fabricación del molde maestro flexográfico de fotopolímero (Fmold), (2) fabricación de un molde macho de resina epóxica reutilizable (ERmold) utilizando el Fmold mediante copia de la réplica y (3) transferencia del ERmold en PDMS. Este proceso se resume esquemáticamente en figura 2.1. El Molde maestro flexográfico de fotopolímero (Fmold): El fotopolímero Flexcel NX y la capa térmica de imagen (TIL) utilizadas en la fabricación de los moldes fueron suministrados por Eastman Kodak ${ }^{24}$. Los pasos 
de fabricación del Fmold se han descrito en un trabajo anterior ${ }^{10}$. Brevemente, la red de microcanales se diseñó con un paquete informático editor de diseño ${ }^{25}$ este diseño fue transferido al TIL con una fuente de láser infrarrojo de 2400 ppi.

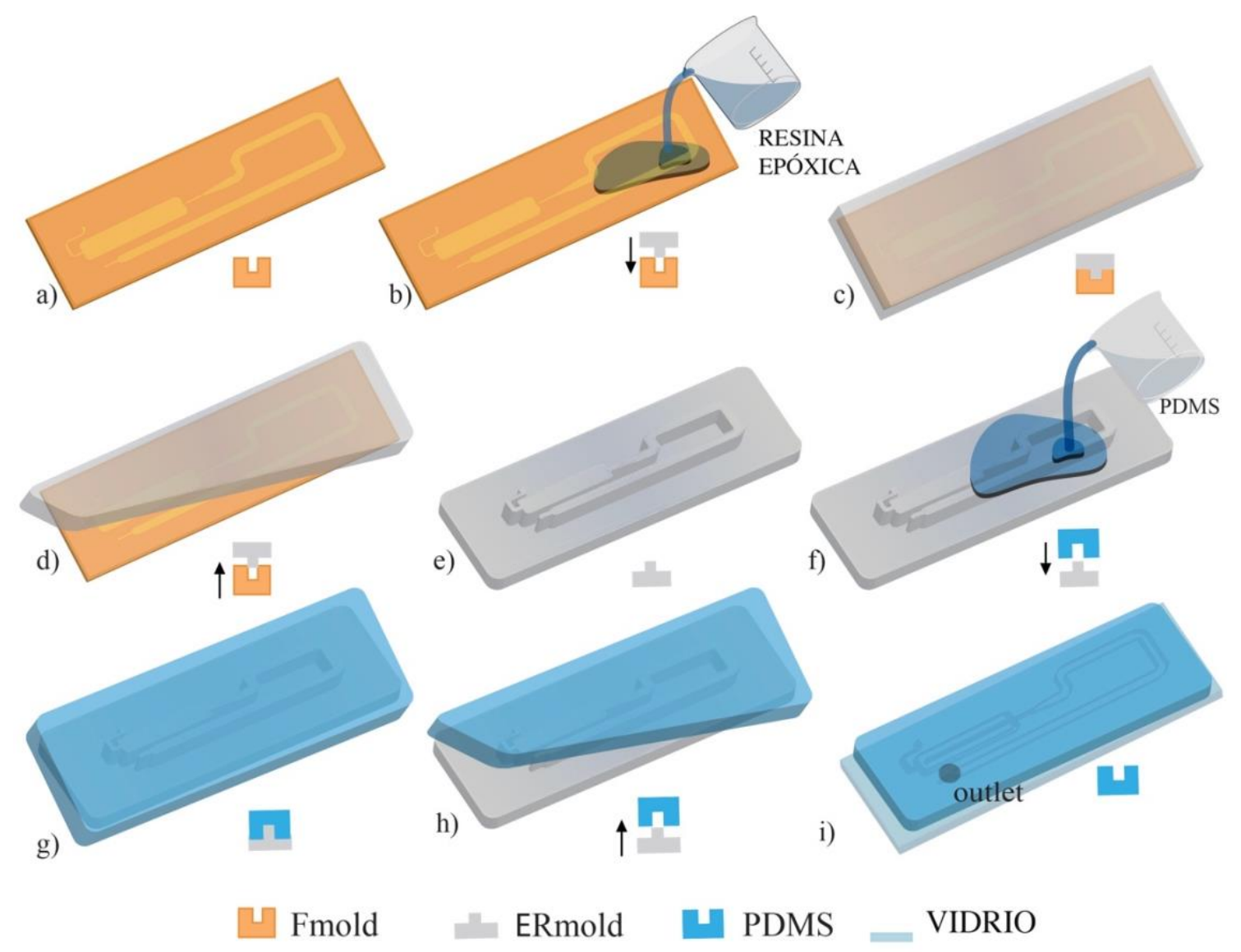

Figura. 2.1. Fabricación del microdispositivo de PDMS. (a) Molde maestro del fotopolimérico flexográfico (Fmold). $(b, c)$ La resina epóxica se cuela sobre el molde F y se cura a $25^{\circ} \mathrm{C}$. $(d, e)$ Después de $72 \mathrm{~h}$, se despega el molde ER para formar el molde macho. ( $f, g)$ El PDMS se vierte sobre el ERmold y se cura a $40^{\circ}$ C durante la noche. (h) Se despega la réplica de PDMS. (i) Se perforan los puertos de entra y salida para las conexiones y luego la réplica se une irreversiblemente a un portaobjetos de vidrio por exposición al plasma.

En el siguiente paso, se expuso la placa de fotopolímero a la luz UVA a $0.45 \mathrm{~J}$ en el reverso y luego en el anverso se expuso a luz UVA a 19 J durante 360 s, después se eliminó el TIL. Se utilizaron diferentes períodos de exposición a los rayos UVA en el reverso para controlar la altura de los microcanales. Posteriormente, la placa de fotopolímero se lavó con disolvente PROSOL N-1 (suministrado por Eastman 
Kodak) a $360 \mathrm{~mm} \cdot \mathrm{min}^{-1}$ y se secó en estufa durante $30 \mathrm{~min}$ a $50^{\circ} \mathrm{C}$. Finalmente, la placa de fotopolímero se expuso a luz UVC a $10 \mathrm{~J}$ durante 17 min y luz UVA a $4 \mathrm{~J}$ durante 2 min en la parte frontal. Este molde fue codificado como Fmold. Antes de su uso, el Fmold se colocó en una estufa a $100{ }^{\circ} \mathrm{C}$ por $12 \mathrm{~h}$ y luego se trató en una cámara de vacío por $1 \mathrm{~h}$. a $25^{\circ} \mathrm{C}$, seguido de un proceso de limpieza en solución de etanol al $70 \%$ en baño ultrasónico por $7 \mathrm{~min}$, secado a $40{ }^{\circ} \mathrm{C}$ por $10 \mathrm{~min}$ y con nitrógeno. El molde de resina epóxica (ERmold): disponible comercialmente y un agente de curado (Cristal-Tack, Novarchem - Argentina) se mezclaron con agitación manual durante 3 minutos en una proporción en peso de 2:1 y se trataron con un sonicador (TESTLAB Ultrasonic Cleaner) durante 7 min para eliminar las burbujas de aire. Luego, la mezcla se vertió sobre el molde Fmold y se curó a temperatura ambiente durante $72 \mathrm{~h}$. Después del curado, el molde de resina epóxica se despegó del molde Fmold para formar el molde macho (Figura. 2.1d), este molde se conoce como ERmold.

Microdispositivo PDMS: Brevemente, el PDMS se mezcló con el agente de curado en una proporción en peso de 10:1 (Sylgard 184 Silicone Elastomer Kit), como fue descrito por Peñaherrera et al. ${ }^{26}$ Luego, la mezcla se colocó al vacío durante 30 min para eliminar las burbujas de aire, se vertió en el Ermold y se curó en una estufa a $40^{\circ} \mathrm{C}$ durante la noche (Figura. 2.1f, $2.1 \mathrm{~g}$ ). Después del curado, la réplica de PDMS se despegó del molde y se perforaron los orificios para las entradas y salidas de los canales de $1 \mathrm{~mm}$ de diámetro. (Integra Miltex®Ted Pella, Inc). Finalmente, la réplica se unió de forma irreversible a una oblea de vidrio después de la exposición a un generador de alta frecuencia (BD-10AS, Chicago) durante $120 \mathrm{~s}$.

\subsubsection{Caracterización.}

La caracterización morfológica de los Fmolds, ERmolds y las réplicas de PDMS se llevó a cabo utilizando un microscopio electrónico de barrido (TESCAN FEG SEM MIRA3). Para evitar daño de las muestras, las mediciones SEM se realizaron a voltajes de $7 \mathrm{kV}$. Previamente, los moldes fueron metalizados con una capa de oro de $20 \mathrm{~nm}$. Las mediciones cuantitativas se realizaron con el paquete informático MIRA TC versión 4.2.24.0. Las medidas de perfilometría fueron realizado con el perfilómetro Dektak XT de Bruker, y el análisis se llevó a cabo utilizando el paquete informático Vision 64. Se realizaron exploraciones lineales 
con una punta de radio de $25 \mu \mathrm{m}$, a una velocidad de escaneo de $10 \mu \mathrm{ms}^{-1}$ y a una frecuencia de muestreo de $0,01 \mathrm{Hzmm}^{-1}$. Antes de la caracterización, los moldes estuvieron en una estufa a $40^{\circ} \mathrm{C}$ durante $1 \mathrm{~h}$.

\subsection{Resultados y discusión.}

\subsubsection{Replicación de características.}

La figura 2.2 muestra imágenes de SEM de PDMS réplicas con diferentes topologías, estructuras y dimensiones. Características: circular, curvas, serpenteante, cuadrado, diagonal y lineal y sin canales lineales, con dimensiones de ancho que van desde $80 \mu \mathrm{m}$ hasta $2200 \mu \mathrm{m}$. La replicación exitosa de las topologías microfluídicas en Fmold y ERmold demuestran que la metodología desarrollada permite obtener réplicas de PDMS a través de la plancha de impresión flexográfica del fotopolímero.

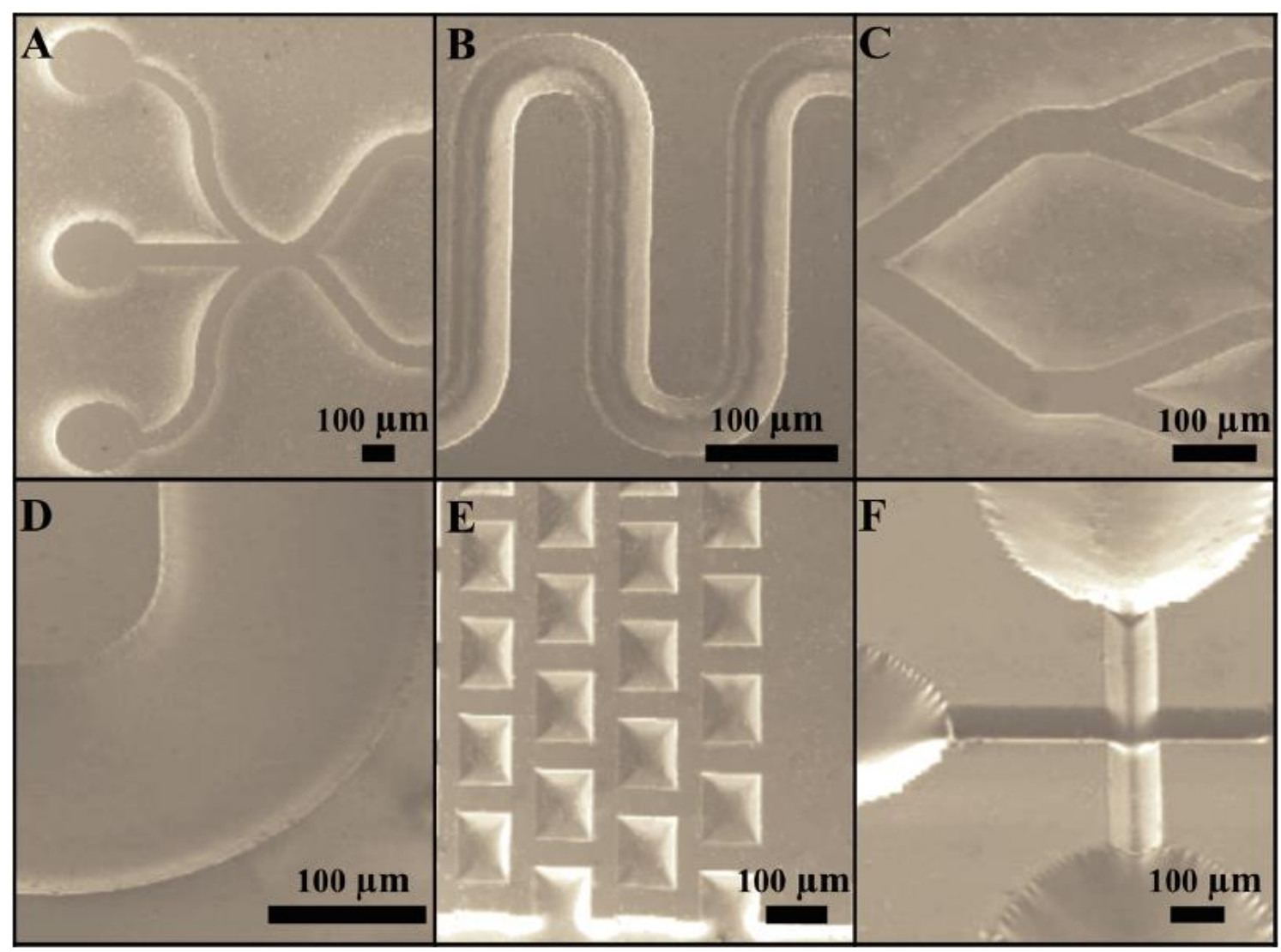

Figura. 2.2 Imágenes SEM de topologías de canales de microfluídica PDMS moldeados a partir de ERmold. Replicas de topologías microfluídicas que van 
desde patrones lineales y curvos: A: circular, B: serpentina, C: diagonal, D: curvo, E: cuadrado, F: intersección lineal. (barra de escala: $100 \mu \mathrm{m}$ ).

Tabla 2.1. Fidelidad de la replicación de Fmold/ERmold. Profundidad, altura y ancho medidos en el microcanal después de cada réplica.

\begin{tabular}{cccccc}
\hline Sección & $\begin{array}{c}\text { Diseño por L-edit } \\
\text { paquete } \\
\text { informático }\end{array}$ & Fmold & $\begin{array}{c}\text { ERmold- } \\
\mathbf{1}\end{array}$ & $\begin{array}{c}\text { ERmold- } \\
\mathbf{2}\end{array}$ & $\begin{array}{c}\text { ERmold- } \\
\mathbf{3}\end{array}$ \\
\hline Altura/Profundidad $(\boldsymbol{\mu m})_{\mathbf{a}}$ & & & & & \\
----- & ----- & $144 \pm 1.6$ & $141 \pm 1.6$ & $143 \pm 2.2$ & $143 \pm 1.6$ \\
Ancho( $\boldsymbol{\mu m})_{\mathbf{b}}$ & & & & & \\
A & 500 & $518 \pm 2.5$ & $505 \pm 0.5$ & $503 \pm 3.4$ & $507 \pm 7.9$ \\
B & 400 & $411 \pm 0.5$ & $395 \pm 2.1$ & $395 \pm 3.1$ & $392 \pm 1.1$ \\
C & 70 & $83 \pm 0.5$ & $75 \pm 4.2$ & $78 \pm 2.4$ & $79 \pm 4.2$ \\
\hline
\end{tabular}

a Las medidas de altura y profundidad se determinaron mediante la técnica de perfilometría $(n=6)$.

b Las medidas de ancho se determinaron mediante la técnica SEM $(n=3)$.

\subsubsection{Fidelidad de la replicación de Fmold/ERmold y durabilidad de Fmold.}

La fidelidad de replicación de Fmold al ERmold fue evaluada comparando las dimensiones características de los moldes. Para ello, un dispositivo microfluídico generador de gotas de emulsión única de enfoque de flujo fue diseñado. Se utilizaron medidas de perfilometría e imágenes de SEM para determinar las dimensiones de profundidad, altura y ancho. Además, la estabilidad y durabilidad del Fmold se evaluaron comparando tres réplicas de ERmold obtenidas del mismo Fmold. La figura 2.3 muestra las imágenes SEM de tres secciones de interés en el Fmold y la primera, segunda y tercera réplicas de ERmold. Las regiones seleccionadas se componen de una unión en T (sección A), curva (sección B) e intersección lineal (sección C) que corresponden a segmentos del microcanal. La Tabla 1 enumera las dimensiones de altura, profundidad y ancho del Fmold con respecto a las réplicas de ERmold en las secciones A, B y C. La dimensión del ancho del ERmold fue obtenido por SEM, donde se aprecia una ligera contracción $(<10 \%)$ en comparación con Fmold. Además, el análisis de perfilometría muestra que las dimensiones de las réplicas en la altura y profundidad tanto en el Fmold 
como en ERmold están muy cerca $(144 \mu \mathrm{m})$, se observa una pequeña contracción $(<3 \%)$. Los resultados demostraron que Fmold es un molde reutilizable que permite obtener ERmolds con éxito. En cuanto a la comparación entre el ancho del canal del Fmold y el diseñado por el paquete informático L-edit, se observan algunas diferencias. El ancho del canal dibujado es de $500 \mu \mathrm{m}, 400 \mu \mathrm{m}$ y $70 \mu \mathrm{m}$ en las secciones A, B y C, respectivamente. Sin embargo, los anchos de canal en estas secciones es 18,11 y $13 \mu \mathrm{m}$ más alto que el diseñado utilizando por el paquete informático. Esto puede deberse al proceso de obtención de imágenes de las microestructuras en el TIL, ya que el láser tiene un diámetro de 10,5 $\mu \mathrm{m}$. En consecuencia, las medidas finales del ancho de canal obtenidas en el TIL son más grandes que los dibujados por el paquete informático.

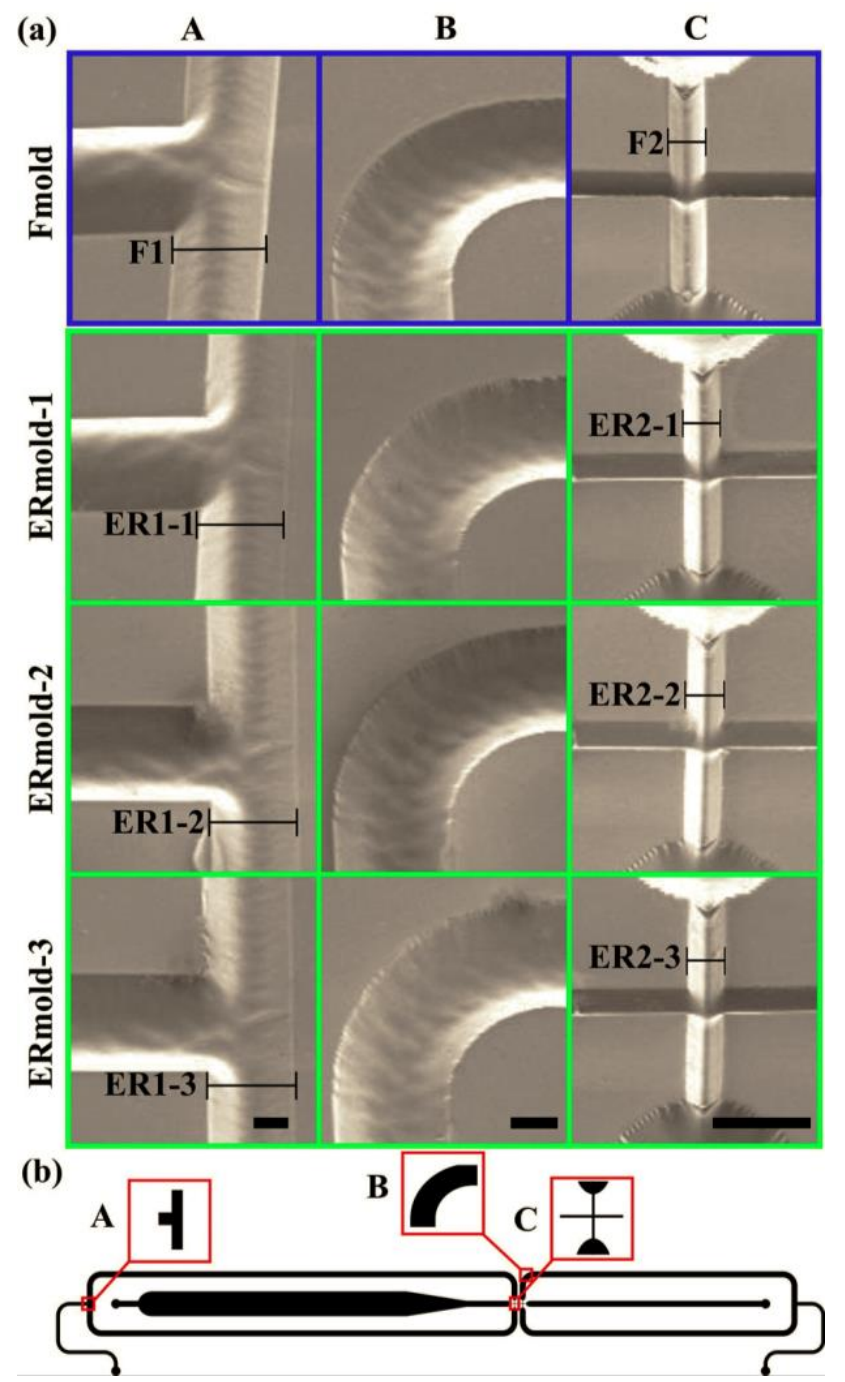

Figura. 2.3. Precisión en las características de Fmold a ERmold. (a) Imágenes SEM de secciones seleccionadas del Fmold fabricado (fila azul), ERmold-1 (fila verde), ERmold-2 (fila verde) y ERmold-3 (fila verde). Sección A: Unión en T, sección B: 
curva, sección C: segmentos la intersección del canal lineal. (b) Enfoque en el diseño de dispositivo microfluídico donde se generan las gotas de doble emulsión. (Barra de escala: $200 \mu \mathrm{m}$ ).

\subsubsection{Fidelidad de replicación ERmold / PDMS y durabilidad ERmold.}

La Tabla 2.2 muestra las medidas de SEM y perfilometría de las dimensiones del canal para el Fmold y el ERmold, además se detallan la primera, quinta y décima réplicas de PDMS de un dispositivo microfluídico que genera gotas de doble emulsión. Se puede apreciar que las dimensiones del canal (ancho, alto, profundidad) varían en menos del 10\%, lo que demuestra que el PDMS puede replicar con alta fidelidad. La figura 2.4 muestra las imágenes de SEM de las tres secciones de las réplicas de PDMS; primera, quinta y décima. La geometría del microcanal no cambió durante los múltiples pasos. A partir de estos resultados, se demostró que las características de transferencia del ERmold al PDMS son precisas. Adicionalmente, se determinó la estabilidad y durabilidad del ERmold. Los resultados evidencian que el ERmold puede emplearse en múltiples veces para obtener réplicas de PDMS. Por otro lado, la precisión es comparable a las tolerancias fotolitográficas típicas $(10 \%)^{27}$, haciendo que la metodología propuesta sea candidato ideal para la fabricación de dispositivos microfluídicos con diferentes propósitos ya que los microcanales poseen dimensiones relevantes para una amplia gama de aplicaciones. Además, se demostró la reutilización y durabilidad del ERmold; la resina epóxica comercial seleccionada genera moldes maestros que se pueden utilizar para obtener réplicas de PDMS con un mínimo cambios en las dimensiones y de las características. 
Tabla 2.2

Replicación de ERmold/PDMS. Medida de la profundidad, ancho y alto del microcanal después del proceso de desmolde.

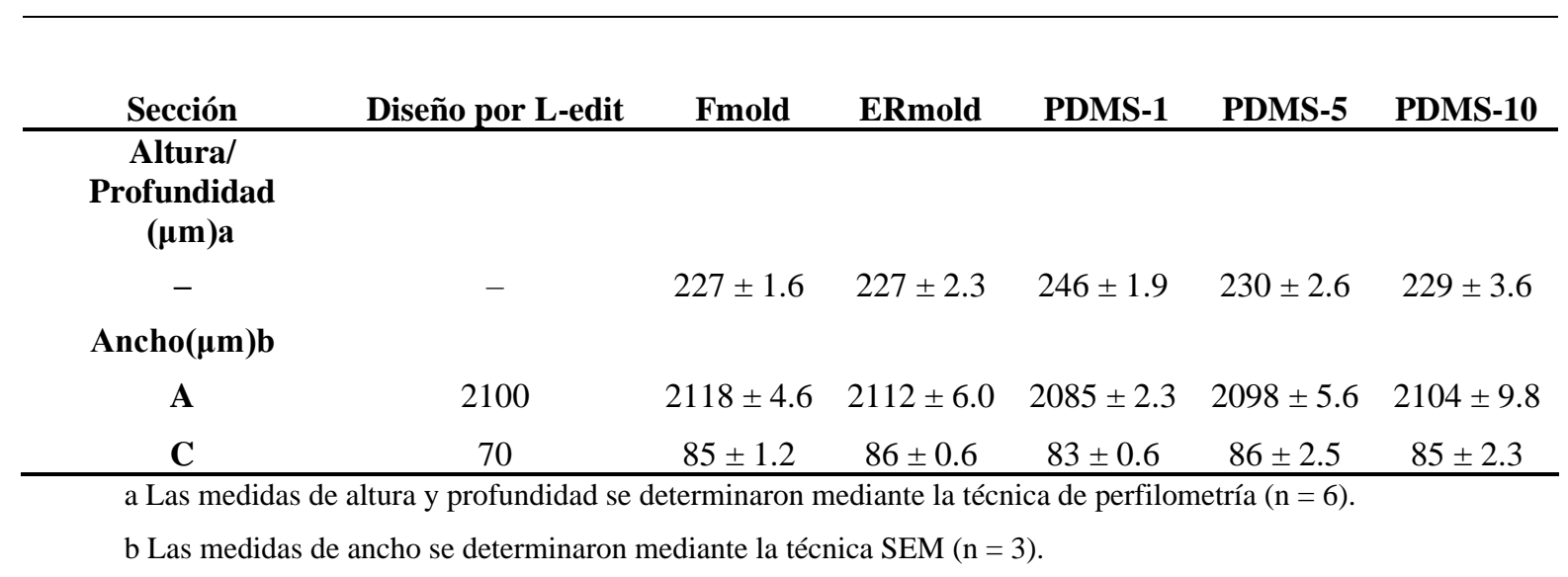

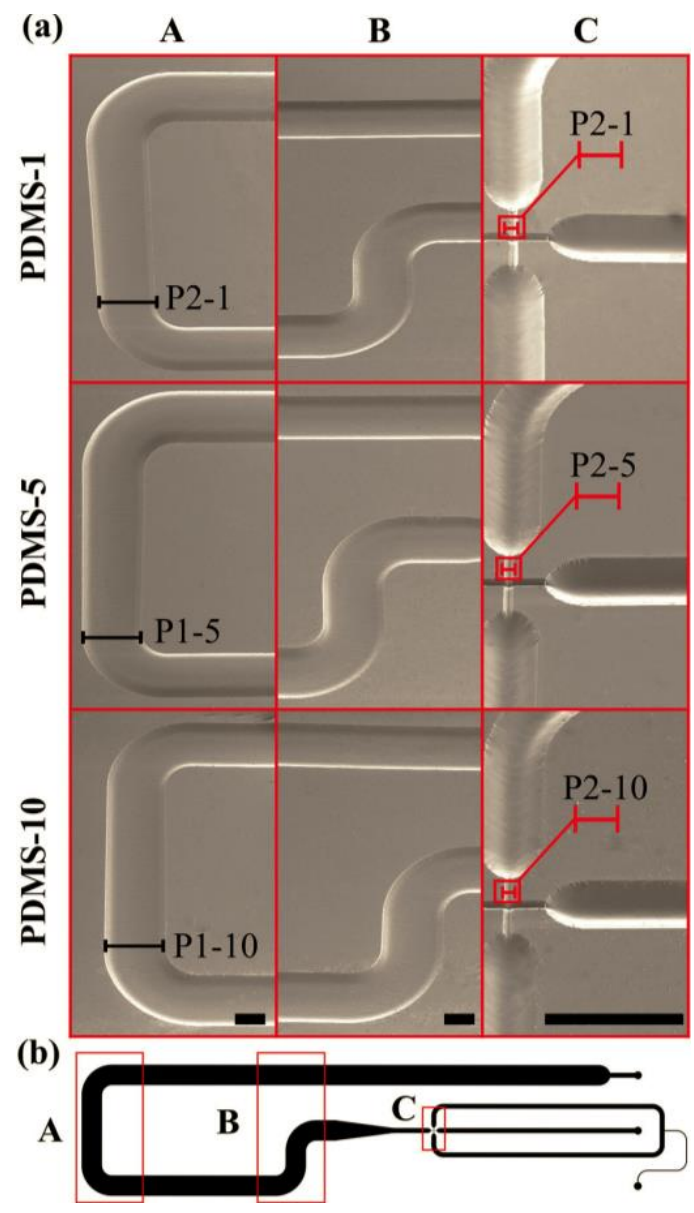

UTN, Carrera Doctorado en Ingeniería, mención Materiales 
Figura. 2.4. Precisión en la copia de características de ERmold a réplica de PDMS. (a) Imágenes SEM de secciones seleccionadas de las réplicas de PDMS. (b) Enfoque en el sitio de emulsión del dispositivo de microfluídica generador de gotas. (Barra de escala: $1000 \mu \mathrm{m}$ ).

\subsection{Conclusiones.}

Para una variedad de áreas de investigación, un aspecto crítico es seleccionar una metodología para construir moldes para fabricar microdispositivos PDMS. Demostramos que ERMold podría considerarse una buena opción para obtener réplicas de PDMS con distintas topologías. Sorprendentemente, el enfoque metodológico propuesto aquí permite fabricar moldes reutilizables con alta capacidad de replicación y que contienen estructuras que van desde micrones hasta milímetros. La funcionalidad y versatilidad de la metodología ha demostrado con éxito la fabricación de varias topologías. 


\subsection{Referencias.}

1. S. Kim, H. Sojoudi, H. Zhao, D. Mariappan, G.H. McKinley, K.K. Gleason, A.J. Hart, Ultrathin high-resolution flexographic printing using nanoporous stamps, Sci. Adv. 2 (2016) doi:https://doi:10.1126/sciadv.1601660.

2. D. Novaković, S. Dedijer, S.M. Polja, A model for improving the flexographic printing plate making process, Tech. Gaz 17 (2010) 403-410 https://hrcak.srce.hr/ 62914.

3. J. Olkkonen, K. Lehtinen, T. Erho, Flexographically printed fluidic structures in paper, Anal. Chem. 82 (2010) 10246-10250, https://doi.org/10.1021/ac1027066.

4. J.S. Sagu, N. York, D. Southee, K.G.U. Wijayantha, Printed electrodes for flexible, light-weight solid-state supercapacitors - a feasibility study, Circuit World 41 (2015) 80-86, https://doi.org/10.1108/CW-01-2015-0004.

5. N. Graddage, T.-Y. Chu, H. Ding, C. Py, A. Dadvand, Y. Tao, Inkjet printed thin and uniform dielectrics for capacitors and organic thin film transistors enabled by the coffee ring effect, Org. Electron. 29 (2016) 114-119, https://doi.org/10.1016/j. orgel.2015.11.039.

6. S. Ma, F. Ribeiro, K. Powell, J. Lutian, C. Møller, T. Large, J. Holbery, Fabrication of novel transparent touch sensing device via drop-on-Demand inkjet printing technique, ACS Appl. Mater. Interfaces 7 (2015) 21628-21633, https://doi.org/10. 1021/acsami.5b04717.

7. F. Pastorelli, T.M. Schmidt, M. Hösel, R.R. Søndergaard, M. Jørgensen, F.C. Krebs, The organic power transistor: roll-to-Roll manufacture, thermal behavior, and power handling when driving printed electronics, Adv. Eng. Mater. 18 (2016) 51-55, https://doi.org/10.1002/adem.201500348.

8. K. Suganuma, Introduction to Printed Electronics, 1st ed., Springer, New York, 2014, https://doi.org/10.1007/978-1-4614-9625-0.

9. L.R. Lindvold, J. Stensborg, T.P. Rasmussen, UV-assisted rotational moulding of microstructures using a conventional flexographic printing machine, Micromach. Technol. Micro-Optics Nano-Optics, International Society for Optics and Photonics, 2003, pp. 46-54, https://doi.org/10.1117/12.477838.

10. N. Bourguignon, C. Olmos, M. Sierra-Rodero, A. Peñaherrera, G. Rosero, P. Pineda, K. Vizuete, C. Arroyo, L. Cumbal, C. Lasorsa, M. Pérez, Betiana, Accessible and cost-effective method of PDMS microdevices fabrication using a reusable photopolymer mold, J. Polym. Sci. B 56 (2018) 1433-1442, https://doi.org/10.1002/ polb.24726. 
11. X. Chen, J. Shen, M. Zhou, Rapid fabrication of a four-layer PMMA-based microfluidic chip using $\mathrm{CO} 2$-laser micromachining and thermal bonding, J. Micromech. Microeng. 26 (2016) 107001 https://doi.org/10.1088/09601317/26/10/ 107001.

12. M.L. Hupert, W.J. Guy, S.D. Llopis, H. Shadpour, S. Rani, D.E. Nikitopoulos, S.A. Soper, Evaluation of micromilled metal mold masters for the replication of microchip electrophoresis devices, Microfluid. Nanofluidics 3 (2007) 1-11, https:// doi.org/10.1007/s10404-006-0091-x.

13. J. Kotowski, D. Šnita, Fabrication and application of stainless steel stamps for the preparation of microfluidic devices, Microelectron. Eng. 125 (2014) 83-88, https:// doi.org/10.1016/j.mee.2014.04.009.

14. C.J. Easley, R.K.P. Benninger, J.H. Shaver, W. Steven Head, D.W. Piston, Rapid and inexpensive fabrication of polymeric microfluidic devices via toner transfer masking, Lab Chip 9 (2009) 1119-1127, https://doi.org/10.1039/B816575K.

15. L. Yang, L. Zhu, Z. Li, B. Lu, Fabrication of PDMS microfluidic chips used in rapid diagnosis by micro jetting, Multimed. Tools Appl. 77 (2018) 3761-3774, https://doi.org/10.1007/s11042-016-3958-1.

16. X. Liu, Q. Wang, J. Qin, B. Lin, A facile "liquid-molding" method to fabricate PDMS microdevices with 3-dimensional channel topography, Lab Chip 9 (2009) 1200-1205, https://doi.org/10.1039/b818721e.

17. M.A. Stoller, A. Konda, M.A. Kottwitz, S.A. Morin, Thermoplastic building blocks for the fabrication of microfluidic masters, RSC Adv. 5 (2 015) 9793497943, https://doi.org/10.1039/C5RA22742A.

18. Z.I, M.T.G, B.A, I.B, C. Elbuken, Rapid fabrication of microfluidic PDMS devices from reusable PDMS molds using laser ablation, J. Micromech. Microeng. 26 (35008) (2016), https://doi.org/10.1088/0960-1317/26/3/035008.

19. E. Joanni, J. Peressinotto, P.S. Domingues, G. de O. Setti, D.P. de Jesus, Fabrication of molds for PDMS microfluidic devices by laser swelling of PMMA, RSC Adv. 5 (2015) 25089-25096, https://doi.org/10.1039/C5RA03122B.

20. L. Gutzweiler, F. Stumpf, L. Tanguy, G. Roth, P. Koltay, R. Zengerle, L. Riegger, Semi-contact-writing of polymer molds for prototyping PDMS chips with low surface roughness, sharp edges and locally varying channel heights, J. Micromech. Microeng. 26 (2016) 45018, https://doi.org/10.1088/09601317/26/4/045018.

21. K. ichiro Kamei, Y. Mashimo, Y. Koyama, C. Fockenberg, M. Nakashima, M. Nakajima, J. Li, Y. Chen, 3D printing of soft lithography mold for rapid production of polydimethylsiloxane-based microfluidic devices for cell stimulation with concentration gradients, Biomed. Microdevices 17 (2015). 
22. S. Waheed, J.-M.Cabot Canyelles, N. Macdonald, R.M. Guijt, T. Lewis, B. Paull, M.C. Breadmore, 3D printed microfluidic devices: enablers and Barriers, Lab Chip 16 (2016) 1993-2013, https://doi.org/10.1039/C6LC00284F.

23. Z. Li, L. Hou, W. Zhang, L. Zhu, Preparation of PDMS microfluidic devices based on drop-on-demand generation of wax molds, Anal. Methods 6 (2014) 47164722,https://doi.org/10.1039/C4AY00798K.

24. Kodak, Flexcel NX, 2017. https://www.kodak.com/uploadedFiles/ FlexcelNXCPlatesbrochure.pdf (Accessed 22, February 2018).

25. K Layout - High Performance Layout Viewer and Editor, KLayout - High Perform. Layout Viewer Ed. (2018) Available Online Http//www.klayout.de/index.php

26. A. Peñaherrera, C. Payés, M. Sierra-Rodero, M. Vega, G. Rosero, B. Lerner, G. Helguera, M.S. Pérez, Evaluation of cell culture in microfluidic chips for application in monoclonal antibody production, Microelectron. Eng. 158 (2016) 126-129, https://doi.org/10.1016/j.mee.2016.03.059.

27. S.P. Desai, D.M. Freeman, J. Voldman, Plastic masters-rigid templates for soft lithography, 


\section{Capítulo III}

\section{Caracterización del proceso de fabricación de microporos sobre sustrato de silicio por método electroquímico.}




\subsection{Resumen.}

Para poder realizar el sensado de células y continuar con los objetivos planteados, en el presente capítulo, se estudió el proceso de fabricación de una serie de microporos sobre obleas de silicio cristalino mediante la técnica del grabado húmedo. Se evaluó la incidencia de distintos factores como el voltaje, la temperatura y el agente de frenado sobre las características específicas de la formación. A partir de los datos obtenidos de la evolución de las corrientes fue posible estandarizar el proceso y determinar el momento de formación del poro, lo cual es esencial en cuanto a la disponibilidad de un método compatible con las exigencias de la industria. Finalmente, se concluyó que la fabricación de poros en forma controlada, las condiciones óptimas corresponden a una temperatura de 84 ${ }^{\circ} \mathrm{C}, \mathrm{HCl}$ como agente de frenado y voltajes de $0,1 \mathrm{~V}, 0,5 \mathrm{~V}$ y $1 \mathrm{~V}$ respectivamente. Los resultados encontrados son de gran importancia en los campos de la medicina y la biología en relación con la utilidad de los poros como dispositivos de sensado.

\subsection{Introducción.}

Durante la última década las investigaciones en las áreas de la nanotecnología y la nanobiotecnología han motivado al desarrollo de dispositivos con tamaños en el orden de los nanómetros. Actualmente, uno de los grandes intereses se centra en la fabricación de microporos y nanoporos que permitan el sensado de células y moléculas como nucleótidos, enantiómeros, polímeros como PEG (polietilenglicol), RNA, DNA y polipéptidos. Esta línea de investigación representa perspectivas positivas en cuanto a la secuenciación de ADN de tercera generación y el diagnóstico médico ${ }^{1}$. Entre los métodos que reporta la literatura para la fabricación de poros se encuentran metodologías que hacen uso de la microscopía electrónica ${ }^{2-6}$, métodos de grabado químico ${ }^{7,8}$ y métodos electroquímicos ${ }^{9-13}$. La fabricación de nanoporos mediante técnicas de microscopía electrónica resulta ser muy útil y permite tener un control adecuado con relación al tamaño y localización del poro. No obstante, estas tecnologías son costosas y producen poros de alta fragilidad que presentan complicaciones al momento de adaptarlos a las exigencias masivas de la industria médica y biológica, así como a los sucesivos traslados y manipulaciones de los que deberán ser objeto. En cuanto 
al método electroquímico, este consiste en la aplicación de un voltaje durante el proceso de grabado químico controlado, seguido de una neutralización mediada por un agente de frenado. Entre las ventajas de los poros obtenidos mediante la técnica se destacan: alta resistencia, geometría controlada, estabilidad, y control en los tamaños ${ }^{9-13}$. Además, la fabricación puede llevarse a cabo en un laboratorio sin instalaciones costosas. Para la fabricación de poros mediante el método electroquímico se usan generalmente sustratos de silicio cristalino. Dicho material se expone localmente a un agente como ácido fluorhídrico, hidróxido de sodio, hidróxido de potasio $(\mathrm{KOH})$, hidróxido de tetra-metil amonio, entre otros, agentes que lo corroen químicamente. El grabado químico con $\mathrm{KOH}$ ha sido especialmente estudiado debido a su bajo costo, alta relación de ataque (100) / (111), su naturaleza no tóxica y su facilidad de manipulación en laboratorio ${ }^{7,14}$. Durante el proceso, los átomos de silicio son arrancados de la estructura cristalina al entrar en contacto con los hidróxidos presentes en el medio. De esta manera, cuando se expone al ataque químico una región acotada sobre la superficie del material, se genera un cambio de características anisótropas con relación a la reacción sobre cada plano cristalino. En particular, para el plano <111> se registran velocidades menores en comparación con el plano $<100>15$. De este modo, el ataque químico del sustrato resulta en una pirámide de base cuadrada de unos $54.74^{\circ}$ de inclinación ${ }^{16}$. Sobre la base de las características particulares del método electroquímico, este trabajo de tesis presentará la caracterización de la fabricación de microporos bajo diferentes condiciones de control. Los resultados del proceso se muestran teniendo en cuenta la incidencia de los siguientes parámetros en cuestiones específicas de la formación; a) potencial $(0.1,0.5$ y $1 \mathrm{~V}), \mathrm{b})$, agente de frenado (ácido clorhídrico, ácido fórmico) y c) temperatura $\left(65^{\circ} \mathrm{C}\right.$ y $\left.84^{\circ} \mathrm{C}\right)$. A partir del estudio de cada uno de los parámetros mencionados es posible obtener las condiciones óptimas del proceso y al mismo tiempo extrapolar el procedimiento para la fabricación de nanoporos. Cabe resaltar que hasta el momento no se ha reportado la caracterización del proceso de formación de poros bajo las condiciones establecidas en este trabajo. 


\subsection{Materiales y métodos.}

Para la fabricación de los poros se utilizaron obleas de silicio cristalino de $520 \mu \mathrm{m}$ de espesor (Virginia Semiconductor In.) orientadas según el plano $<100>$ de la estructura cristalográfica. Las obleas de silicio fueron recubiertas por una capa de $200 \mathrm{~nm}$ de nitruro de silicio $\left(\mathrm{Si}_{3} \mathrm{~N}_{4}\right)$ mediante el método de deposición química por vapor asistida por plasma (PACVD) a $600{ }^{\circ} \mathrm{C}$. Como primera etapa del proceso, se llevó a cabo la remoción localizada de $\mathrm{Si}_{3} \mathrm{~N}_{4}$ por medio de ablación láser de ventanas cuadradas convenientemente localizadas sobre la superficie de la oblea. El recubrimiento de $\mathrm{Si}_{3} \mathrm{~N}_{4}$, resistente al grabado húmedo, posibilita la localización precisa de la zona de ataque, y en consecuencia el control de la posición del poro resultante (Figura 3.1) ${ }^{16}$. En la segunda etapa se lleva a cabo un proceso de grabado húmedo rápido con una solución acuosa de $\mathrm{KOH}$ (aq) $7 \mathrm{M}$ a $80^{\circ} \mathrm{C}$ sobre ambos lados de la oblea, que finaliza cuando la separación mínima entre los hemisferios se encuentra en el orden de 100 y $200 \mu \mathrm{m}$ (figura 3.1).

\section{Oblea de silicio}

\section{Depósito de $\mathrm{Si}_{3} \mathrm{~N}_{4}$}

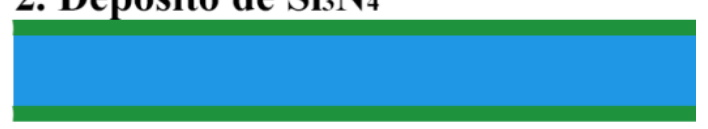

\section{Remoción localizada, vía laser}

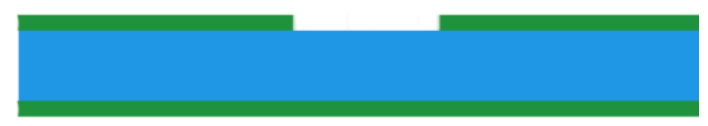

\section{Grabado Húmedo (KOH 7M)}

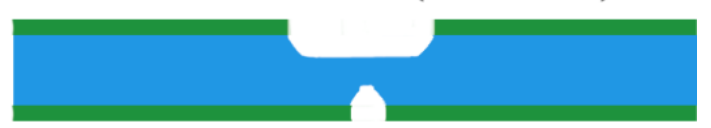

Figura. 3.1. Ilustración esquemática de las etapas iniciales del proceso de formación de poros. 1.1) Oblea de silicio, 1.2) Oblea de silicio con deposición de nitruro de silicio, 1.3) Remoción localizada de nitruro de silicio y 1.4) grabado húmedo con $\mathrm{KOH} 7 \mathrm{M}$.

Posteriormente, se realiza un segundo ataque químico en presencia de potencial y temperatura, que culmina con la apertura del poro y el mecanismo de frenado 
autocontrolado por la neutralización de los reactivos. Para ello, como se puede ver en la figura 3.2 se utiliza una celda en la que se ubica en un lado una solución de $\mathrm{KOH} 4 \mathrm{M}$ y en el otro lado el agente de frenado $(\mathrm{HCl} 12 \mathrm{M}$ y HCOOH 30 M según corresponda). En cada compartimiento se introduce un electrodo de platino el cual se conecta a con un dispositivo Keithley 2612b Single and dual channel scalable sourcing and measurement (Keithley Instruments), que entrega el voltaje indicado y es capaz de discriminar corrientes del orden de los $0,1 \mathrm{pA}$ y tensiones de hasta $0,1 \mu \mathrm{V}$. El mismo se controla por medio de conexión USB con el software Test Script Builder (TSB), como se ve en la figura 3.2. Para tomar mediciones de corriente en el tiempo con una frecuencia de 0,1Hz. En esta etapa el encuentro de ambas pirámides invertidas da lugar a la formación del poro y al frenado químico, que disminuye la velocidad del grabado húmedo. Cabe resaltar que previamente nuestro grupo había reportado el proceso de formación de nanoporos bajo condiciones de $\mathrm{KOH} 4 \mathrm{M}$, sin aplicar voltaje al procedimiento ${ }^{7}$. Finalmente, para concluir con el proceso, la oblea es sometida a un lavado con solución piraña (mezcla de $\mathrm{H}_{2} \mathrm{SO}_{4}$ y $\mathrm{H}_{2} \mathrm{O}_{2}$ en proporción 3:1) para remover las sales remanentes que quedan adheridas a la superficie. Las obleas se codificaron de acuerdo con el agente de frenado utilizado, la temperatura y las condiciones de voltaje aplicadas en el proceso respectivamente. La nomenclatura corresponde con la codificación presentada en la tabla 3.1.

Tabla 3.1 Codificación de las obleas y condiciones de fabricación de poros.

\begin{tabular}{|c|c|c|c|}
\hline CODIFICACIÓN & TEMPERATURA $\left({ }^{\circ} \mathbf{C}\right)$ & $\begin{array}{c}\text { AGENTE DE } \\
\text { FRENADO }\end{array}$ & $\begin{array}{c}\text { VOLTAJE } \\
\text { APLICADO (V) }\end{array}$ \\
\hline C-84-1 & $84 \pm 1$ & $\mathrm{HCl}$ & 1 \\
\hline $\mathbf{C - 8 4 - 0 . 5}$ & $84 \pm 1$ & $\mathrm{HCl}$ & 0,5 \\
\hline $\mathbf{C - 8 4 - 0 . 1}$ & $84 \pm 1$ & $\mathrm{HCl}$ & 0,1 \\
\hline $\mathbf{F - 8 4 - 1}$ & $84 \pm 1$ & $\mathrm{HCOOH}$ & 1 \\
\hline $\mathbf{F - 8 4 - 0 . 5}$ & $84 \pm 1$ & $\mathrm{HCOOH}$ & 0,5 \\
\hline $\mathbf{F - 8 4 - 0 . 1}$ & $84 \pm 1$ & $\mathrm{HCOOH}$ & 0,1 \\
\hline $\mathbf{C - 6 5 - 1}$ & $65 \pm 1$ & $\mathrm{HCl}$ & 1 \\
\hline $\mathbf{C - 6 5 - 0 . 5}$ & $65 \pm 1$ & $\mathrm{HCl}$ & 0,5 \\
\hline $\mathbf{C - 6 5 - 0 . 1}$ & $65 \pm 1$ & $\mathrm{HCl}$ & 0,1 \\
\hline $\mathbf{F - 6 5 - 1}$ & $65 \pm 1$ & $\mathrm{HCOOH}$ & 1 \\
\hline $\mathbf{F - 6 5 - 0 . 5}$ & $65 \pm 1$ & $\mathrm{HCOOH}$ & 0,5 \\
\hline $\mathbf{F - 6 5 - 0 . 1}$ & $65 \pm 1$ & $\mathrm{HCOOH}$ & 0,1 \\
\hline
\end{tabular}




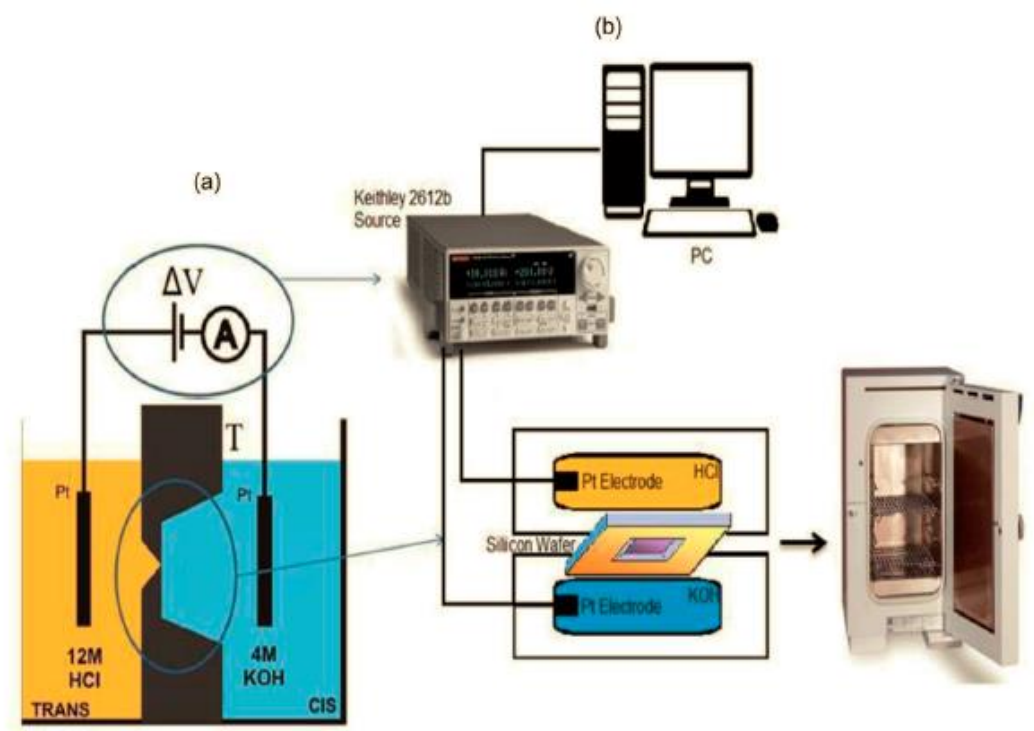

Figura. 3.2. Ilustración esquemática: segunda etapa de grabado químico. a) Celda con dos compartimientos para solución de grabado $\mathrm{KOH} 4 \mathrm{M}$ y solución de frenado (HCL 12 M y HCOOH 30M), b) Conexión de electrodos de platino conectados con un dispositivo Keithley 2612b.

\subsection{Resultados.}

Se estudió la influencia de factores como la temperatura, el voltaje y el agente de frenado durante el grabado húmedo, a fin de caracterizar el proceso de formación de poros. Al respecto, Seidel et al. ${ }^{17}$, y Chen et al. ${ }^{8}$, reportaron que el aumento de la temperatura incrementa la velocidad del ataque químico. Por otra parte, Harrel et al. ${ }^{18}$, mostraron que el incremento del voltaje aplicado al proceso electroquímico genera un aumento del tamaño de poro. Recientemente, Apel et $a l{ }^{12}$, reportaron que las características químicas del agente de frenado afectan la geometría del poro. En cuanto a los perfiles de corriente y tiempo, Park et al. ${ }^{19}$, reportaron que antes de la formación del poro, se genera fluido de corriente ("ruido") que es posible minimizar aplicando un voltaje de $800 \mathrm{mV}$. En base a lo anterior, se han variado las temperaturas del proceso $\left(65^{\circ} \mathrm{C} \mathrm{y} 84^{\circ} \mathrm{C}\right)$, y se han establecido voltajes de $0,1 \mathrm{~V}, 0,5 \mathrm{~V}$ y $1 \mathrm{~V}$, respectivamente. En relación con el agente de frenado, se han realizado experimentos con $\mathrm{HCl} 12 \mathrm{M} \mathrm{y} \mathrm{HCOOH} 30 \mathrm{M}$. 


\subsubsection{Caracterización del proceso de fabricación de poros: $\mathrm{HCl}, \mathrm{KOH} 4 \mathrm{M}, 84^{\circ} \mathrm{C}$}

La figura 3.3 muestra los resultados de la evolución de las corrientes registradas durante el grabado húmedo obtenido bajo las siguientes condiciones: $84^{\circ} \mathrm{C}, 1 \mathrm{~V}$ y HCl 12 M como agente de frenado (C-84-1, según la tabla 3.1). Como es evidente, en la gráfica se pueden reconocer, posterior a la estabilización inicial, tres etapas compatibles con los fenómenos de movimiento iónico predominantes durante el ataque químico; la apertura y la neutralización. En una primera instancia, previa a las 2 h de medición, se observa un ascenso sostenido y relativamente ordenado de la corriente eléctrica, compatible con la etapa de ataque químico esperada antes de apertura del poro. Durante este lapso, el comportamiento de la corriente se relaciona con la generación de electrones debidos a la reacción química entre el silicio y el $\mathrm{KOH}{ }^{15,18}$. Alrededor de 1,76 horas después del inicio del proceso se observa un cambio en el comportamiento del gráfico: un nuevo ascenso, más desordenado y con menor rapidez. Al momento en que ocurre este primer cambio se le ha denominado $\mathrm{T}_{1}$.

Se encontró que el momento en que finaliza esta primera etapa, $\mathrm{T}_{1}$, donde se encuentran las etapas 1 y 2, es comparable el tiempo teórico correspondiente a la apertura del poro, según la ecuación 3.1 (tabla 3.2).

Ecuación 3.1

$$
T_{1}=T_{R}=\frac{\left(D_{0}-D_{1}\right)}{V}
$$

Donde $D_{0}=520 \mu \mathrm{m}$ es el espesor de oblea, $D_{1}$ es la profundidad alcanzada durante el primer grabado y $V=1,40 \mu \mathrm{m} / \mathrm{min}$ es la velocidad de grabado químico a $84{ }^{\circ} \mathrm{C}$ con $\mathrm{KOH} 4 \mathrm{M}^{17}$. Es por esta correspondencia que la etapa 2, relativa a $\mathrm{t}>\mathrm{T}_{1}$, se ha denominado apertura del poro. 


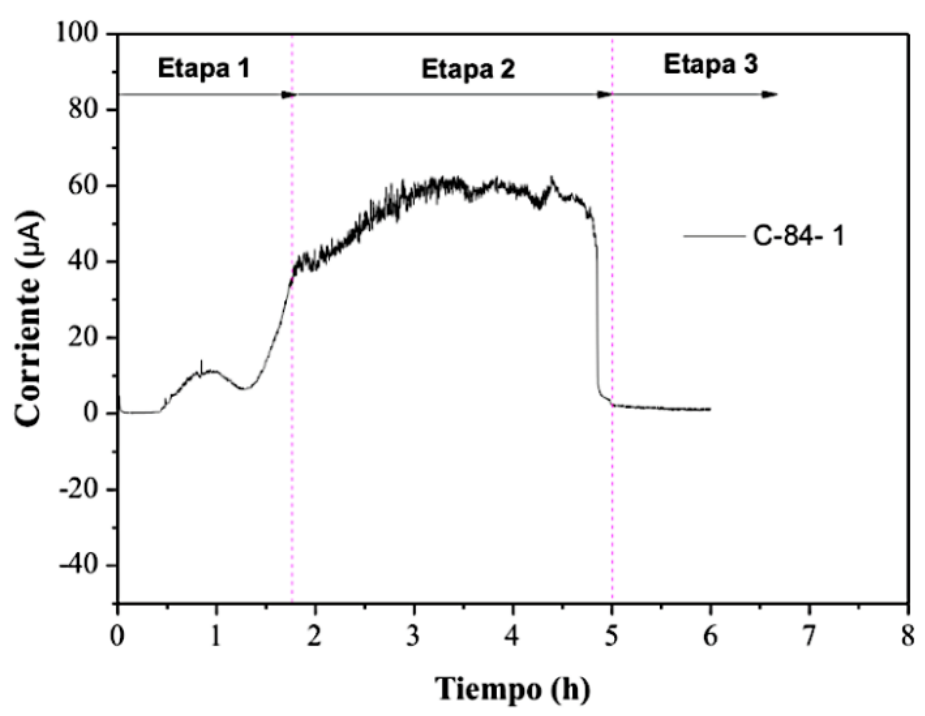

Figura. 3.3. Evolución de la corriente para la condición C-84-1I. T1, T2 y T3 corresponden con los tiempos característicos del proceso.

La figura 3.4 muestra de forma más detallada las etapas del proceso. Previo a las 2 horas de medición, se observa un ascenso sostenido y relativamente ordenado de la corriente eléctrica que corresponde con el ataque químico (Figura 3.4a). Durante el inicio de apertura del poro la corriente sufre un incremento exponencial debido al flujo adicional de iones por el poro, como se puede observar figuras $3.4 \mathrm{~b}$ y $3.4 \mathrm{c}$ (este último gráfico corresponde a una linealización de la dependencia). Para finalizar, una vez que la neutralización y el frenado del grabado húmedo son suficientemente importantes $\left(\mathrm{t}>\mathrm{T}_{2}\right)$, la corriente presenta un marcado decaimiento, dando por finalizado el proceso y deteniendo la apertura del microporo, como se puede observar en la figura $3.4 \mathrm{~d}$, que resalta la etapa final del mismo. Es importante indicar que se ha denominado etapa de neutralización y frenado del grabado húmedo al momento que, para el experimento C-84-1, comienza a las 4,74 horas del proceso y para el cual el ácido clorhídrico $12 \mathrm{M}$ y el $\mathrm{KOH} 4 \mathrm{M}$ han estado en contacto durante aproximadamente 3 horas. Debido a este fenómeno, dichos compuestos reaccionan dando lugar a sales de $\mathrm{KCl}$. Adicionalmente, la concentración de $\mathrm{KOH}$ disminuye y por tanto el ataque a la superficie del silicio es mucho menor en comparación con las condiciones iniciales del experimento. 
a)

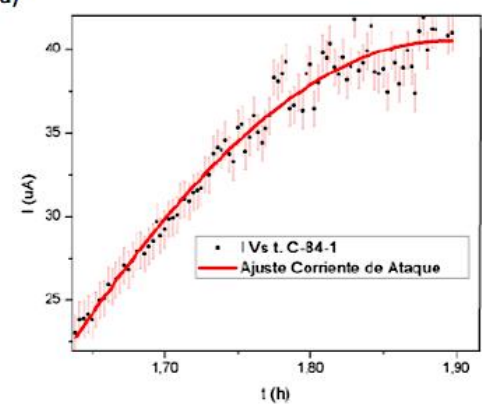

c)

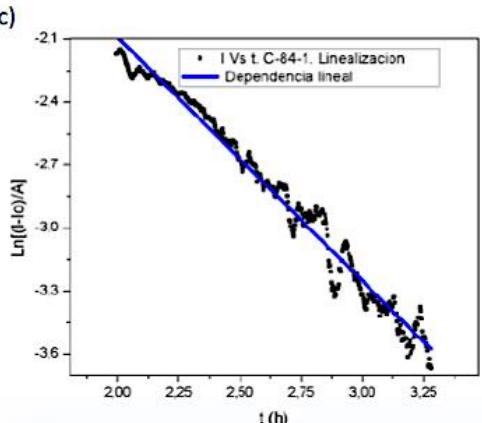

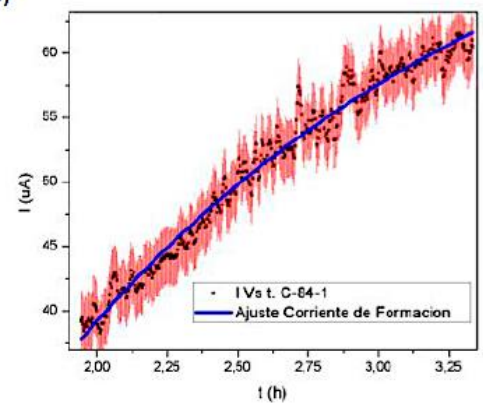

d)

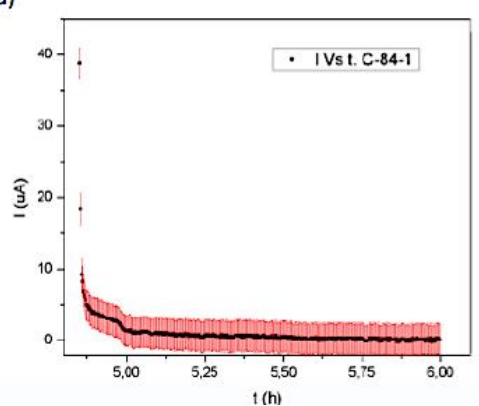

Figura. 3.4. Descripción de las etapas del proceso de fabricación de poros. a) Comportamiento inicial correspondiente al ataque químico, b) Dependencia exponencial luego de apertura de poro, c) Trasformación exponencial del grafico 4b, d) Etapa de neutralización.

A partir de las anteriores consideraciones, se realizó una comparación del comportamiento de los experimentos realizados a $84{ }^{\circ} \mathrm{C}$ bajo diferentes voltajes, y con $\mathrm{HCl}$ como agente de frenado (Figura 3.5). En los gráficos de evolución de corrientes para las tres condiciones $(0,1 \mathrm{~V}, 0,5 \mathrm{~V}$ y $1 \mathrm{~V})$ se observan comportamientos similares, en donde se pueden diferenciar las 3 etapas discutidas previamente. Además, las corrientes de las 3 curvas resultan razonablemente proporcionales al voltaje utilizado para cada experiencia. En particular, las estabilizaciones intermedias de cada experimento en torno a $55 \mu \mathrm{A}, 25 \mu \mathrm{A}$ y $5 \mu \mathrm{A}$ respectivamente confirman esta suposición. También, al igual que en la condición C-84-1, se encontró que para las condiciones C- 84-0.5 y C-84-0.1, el instante T1 es comparable con el tiempo teórico de apertura de poro calculado según la ecuación 3.1 (tabla 3.2). Por otro lado, en el grafico obtenido para la oblea C-840.5 , se observa que a las 3,5 horas ocurre una disminución drástica de la corriente. Este comportamiento coincide con la apertura de un segundo poro en la misma oblea, lo que incrementa la velocidad de neutralización. 
(a)

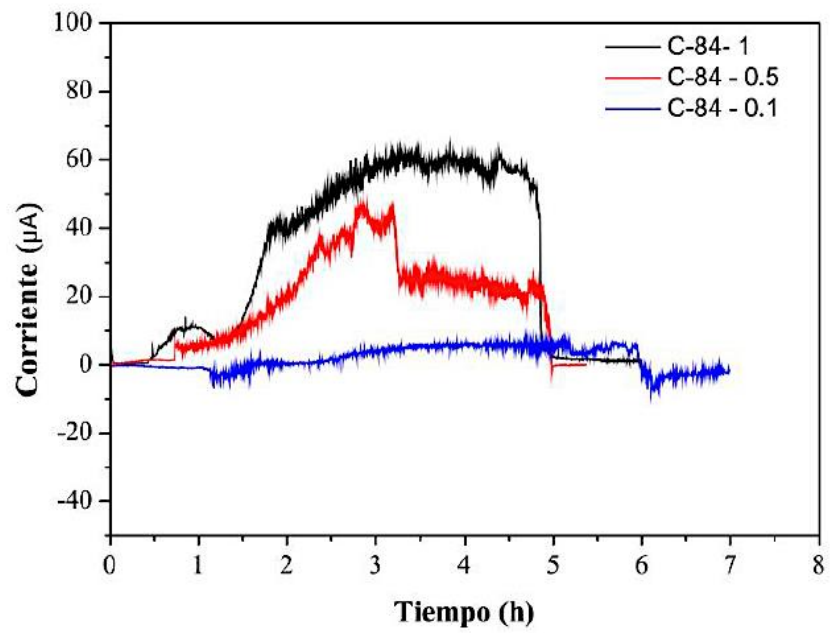

(b)

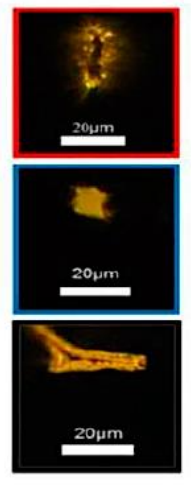

Figura. 3.5. Comparación de las curvas de evolución de la corriente, condiciones: $\mathrm{HCl}, 84{ }^{\circ} \mathrm{C}$. a) Línea negra: condición $1 \mathrm{~V}$, Línea roja: condición $0,5 \mathrm{~V}$ y Línea azul: condición $0,1 \mathrm{~V}, \mathrm{~b}$ ) Imágenes de los microporos obtenidos.

Apel et al. ${ }^{19}$ mencionan que al aplicar voltajes mayores a $0,1 \mathrm{~V}$, la electromigración es por lo menos 4 veces mayor que la difusión (este número asciende a 35 si se utiliza $1 \mathrm{~V}$ de potencial). El aumento del voltaje genera por tanto un aumento en la importancia de electromigración de iones $\mathrm{OH}$ - frente a mecanismos difusivos. Por esta razón, tanto los valores de corrientes obtenidos como las dependencias específicas de cada etapa son más visibles con el aumento del voltaje aplicado. A voltajes altos, entonces, este fenómeno permite distinguir con claridad las regiones mencionadas, y realizar análisis e hipótesis a partir de supuestos puramente eléctricos.

Tabla 3.2: Tiempo de apertura de poro teórico y experimental para tres obleas tratadas a distintas condiciones.

\begin{tabular}{|c|c|c|c|}
\hline OBLEA & $\begin{array}{c}\text { PROFUNDIDA } \\
\text { D TOTAL } \\
\text { OBTENIDO } \\
\text { DEL PRIMER } \\
\text { GRABADO } \boldsymbol{\mu m}\end{array}$ & $\begin{array}{c}\text { TIEMPO DE } \\
\text { APERTURA }^{\mathbf{1}}\end{array}$ & $\begin{array}{c}\text { TIEMPO DE } \\
\text { APERTURA }^{2}\end{array}$ \\
\hline $\mathrm{C}-84-1$ & 365 & 1,84 horas & 1,8 horas \\
\hline $\mathrm{C}-84-0,5$ & 315 & 2,44 horas & 2,4 horas \\
\hline $\mathrm{C}-84-0,1$ & 310 & 2,5 horas & 2,8 horas \\
\hline
\end{tabular}

1. Valor determinado según ecuación 3.1.

2. Dato obtenido de la curva de evolución de corrientes, figura 3.5.

UTN, Carrera Doctorado en Ingeniería, mención Materiales 
Para determinar la reproducibilidad de los experimentos se han llevado a cabo 2 fabricaciones bajo las condiciones de $\mathrm{HCl}, 84^{\circ} \mathrm{C}, 0,5 \mathrm{~V}$. La figura 3.6 muestra los gráficos de corriente eléctrica obtenidos durante proceso. Se encontró que, bajo estas condiciones, el instante T1 (tiempo de apertura de poro) coincidió con el tiempo de apertura obtenido a partir de la ecuación 3.1. Para la oblea C-84-0.5 replica 1 correspondió con 2,9 horas y para C-84-0.5 replica 2 correspondió con 2,7 horas.

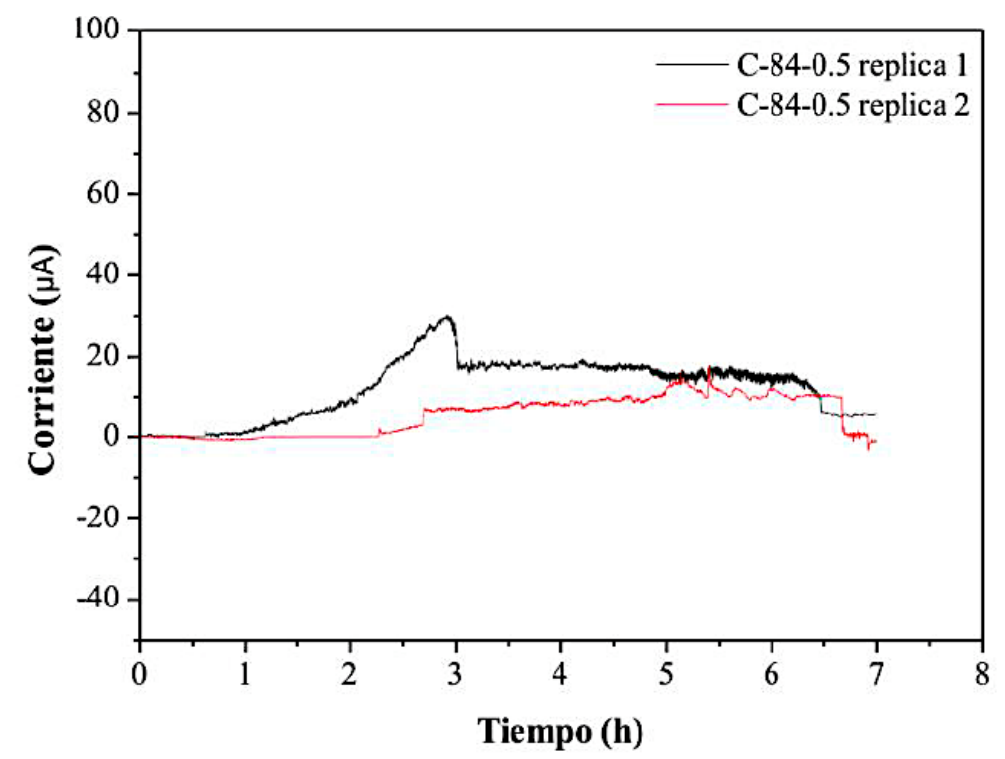

Figura. 3.6. Comparación de las curvas de evolución de la corriente, condiciones: $\mathrm{HCl}, 84{ }^{\circ} \mathrm{C}$. Línea negra: 0,5 V-replica 1, Línea roja: 0,5 V-replica 2.

Tabla 3.3: Tiempo de apertura de poro teórico y experimental para tres obleas tratadas a distintas condiciones.

\begin{tabular}{|c|c|c|c|}
\hline OBLEA & $\begin{array}{c}\text { PROFUNDIDAD } \\
\text { TOTAL OBTENIDA } \\
\text { DEL PRIMER } \\
\text { GRABADO } \mu \mathrm{m} \\
\end{array}$ & $\begin{array}{l}\text { TIEMPO DE } \\
\text { APERTURA }^{1}\end{array}$ & $\begin{array}{l}\text { TIEMPO DE } \\
\text { APERTURA }^{2}\end{array}$ \\
\hline $\begin{array}{l}\text { C-84-0.5 } \\
\text { replica } 1\end{array}$ & 280 & 2,85 horas & 2,9 horas \\
\hline $\begin{array}{l}\text { C-84-0.5 } \\
\text { replica } 2\end{array}$ & 280 & 2,85 horas & 2,7 horas \\
\hline
\end{tabular}


1. Valor determinado según ecuación 3.1.

2. Dato obtenido de la curva de evolución de corrientes, figura 3.6.

\subsubsection{Caracterización del proceso de fabricación de poros: HCOOH, КОН $4 \mathrm{M}, 84{ }^{\circ} \mathrm{C}$}

En la figura 3.7 se muestran los resultados obtenidos para los experimentos F-841, F-84-0.5 y F-84-0.1. En este caso, el proceso de fabricación de poros se llevó a cabo siguiendo el procedimiento utilizado en el apartado 3.1, con ácido fórmico como agente de frenado. En todos los casos de la figura 3.7 se observan valores correspondientes a tres etapas bien definidas. En primer lugar, una evolución ordenada de la corriente, relacionada con la reacción química entre el silicio y el $\mathrm{KOH}^{17,20}$. Luego se registra una fuerte fluctuación, cuya magnitud media resulta directamente proporcional al voltaje aplicado. Y finalmente una estabilización final, que concluye con el proceso.

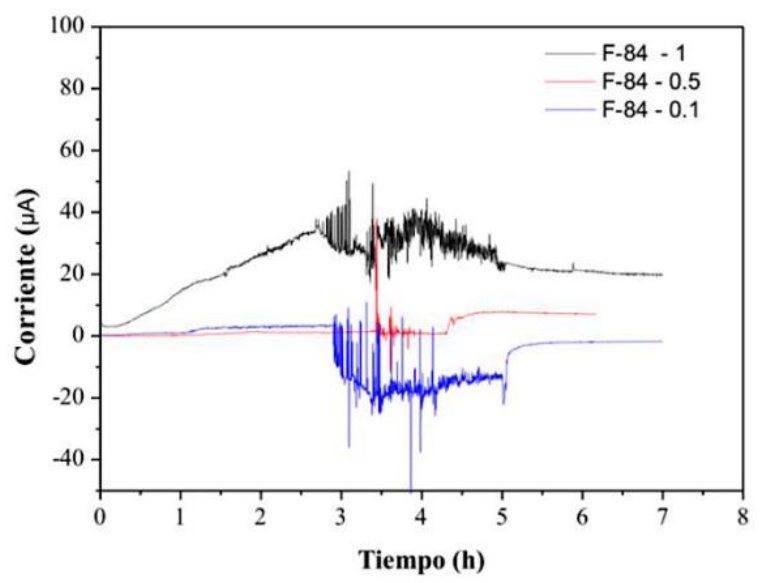

Figura. 3.7. Comparación de las curvas de evolución de la corriente, condiciones: $\mathrm{HCOOH}, 84^{\circ} \mathrm{C}$. a) Línea negra: condición $1 \mathrm{~V}$, Línea roja: condición 0,5 V y Línea azul: condición $0,1 \mathrm{~V}$.

La tabla 3.4 muestra los valores de profundidad total obtenidos después del primer grabado para las obleas F-84-1, F-84-0.5 y F-84-0.1. De acuerdo con estos valores, los tiempos de apertura según la ecuación 3.1 deberían ser inferiores a 2 horas. No obstante, para las obleas F-84-1, F-84-0.5 y F-84-0.1 se observaron cambios de 
magnitud de la corriente cerca de las 2,8 horas, 3,4 y 2,9 horas, respectivamente. Además, para el caso de las obleas F-84-0.5 y F-84-0.1, el proceso no se frenó y la superficie de silicio fue atacada completamente. Dado que el experimento, por el contrario, se llevó a cabo durante aproximadamente 5,5 horas, se puede atribuir un lapso suficiente para el desarrollo de las etapas de ataque se puede atribuir a las propiedades químicas del ácido fórmico la ineficiencia del proceso de frenado.

Tabla 3.4: Tiempo de apertura de poro teórico y experimental para tres obleas tratadas a distintas condiciones.

\begin{tabular}{|c|c|c|c|}
\hline OBLEA & $\begin{array}{c}\text { PROFUNDIDAD } \\
\text { TOTAL } \\
\text { OBTENIDA DEL } \\
\text { PRIMER } \\
\text { GRABADO } \boldsymbol{\mu m} \\
\end{array}$ & $\begin{array}{l}\text { TIEMPO DE } \\
\text { APERTURA }^{1}\end{array}$ & $\begin{array}{l}\text { TIEMPO DE } \\
\text { APERTURA }^{2}\end{array}$ \\
\hline F-84-1 & 420 & 1,19 horas & 2,8 horas \\
\hline F-84-0.5 & 420 & 1,19 horas & 3,4 horas \\
\hline F-84-0.1 & 355 & 1,96 horas & 2,9 horas \\
\hline
\end{tabular}

1. Valor determinado según ecuación 3.1.

2. Dato obtenido de la curva de evolución de corrientes, figura 3.7.

La figura 3.8 muestra imágenes de microporos tomadas mediante microscopía electrónica de barrido, obtenidas bajo las mismas condiciones experimentales anteriormente descritas: $\mathrm{HCOOH}, 84{ }^{\circ} \mathrm{C} 1 \mathrm{~V}$. Se puede observar que cuando la ablación del nitruro de silicio coincide con la parte lateral de la ventana, la forma del poro obtenido es irregular, mientras que cuando la ablación del nitruro del silicio coincide con la parte interna de la ventana, éste toma forma cuadrada. 

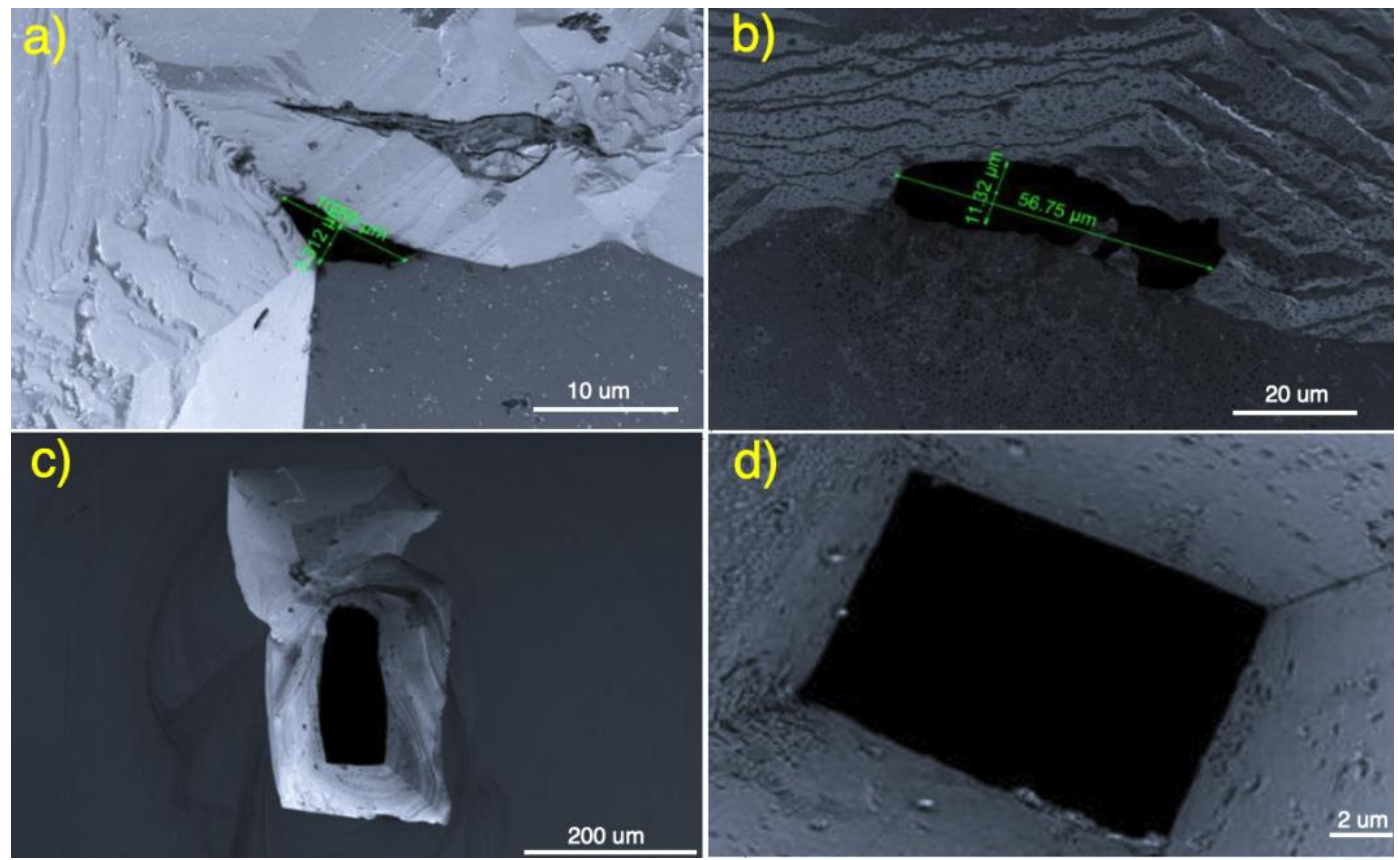

Figura. 3.8. Imágenes de poros obtenidas mediante microscopia electrónica de barrido. a y b) microporos formados en la parte lateral de la ventana, c y d) microporos formados dentro de la ventana. Condiciones a: $\mathrm{HCOOH}, 84{ }^{\circ} \mathrm{C}, 1 \mathrm{~V}$.

\subsubsection{Caracterización del proceso de fabricación de poros: $\mathrm{HCOOH}, \mathrm{HCl}, \mathrm{KOH} 4 \mathrm{M}, 65^{\circ} \mathrm{C}$}

Seidel et al. ${ }^{17}$ indicaron que la velocidad de ataque químico es influenciada por la temperatura aplicada. Una menor temperatura genera menor velocidad, y a su vez la disminución de la velocidad permite un mayor control sobre el tamaño del poro obtenido. Por este motivo, la caracterización del proceso de fabricación de poros también se llevó a cabo a $65^{\circ} \mathrm{C}$. La figura 3.9 exhibe las superficies de las obleas C-65-1, F-65-1, C-65-0.5, F-65-0.5, C-65-0.1 y F-65-0.1 obtenidas después del grabado electroquímico. Aunque las obleas se expusieron entre 13 y 16 horas al ataque químico con $\mathrm{KOH}$, aplicando voltajes de $1 \mathrm{~V}, 0,5 \mathrm{~V}$ y $0,1 \mathrm{~V}$ respectivamente, no se obtuvieron poros en ninguno de los casos. De acuerdo con la velocidad de ataque del $\mathrm{KOH}$ a $65^{\circ} \mathrm{C}$, se debería alcanzar una profundidad entre 400 y $500 \mu \mathrm{m}$, lo cual corresponde a una profundidad en exceso para todas las obleas. En la tabla 3.5 se indican las profundidades finales obtenidas posteriores al ataque químico, se puede observar que la profundidad de ataque se encuentra entre $20 \mu \mathrm{m}$ y $100 \mu \mathrm{m}$. Estos resultados indican que posiblemente a la temperatura de 65 
${ }^{\circ} \mathrm{C}$ se genera un alto grado de burbujas de hidrógeno producidas en la reacción ( $\mathrm{Si}$ $+2(\mathrm{OH})-+4 \mathrm{H} 2 \mathrm{O} \rightarrow \mathrm{Si}(\mathrm{OH}) 6-+2 \mathrm{H} 2)$, que enmascaran la superficie y que da lugar a la disminución de la velocidad de ataque químico ${ }^{17,20}$. Por otro lado, en las imágenes también se observa que la mayoría de las superficies presentan rugosidad, lo que es congruente con los resultados obtenidos por Palik et al. ${ }^{20}$, quienes indicaron que cuando disminuye la temperatura de ataque químico se genera un mayor grado de rugosidad por un aumento de formación de silicatos.

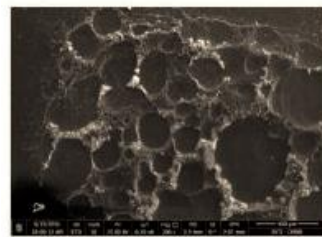

C-65-1

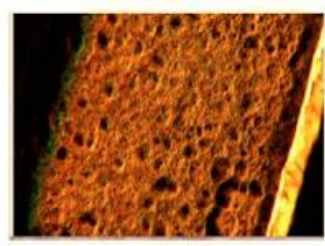

F-65-1

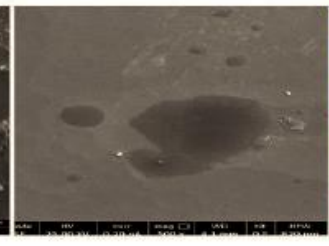

C-65-0.5

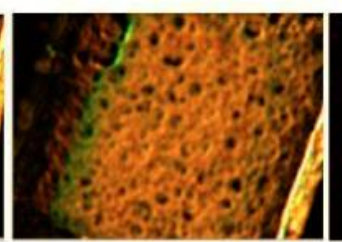

F-65-0.5

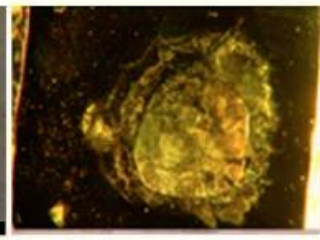

C-65-0.1

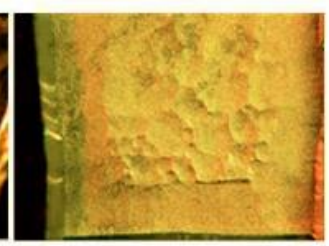

F-65-0.1

Figura. 3.9. Superficie obtenida posterior al proceso electroquímico de formación de poros. Condiciones: $\mathrm{KOH} 4 \mathrm{M}, \mathrm{HCOOH} 30 \mathrm{M}$, Temperatura: $65^{\circ} \mathrm{C}$.

Tabla 3.5: Tiempo de apertura de poro

\begin{tabular}{|c|c|c|c|}
\hline OBLEA & $\begin{array}{c}\text { PROFUNDIDAD } \\
\text { TOTAL } \\
\text { OBTENIDA DEL } \\
\text { PRIMER } \\
\text { GRABADO } \boldsymbol{\mu m}\end{array}$ & $\begin{array}{c}\text { PROFUNDIDAD } \\
\text { TOTAL } \\
\text { OBTENIDA DEL } \\
\text { SEGUNDO } \\
\text { GRABADO }\end{array}$ & $\begin{array}{c}\text { TIEMPO } \\
\text { APROXIMADO DE } \\
\text { APERTURA }\end{array}$ \\
\hline F-65-1 & 400 & 500 & 4 horas \\
\hline F-65-0.5 & 400 & 490 & 4 horas \\
\hline F-65-0.1 & 360 & 400 & 5.3 horas \\
\hline C-65-1 & 480 & 500 & 1.3 horas \\
\hline C-65-0.5 & 440 & 500 & 2.7 horas \\
\hline C-65-0.1 & 420 & 500 & 3.3 horas \\
\hline
\end{tabular}

1. Valor determinado según ecuación 3.1. 
De acuerdo con los resultados de la literatura, la velocidad de ataque está relacionada con la variación de las condiciones de fabricación, tales como el voltaje ${ }^{18}$, la temperatura ${ }^{17,20}$ y la concentración de agente de ataque químico ${ }^{17,20}$. Seidel et al. ${ }^{17}$ reportaron el efecto de la temperatura y la concentración de $\mathrm{KOH}$ en la velocidad del ataque químico. La velocidad de ataque aumenta antes de una concentración de $\mathrm{KOH}$ 20-30\%, luego disminuye. También reportaron que el aumento de la temperatura produce un aumento en la velocidad de ataque químico. Adicionalmente, Harrel et al. ${ }^{18}$ mostraron una relación directa entre el voltaje aplicado y el tamaño del poro. En relación con el proceso de caracterización, se ha reportado que no existe corriente de fondo cuando el ataque químico se hace sobre materiales como politereftalato de etileno ${ }^{21}$, polimida $^{23}$, policarbonato ${ }^{24}$. En contraste, cuando el material es silicio, se genera corriente de fondo por efecto de la generación de electrones que se producen en la reacción entre el $\mathrm{KOH}$ y el silicio $(\mathrm{Si}+4 \mathrm{OH} \rightarrow \mathrm{Si}(\mathrm{OH}) 4+4 \mathrm{e}-)$. $\mathrm{Al}$ respecto, Park et al. ${ }^{19}$ reportaron que en sus ensayos se minimizó este fondo de corriente aplicando voltajes de $800 \mathrm{mV}$, por efecto la diferencia de potencial electroquímico entre las interfaces $\mathrm{KCl} / \mathrm{Si} \mathrm{y} \mathrm{KOH}$ / $\mathrm{Si}^{17}$. En general, los estudios anteriores indicaron que el voltaje, la temperatura y la concentración de $\mathrm{KOH}$ son factores clave en el tamaño del poro y en la caracterización del proceso de fabricación. En cuanto a los resultados obtenidos en el presente trabajo, se pudo observar que bajo las condiciones estudiadas los perfiles de corriente en función del tiempo presentan valores de fondo que se minimizan cuando se aplica voltajes de 0,1 V. Por otra parte, las dependencias relativas a la caracterización de la fabricación de microporos bajo las condiciones de $\mathrm{HCl}, 84{ }^{\circ} \mathrm{C}$ y voltajes de $1 \mathrm{~V}, 0,5 \mathrm{~V}$ y $0,1 \mathrm{~V}$, permiten diferenciar 3 tiempos característicos en el proceso, correspondientes a las etapas de ataque químico, apertura y neutralización, que pueden ser determinados a partir de las curvas de evolución de corrientes. En este sentido, la comparación entre el tiempo de apertura teórico y el tiempo de apertura experimental pone de manifiesto que es posible caracterizar el proceso de fabricación de poros sobre este sustrato. Por otra parte, el conocimiento de cada una de las etapas permitió determinar el momento de apertura del poro, lo que resulta de gran utilidad para la fabricación de nanoporos, ya que el proceso se detendría al instante denominado como T1. Por otro lado, mediante la metodología utilizada es posible obtener diferentes tamaños de poro, ya que el proceso modula dicho parámetro en función del tiempo en que el $\mathrm{KOH}$ 
4M está en contacto con la superficie del silicio. En lo relacionado con los experimentos a $84{ }^{\circ} \mathrm{C}$ con $\mathrm{HCOOH}$, los perfiles de corriente-tiempo, no permitieron determinar el momento de formación del poro. Además, cabe destacar que características particulares de este ácido, como su dificultad para disociarse, vuelven menos efectivo el mecanismo de frenado, dando lugar a 1) ataques químicos en toda la superficie de silicio de la oblea, lo que genera una ventana de características macroscópicas, y por tanto 2) no es posible tener un control del tamaño del poro. Respecto a los resultados obtenidos bajo las condiciones de 65 ${ }^{\circ} \mathrm{C}$, con $\mathrm{HCOOH}$ y $\mathrm{HCl}$ como agentes de frenado, se puede indicar que en estos casos no fue posible un eficiente ataque químico al silicio cristalino y por tanto obtener poros ni caracterizar el proceso bajo estas condiciones. 


\subsection{Conclusiones}

El estudio de los perfiles de evolución de las corrientes ha puesto en evidencia que es posible la fabricación de poros de forma controlada. Se encontró que las condiciones de voltaje, reactivos y temperaturas aplicadas durante el proceso de formación influyen sobre características relevantes de la fabricación, determinándose las condiciones óptimas para una temperatura de $84{ }^{\circ} \mathrm{C}$ y $\mathrm{HCl}$ como agente de frenado. Por el contrario, bajo condiciones de temperatura a $65^{\circ} \mathrm{C}$ no se genera un ataque eficiente de la superficie del silicio y por tanto no es posible obtener poros en esta situación. Finalmente, el análisis de la evolución de las corrientes del proceso para condiciones óptimas de la fabricación permite caracterizar la formación microporos y ofrece un mecanismo altamente funcional para el control de su tamaño. 


\subsection{Referencias}

1. HAQUE, F., LI, J., WU, H.-C., et al., "Solid-state and biological nanopore for real-time sensing of single chemical and sequencing of DNA", Nano Today, v. 8, pp. 56-74, Feb.2013.

2. LIU, S., ZHAO, Q., LI, Q., ZHANG., H, et al., "Controlled deformation of Si 3 $\mathrm{N} 4$ nanopores using focused electron beam in a transmission electron microscope", Nanotechnology, v. 22, pp. 113201-1 / 113201-4,Sept 2011.

3. LANYON, Y. H., MARZI, D.G., WATSON, Y.E., et al.,"Fabrication of Nanopore Array Electrodes by Focused Ion Beam Milling", Analytical Chemistry, v.79, pp. 3048-3055, March 2007.

4. SPINNEY, P.S., HOWITT, D.G., SMITH, R.L., et al., "Nanopore formation by low-energy focused elec-tron beam machining", Nanotechnology, v. 21, n.37, PP. 375301, Aug. 2010.

5. GADGIL, V,J.,TONG, H,D.,CESA, Y., et al., "Fabrication of nano structures in thin membranes with focused ion beam technology", Surface and Coatings Technology, v. 203, pp.2436-2441, June, 2009.

6 STORM, A. J., CHEN, J. H., LING, X. S., et al., "Fabrication of solid-state nanopores with single-nanometre precision", Nat Mater, v. 2, p. 537-540, July 2003.

7. VEGA, M., LERNER, B., LASORSA, C. A., et al., "Automated and low cost method to manufacture addressable solid-state nanopores", Microsystem Technologies, v. 22, pp. 109-117, Dic 2014.

8 CHEN, J., DENG, T., WU, C. N., et al., "Fabrication of Silicon Nanopore Arrays with Three-Step Húmedo Grabado", ECS Transactions, v. 52, pp.371-376, Aug. 2013.

9. YANAGI, I., AKAHORI, R., HATANO, T., et al., "Fabricating nanopores with diameters of sub-1 nm to $3 \mathrm{~nm}$ using multilevel pulse-voltage injection", Scientific Reports, v. 4, pp 1-7, May. 2014.

10. BRIGGS, K., KWOK, H., TABARD-COSSA, V. "Automated Fabrication of 2-nm Solid-State Na-nopores for Nucleic Acid Analysis”, Small, v.10, pp. 2077 2086, March. 2014.

11. KUAN, A.T., LU, B., SZALAY,T., et al, "Electrical pulse fabrication of graphene nanopores in electro-lyte solution", Applied Physics Letters, v. 106, 203109 -1 -203109 -9, May. 2015.

12. APEL, P. Y., BASHEVOY, V., BLONSKAYA, I., et al.,"Shedding light on the mechanism of asym-metric track grabado: an interplay between latent track structure: etchant diffusion and osmotic flow", Phys. Chem. Chem. Phys, v. 18, pp. 25421-25433 Aug. 2016. 
13. SEXTON, L., MARTIN L.P. "Developing synthetic conical nanopores for biosensing applications”, Mol. BioSyst., v. 3, pp. 667-685, September 2007.

14. HOLZE, R. "Electrochemistry of silicon and its oxides", Journal of Solid State Electrochemistry, v.7, pp. 318-319, April 2003.

15. SATO, K.,SHIKIDA, M., MATSUCHIMA, Y., et al., "Characterization of orientation-dependent etch-ing properties of single-crystal silicon: effects of $\mathrm{KOH}$ concentration", Sensors and Actuators A, v. 64, pp. 87-93, 1988.

16. COLLINS, S., "Etch Stop Techniques for Micromachining", Journal of the Electrochemical Society, v. 144. n.6, pp. 2242-262, 1997.

17. SEIDEL, H., CSPREGI, L.,HEUBERGER,A., et al., "Anisotropic Grabado of Crystalline Silicon in Al-kaline Solutions, I. Orientation Dependence and Behavior of Passivation Layers", J. Electrochem. Soc, v.137, pp. 3612-3626, Nov 1990.

18. HARRELL, C. C., SIWY, Z. S., MARTIN, C. R. "Conical Nanopore Membranes: Controlling the Na-nopore Shape”, Small , v. 2, pp. 194-198, Nov. 2006.

19. PARK, S. R., PENG, H., LING, X. S. "Fabrication of Nanopores in Silicon Chips Using Feedback Chemical Grabado", Small , v.3, pp. 116-119, Oct. 2006.

20. CHEN, L., CHEN, M., LIEN, C., et al., "The Band Model and the Grabado Mechanism of Silicon in Aqueous KOH", Journal of The Electrochemical Society, v. 142, pp. 170-176. Jun.1995.

21. APEL, P. Y., KORCHEV, Y. E., SIWY, Z., et al., "Diode-like single-ion track membrane prepared by electro-stopping. Nuclear Instruments and Methods in Physics Research", Section B: Beam Interactions with Materials and Atoms, v. 184, pp. 337-346, Nov2001.

22. PALIK, E. D., GLEMBPCKI, O. J., HEARD, I., et al., “Grabado roughness for (100) silicon surfaces in aqueous KOH", Journal of Applied Physics, v.70, Oct 1991.

23. SIWY, Z., DOBREV, D., NEUMANN, R., et al., "Electro-responsive asymmetric nanopores in polyi-mide with stable ion-current signal", Applied Physics A, v.76, pp.781-785, March 2003.

24. CHTANKO, N., TOIMIL MOLARES, M. E., CORNELIUS, T., et al., "Etched Single-Ion-Track Tem-plates for Single Nanowire Synthesis", The Journal of Physical Chemistry B, v. 108, pp. 9950-9954, June 2004. 


\section{Capítulo IV}

\section{Dispositivo híbrido de microfluídica de estado sólido para la detección óptica rápida de células}




\subsection{Resumen.}

Este capítulo presenta una metodología para la detección y el conteo de células utilizando un dispositivo que combina un microporo de estado sólido y un canal de microfluídica de PDMS. Se presentan las condiciones óptimas para la fabricación de microporos en estado sólido a partir de obleas de silicio cristalino, donde se pueden obtener microporos de tamaño variable usando una concentración de agente grabador de $50 \%$ en peso de $\mathrm{KOH}$, a diferentes temperaturas $\left(40,60,80{ }^{\circ} \mathrm{C}\right)$ y voltajes $(100,500,1000 \mathrm{mV})$. Se utilizó SEM y técnicas de perfilometría para la caracterización de los microporos. Con el fin de encontrar las condiciones óptimas para la detección de células, se realizó una simulación COMSOL Multifísic, donde se evaluaron los parámetros de caída de presión, esfuerzo cortante, viscosidades del fluido y tasas de flujo. Se demuestra la viabilidad potencial del dispositivo para la detección y el conteo celular, evitando el daño celular.

\subsection{Introducción.}

La fabricación de micro y nanoporos ha atraído interés significativo, especialmente en los campos de biosensores, fuídica y procesamiento de la información ${ }^{1-6}$. En particular, la fabricación de micro y nanoporos por métodos electroquímicos de grabado ha captado la atención de muchos investigadores. Este método permite un control preciso del tamaño de los poros, a bajo costo de fabricación y condiciones ideales para la automatización ${ }^{7-10}$. En el proceso de grabado electroquímico, un material de estado sólido es colocado entre un agente de grabado y una solución de detención. Una vez que se forma el poro, se produce un frenado químico concluyendo el proceso. Además, se colocan electrodos de Pt en cada solución y la corriente es monitoreada durante el proceso de grabado ${ }^{7}$. El monitoreo de la corriente eléctrica como una función del tiempo (gráficos $\mathrm{I}-\mathrm{t}$ ) es un predictor eficaz del grabado y el tiempo un descriptor del proceso de frenado ${ }^{10,12-17}$. Características como; resistencia, durabilidad y versatilidad de aplicaciones industriales hacen a las obleas de silicio cristalino excelentes candidatos para ser utilizados como soporte de los poros en estado sólido ${ }^{18}$. El KOH acuoso es la solución de grabado alcalino más utilizada debido al bajo costo, alta relación de grabado (100) / (111) y naturaleza no tóxica ${ }^{19}$. El control adecuado de la apertura 
de los poros durante el grabado electroquímico se puede lograr mediante el control de la corriente eléctrica. Estudios anteriores han informado que, antes de la apertura de los poros, la corriente sufre cambios cuando el material que se está grabando es formado ${ }^{13-15}$. En el caso del silicio como una estructura de soporte y $\mathrm{KOH}$ como solución de grabado, este comportamiento es diferente. Durante el proceso de grabado, el silicio y el $\mathrm{KOH}$ reaccionan generando corriente eléctrica ${ }^{12}$. Además, las variables de control como el material de soporte (silicio), concentración de la solución de grabado, voltaje, temperatura ${ }^{20,21,22}$ solución de frenado ${ }^{10}$ y polaridad de la tensión aplicada ${ }^{13}$ son factores clave para determinar el tamaño y la forma de los poros. Los microporos de estado sólido individuales se han utilizado con éxito para la detección eléctrica y conteo de objetos biológicos como células $^{23-25}$. Un método para la detección y el conteo puede ser llevado a cabo conduciendo objetos biológicos a través de un solo poro utilizando un campo de presión externo o eléctrico. Durante la translocación eléctrica, se puede obtener información sobre las características física de los objetos (es decir, diámetro y longitud) se pueden obtener a partir de la variación de la corriente iónica. Este análisis basado en la translocación eléctrica depende de la capacidad de identificar los objetivos de acuerdo con sus dimensiones físicas ${ }^{26}$. Además, se han creado varias implementaciones para celdas ópticas enfocadas en microcanales que involucran contracción, expansión ${ }^{27}$ y arreglo de estructuras, que permiten controlar el enfoque de flujo hidrodinámico se han desarrollado en dispositivos microfluídicos para el conteo de células de tumores, muestras de sangre, entre otros $^{28-37}$. En este trabajo presentamos una metodología para la fabricación un dispositivo de microfluídica de PDMS como contador de células con un microporo de estado sólido integrado. La metodología comprendió tres pasos; (I) proceso de fabricación de poros; la influencia de la concentración de grabador, voltaje, temperatura y solución de frenado, las características específicas de los poros, como geometría, morfología de la superficie de silicio y dimensión de microporos fueron evaluados. Las técnicas de perfilometría y microscopía electrónica de barrido (SEM) fueron utilizadas para caracterizar los microporos, (II) fabricación de microdispositivos PDMS para detección y conteo de células y (III) la simulación como una herramienta conveniente que define el objetivo de enfoque zonas donde las células convergen para una posterior detección y conteo. Además, la caída de presión, perfil de velocidades y esfuerzo cortante fueron estudiadas. La 
metodología mencionada anteriormente propone e introduce una fabricación alternativa de un dispositivo de PDMS para la detección y conteo de células. Este enfoque proporciona un proceso fácil y rentable para la identificación células. cuantitativa en condiciones de flujo, con alto potencial para ser implementado.

\subsection{Materiales y métodos.}

\subsubsection{Fabricación y caracterización de microporos.}

Las obleas de silicio cristalino tipo Ph100i tienen $500 \mu \mathrm{m}$ de espesor con una capa de nitruro de silicio de baja tensión $\left(\mathrm{Si}_{3} \mathrm{~N}_{4}\right)$ de $200 \mathrm{~nm}$ de espesor en ambos lados se utilizaron para la fabricación de microporos (Addison Ingeniería). Inicialmente, áreas específicas $\left(3 \times 3 \mathrm{~mm}^{2}\right)$ de capas de $\mathrm{Si}_{3} \mathrm{~N}_{4}$ fueron extraído de la parte delantera y de la parte posterior $\left(200 \times 200 \mu \mathrm{m}^{2}\right)$ por el método de eliminación de láser de $\mathrm{CO}_{2}$. El láser de $\mathrm{CO}_{2}$ comercial se usa comúnmente para el corte artístico acrílico. Después, se llevaron a cabo dos pasos de grabado consecutivos. En el primer paso, donde la oblea se sumergió en una solución 39\% en peso de $\mathrm{KOH}$ (Stanton> 99\%) a $80^{\circ} \mathrm{C}$ durante 3 horas seguido de un lavado extenso con agua desionizada (DI). Luego, se introdujo la oblea de silicio en un dispositivo fabricado teflon. El dispositivo está constituido por dos celdas (Figura 4.1). El anverso de la oblea estaba en contacto con la solución de grabado (50\% en peso de $\mathrm{KOH}$ o $20 \%$ en peso de $\mathrm{KOH}$ ) y en la parte posterior estaba en contacto con la solución de frenado ( $\mathrm{HCOOH} 30 \mathrm{M} \mathrm{o} \mathrm{HCl} 12$ M). Para evitar la evaporación o mezcla de reactivos, las celdas fueron cerradas. A continuación, se aplicó un voltaje y la corriente se midió en función del tiempo a través de un Keithley 2612b. El último paso de grabado se realizó en diferentes temperaturas $\left(40,60,80^{\circ} \mathrm{C}\right)$ y voltajes aplicados $(100,500$, $1000 \mathrm{mV}$ ). Luego, las superficies de las obleas se limpiaron con una solución piraña, durante cinco minutos, seguido de lavado con agua desionizada (DI) y se secó a $40{ }^{\circ} \mathrm{C}$ durante 1 hora. Finalmente, los microporos fabricados se codificaron con la concentración de la solución de grabado, solución de frenado, temperatura y voltaje. Además, la fabricación de poros se llevó a cabo con una solución de 50\% en peso de $\mathrm{KOH}$ a 40 y $60{ }^{\circ} \mathrm{C}$ en una segunda etapa de grabado. Después del primer paso de grabado, la cara frontal de la oblea fue sumergida en una solución de $\mathrm{KOH}$ al $50 \%$ en peso a $80^{\circ} \mathrm{C}$. La medición de la corriente eléctrica durante el grabado 
electroquímico se realizó con electrodos de Pt. El electrodo positivo se colocó en la solución de frenado y el polo negativo en la solución de $\mathrm{KOH}$. Los electrodos estaban conectados a un Keithley 2612b a dos canales escalables (Keithley Instruments). La corriente eléctrica fue monitoreada en tiempo real con un paquete informático Test Script Builder (TSB). Las imágenes de microporos se obtuvieron utilizando SEM (TESCAN FEG SEM MIRA3). La rugosidad fue caracterizada con un perfilómetro Dektak XT de Bruker. La rugosidad media (Ra) se determinó con el paquete Vision 64, tomado en posiciones aleatorias en longitudes de 1.2 $\mathrm{mm}$. Se realizaron exploraciones lineales con una punta de radio de $25 \mathrm{~mm}$ a 40 $\mathrm{mm} \mathrm{s}^{-1}$ velocidad de escaneo y una frecuencia de muestreo de datos de $250 \mathrm{~Hz} \mathrm{~mm}^{-}$ 1. Las mediciones de rugosidad informadas en este trabajo fueron reproducibles sobre al menos tres puntos de la superficie de la muestra.

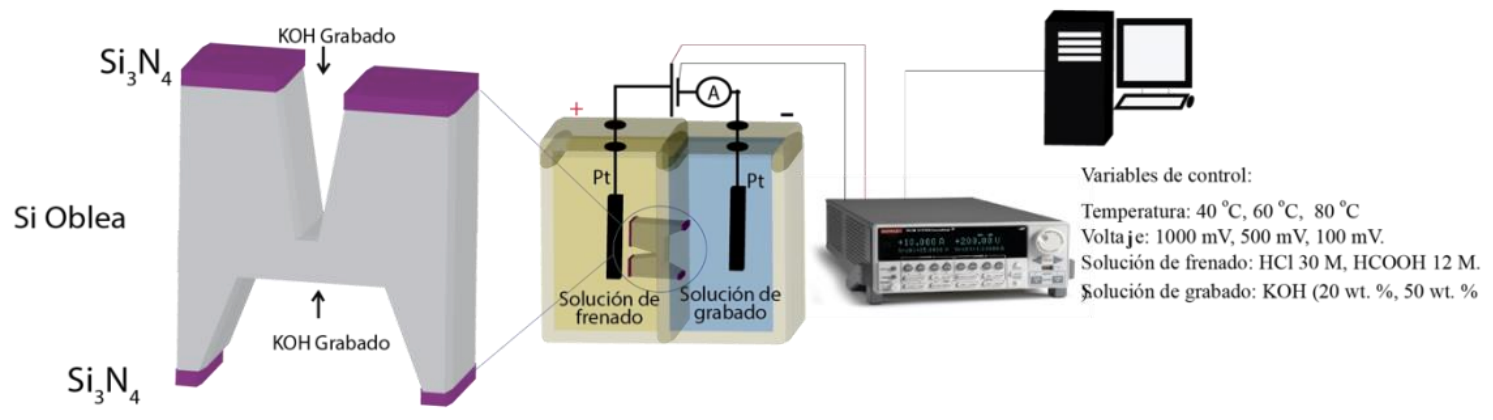

Figura. 4.1. Fabricación de microporos de silicio por el método electroquímico. Imagen esquemática de la configuración de grabado. 


\subsection{Fabricación del dispositivo de microfluíca la para detección visual de células y el conteo celular.}

\subsubsection{Fabricación de microcanales de PDMS e integración del microporo.}

Se realizó la fabricación del canal de microfluídica PDMS utilizando un método económico y accesible desarrollado por nuestro grupo de investigación ${ }^{39}$. Brevemente, se hizo un molde utilizando un fotopolímero Fmold como molde maestro flexográfico (Fmold). Entonces, se fabricó un molde de resina (ERmold) ${ }^{40}$. El fotopolímero Flexcel NX y la capa térmica de imagen (TIL) utilizadas en el molde de la fabricación fueron proporcionados por Eastman Kodak. Además, la resina epóxica y el agente de curado fueron suministrados por Cristal-Tack, Novarchem - Argentina. El Fmold y ERmold fueron diseñados con canales de 144 mm de espesor y $500 \mu \mathrm{m}$ de ancho, utilizando Layout editor paquete informático. ${ }^{41}$ El diseño consta de un solo canal con un conducto en el medio y dos salidas (Figura. 4.2a). El PDMS fue mezclado con agente de curado en una proporción en peso de 10:1 (Sylgard 184 Kit de elastómero de silicona), fue descrito previamente por Olmos et al. ${ }^{40}$ Luego, la mezcla se colocó al vacío durante 30 min para eliminar las burbujas de aire, la solución fue vertida sobre el ERmold y se curo en una estufa a $40{ }^{\circ} \mathrm{C}$ durante la noche. Después del curado, la réplica de PDMS se despegó del molde y se perforaron los agujeros para formar las entradas y salidas de los canales utilizando un punzón de biopsia de $1 \mathrm{~mm}$ de diámetro (Integra Miltex®Ted Pella, $\mathrm{C}^{\mathrm{a}}$ ). Posteriormente, la réplica se unió de manera irreversible a una oblea de vidrio, después de la exposición a un generador de alta frecuencia (BD-10AS, Chicago) durante 120 s. Después, el microporo se colocó y se adhirió al bloque PDMS (5 $\mathrm{mm}$ de espesor) como se muestra en la figura 4.2b. Posteriormente, el bloque de PDMS se unió a la réplica de PDMS como se muestra en la figura 4.2c. Finalmente, las células fueron introducidas con una bomba de jeringa y detectadas con el microscopio como se muestra en la configuración de la figura. 42c. 


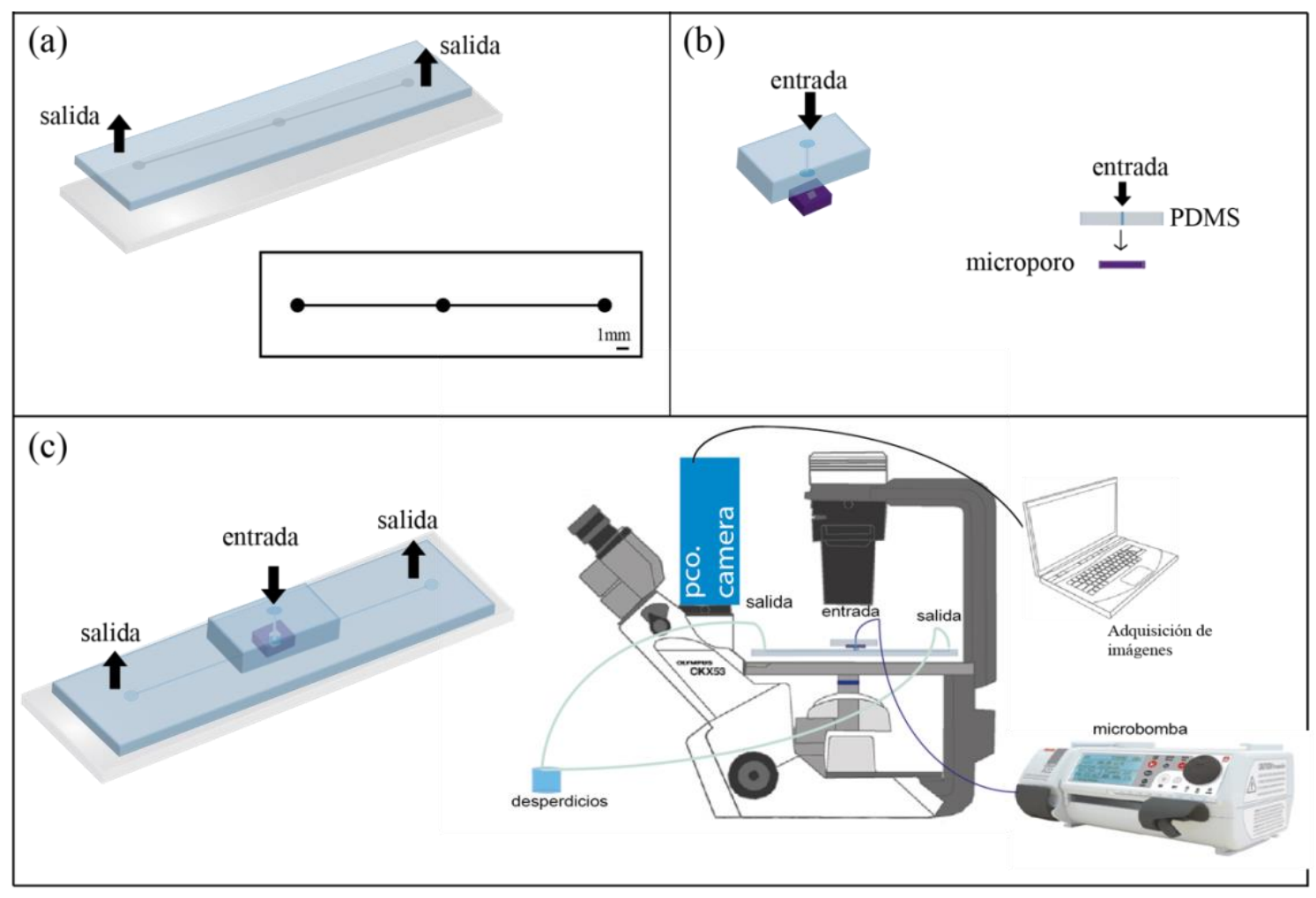

Figura.4.2. Fabricación y configuración para el conteo de células (a) diseño de microcanales y unión de réplica de PDMS en un portaobjetos de vidrio, (b) el microporo está unido y alineado con bloque PDMS (5 mm de espesor), (c) esquema del dispositivo microfluídico y el montaje de la configuración.

\subsubsection{Línea celular, cultivo celular y transfección transitoria.}

En el estudio se utilizó la línea celular HEK-293 (ATCC® CRL-3216 TM). Las células se mantuvieron en medio DMEN por sus siglas en inglés Dulbecco Modified Eagle Medium (Lonza BioWhittaker, cat. No. 12-604F, Walkersville, MD) suplementado con suero bovino fetal al 10\% (FBS, Invitrogen, No. 10082147), $100 \mathrm{U} \mathrm{mL}^{-1}$ de penicilina y $100 \mu \mathrm{g} \mathrm{mL}^{-1}$ estreptomicina (CORNING Cellgro, cat. no. 30-002-CI, Manassas, VA) en una incubadora humidificada con $\mathrm{CO}_{2}$ al $6 \%$. En total, se sembraron $1.5 \times 10^{4}$ células HEK-293 por pocillo de una placa de seis pocillos, en DMEM, 10\% FBS y 2\% de antibióticos (100 UmL 1 penicilina y $100 \mu \mathrm{g}$ mL 1 estreptomicina). $24 \mathrm{~h}$ después, el medio fue reemplazado con medio DMEM suplementado con 10\% FBS y sin antibióticos. Las células permanecieron con este medio durante $24 \mathrm{~h}$. Posteriormente, las células fueron lipofectadas 
(Lipofectamine 2000, Invitrogen) con la proteína fluorescente verde potenciadora (GFP) a través del plásmido (pCX-EGFP) siguiendo las instrucciones del fabricante. También se ha utilizado Opti-MEM I Reduced Serum Medio (Invitrogen, cat. $\mathrm{N}^{\circ} 31985$ ) para la transfección. Después de 24 h, el medio se reemplazó con medio completo DMEM. La fluorescencia verde se debe a la expresión de GFP en células HEK-293 observado por microscopio fluorescente Carl Zeiss Axiovert S200 (488 nm) 48 h después de la lipofección. Finalmente, las células se lavaron dos veces con PBS, fueron despendidas de la superficie con tripsina-EDTA $0.05 \%$ (Thermo-Fisher Scientific, cat. No. 25300054) y cuantificado con una cámara Neubauer y resuspendidas en medio DMEM filtrado sin FBS ni antibióticos, bajo flujo limpio, a $2 \times 10^{5}$ células por $\mathrm{mL}$ antes de su uso.

\subsection{Montaje de configuración y detección/cuantificación visual.}

Para identificar y contar células individuales, se utilizó un microscopio invertido Olympus CKX53 con lente LUCPLFLN 40 - FIUBA Fluid Dynamics Lab (LFD, líneas 214-215) para identificar y contar las células individuales. Se inyectaron 5 ml de suspensión de células HEK-293 desde la entrada del dispositivo de microfliuídica. La suspensión celular se bombeó utilizando una jeringa controlada por una microbomba de jeringa (ADOX active A22) y los residuos se retiraron a través de diferentes tubos de teflón colocados en las salidas (Figura. 4.2c). Se evaluaron seis velocidades de flujo de 1.6, 3.3, 5.0, 6.6, 8.3, 10.0 y $16.6 \mathrm{ml} \mathrm{min}{ }^{-1}$. Mientras las células pasaban a través del microporo, 1000 imágenes fueron recolectadas durante 2 segundos, para cada flujo. Las imágenes de cada caudal se recogieron con la cámara PCO 1200HS y se analizaron utilizando un paquete informático de procesamiento de imágenes. La cuantificación de células se llevó a cabo utilizando una macro desarrollada a partir de la plataforma ImageJ (ESI: cuantificación de células). El análisis de imagen de ImageJ-FIJI permitió incrementar el contraste, acentuar los detalles de cada imagen y contar las células. 


\subsection{Simulaciones del flujo.}

Para predecir las zonas objetivo de alta concentración celular donde puedan ser detectadas ópticamente al pasar a través del microporo, perfiles de caída de presión, velocidad y esfuerzo cortante se calcularon mediante el paquete informático Comsol 5.3a. Velocidades de flujo $\left(1.6 \mathrm{ml} \mathrm{min}^{-1}, 3.3 \mathrm{ml} \mathrm{min} \mathrm{m}^{-1}, 5 \mathrm{ml}\right.$ $\min ^{-1}, 6.6 \mathrm{ml} \mathrm{min}^{-1}, 8.3 \mathrm{ml} \mathrm{min}{ }^{-1}, 10 \mathrm{ml} \mathrm{m^{-1 }}, 16.6 \mathrm{ml} \mathrm{min}^{-1}$ ) y un intervalo de viscosidades $0.89 \mathrm{cP}$ (agua); $0.94 \mathrm{cP}$ (DMEM alto en glucosa + FBS); $1.1 \mathrm{cP}$ (orina); $1.5 \mathrm{cP}$ (plasma) fueron datos de entrada para el modelo. El programa simuló el flujo de microfluidos que pasa a través de la región de microporos y el canal PDMS utilizando las ecuaciones de Navier-Stokes con un número de Reynolds muy bajo. Las condiciones de contorno para el modelo 3D incluyeron flujo progresivo y sin rozamiento (laminar sin tener en cuenta el término inercial), presión cero en las salidas y las propiedades del agua como material fluido. La densidad de la malla se construyó para incluir > 900000 elementos de libertad, con una calidad de elemento promedio de $>0.638$

\subsection{Resultados y discusión.}

\subsubsection{Fabricación de microporos: influencia de las variables de control.}

Utilizando el método electroquímico descrito anteriormente, se fabricaron una serie de microporos, bajo diferentes condiciones de voltaje, temperatura, medio de detección y concentración de la solución de grabado. Los microporos producidos en diferentes condiciones se pueden ver en la figura. 4.3. La geometría piramidal resultante es una estructura típica del grabado en húmedo sobre silicio (Figura. 4.1). Además, es importante señalar que la formación de poros con forma rectangular también fue posible por las altas concentraciones de la solución de grabado (50\% en peso de $\mathrm{KOH})$. Cuando se utilizaron concentraciones bajas de solución de grabado ( $20 \%$ en peso de $\mathrm{KOH}$ y $80^{\circ} \mathrm{C}$ ), los poros presentaron formas irregulares. También se encontró que en condiciones de $20 \%$ en peso de $\mathrm{KOH}$ y $60{ }^{\circ} \mathrm{C}$, no era posible la formación de poros. Estos resultados concuerdan con hallazgos previos ${ }^{17}$. La geometría, la arquitectura y la forma de las paredes que 
componen el poro pueden tener un impacto significativo en los microfluidos, especialmente en la distribución del flujo y, por lo tanto, influir en el transporte de las células dentro de la red a través del microporo ${ }^{43}$. La calidad de las superficies se examinó mediante SEM. Las figuras 4.3 y 4.4 revelan diferencias en las características a nivel microscópico. Al $50 \%$ en peso de $\mathrm{KOH}$, las superficies grabadas están libres de micropirámides. Por el contrario, a concentraciones más bajas de la solución de grabado se puede observar una alta densidad de montículos o micropirámides. La presencia de micropirámides, así como la ausencia de poros se atribuye el alto grado de producción de burbujas de hidrógeno durante el grabado, lo que no permite una disolución homogénea de la superficie del silicio. Esta observación está de acuerdo con los resultados previos informados por Palik et al $^{44}$. Además, se evaluaron las influencias de las variables de control sobre la rugosidad de los microporos fabricados con $\mathrm{KOH}$ al $50 \%$ en peso. Los datos de rugosidad resultantes $(\mathrm{Ra})$ son muy cercanos entre ellos, presentando valores en el orden de nanómetros (Tabla S1 - ESI ${ }^{*}$ ). Estos resultados indican que el tiempo de grabado y el voltaje no inducen cambios significativos en la morfología de la superficie. Con base en los datos experimentales, las condiciones óptimas para la fabricación de los poros se pueden lograr utilizando $50 \%$ en peso de $\mathrm{KOH}$, temperaturas de $40,60,80^{\circ} \mathrm{C}$ y voltajes de $100,500,1000 \mathrm{mV}$.

\footnotetext{
* Las tablas, el video de la sección 4.7.3 y figuras suplementarias están como accesos directos (hipervínculos), y se pueden visualizar en el archivo original enviado a la revista.

Video link: http://www.rsc.org/suppdata/c9/ra/c9ra09939e/c9ra09939e2.avi

Tablas y Figuras link: http://www.rsc.org/suppdata/c9/ra/c9ra09939e/c9ra09939e1.pdf
} 


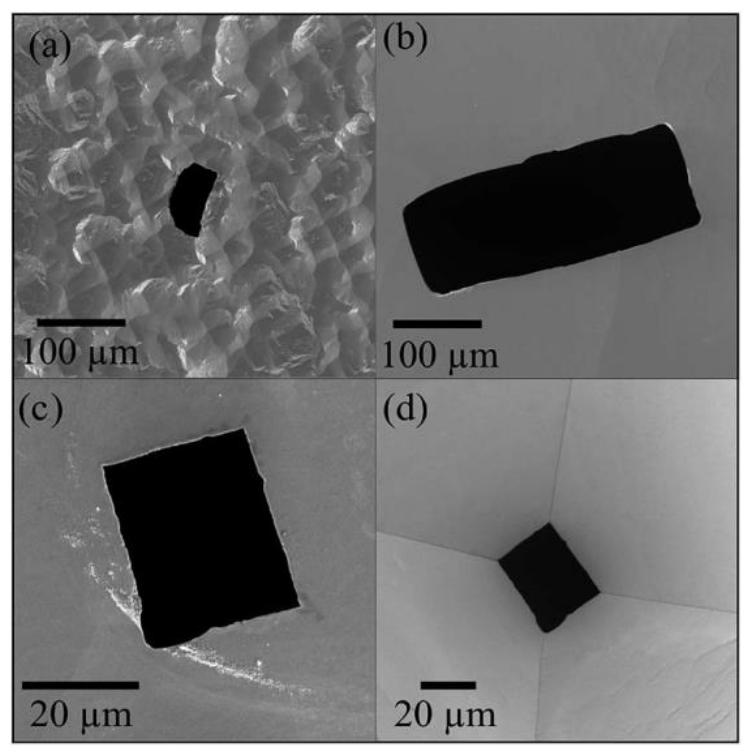

Figura. 4.3. Imágenes de SEM de los microporos. (a) KOH20-HCl-80-1 (anverso), (b) KOH50-HCl-80-1 (anverso), (c) KOH50-HCOOH-80-0.1 (anverso), (d) KOH50- HCOOH-80-0.1 (reverso). Los códigos de los microporos corresponden con la concentración de $\mathrm{KOH}$, seguido del ácido, la temperatura y el voltaje aplicados durante el grabado electroquímico.

\subsubsection{Perfiles eléctricos.}

Con respecto a la monitorización de la corriente eléctrica, la figura 4.5 ilustra los gráficos de corriente versus tiempo $(\mathrm{I}-\mathrm{t})$ registrados durante el proceso de grabado de la fabricación de poros con $50 \%$ en peso de $\mathrm{KOH}$.

Como puede observarse, todos los perfiles I - $\mathrm{t}$ siguen un comportamiento similar; (1) un aumento progresivo de la corriente eléctrica. Este comportamiento se puede atribuir a la reacción redox $\left(\mathrm{Si}+4 \mathrm{OH}-----\rightarrow \mathrm{Si}(\mathrm{OH}) 4+4 \mathrm{e}^{-}\right)$y (2) una fuerte fluctuación de la corriente. Además, en términos de órdenes de magnitud, también se pueden observar los fuertes efectos de las variables de control sobre la corriente eléctrica.

Las gráficas I - t (Figura. 4.5) muestran que las magnitudes de corriente son mayores en los casos en los que la solución de frenado utilizada fue HCl 12 M. Probablemente, este comportamiento esté asociado con la química características del ácido. El ácido fórmico tiene un menor grado de disociación mientras que el ácido clorhídrico es un ácido fuerte que se disocia completamente en solución 
acuosa. Cuanto mayor sea la disociación, mayor será la conductancia y, por tanto, la corriente eléctrica. En cuanto a la temperatura, la conductividad aumenta con la temperatura debido a la alta disociación y al aumento de la velocidad de los iones. De hecho, la magnitud de la corriente eléctrica registrada a $40^{\circ} \mathrm{C}$ es menor que la registrada a $80^{\circ} \mathrm{C}$. Sin embargo, no se observaron diferencias significativas entre las curvas registradas a $60 \mathrm{y} 80^{\circ} \mathrm{C}$. El efecto de los voltajes aplicados en el I - t, así como sus características se exploraron mediante la realización de una serie de experimentos de grabado a 100, 500 y $1000 \mathrm{mV}$.

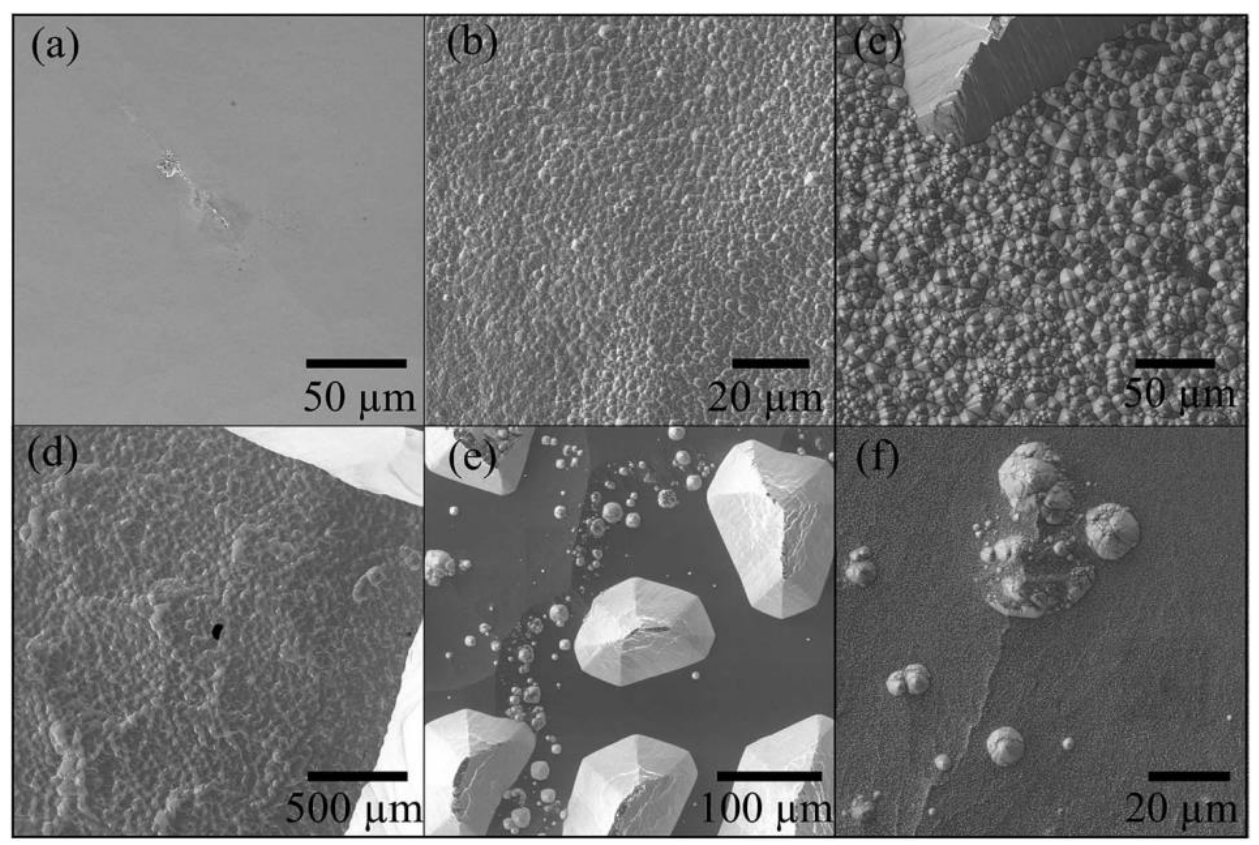

Figura. 4.4. Imágenes de SEM de la superficie del silicio; (a) $50 \mathrm{wt} \% \mathrm{KOH}, 1 \mathrm{~V}$ a $40{ }^{\circ} \mathrm{C}$, (b) $20 \mathrm{wt} \% \mathrm{KOH}, 1 \mathrm{~V}$ a $60{ }^{\circ} \mathrm{C}$, (c) $20 \mathrm{wt} \% \mathrm{KOH}, 1 \mathrm{~V}$ a $60{ }^{\circ} \mathrm{C}$, (d) $20 \mathrm{wt} \%$ $\mathrm{KOH}, 1 \mathrm{~V}$ a $80^{\circ} \mathrm{C}$, (e) $20 \mathrm{wt} \% \mathrm{KOH}, 1 \mathrm{~V}$ a $80^{\circ} \mathrm{C}$ (f) $20 \mathrm{wt} \% \mathrm{KOH}, 1 \mathrm{~V}$ a $80^{\circ} \mathrm{C}$.

La comparación de los gráficos I - t indica que el voltaje aplicado influye en la magnitud de las corrientes acorde a lo esperado. La conductividad es directamente proporcional al voltaje debido a la velocidad de los iones. La tensión aplicada de $1000 \mathrm{mV}$ promueve una alta movilidad y, en consecuencia, se obtuvo una alta magnitud de corrientes en todos los casos. En resumen, la magnitud de la corriente eléctrica mostró una fuerte relación con los parámetros aplicados en el proceso de 
grabado. Con respecto a la fluctuación repentina de la corriente ('breakthrough'), la literatura ha indicado que este comportamiento está asociado con la apertura del poro $^{10,12-15}$. Para verificar el tiempo de apertura dentro de las gráficas I - t, tiempos nominales de apertura se calcularon mediante la ecuación (1) y se compararon con las gráficas $\mathrm{I}-\mathrm{t}$.

\section{Ecuación $4.1 \quad t_{b}=\frac{[D]}{V}$}

donde tb es el tiempo nominal de apertura de los poros, D corresponde al espesor final de la oblea de silicio obtenido antes del ataque electroquímico y $\mathrm{V}$ es la tasa de ataque de la solución de grabado. La velocidad a la que el $50 \%$ en peso de $\mathrm{KOH}$ graba la oblea de silicio h100i a 80,60 y $40^{\circ} \mathrm{C}$ es de aproximadamente $46.2 \mathrm{~m} . \mathrm{mh}^{1}$, $14.3 \mathrm{~m} . \mathrm{mh}^{-1}$ y $3.8 \mathrm{~m} . \mathrm{mh}^{-1}$ respectivamente ${ }^{45}$. La comparación entre los tiempos de apertura de los poros obtenidos de los gráficos I - t y los tiempos nominales indica que no hubo diferencias significativas, se encontraron valores menores al 10\% (Figura. S1 - ESI). Con base en los resultados descritos anteriormente, es posible identificar la formación de un único microporo; un cambio repentino de la corriente eléctrica está relacionado con la apertura de los poros. Además, los resultados obtenidos están en buena concordancia con trabajos previos reportados por Park et $a l^{46}$. y Apel et $a l^{13}$. Además, Harrell, reporta que a un mayor temperatura y voltaje se forma una mayor apertura de poros en la base. Por tanto, considerando el análisis anterior, si el grabado electroquímico se realiza a $40{ }^{\circ} \mathrm{C}$, en condiciones de voltaje de $100 \mathrm{mV}$, es posible fabricar microporos con menor apertura de base y simultáneamente obtener un mayor control sobre el tamaño de poro. Por otro lado, un cambio en la velocidad de grabado puede modificar el tiempo de apertura del poro. Así, la falta de concordancia de los tiempos de apertura de los poros posiblemente se debe a diferentes factores como la producción de burbujas de hidrógeno durante el grabado. La difusión de silicatos de la superficie, reacciones competitivas, productos de grabado de silicio y formación de óxido de silicio seguido de disolución de estos productos frente a una disolución directa de silicio por $\mathrm{KOH}$ demostraron controlar la velocidad de grabado. 


\subsubsection{Aplicación: detección y conteo de células.}

En el conteo y detección de células se utilizó un dispositivo de microfluidos multicapa de PDMS con microporos de estado sólido con $150 \mathrm{~mm}$ de ancho y 150 $\mathrm{mm}$ de altura. Para definir las zonas objetivo de enfoque con alta convergencia celular, se llevaron a cabo simulaciones numéricas utilizando el paquete informático Comsol 5.2a. Se obtuvieron los perfiles de caída de presión, esfuerzo cortante y velocidades. Estos parámetros son críticos para las partículas de enfoque hidrodinámico, pero también podrían adaptarse para detectar células a través de microporos ${ }^{26}$. Además, el dispositivo de microfluidos PDMS se fabricó utilizando metodologías económicas. Por tanto, en la fabricación del dispositivo de microfluidos se utilizó el Fmold que proporciona una buena alternativa a los métodos convencionales de fabricación de microfluidos de fotorresina sobre obleas de silicio. Se puede utilizar múltiples veces con la adquisición de réplicas fiables, sin deslaminación, ya que el molde y las estructuras diseñadas componen una pieza única. Además, los moldes Fmolds se pueden obtener comercialmente a un costo mucho menor que los moldes SU-8. Adicionalmente, dado que la tecnología Flexcel se usa comúnmente en la industria gráfica, Fmolds se pueden adquirir en todo el mundo, sirviendo como soporte para muchos laboratorios que carecen de instalaciones de micro fabricación, como los relacionados con los campos de biología y química, especialmente en laboratorios de microfluidos de países en vías de desarrollo. Además, se utilizó un láser de $\mathrm{CO}_{2}$ comercial comúnmente utilizado para el corte artístico acrílico para la fabricación de microporos. Permite la eliminación de $\mathrm{Si}_{3} \mathrm{~N}_{4}$ con alta precisión, evitando el uso de equipos costosos (dependientes de la sala limpia) como el grabado de iones reactivos (RIE). 

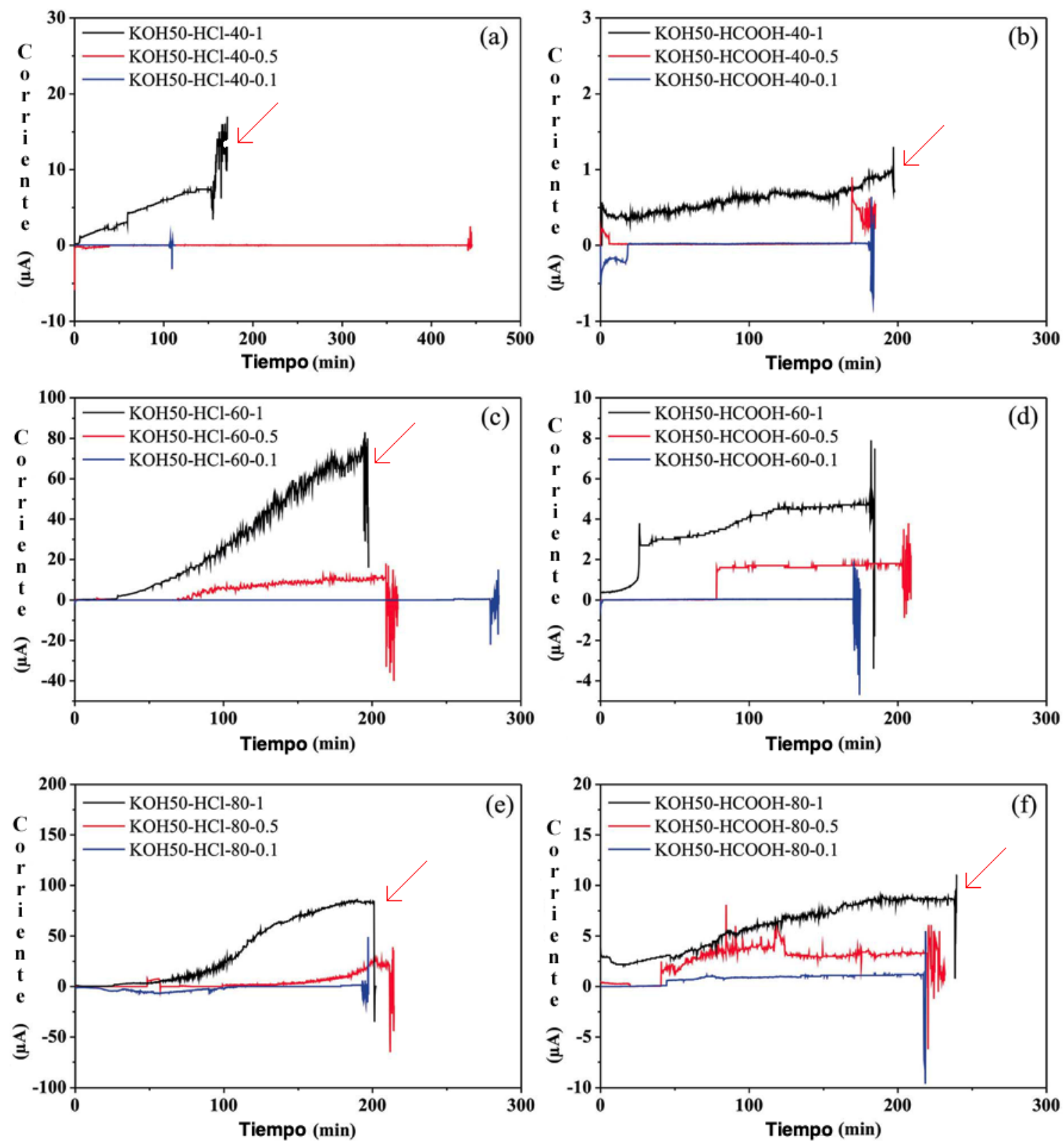

Figura. 4.5. Gráficos de I - t registrados durante el grabado electroquímico en $\mathrm{KOH}$ al $50 \%$ en peso para obleas de silicio sometidas a diferentes condiciones: (a) $\mathrm{HCl}$ $12 \mathrm{M}$ a $80{ }^{\circ} \mathrm{C}$; (b) $\mathrm{HCl} 12 \mathrm{M}$ a $60{ }^{\circ} \mathrm{C}$; (c) $\mathrm{HCl} 12 \mathrm{M}$ a $40{ }^{\circ} \mathrm{C}$; (d) $\mathrm{HCOOH} 12 \mathrm{M}$ a $80{ }^{\circ} \mathrm{C}$; (e) $\mathrm{HCOOH} 12 \mathrm{M} \mathrm{a} 60{ }^{\circ} \mathrm{C}$; (f) $\mathrm{HCOOH} 12 \mathrm{Ma} 40{ }^{\circ} \mathrm{C}$. Se aplicaron tensiones de $1000 \mathrm{~V}, 500 \mathrm{~V}$ y $100 \mathrm{~V}$ durante el proceso de grabado. Las flechas rojas indican el tiempo de apertura de los poros. 


\subsubsection{Simulación: determinación de zonas objetivo de enfoque.}

Los parámetros de caída de presión y esfuerzo cortante se calcularon variando el rango de viscosidades y caudales. La figura. 4.6 muestra la caída de presión y el esfuerzo cortante obtenidos bajo una viscosidad de $1.5 \mathrm{cP}$ y un caudal de $16.6 \mathrm{~mL}$ $\min ^{-1}$. Como se puede ver en el mapa de calor, la caída de presión en el microporo surge hasta los $40 \mathrm{~Pa}$. Los resultados indicaron que la caída de presión disminuye gradualmente al final del microporo y continúa disminuyendo a lo largo del microcanal de PDMS que conduce a la salida donde la presión se reduce a cero. ESI, Figura. S2 muestra el mapa de calor de la distribución de la caída de presión bajo diferentes viscosidades y caudales.

La caída de presión sigue el mismo comportamiento en áreas cercanas al final del microporo. La caída de presión más baja se obtuvo con una viscosidad de $0.89 \mathrm{cP}$ y un caudal de $0.1 \mathrm{~mL}$. $\mathrm{min}^{-1}$. La distribución del esfuerzo cortante en el microporo y el microcanal PDMS se muestra en la figura 4.7. Los resultados muestran una disminución gradual del esfuerzo cortante en el extremo del microporo y continúa disminuyendo a lo largo del microcanal. ESI, Figura. S3 muestra los resultados para los valores de viscosidades y tasas de flujo propuestos en los métodos. Los resultados demuestran que en todas las condiciones evaluadas el esfuerzo cortante disminuye después de la formación del microporo. 


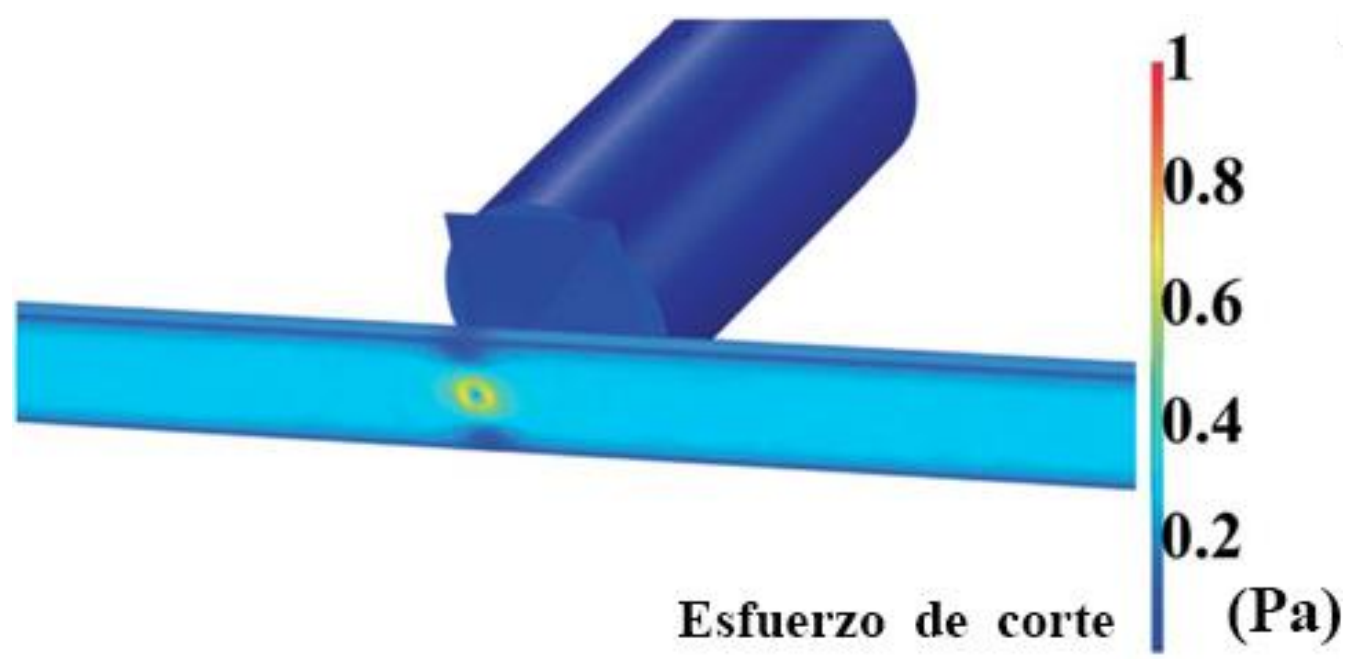

Figura. 4.6. Distribución del esfuerzo cortante en el microcanal de microporo y PDMS. Condiciones: viscosidad de $1.5 \mathrm{cP}$ y caudal de $16.6 \mathrm{ml} \mathrm{min}{ }^{-1}$.

Además, el esfuerzo cortante mínimo se observa con una viscosidad de $0.89 \mathrm{cP}$ y un caudal de $0.1 \mathrm{~mL} \cdot \mathrm{min}^{-1}$. Los resultados de la caída de presión y las magnitudes del esfuerzo cortante se resumen en la figura. $4.8 \mathrm{a}$ y $\mathrm{b}$ respectivamente. Cuando las diferencias entre los subconjuntos son mayores que $3.4 \mathrm{~mL} \mathrm{~min}^{-1}$ de tasa baja, los valores de caída de presión y esfuerzo cortante fueron significativamente diferentes ( $\mathrm{p}<0.05$ ) calculados por ANOVA de dos vías seguido de la prueba de Tukey. Además, bajo el mayor caudal y viscosidad (16.6 mL.min ${ }^{-1} 1$ y $\left.1.5 \mathrm{cP}\right)$, se obtuvieron valores más altos de caída de presión y esfuerzo cortante. El cultivo celular en microfluídica, puede verse afectado por la tensión de cizallamiento en las paredes, especialmente en las zonas de transición que es un factor crítico porque las fuerzas de cizallamiento pueden alterar el comportamiento celular o incluso dañar la estructura del citoesqueleto si los valores son excesivamente altos ${ }^{47,48}$. Por esta razón, es importante conocer el comportamiento de esfuerzo cortante dentro del microporo. A partir de los resultados, el esfuerzo cortante máximo observado se ubicó en el centro del canal (0.8 Pa). Deacuerdo con la literatura, un esfuerzo cortante superior a 56.4 Pa causa deformabilidad y daño celular. En nuestro sistema microfluídico el valor es mucho menor, por lo que la arquitectura del dispositivo evitaría el daño celular ${ }^{49,50}$. Finalmente, la simulación permitió establecer zonas 
óptimas de enfoque para detectar células utilizando diferentes caudales evitando un esfuerzo cortante perjudicial para las células.
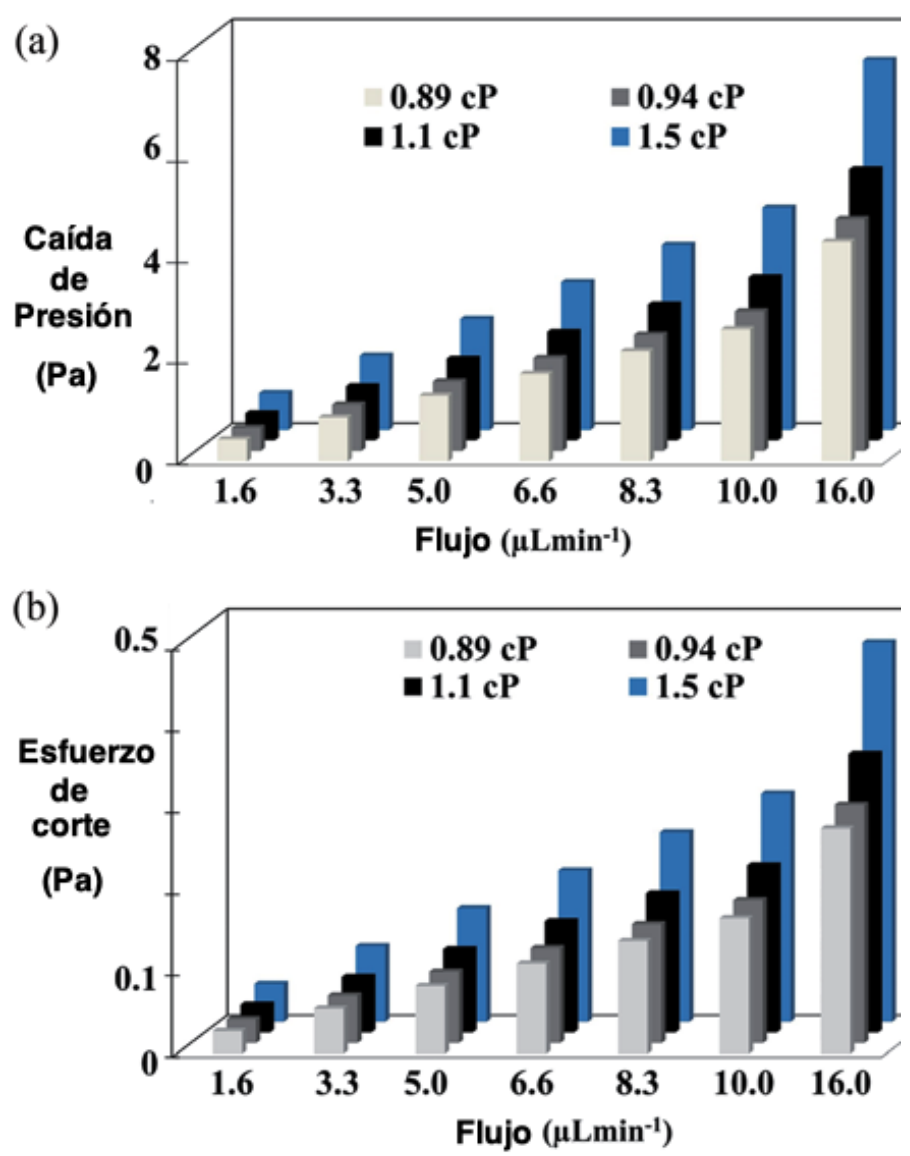

Figura. 4.7. (a) Caída de presión y (b) esfuerzo cortante calculado a diferentes velocidades de flujo y viscosidades.

Mediante el paquete informático COMSOL 5.3a, también se logró calcular el perfil de velocidades. La Figura. 4.9 muestra el perfil de velocidad de los fluidos que pasan por la sección transversal del microporo con una viscosidad de $1.5 \mathrm{cP}$ y un caudal de $16.6 \mathrm{ml} \mathrm{min}{ }^{-1}$. El perfil muestra que la velocidad máxima se produce al comienzo del microporo y disminuye en la zona entre el microporo y el canal siguiendo un patrón concéntrico. El flujo secundario se muestra en vectores; (a) pasando por el centro del microporo hacia el canal de PDMS y (b) direcciones de los vectores que comienzan a converger y cambiar en el microcanal para seguir su borde. 
Además, ESI, Figura. S4 muestra la distribución de los perfiles de velocidad en el microcanal de microporo y PDMS a una viscosidad de $0.89 \mathrm{cP}$ y velocidades de flujo variables. Los resultados demuestran que en la parte inicial del microporo las velocidades aumentan como se esperaba. Además, el perfil de velocidades presenta una distribución parabólica. Este perfil de velocidad se debe a la conjunción de un microporo de silicio rectangular y los canales de $\mathrm{PDMS}^{51}$. A partir de los resultados obtenidos, la zona óptima para la detección visual de células se encuentra en la zona de transición del microporo y el canal PDMS donde la velocidad disminuye.

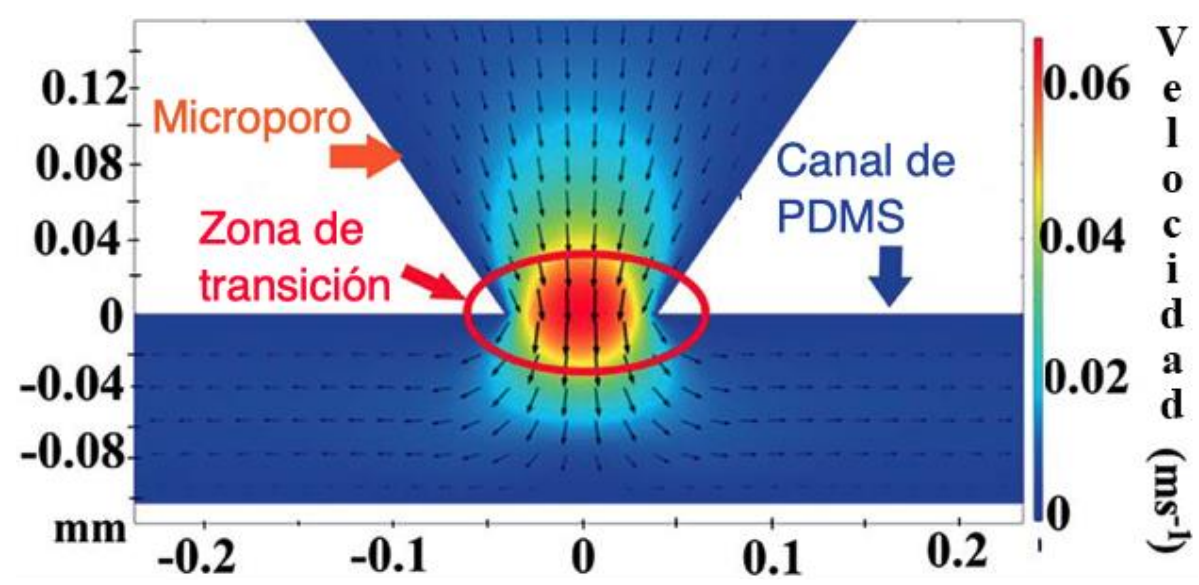

Figura. 4.8. Perfiles de velocidad en la sección transversal del microporo. Condiciones: viscosidad de $1.5 \mathrm{cP}$ y caudal de $16.6 \mathrm{~mL} \cdot \mathrm{min}^{-1}$.

\subsubsection{Detección y conteo de células.}

El montaje del sistema para identificar y contar células se ensambló como se describió en la Sección 4.2, como resultado, integramos sistemáticamente un microporo y un canal PDMS. La arquitectura desarrollada en el dispositivo de microfluídica permite detectar las células y el conteo aplicando diferentes caudales. La detección óptica se estableció entre el microporo y la zona de transición de PDMS. La figura. 4.10 presenta imágenes representativas obtenidas por microscopia óptica de una sola célula que pasa a través del microporo. Una vez que las células atravesaron en el microporo, las imágenes se registraron y se 
analizaron utilizando el paquete informático ImageJ FIJI ${ }^{42}$. Este paquete informático permitió la detección y el conteo de los núcleos de las células. La figura 4.10 muestra un núcleo celular bajo un campo claro del microscopio; El núcleo es el más brillante (Figura. 10b) en contraste con la célula completa (Figura. 10a). El video muestra la célula pasando a través del microporo (ESI, Video 1). A partir de los resultados de la simulación, se encontraron las mejores condiciones hidrodinámicas para la detección con una tasa de flujo de $1.6 \mathrm{~mL} \mathrm{~min}^{-1}$ y $0.89 \mathrm{cP}$ de viscosidad como se explica en la Sección 4.1. Sin embargo, es importante señalar que bajo la viscosidad del DMEM $(0.94 \mathrm{cP})$, se logra un esfuerzo cortante bajo evitando la deformabilidad y daño celular. Como se puede observar en la Figura. 4.10, en concordancia con los resultados de la simulación, se detectaron células en la zona de transición y se encontró que el número de células aumenta con el aumento de la tasa de flujo como se muestra en la Figura. 4.11.

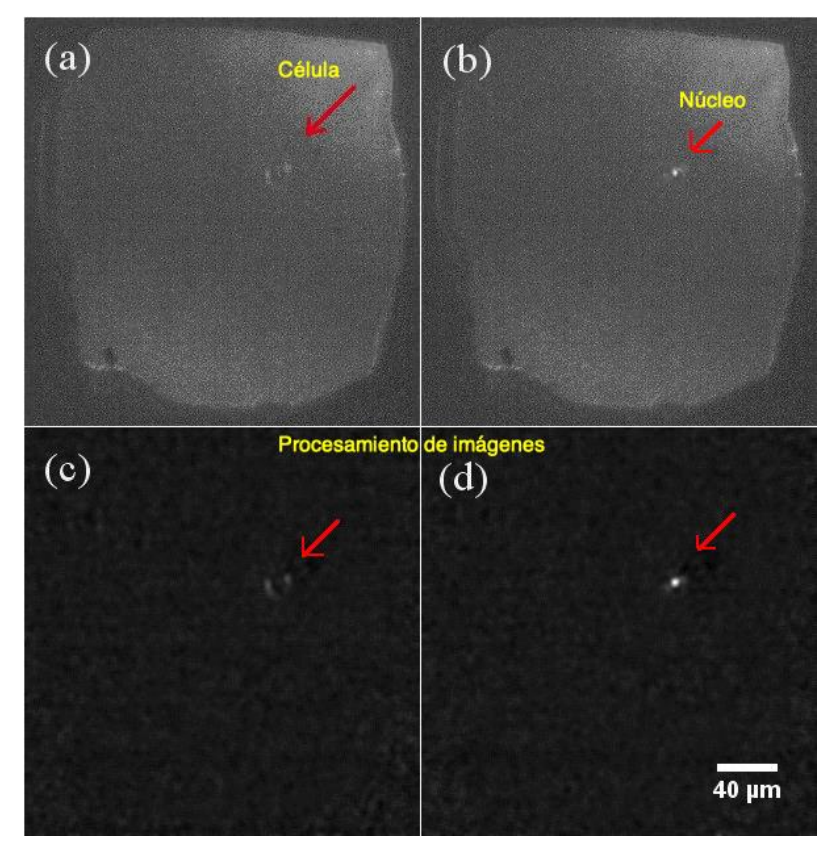

Figura. 4.9. Identificación de células completas bajo un campo claro del microscopio. (a) Imagen de la célula, (b) imagen del núcleo de la célula, (c) imagen del procesamiento por ImageJ-FIJI de una célula, (d) imagen del procesamiento del núcleo de la célula por ImageJ-FIJI. Dimensiones del microporo: $\sim 150 \mu \mathrm{m} \mathrm{x}$ $150 \mu \mathrm{m}$. 
A partir del análisis, se estableció una correlación lineal entre el número de células que atraviesan el poro con diferentes caudales. La relación lineal entre las tasas de flujo y el número de células muestra un comportamiento del fluido muy parecido al de un fluido newtoniano. Este comportamiento se puede atribuir al hecho de que las células asumen un movimiento de forma constante en respuesta a las fuerzas cortantes de las tasas de flujo ${ }^{52-54}$. Finalmente, el esfuerzo cortante, la caída de presión y el perfil de velocidades permitieron establecer una zona para identificar y detectar ópticamente las células. Por lo tanto, se desarrolló una metodología novedosa que se puede aplicar en la evaluación visual y no destructiva del análisis de células de recuento cuantitativo utilizando equipos de uso común y sin requisitos de reactivos adicionales ni equipos demasiado sofisticados.

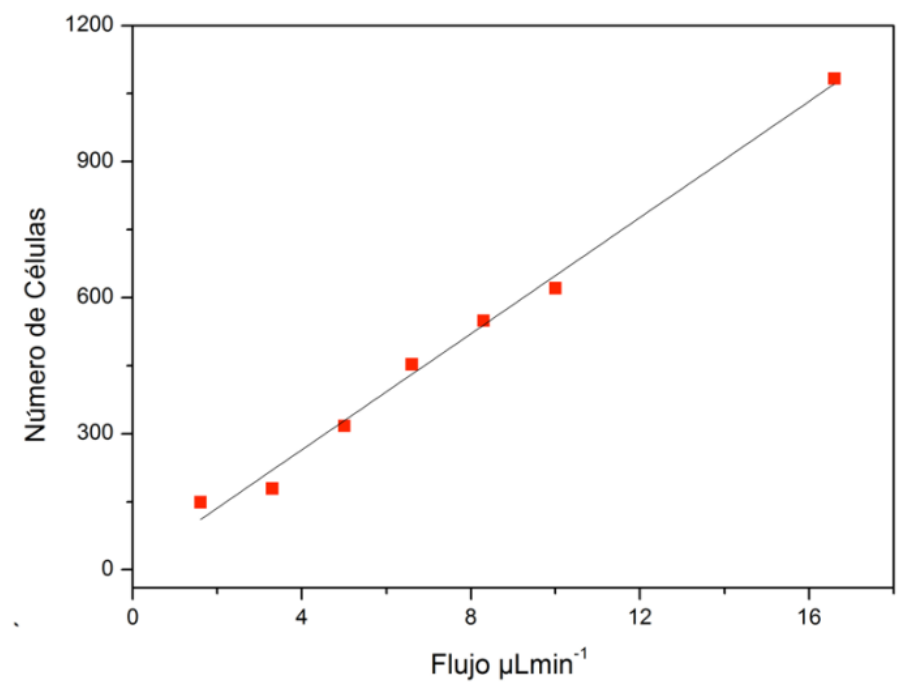

Figura. 4.10. Células HEK-293 medidas a diferentes velocidades de flujo. 


\subsection{Conclusiones.}

Se realizó la integración entre el canal de microfluidos multicapa y el microporo en estado sólido para la detección y el conteo de células. Se presentaron dos métodos de fabricación accesibles y económicos para fabricar los microporos y los microcanales de PDMS. Se obtuvieron microporos de diferentes tamaños bajo la concentración de la solución de grabado de $50 \%$ en peso de $\mathrm{KOH}$, temperaturas $\left(40,60,80^{\circ} \mathrm{C}\right)$ y voltajes $(100,500,1000 \mathrm{mV})$. Se encontró que el perfil eléctrico depende del voltaje, la temperatura y el reactivo como la solución de frenado, mientras que la concentración del agente de grabado influye en las características morfológicas de la superficie. Los parámetros de caída de presión, esfuerzo cortante, viscosidades de fluidos y tasas de flujo en las simulaciones computacionales permitieron encontrar las condiciones óptimas para realizar la detección de las células evitando el daño o la deformación celular. Además, se logró fabricar los microporos en estado sólido evitando el uso de litografía dependientes de la sala limpia, o equipos costosos como FIB. Se demostró que la integración de un microcanal multicapa con un único microporo de estado sólido en un dispositivo de microfluidos es un método muy bueno y asequible para la detección y el conteo de células, que permite realizar estos experimentos no solo en laboratorios altamente equipados sino también en cualquier laboratorio con capacidades químicas básicas. 


\subsection{Referencias.}

1. A. Ilyas, W. Asghar, Y. T. Kim and S. M. Iqbal, Biosens. Bioelectron., 2014, $62,343-349$.

2. S. Tan, L. Wang, J. Yu, C. Hou, R. Jiang, Y. Li and Q. Liu, Nanoscale Res. Lett., 2015, 10, 205.

3. N. A. W. Bell and U. F. Keyser, Nat. Nanotechnol., 2016, 11, 645-651.

4. T. Gilboa, C. Torfstein, M. Juhasz, A. Grunwald, Y. Ebenstein, E. Weinhold and A. Meller, ACS Nano, 2016, 10, 8861-8870.

5. S. Carson, S. T. Wick, P. A. Carr, M. Wanunu and C. A. Aguilar, ACS Nano, 2015, 9, 12417-12424.

6, D. G. Haywood, A. Saha-Shah, L. A. Baker and S. C. Jacobson, Anal. Chem., 2015, 87, 172-187.

7. L. T. Sexton, L. P. Horne and C. R. Martin, Mol. BioSyst., 2007, 3, 667-685.

8. P. Apel, Radiat. Meas., 2001, 34, 559-566.

9. Z. Yuan, C. Wang, X. Yi, Z. Ni, Y. Chen and T. Li, Nanoscale Res. Lett., 2018, 13,56 .

10. P. Y. Apel, V. V. Bashevoy, I. V. Blonskaya, N. E. Lizunov, O. L. Orelovitch and C. Trautmann, Phys. Chem. Chem.Phys., 2016, 18, 25421-25433.

11. M. Vega, B. Lerner, C. A. Lasorsa, K. Pierpauli and M. S. Perez, Microsyst. Technol., 2016, 22, 109-117.

12. S. R. Park, H. Peng and X. S. Ling, Small, 2007, 3, 116-119.

13. P. Y. Apel, Y. E. Korchev, Z. Siwy, R. Spohr and M. Yoshida, Nucl. Instrum. Methods Phys. Res., Sect. B, 2001, 184, 337-346.

14. Z. Siwy, D. Dobrev, R. Neumann, C. Trautmann and K. Voss, Appl. Phys. A, 2003, 76, 781-785.

15. N. Chtanko, M. E. Toimil Molares, T. Cornelius, D. Dobrev and R. Neumann, J. Phys. Chem. B, 2004, 108, 9950-954.

16. T. Deng, J. Chen, C. N. Wu and Z. W. Liu, ECS J. Solid State Sci. Technol., 2013, 2, P419-P422.

17. T. Fernandez, B. Lerner, F. Golmar, F. Sacco, M. Der,M. Perez, G. Rosero, I. Santizo, C. Olmos, P. Granell, M. Dieguez and C. Lasorsa, Mat'eria, 2018, 12127. 
18. A. Santos and T. Kumeria, Electrochemically Engineered Nanoporous Materials, ed. D. Losic and A. Santos, Springer International Publishing, Cham, 2015, pp. 1-36.

19. R. Holze, J. Solid State Electrochem., 2003, 7, 318-319.

20. T. Schmidt, M. Zhang, S. Yu and J. Linnros, Appl. Phys. Lett., 2014, 105, 123111 .

21. C. C. Harrell, Z. S. Siwy and C. R. Martin, Small, 2006, 2, 194-198.

22. J. Chen, T. Deng, C. N. Wu and Z. W. Liu, ECS Trans., 2013, 52, 371-376.

23. W. H. Coulter, Means for counting particles suspended in a fluid, US Pat., 2656508A, 1949.

24. B. Poutrel and C. Lerondelle, J. Dairy Sci., 2010, 2575-2579.

25. J. H. Nieuwenhuis, F. Kohl, J. Bastemeijer, P. M. Sarro and M. J. Vellekoop, Sens. Actuators, B, 2004, 44-50.

26. S. M. Bezrukov, J. Membr. Biol., 2000, 1-13.

27. E. Leclerc, Y. Sakai and T. Fujii, Biomed. Microdevices, 2003, 109-114.

28. D. Di Carlo, D. Irimia, R. G. Tompkins and M. Toner, Proc. . Acad. Sci. U. S. A., 2007, 18892-18897.

29. Y. Lee, B. Kim and S. Choi, Sensors, 2018, 18(4), 1124.

30. Y. Fu, Q. Yuan and J. Guo, Micro $\square$ uid. Nano $\square$ uid., 2017, 20.

31. J. Guo, C. M. Li and Y. Kang, Biomed. Microdevices, 2014, 681-686.

32. J. Guo, X. Huang and Y. Ai, Anal. Chem., 2015, 6516-6519.

33. J. Guo, H. Li, Y. Chen and Y. Kang, IEEE Sens. J., 2014, 2112-2117.

34 J. Guo, X. Huang, D. Shi, H. Yu, Y. Ai, C. M. Li and Y. Kang, RSC Adv., 2014, 4, 56342-56345.

35. J. Guo, W. Lei, X. Ma, P. Xue, Y. Chen and Y. Kang, IEEE Trans. Biomed. Circuits Syst., 2014, 35-41.

36. J. Guo, T. S. Pui, Y. L. Ban, A. R. A. Rahman and Y. Kang, IEEE Trans. Biomed. Eng., 2013, 3269-3275.

37. C. Ren, S. Zhang, D. Song and J. Guo, IEEE Trans. Dielectr. Electr. Insul., 2016, 1895-1897.

38. D. Belgorosky, T. Fern`andez-Cabada, A. B. Pẽnaherrera-Pazmĩno, Y. Langle, R. Booth, S. Bhansali, M. S. P'erez,A. M. Eijan and B. Lerner, J. Cell. Physiol., 2018, 233, 6327-6336. 
39. N. Bourguignon, C. Olmos, M. Sierra-Rodero, A. Pẽnaherrera, G. Rosero, P. Pineda, K. Vizuete, C. Arroyo, L. Cumbal, C. Lasorsa, M. P'erez and B. Lerner, J. Polym. ., Part B: Polym. Phys., 2018, 56, 1433-1442.

40. C. M. Olmos, A. Vaca, G. Rosero, A. Pe naherrera, C. Perez, I. de S'a Carneiro, K. Vizuete, C. R. Arroyo, A. Debut,M. S. P'erez, L. Cumbal and B. Lerner, Sens. Actuators, B, 2019, 742-748.

41. KLayout - High Perform. Layout Viewer Ed., available online, http://www.klayout.de/index.php, 2018.

42. J. Schindelin, I. Arganda-Carreras, E. Frise, V. Kaynig, M. Longair, T. Pietzsch, S. Preibisch, C. Rueden, S. Saalfeld, B. Schmid, J. Y. Tinevez, D. J. White, V. Hartenstein, K. Eliceiri, P. Tomancak and A. Cardona, Nat. Methods, 2012, 9, 676-682.

43. C. Guermonprez, S. Michelin and C. N. Baroud, Biomicrofluidics, 2015, 9(5), 054119 .

44. E. D. Palik, O. J. Glembocki, I. Heard, P. S. Burno and L. Tenerz, J. Appl. Phys., 1991, 70, 3291.

45. H. Seidel, L. Csepregi, A. Heuberger and H. Baumg“artel, J. Electrochem. Soc., 1990, 137, 3612-3626.

46. S. R. Park, H. Peng and X. S. Ling, Small, 2007, 3, 116-119.

47. C. Born, Z. Zhang, M. Al-Rubeai and C. R. Thomas, Biotechnol. Bioeng., 1992, 1004-1010.

48. F. Rivero, B. K“oppel, B. Peracino, S. Bozzaro, F. Siegert, C. J. Weijer, M. Schleicher, R. Albrecht and A. A. Noegel, J. Cell Sci., 1996, 109, 2679-2691.

49. T. G. Papaioannou and C. Stefanadis, Hellenic J. Cardiol., 2005, 46, 9-15.

50. S. S. Lee, K. H. Ahn, S. J. Lee, K. Sun, P. T. Goedhart and M. R. Hardeman, Korea Aust. Rheol. J., 2004, 141-46.

51. D. Huber, A. Oskooei, X. Casadevall Solvas, A. Demello and G. V. Kaigala, Chem. Rev., 2018, 118, 2042-2079.

52. H. Amini, W. Lee and D. Di Carlo, Lab Chip, 2014, 14, 2739.

53. J. Zhou and I. Papautsky, Lab Chip, 2013, 13, 1121.

54. D. Di Carlo, Lab Chip, 2009, 9, 3038. 


\section{Capitulo V}

\section{Dosis metronómicas y respuesta a la}

combinación esquemática de fármacos probadas en modelos de microfluídica para el tratamiento de células de cáncer de mama (JIMT-1). 


\subsection{Resumen.}

El análisis de biomoléculas y células con los dispositivos de microfluídica, es uno de los objetivos de la presente tesis. Se investigó el comportamiento de ciertas biomoléculas en la muerte celular por dosis bajas de quimioterapia (LDM, por sus siglas en inglés "Low-dose metronomic") como alternativa a la quimioterapia convencional y es el uso más común de las dosis de bajo nivel de las quimioterapias tradicionales en pacientes. La selección de pacientes, dosis de las drogas y los intervalos de dosificación en LDM es empírica. En este trabajo de tesis se examinaron sistemáticamente la interacción dependiente del horario de las drogas en la línea celular de cáncer de mama (BCC, por sus siglas en inglés "Breast cancer cell”) cultivadas en LOC. Los estudios de LDM fueron combinados con tinción celular para caracterizar los diferentes estados celulares y modos de muerte celular, incluyendo apoptosis caspasa dependiente, muerte celular caspasa independiente y muerte celular autofagia dependiente. Las imágenes adquiridas por microscopía fueron examinadas mediante el plugin de Fiji para segmentación entrenada WEKA para analizar el área celular en 7500 imágenes y se evidenciaron diferentes tipos de muerte celular. Paclitaxel combinado con quimioterapia LDM demostró una reducción en el área cubierta por células vivas. En contraste, hubo una inducción de niveles altos de muerte celular debida a apoptosis caspasa dependiente. Además, los microdispositivos usados en este estudio también son alternativas atractivas para tinción celular para caracterizar y estudiar el crecimiento celular y desarrollo in situ. 


\subsection{Introducción.}

El descubrimiento de formas para contrarrestar o bloquear el crecimiento maligno ha representado una fuerza impulsora en la investigación de la biología del cáncer durante las últimas cuatro décadas ${ }^{1}$. El cáncer de mama humano (BC, por sus siglas en inglés "Breast cancer") es la malignidad más común en mujeres ${ }^{2}$. Este tipo de cáncer está compuesto por poblaciones fenotípicamente diversas de células de cáncer de mama $(\mathrm{BCC})^{3}$. Ha sido demostrado que paclitaxel tiene actividad inicial en $\mathrm{BC}^{4}$, y cuando se combina con doxorubicina es el agente conocido más activo contra BC cuando se usan en diferentes horarios ${ }^{5}$.

La quimioterapia LDM es un nuevo uso de la quimioterapia y se define como la utilización convencional de dosis bajas sin períodos prolongados en ausencia de droga $^{6}$. De hecho, la heterogeneidad entre tumores ha sido observada en carcinomas de mama en varios individuos ${ }^{7}$.

Adicionalmente, la heterogeneidad tumoral puede influenciar el comportamiento biológico y la respuesta terapéutica ${ }^{8}$. Consecuentemente, las medicinas contra el cáncer y la heterogeneidad de los tumores pueden incitar diferentes modos de muerte celular que incluyen apoptosis caspasa dependiente, muerte celular caspasa independiente, muerte celular reproductiva (senescencia), o muerte celular debida a autofagia ${ }^{9}$. Estas vías no estándares muestran la complejidad inesperada de la comunicación cruzada entre los senderos de la muerte celular que se refleja en una diversidad de fenotipos que no han sido caracterizados en modelos microfluídicos ${ }^{10}$. La microfluídica permite la miniaturización de procesos convencionales químicos y biológicos de laboratorio. La tecnología LOC ha sido aceptada por las comunidades de investigación biológica y médica como una herramienta prometedora para la ingeniería de microambientes a nivel celular ${ }^{11}$. El cultivo celular en sistemas microfluídicos no solo provee un ambiente de cultivo celular apropiado, también permite suministrar medio de cultivo provisto de oxígeno, dióxido de carbono y suplementos a las células mientras se extraen los productos metabólicos en un caudal controlado ${ }^{1,12}$. Las características únicas de la microfluídica en el cultivo celular, tales como patrones geométricos finos, flujo laminar, y mezcla basada en difusión, provee un diverso rango de estrategias de control de fluidos. Se han desarrollado un gran número de métodos que posibilitan 
la modulación del ambiente extracelular a través de una vía de control dinámica de la concentración de moléculas señal que permiten el análisis a nivel de célula única $^{13,14,15,16,17,18,19}$. Las características de los dispositivos LOC los hacen apropiados para la investigación de células cancerosas. Las células tumorales mostraron viabilidad aumentada, invasión y respuestas a drogas cuando fueron cultivadas en sistemas de cultivo LOC $^{20}$. Los ensayos convencionales $2 \mathrm{D}$ han sido utilizados ampliamente para evaluar el rol de los quimioatractantes en la migración de células cancerosas ${ }^{21,22}$. Wang et al. Utilizó una plataforma 2D que simplifica el ambiente tumoral, sin limitarse a células creciendo en monocapas. Ellos desarrollaron una plataforma microfluídica para teñir células dentro de los dispositivos LOC ${ }^{23,24}$. De hecho, la tinción celular dentro de los dispositivos de microfluídica es una herramienta poderosa para detectar cambios intracelulares mediante imágenes en tiempo real. Esto permite la determinación de los cambios de los estados celulares, así como también la distinción entre células vivas y muertas, lisadas o células en senescencia y otros cambios dinámicos en el estado celular 25,26,27,28. Por esta razón, la capacidad de desarrollar nuevos enfoques para análisis celular posibilitará la evaluación de esta heterogeneidad. Considerando los beneficios de la tecnología LOC combinada con las ventajas de usar una cantidad baja de células y reactivos, la presente investigación utilizó microdispositivos LOC para el estudio y caracterización del comportamiento biológico de las células de cáncer de mama (JIMT-1) usando diferentes tinciones para evaluar la viabilidad celular (LC), apoptosis programada caspasa dependiente (AP), autofagia (AG), y muerte celular (PI), en dispositivos con microcámaras antes y después de la introducción de dos tipos diferentes de tratamientos con drogas aplicados in vitro con células de cáncer de mama. 


\subsection{Materiales y métodos.}

\subsubsection{Cultivo celular.}

Las células JIMT-1 ATCC 589 (DSMZ) fueron cultivadas en medio DMEM (Gibco) suplementado con suero fetal bovino inactivado por calor (FBS por sus siglas en inglés "Fetal bovine serum") 10\% (w/v) (Gibco), L-glutamina 2 mmol. $\mathrm{L}^{-1}$ (Gibco), penicilina 100 unidades $\mathrm{mL}^{-1}$, estreptomicina $100 \mu \mathrm{g} . \mathrm{mL}$ (Gibco) a 37 ${ }^{\circ} \mathrm{C}$ en una incubadora con $5 \%$ de $\mathrm{CO}_{2}$. Para los ensayos de microscopía, se cultivaron 20000 células por pocillo en uno de los 8 pocillos del dispositivo $\mu$ Slide (número de catálogo 808126, Ibidi GmbH).

\subsubsection{Modos de muerte celular y caracterización.}

Se utilizaron los kits de imagen celular Live/Dead (Sigma), autofagia (CYTO-ID), Caspasa-3 y -7 (Invitrogen) y ioduro de propidio (PI) (Sigma-Aldrich) para identificar los diferentes modos de muerte celular. Para el ensayo de Live/Dead (LC), las células viables emiten fluorescencia verde, mientras que las células muertas emiten fluorescencia roja ${ }^{29}$. Las células en autofagia del ensayo de autofagia (AG) emiten fluorescencia verde, y los controles positivos y negativos fueron realizados de acuerdo con las instrucciones de fabricante (Enzo ENZ51031-K200) ${ }^{30}$. En los ensayos de caspasa-3 y -7 (AP), las células apoptóticas emiten fluorescencia verde ${ }^{31}$. En el ensayo de PI, las células muertas emiten fluorescencia roja. Las células fueron cultivadas en dispositivos de microfluídica, como se describió anteriormente y los marcajes PI, LC, AG y AP fueron evaluados en los días 1, 2, 4, and 5 después del tratamiento. Se utilizó solución fostato tampón salina (PBS, por sus siglas en inglés "Phosphate buffer saline") (HyClone) para lavar las cámaras de cultivo en los dispositivos durante 3 minutos. Las células fueron incubadas con el kit de imagen durante 30 minutos a $37^{\circ} \mathrm{C}$. A continuación, se utilizó PBS para extraer el reactivo durante $5 \mathrm{~min}$. Antes de examinar las cámaras de cultivo bajo el microscopio de fluorescencia, los dispositivos se llenaron con medio DMEM fresco. Finalmente, la viabilidad celular fue medida al evaluar el porcentaje de células fluorescentes en los cultivos celulares. 


\subsubsection{Tratamiento combinado de células con paclitaxel, doxorrubicina y examen de los efectos de los fármacos.}

Las drogas paclitaxel y doxorrubicina fueron añadidas al cultivo celular para evaluar sus efectos tanto solas como en combinación (Sigma Aldrich) ${ }^{34}$. Primero, las células JIMT-1 fueron sembradas en los dispositivos y crecieron por 2 días. El medio de cultivo fue renovado cada 24 horas. Es decir que se utilizó medio fresco que contenía doxorrubicina en una concentración de $0.01 \mu \mathrm{M}$. Después de 4 horas de exposición a la doxorrubicina, se adicionó paclitaxel a una concentración final de $0.001 \mu \mathrm{M}$. Las células fueron cultivadas para adquisición de imágenes en tiempo real y caracterización biológica a través del marcaje descrito anteriormente por 24 horas adicionales.

La caracterización y el análisis del modo de muerte celular fueron realizados para evaluar la eficiencia del tratamiento. La primera etapa después de cuatro horas de exposición a doxorrubicina y la segunda etapa después de la exposición a la combinación de doxorrubicina y paclitaxel.

\subsubsection{Tratamiento con paclitaxel metronómico y evaluación de los efectos de los fármacos.}

Se estudiaron los efectos del paclitaxel suministrado a diferentes tiempos ${ }^{35}$. Primero, las células JIMT-1 fueron cultivadas en los dispositivos como se describió previamente. Después de 24 horas, se renovó el medio de cultivo con paclitaxel a una concentración de $0.001 \mu \mathrm{M}$. El medio fue reemplazado como medio fresco que contuvo paclitaxel a una concentración de $0.001 \mu \mathrm{M}$ cada 24 horas por los siguientes 5 días. La caracterización biológica mediante los diferentes marcadores se realizó de la forma descrita anteriormente.

\subsubsection{Procesamiento y cuantificación de imágenes.}

Las imágenes en campo claro y oscuro fueron obtenidas utilizando un microscopio de fluorescencia (Olympus ScanR High Content Screening Station) mediante el objetivo de 20X UPLSAPO NA 0.75. Las imágenes fueron clasificadas de acuerdo 
con la viabilidad celular (LC), apoptosis programada (AP), autofagia (AG), o muerte celular (PI). En total, se analizaron 7500 imágenes con el programa Fiji (v.2.0.0) a través del plugin de entrenamiento de segmentación WEKA (v.3.2.33): El plugin WEKA del programa ImageJ es una plataforma de fuente abierta para análisis de imágenes biológicas que combina una recopilación de algoritmos de aprendizaje de computadora con una colección de aspectos de imagen para producir segmentaciones basadas en pixel $^{36,37}$. Todos los experimentos fueron realizados por triplicado y los datos están presentados como la media \pm desviación estándar (SD por sus siglas en inglés "standard deviation"). Se utilizaron el análisis de varianza (ANOVA) y la prueba de T de Student para comparar cada grupo. Los valores $\mathrm{P}$ menores que 0.05 fueron considerados estadísticamente significativos están indicados con asteriscos.

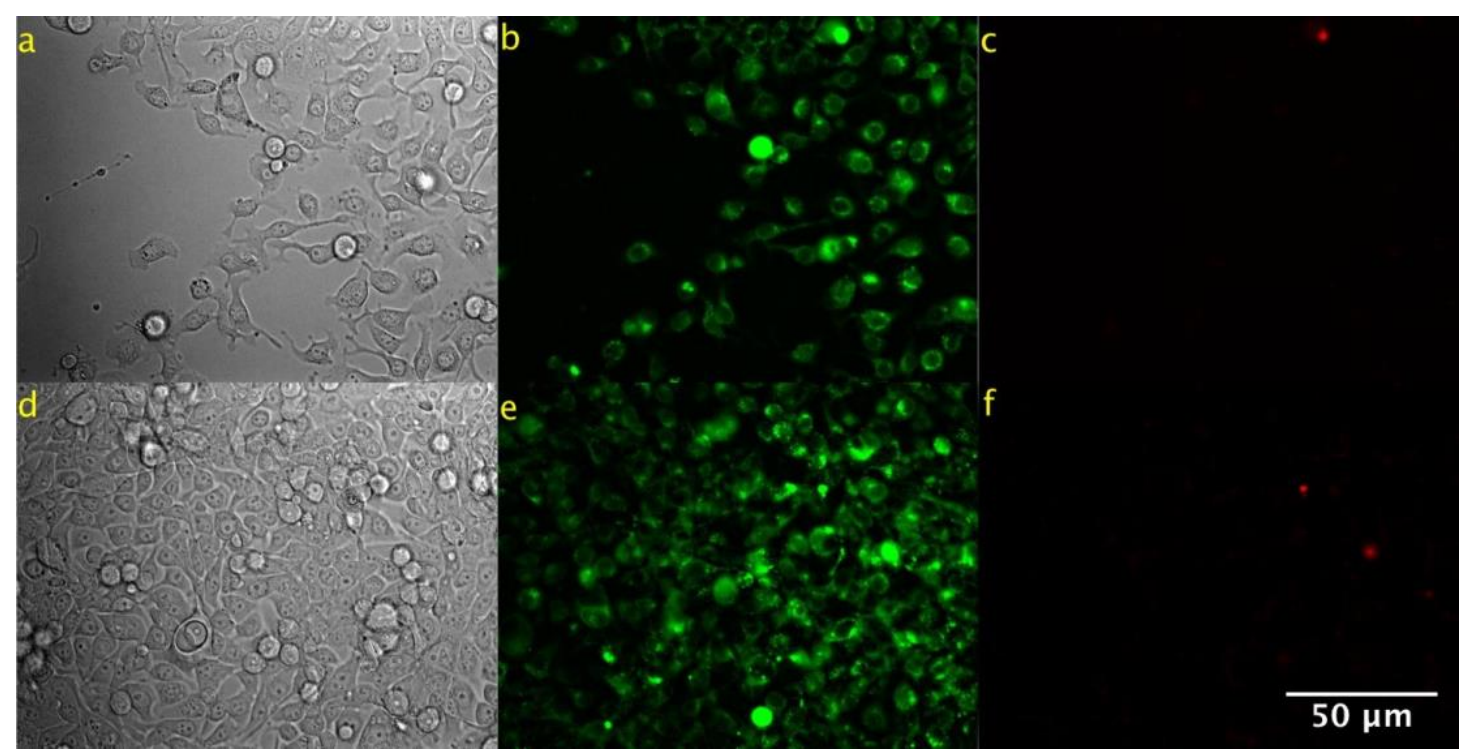

Figura. 5.1. Imágenes de microscopía representativas de autofagia y marcaje con PI en células de cáncer de mama después de tres días de crecimiento en dos pocillos diferentes en los microdispositivos. (a,d) Imágenes en campo claro del cultivo. $(b, e)$ Imágenes de fluorescencia de células después del tratamiento con el kit de autofagia que etiqueta preferencialmente vacuolas autofágicas, mostradas en verde (c,f) Imágenes de fluorescencia después del marcaje con PI. Las células muertas están mostradas en rojo. 


\subsection{Resultados y discusión}

\subsubsection{Seguimiento del crecimiento de las células de cáncer de mama dentro de las cámaras de cultivo celular.}

La evaluación de los diferentes esquemas y la eficacia de las drogas terapéuticas es importante. Pocas publicaciones han reportado los efectos de drogas en la caracterización de las células de cáncer de mama en dispositivos de microfluídica. Se utilizaron microdispositivos para rastrear el desarrollo de las células de cáncer de mama en un período de 5 días. Para entender de mejor manera el desarrollo y la caracterización de las células en las microcámaras, se analizaron los porcentajes de células vivas, muertes, en autofagia y células apopóticas durante un período de 5 días. Los resultados del crecimiento bajo estas diferentes condiciones pueden ser observadas en la figura 5.2.
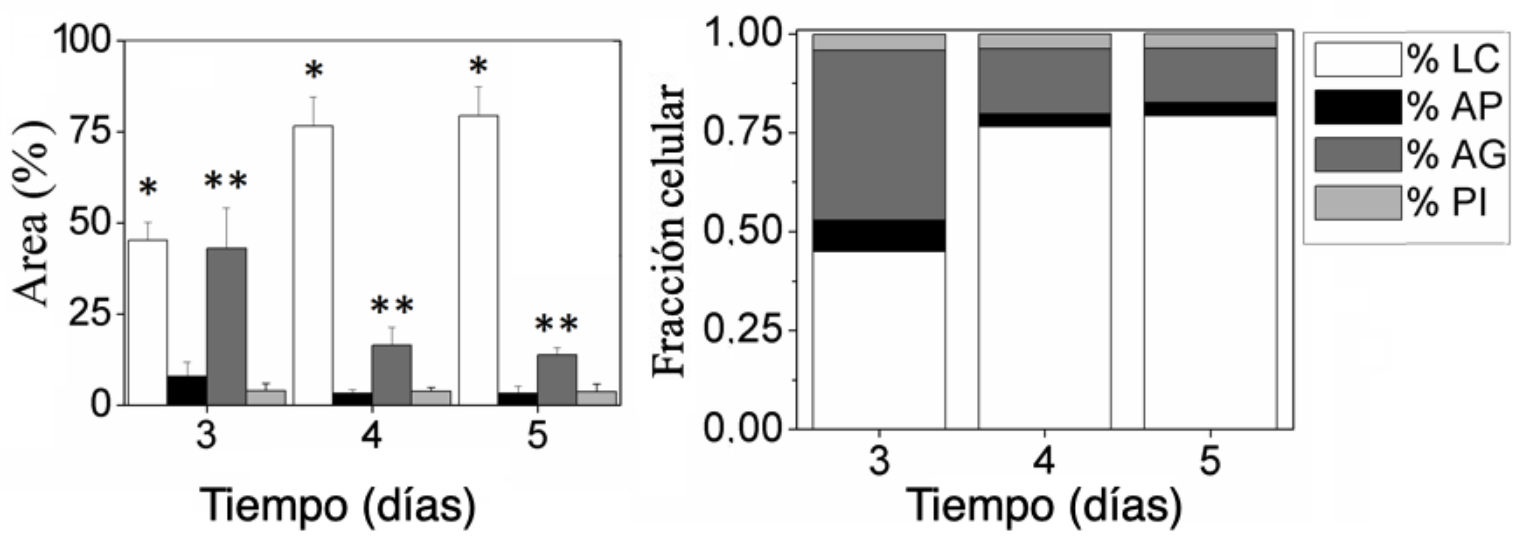

Figura. 5.2. Distribución celular después de la caracterización con marcadores de fluorescencia por 5 días. A la derecha se presenta un gráfico de barras que ilustra la composición de la fracción celular por día durante el período de tiempo de 5 días. A la izquierda, la superficie del área cubierta por células vivas (LC) aumentó mientras los niveles del proceso de autofagia (AG) disminuyó significativamente. (*) y (**) indican la diferencia significativa de cada día entre los subgrupos $(\mathrm{p}<0.05)$. 
Se observaron diferencias significativas en los porcentajes de LC y AG durante el período de tiempo de 5 días. El porcentaje de células vivas incremento durante el período de tiempo de 5 días (Figura 5.2). En contraste, las células en autofagia ocuparon un porcentaje alto del área celular total en el día 3. Sin embargo, éste disminuyó en el día 5. Notablemente, hay crecimiento durante el período de 5 días, esto se detecta mediante los marcadores de células vivas. Los dispositivos fueron capaces de proveer condiciones homogéneas para mantener la viabilidad celular en el cultivo durante este período de tiempo ${ }^{38}$.

\subsubsection{Efecto de los esquemas de fármacos de paclitaxel, doxorrubicina y la evaluación de LC, AG, PI y AP.}

Recientemente, ha habido un interés considerable en los agentes quimioterapéuticos sinérgicos para el tratamiento del cáncer de mama ${ }^{39,40}$. Pocas publicaciones reportan el efecto de las drogas en la caracterización de células de cáncer de mama en sistemas de microfluídica. Por otro lado, ensayos clínicos previos han demostrado beneficios al combinar doxorrubicina (DOX) y paclitaxel (PTX) al tratar a pacientes con cáncer de mama. De todas formas, los efectos secundarios como neutropenia y falla cardíaca congestiva han limitado su dosificación a pacientes ${ }^{41,42,43}$. Para analizar los efectos de las drogas en células mediante los dispositivos, es apropiado mantener el cultivo celular en crecimiento bajo condiciones homogéneas ${ }^{44}$. Primero se estudió el efecto de la DOX y su análisis está ilustrado en la figura 5.3. Se incubaron las muestras por 4 horas con DOX a una concentración de $0.01 \mu \mathrm{M}$. El nivel de apoptosis en las células se estimó mediante la cuantificación del área marcada relativa a la población celular completa utilizando el ensayo AP descrito anteriormente. Se encontraron diferencias significativas en la actividad apoptótica con respecto a las células control después de 4 horas de exposición a DOX. El efecto de DOX en las primeras 4 horas reduce el porcentaje de área ocupada por células vivas y produce un incremento de células apoptóticas. 

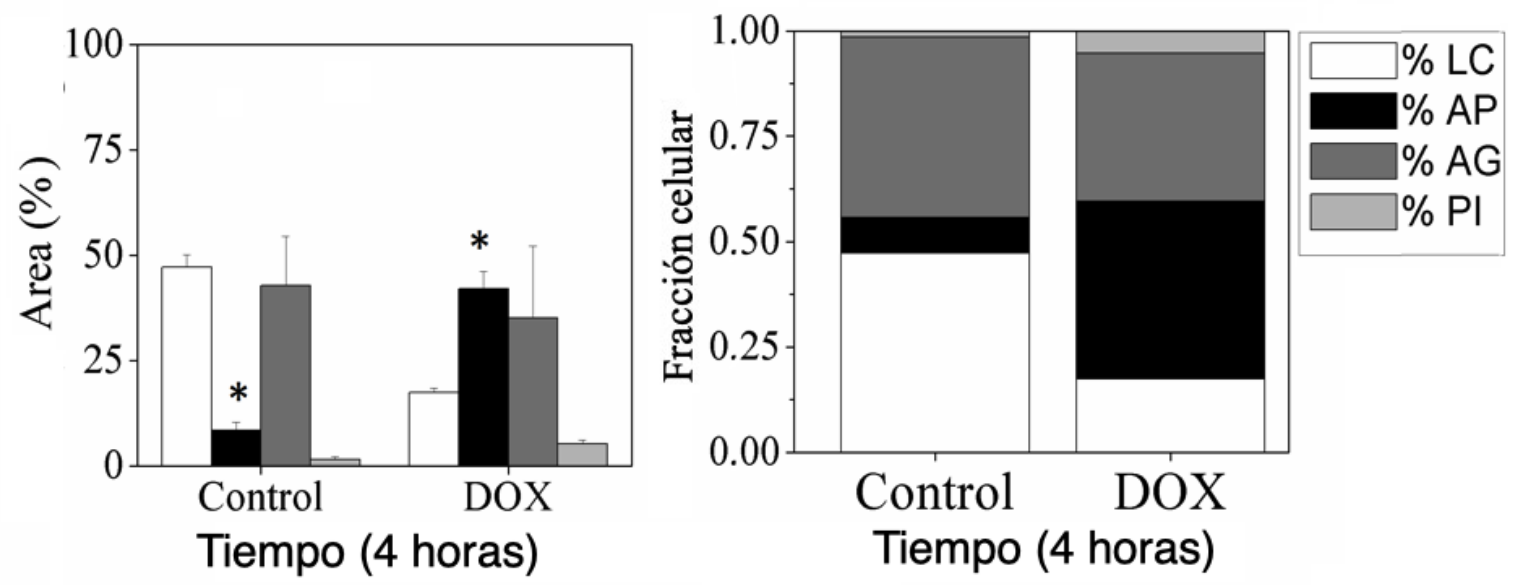

Figura. 5.3. Efecto de la doxorrubicina en las células después de 4 horas. A la izquierda, el proceso de apoptosis (AP) aumentó significativamente con respecto al control. El área cubierta por las células vivas (LC) no disminuyó significativamente en comparación con el control. A la derecha, el gráfico de barras muestra los valores de los resultados en la composición de la fracción celular. (*) indica la diferencia significativa de cada día entre los subgrupos $(\mathrm{p}<0.05)$.

Estos resultados fueron consistentes con un aumento en la actividad de la caspasa. Estudios anteriores también han demostrado que las células cancerosas que se exponen a esquemas con tratamientos de quimioterapia pueden afectar significativamente la inducción de vías proapoptóticas con $\mathrm{DOX}^{45}$. Además, nuestros resultados (Figura 5.3) indican que la viabilidad celular no se redujo significativamente. Además, se detectó un ligero aumento en el área de células en autofagia en comparación con el control.

A continuación, se evaluó el efecto de paclitaxel a las 24 horas en muestras que habían sido previamente expuestas a doxorrubicina. Los resultados obtenidos del análisis de imágenes pueden ser observados en la Figura 5.4. No se encontraron diferencias significativas en los ensayos de LC, AP y AG. De todas formas, el área marcada por PI mostró un incremento leve pero significativo comparado con los controles. 

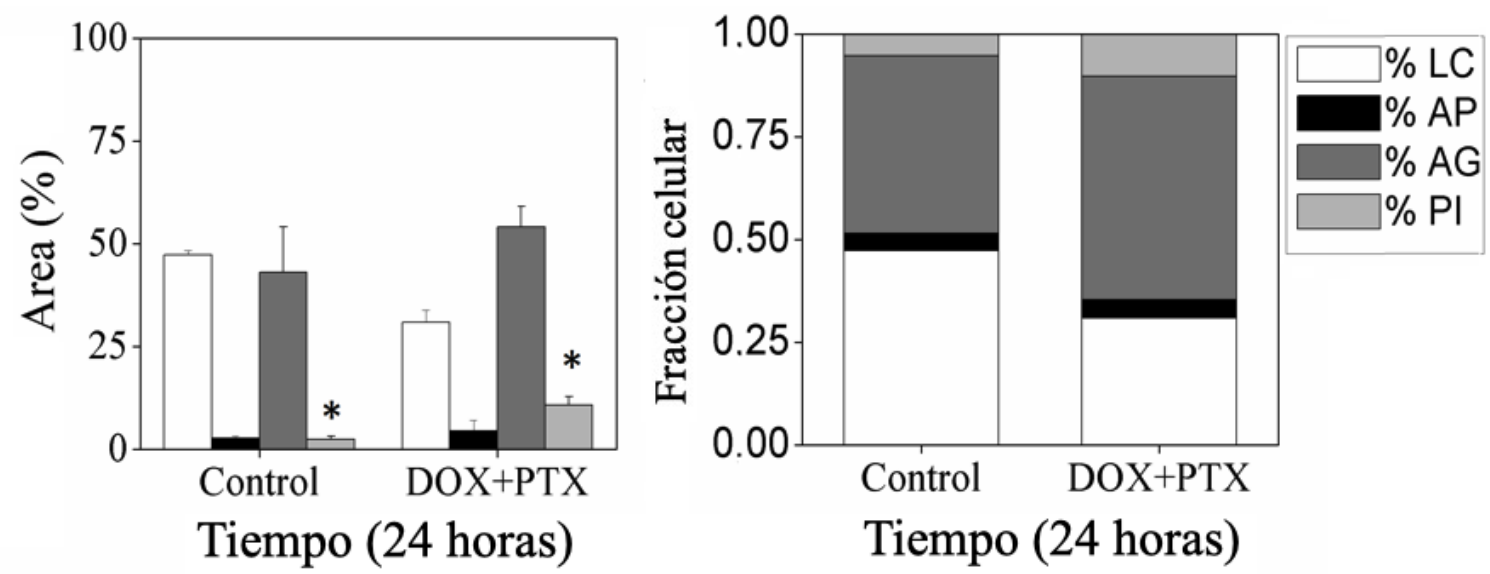

Figura. 5.4. Doxorrubicina combinada con paclitaxel. La gráfica de barras denota el efecto de PTX después de 24 horas sobre los modos de muerte celular. El marcaje con yoduro de propidio (PI) incrementó significativamente con respecto al control. El área cubierta por las células vivas (LC) no disminuyó significativamente en comparación con el control. A la derecha se muestra un gráfico de barras con la composición de la fracción celular por día durante 4 horas. (*) indica la diferencia significativa de cada día entre subgrupos $(\mathrm{p}<0.05)$.

El efecto del PTX combinado con la DOX está ampliamente reportado en tener un efecto inhibitorio sinérgico en el crecimiento de varias líneas celulares de cáncer de mama ${ }^{46,47}$. Los resultados (Figura 5.4) no muestran incrementos adicionales en los porcentajes de AP o de inhibición de crecimiento. Esto puede deberse al hecho de que concentraciones altas de PTX pueden realmente tener el efecto opuesto en el crecimiento celular, como ha sido reportado anteriormente ${ }^{48}$. Factores numerosos contribuyen a la resistencia a paclitaxel en una población celular dado, y se determinó que estos factores son almamente variables. Por lo tanto, el mecanismo exacto de su acción no está claro ${ }^{48,49}$.

\subsubsection{Efecto del tratamiento metronómico con paclitaxel.}

La eficacia del paclitaxel se evaluó a una concentración muy baja en un período de 5 días. Se observó que esta droga tuvo un gran efecto en LC (Figura 5.5), causó tanto la disminución en el área de LC, así también un incremento en el área celular 
ocupada por AP con respecto a los controles (Figura 5.5). El área de células con AG y PI permaneció casi constante durante los mismos períodos de tiempo.

Se determinó que el tratamiento metronómico LDM con PTX conduce a un porcentaje más alto de células que pasan por AP y una disminución considerable en el porcentaje total de células vivas. La terapia LDM ha sido ampliamente reportado en los años recientes en ensayos clínicos y en estudios in vitro utilizando PTX a concentraciones muy bajas ${ }^{50,51,52}$. Se encontró que el PTX en LDM induce AP e inhibe el crecimiento celular (Figura 5.5), por lo que sugiere que éste induce muerte celular mitótica mediante la disrupción de la dinámica de microtúbulos y la activación de puntos de revisión del ensamblado del huso acromático (SAC, por sus siglas en inglés spindle-assembly checkpoint). Adicionalmente, una de las vías proapoptóticas evaluadas fue AG. Sin drogas, se observa que el porcentaje de células en autofagia no disminuyó durante el período de tiempo de varios días, en contraste permaneció constante. Aparentemente, este mecanismo puede proveer energía extra y recursos a las células cancerosas, lo cual promueve su supervivencia en los dispositivos de microfluídica. El porcentaje de células AG permaneció constante bajo el tratamiento con droga en nuestros experimentos. Estos resultados concuerdan con el hecho de que las células cancerosas expuestas a quimioterapia pueden impactar significativamente la inducción de vías proapoptóticas $^{52}$.

En resumen, fue posible la caracterización del crecimiento de células de cáncer de mama en las microcámaras y caracterizarlas durante diferentes tratamientos. Se encontró que el PTX con LDM es el mejor tratamiento para inducir apoptosis en estas células en LOC. Además, la vía AG mostró un mecanismo inesperado para estas células para que sean capaces de adaptarse al crecimiento en LOC, así como también al tratamiento de drogas. 

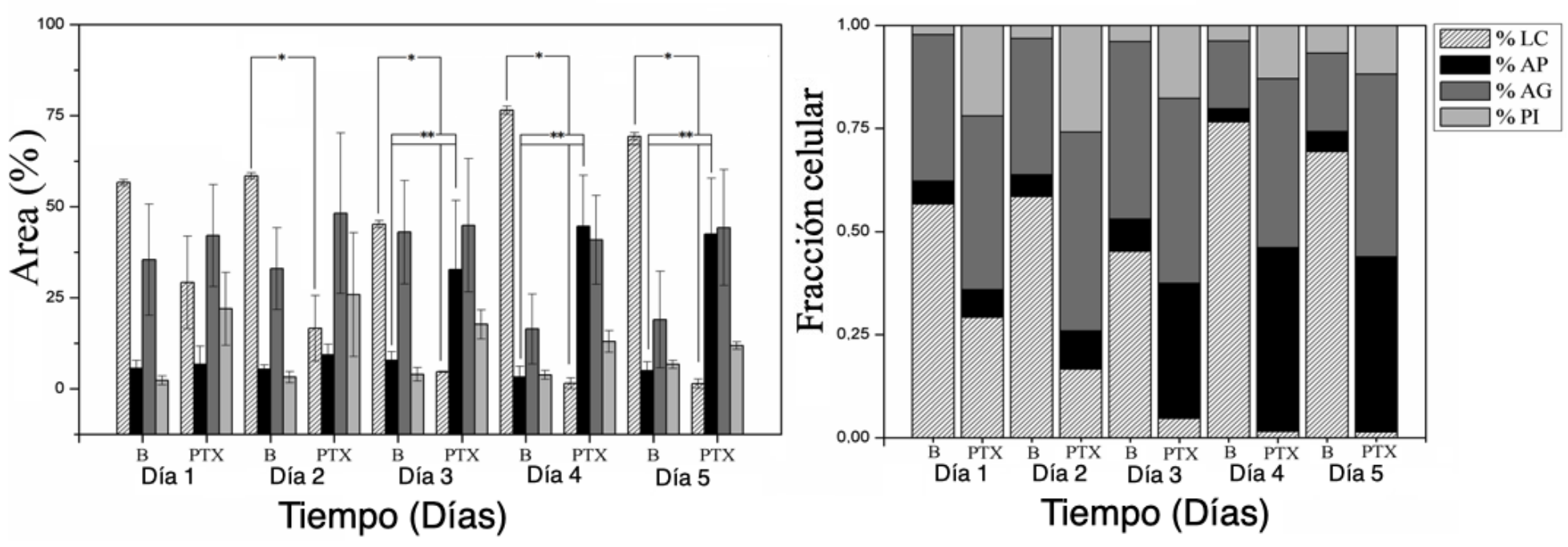

Figura. 5.5. Efecto de paclitaxel (PTX) comparado con el control (B) durante 5 días a concentración baja de PTX. El gráfico de barras denota el valor del porcentaje de área cubierto por células para cada modo de muerte celular estudiado. A la izquierda, el proceso de apoptosis (AP) incrementó significativamente en comparación al control, y el área cubierta por las células vivas (LC) disminuyó significativamente con respecto al control. A la derecha se muestra un gráfico de barras que describe los resultados de la composición de la fracción celular por día durante un perío de 5 días. (**) y (*) indica las diferencias significativas de cada día entre los subgrupos $(\mathrm{p}<0.05)$. 


\subsection{Conclusiones}

Estos resultados confirman la utilidad del LOC como un método efectivo para la cuantificación de la dosis de drogas de células vivas, muertas, en autofagia y células apoptóticas. LOC permiten comparar dos tratamientos diferentes para las células de cáncer de mama. El tratamiento metronómico (LDM) reportó una disminución considerable en el porcentaje total de células vivas y un incremento de células AP con respecto a los controles. En conclusión, los dispositivos LOC tienen no solo las ventajas ya conocidas, sino que son una herramienta poderosa ya que solo requieren leves cantidades de reactivos y pueden ser utilizados bajo parámetros específicos de cultivo. Los dispositivos LOC pueden ser considerados una tecnología nueva para ser usados como un complemento o remplazo de estudios tradicionales en dosis metronómicas de drogas con tratamientos y esquemas diferentes. 


\subsection{Referencias}

1. Hanahan, D. \& Weinberg, R. A. Hallmarks of Cancer: The Next Generation. Cell 144, 646-674 (2011).

2. Arabsalmani, M. et al. Incidence and mortality of kidney cancers, and human development index in Asia; a matter of concern. J. Nephropathol. 6, 30-42 (2017).

3. Al-Hajj, M., Wicha, M. S., Benito-Hernandez, A., Morrison, S. J. \& Clarke, M. F. Prospective identification of tumorigenic breast cancer cells. Proc. Natl. Acad. Sci. 100, 3983 (2003).

4. Reichman, B. S. et al. Paclitaxel and recombinant human granulocyte colonystimulating factor as initial chemotherapy for metastatic breast cancer. J. Clin. Oncol. 11, 1943-1951 (1993).

5. Pazos, C. et al. Phase II of doxorubicin/taxol in metastatic breast cancer. Breast Cancer Res. Treat. 55, 91-96 (1999).

6. Lien, K., Georgsdottir, S., Sivanathan, L., Chan, K. \& Emmenegger, U. Lowdose metronomic chemotherapy: A systematic literature analysis. Eur. J. Cancer 49, 3387-3395 (2013).

7. Turashvili, G. \& Brogi, E. Tumor Heterogeneity in Breast Cancer. Front. Med. 4, 227-227 (2017).

8. Belgorosky, D. et al. Analysis of tumoral spheres growing in a multichamber microfluidic device. J. Cell. Physiol. 233, 6327-6336 (2018).

9. Leist, M. \& Jäättelä, M. Four deaths and a funeral: from caspases to alternative mechanisms. Nat. Rev. Mol. Cell Biol. 2, 589 (2001).

10. Wlodkowic, D., Skommer, J. \& Darzynkiewicz, Z. Cytometry in cell necrobiology revisited. Recent advances and new vistas. Cytometry A 77A, 591606 (2010).

11. Xu, Z. et al. Application of a microfluidic chip-based 3D co-culture to test drug sensitivity for individualized treatment of lung cancer. Biomaterials 34, 4109-4117 (2013).

12. Leclerc, E., Sakai, Y. \& Fujii, T. Cell Culture in 3-Dimensional Microfluidic Structure of PDMS (polydimethylsiloxane). Biomed. Microdevices 5, 109-114 (2003).

13. Zare, R. N. \& Kim, S. Microfluidic Platforms for Single-Cell Analysis. Annu. Rev. Biomed. Eng. 12, 187-201 (2010).

14. Cheong, R., Wang, C. J. \& Levchenko, A. High Content Cell Screening in a Microfluidic Device. Mol. Amp Cell. Proteomics 8, 433 (2009). 
15. King, K. R., Wang, S., Jayaraman, A., Yarmush, M. L. \& Toner, M. Microfluidic flow-encoded switching for parallel control of dynamic cellular microenvironments. Lab. Chip 8, 107-116 (2008).

16. Cheong, R., Wang, C. J. \& Levchenko, A. Using a microfluidic device for high-content analysis of cell signaling. Sci. Signal. 2, pl2-pl2 (2009).

17. Lee, P. J., Gaige, T. A. \& Hung, P. J. Dynamic cell culture: a microfluidic function generator for live cell microscopy. Lab. Chip 9, 164-166 (2009).

18. Eriksson, E. et al. A microfluidic device for reversible environmental changes around single cells using optical tweezers for cell selection and positioning. Lab. Chip 10, 617-625 (2010).

19. Kim, S.-J., Yokokawa, R., Lesher-Perez, S. C. \& Takayama, S. Constant flowdriven microfluidic oscillator for different duty cycles. Anal. Chem. 84, 1152-1156 (2012).

20. Liu, T. et al. A microfluidic device for characterizing the invasion of cancer cells in 3-D matrix. ELECTROPHORESIS 30, 4285-4291 (2009).

21. Wang, S.-J., Saadi, W., Lin, F., Minh-Canh Nguyen, C. \& Li Jeon, N. Differential effects of EGF gradient profiles on MDA-MB-231 breast cancer cell chemotaxis. Exp. Cell Res. 300, 180-189 (2004).

22. Saadi, W., Wang, S.-J., Lin, F. \& Jeon, N. L. A parallel-gradient microfluidic chamber for quantitative analysis of breast cancer cell chemotaxis. Biomed. Microdevices 8, 109-118 (2006).

23. Wang, C., Lu, H. \& Alexander Schwartz, M. A novel in vitro flow system for changing flow direction on endothelial cells. J. Biomech. 45, 1212-1218 (2012).

24. Toh, Y.-C., Raja, A., Yu, H. \& van Noort, D. A 3D Microfluidic Model to Recapitulate Cancer Cell Migration and Invasion. Bioeng. Basel Switz. 5, 29 (2018).

25. Krämer, C. E. M. et al. Non-Invasive Microbial Metabolic Activity Sensing at Single Cell Level by Perfusion of Calcein Acetoxymethyl Ester. PLOS ONE 10, e0141768 (2015).

26. Hoshi, H., O’Brien, J. \& Mills, S. L. A novel fluorescent tracer for visualizing coupled cells in neural circuits of living tissue. J. Histochem. Cytochem. Off. J. Histochem. Soc. 54, 1169-1176 (2006).

27. Byrd, T. F., 4th et al. The microfluidic multitrap nanophysiometer for hematologic cancer cell characterization reveals temporal sensitivity of the calceinAM efflux assay. Sci. Rep. 4, 5117-5117 (2014).

28. Krämer, C. E. M. et al. Non-Invasive Microbial Metabolic Activity Sensing at Single Cell Level by Perfusion of Calcein Acetoxymethyl Ester. PLOS ONE 10, e0141768 (2015). 
29. Zhang, J., Wu, J., Li, H., Chen, Q. \& Lin, J.-M. An in vitro liver model on microfluidic device for analysis of capecitabine metabolite using mass spectrometer as detector. Biosens. Bioelectron. 68, 322-328 (2015).

30. Warenius, H. M. et al. Selective anticancer activity of a hexapeptide with sequence homology to a non-kinase domain of Cyclin Dependent Kinase 4. Mol. Cancer 10, 72 (2011).

31. Utsumi, F. et al. Effect of Indirect Nonequilibrium Atmospheric Pressure Plasma on Anti-Proliferative Activity against Chronic Chemo-Resistant Ovarian Cancer Cells In Vitro and In Vivo. PLOS ONE 8, e81576 (2013).

32. Utsumi, F. et al. Effect of Indirect Nonequilibrium Atmospheric Pressure Plasma on Anti-Proliferative Activity against Chronic Chemo-Resistant Ovarian Cancer Cells In Vitro and In Vivo. PLOS ONE 8, e81576 (2013).

33. Utsumi, F. et al. Effect of Indirect Nonequilibrium Atmospheric Pressure Plasma on Anti-Proliferative Activity against Chronic Chemo-Resistant Ovarian Cancer Cells In Vitro and In Vivo. PLOS ONE 8, e81576 (2013).

34. Holmes, F. A. et al. Sequence-dependent alteration of doxorubicin pharmacokinetics by paclitaxel in a phase I study of paclitaxel and doxorubicin in patients with metastatic breast cancer. J. Clin. Oncol. 14, 2713-2721 (1996).

35. Lien, K., Georgsdottir, S., Sivanathan, L., Chan, K. \& Emmenegger, U. Lowdose metronomic chemotherapy: A systematic literature analysis. Eur. J. Cancer 49, 3387-3395 (2013).

36. Schindelin, J. et al. Fiji: an open-source platform for biological-image analysis. Nat. Methods 9, 676 (2012).

37. Arganda-Carreras, I. et al. Trainable Weka Segmentation: a machine learning tool for microscopy pixel classification. Bioinformatics 33, 2424-2426 (2017).

38. Song, J. W. et al. Microfluidic Endothelium for Studying the Intravascular Adhesion of Metastatic Breast Cancer Cells. PLOS ONE 4, e5756 (2009).

39. Turashvili, G. \& Brogi, E. Tumor Heterogeneity in Breast Cancer. Front. Med. 4, 227-227 (2017).

40. Leist, M. \& Jäättelä, M. Four deaths and a funeral: from caspases to alternative mechanisms. Nat. Rev. Mol. Cell Biol. 2, 589 (2001).

41. Holmes, F. A. et al. Paclitaxel by 24-hour infusion with doxorubicin by 48hour infusion as initial therapy for metastatic breast cancer: Phase I results*. Ann. Oncol. 10, 403-411 (1999).

42. Fisherman, J. S. et al. Phase I/II study of 72-hour infusional paclitaxel and doxorubicin with granulocyte colony-stimulating factor in patients with metastatic breast cancer. J. Clin. Oncol. 14, 774-782 (1996). 
43. Perez, E. A. Doxorubicin and Paclitaxel in the Treatment of Advanced Breast Cancer: Efficacy and Cardiac Considerations. Cancer Invest. 19, 155-164 (2001).

44. Song, J. W. et al. Microfluidic endothelium for studying the intravascular adhesion of metastatic breast cancer cells. PloS One 4, e5756-e5756 (2009).

45. Lee, M. J. et al. Sequential Application of Anticancer Drugs Enhances Cell Death by Rewiring Apoptotic Signaling Networks. Cell 149, 780-794 (2012).

46. Wang, L. et al. De-repression of the $\mathrm{p} 21$ promoter in prostate cancer cells by an isothiocyanate via inhibition of HDACs and c-Myc. Int. J. Oncol. 33, 375-80 (2008).

47. Wang, L. G. et al. Dual action on promoter demethylation and chromatin by an isothiocyanate restored GSTP1 silenced in prostate cancer. Mol. Carcinog. 46, 24-31 (2007).

48. Liebmann, J. E. et al. Cytotoxic studies of paclitaxel (Taxol) in human tumour cell lines. Br. J. Cancer 68, 1104-1109 (1993).

49. Huang, C. et al. FoxM1 Induced Paclitaxel Resistance via Activation of FoxM1/PHB1/RAF-MEK-ERK Pathway and Enhancement of ABCA2 Transporter. Mol. Ther. - Oncolytics 14, (2019).

50. Lien, K., Georgsdottir, S., Sivanathan, L., Chan, K. \& Emmenegger, U. Lowdose metronomic chemotherapy: A systematic literature analysis. Eur. J. Cancer 49, 3387-3395 (2013).

51. Souto, M., Shimada, A., Barbosa, C. C., Cruz Abrahao, M. \& Katz, A. Lowdose metronomic chemotherapy in metastatic breast cancer: A retrospective analysis of 40 patients. J. Clin. Oncol. 33, e11567-e11567 (2015).

52. Jiang, H. et al. Low-Dose Metronomic Paclitaxel Chemotherapy Suppresses Breast Tumors and Metastases in Mice. Cancer Invest. 28, 74-84 (2010).

53. Musacchio, A. \& Salmon, E. D. The spindle-assembly checkpoint in space and time. Nat. Rev. Mol. Cell Biol. 8, 379-393 (2007).

54. Huang, Z., Zhou, L., Chen, Z., Nice, E. \& Huang, C. Stress Management by Autophagy: Implications for Chemoresistance. Int. J. Cancer J. Int. Cancer 139, (2016). 


\section{Capitulo VI}

\section{Desarrollo de microcanales para electroforesis de ADN, aplicación al} estudio de genes de resistencia a roya de la hoja de trigo utilizando marcadores moleculares asociados 


\subsection{Introducción.}

\subsubsection{Electroforesis capilar.}

La electroforesis convencional fue introducida, por el químico sueco Arne Tiselius en 1930, pero hasta 1937 no se desarrolló el primer aparato de electroforesis ${ }^{1}$. La electroforesis (electro $=$ electricidad, foros= llevar) es una técnica de separación que consiste en la migración de iones cargados, debido a la atracción o repulsión por un campo eléctrico. De esta forma, al aplicar un campo eléctrico (E), los aniones (negativos) migrarán hacia el ánodo (positivo) y los cationes (positivos) migrarán hacia el cátodo (negativo). Las especies neutras, no se moverán ${ }^{2}$. La electroforesis convencional se ha usado para provocar la migración de moléculas a través de diferentes medios como geles, papel de filtro o acetato de celulosa. Esta técnica muestra inconvenientes como: tiempos de análisis largos, reproducibilidad baja y dificultad de automatización. Con la finalidad de optimizar estos problemas, se desarrolló una técnica conocida como Electroforesis Capilar (CE), cuyo nombre se debe a que emplea tubos capilares en lugar de los soportes convencionales. Esta técnica fue introducida por Hjertén ${ }^{3}$ en 1967. Estudios posteriores demostraron las ventajas de disminuir el diámetro ${ }^{4,5}$. Finalmente, en 1981 Jorgenson y Lukacs ${ }^{6}$ introdujeron capilares con un diámetro de $75 \mu \mathrm{m}$. Fue en ese momento cuando se dio lugar al comienzo de la electroforesis capilar ${ }^{7}$

\subsubsection{Fundamentos básicos.}

La electroforesis capilar (CE) utiliza el movimiento de las especies cargadas eléctricamente en el seno de un medio electroforético que se encuentra bajo un campo eléctrico que da lugar a la migración de iones en el interior del capilar. Este campo es generado por dos electrodos sumergidos en una solución, de tal manera que cada una de las especies iónicas migrará a distinta velocidad por el interior del capilar, en función de la relación carga/tamaño. La diferencia de potencial entre los electrodos se realiza mediante fuentes de alto voltaje (HVPS). Finalmente se utiliza un detector que puede ser de diferentes tipos: visible-ultravioleta (VIS-UV), masas (MS), diodo, electroquímico (ED) ${ }^{8}$. 


\subsubsection{Parámetros físicos}

Uno de los parámetros responsables del movimiento de las especies dentro del capilar es el flujo electroforético, que viene caracterizado por la velocidad (ve) y la movilidad electroforética $(\mu \mathrm{e})$. La velocidad electroforética se define como la velocidad de migración de las distintas especies de una muestra en el interior del capilar por la acción de un campo eléctrico ${ }^{8}$ :

Ecuación 6.1 $\quad V_{e}=\mu_{e} E=L_{e f} / t_{m}$

Donde $E$ es el campo eléctrico $L_{e f}$ es la longitud efectiva del capilar y $t_{m}$ es el tiempo de migración de la especie. La movilidad electroforética dependerá de la carga (q) y el tamaño de las distintas especies. Viene dada por la expresión:

Ecuación 6.2

$$
\mu_{e}=V_{e /} E=\frac{q}{6 \pi \eta r}
$$

Donde $V_{e}$ es la velocidad electroforética, $\mathrm{r}$ es el radio de las moléculas y $\eta$ es la viscosidad del medio. Los capilares son generalmente de sílice fundida y tienen grupos silanol (R-Si- OH) en su superficie. Éstos, en función del pH (pH>3) están cargados negativamente (R-Si-O-).

Estas cargas atraerán fuertemente a las cargas positivas de la solución tampón, originando una capa fija de iones. Como la densidad de cargas negativas no se llega a compensar totalmente, es atraída otra capa de cationes. Esta nueva capa se encuentra más lejos de los grupos silanol y, por tanto, no está tan fuertemente unida a ellos, generándose lo que se denomina capa móvil. Estas dos capas forman la llamada doble capa "difusa" o doble capa eléctrica. De este modo, cuando se aplica un campo eléctrico, los cationes de la capa móvil son impulsados hacia el cátodo arrastrando con ellos todo el conjunto de la disolución, dando lugar al flujo electroosmótico $^{8}$ (EOF) (Figura 6.1). 


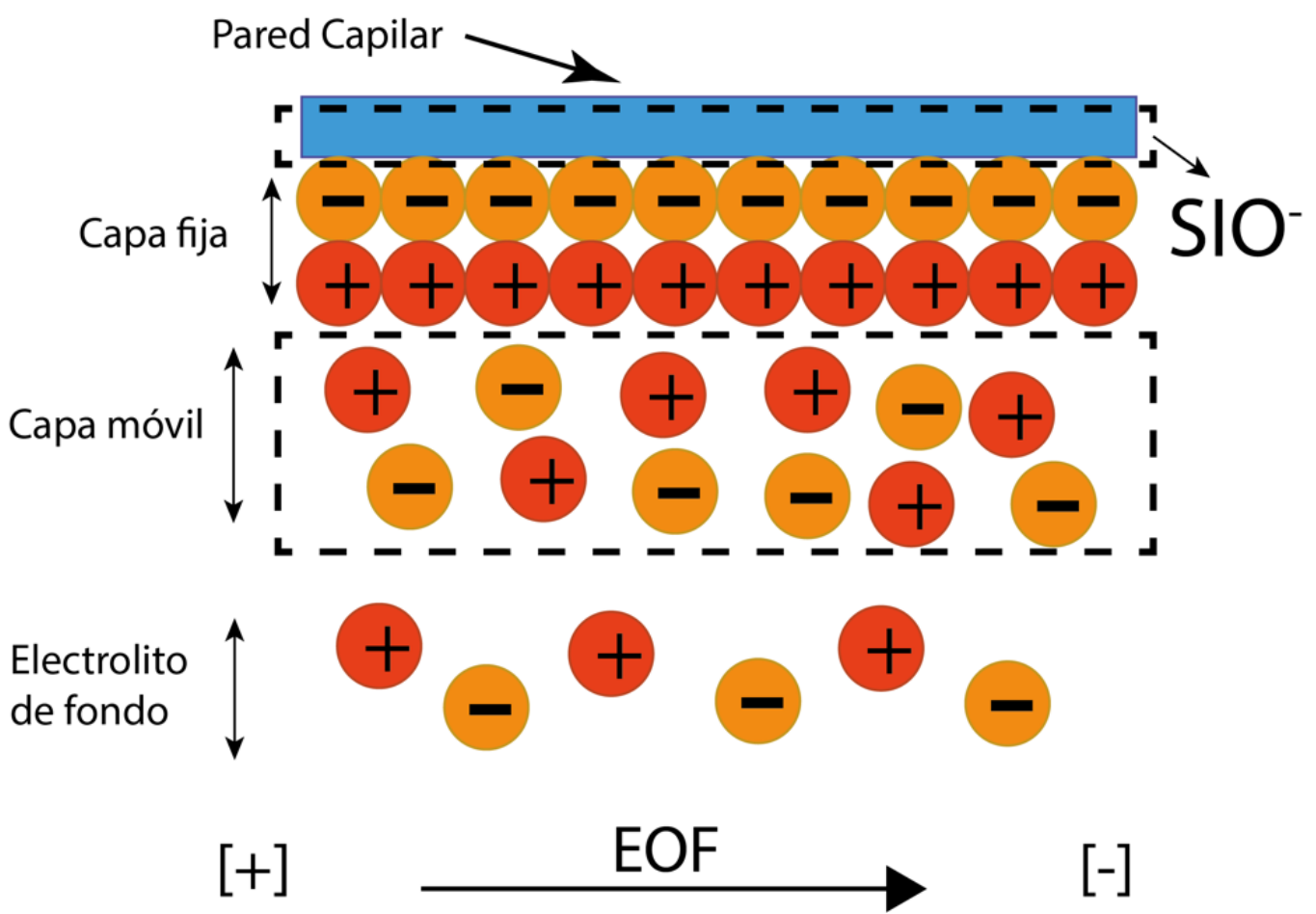

Figura. 6.1. Formación de la doble capa eléctrica y generación del flujo electro osmótico.

El EOF es responsable de la migración de las especies dentro del capilar. Es el movimiento relativo de un líquido con respecto a una superficie cargada bajo la acción de un campo eléctrico y permite la separación simultánea de cationes, aniones y especies neutras. Este flujo tiene una velocidad electro-osmótica $V_{e o}, \mathrm{y}$ una movilidad electro-osmótica $\mu_{e o}$ características; proporcionales al potencial zeta $\zeta$ (que depende del material de las paredes), a la constante dieléctrica ( $\varepsilon$ ) y al campo eléctrico $(E=\mathrm{V} / \mathrm{cm})$; e inversamente proporcional a la viscosidad $(\eta)$ según las ecuaciones ${ }^{8}$ :

Ecuación 6.2

$$
V_{e o}=\mu_{e o} . E
$$

Ecuación 6.2

$$
\mu_{e o}=\frac{\zeta \cdot \varepsilon}{4 \pi \eta}
$$

El flujo electro-osmótico se caracteriza por tener un perfil de velocidades cuasi plano (Figura 6.2.A), a diferencia de lo que ocurre con el flujo producido por presión, que da lugar a flujos laminares y parabólicos (Figura 6.2.B), que ya se discutieron en el capítulo 1. El perfil plano del EOF se debe a que la fuerza 
conductora se distribuye casi uniformemente a lo largo del capilar, lo que hace que todas las especies presenten la misma velocidad causada por el EOF. Esto da lugar a picos estrechos de alta eficacia ${ }^{8}$.
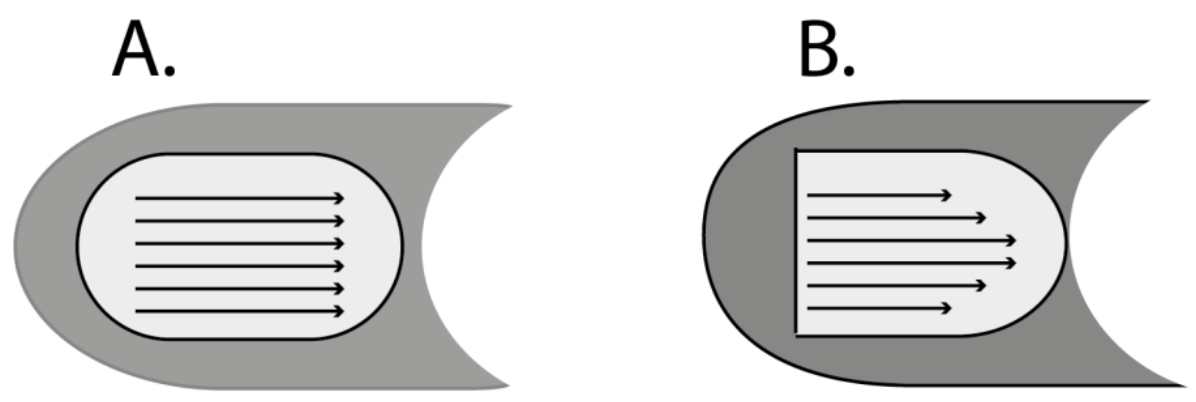

Figura. 6.2. Perfiles de los flujos (A) y electro-osmótico (B) por presión.

Existen diversas variables que pueden modificar el EOF como: el campo eléctrico (Cambios proporcionales en el EOF), la concentración o fuerza iónica de la disolución reguladora (Cambios inversamente proporcionales en la potencial zeta), el $\mathrm{pH}$ disolución reguladora (Aumento del EOF al aumentar el pH), la temperatura (Cambios en la viscosidad y el EOF) y surfactantes ${ }^{8}$.

Una formad de controlar el EOF consiste en adicionar surfactantes en las disoluciones reguladoras empleadas. Estos aditivos actúan aumentando, disminuyendo o incluso cambiando el sentido del EOF. Pueden ser aniónicos, como es el caso del dodecilsulfato sódico (SDS), catiónicos como el bromuro de cetiltrimetilamonio (CTAB) o neutros como el Tween $20^{8}$.

\subsubsection{Parámetros que afectan a la separación.}

Existen tres parámetros que definen la calidad de una separación, relacionados con el voltaje aplicado, las movilidades y la longitud de los capilares. Los parámetros son; tiempo de migración, eficacia, resolución.

\section{- Tiempo de migración}

Uno de los principales objetivos de las técnicas de separación es la disminución de los tiempos de análisis, los cuales vendrán determinados por los tiempos de migración de cada especie. El tiempo de migración de una especie dependerá de la 
longitud del capilar, la movilidad electroforética $(\mu \mathrm{e})$, electro-osmótica $(\mu \mathrm{eo})$ y del campo eléctrico aplicado:

Ecuación 6.3 $\quad t_{m}=\frac{L_{e f}}{\mu_{a} E}=\frac{L_{e f} L_{T}}{\left(\mu_{e}+\mu_{e o}\right)^{V}}$

Donde $\mu_{a}$ es la movilidad aparente $\mu_{e}+\mu_{e o}, L_{e f}$ es la longitud efectiva del capilar y $L_{T}$ es la longitud del capilar. Según esta expresión, cuanto menor sea el tamaño canal y mayor el voltaje y las movilidades, los tiempos de migración serán menores provocando que el análisis sea mas corto.

- Eficacia

Este parámetro viene determinado por el número de platos teóricos $(\mathrm{N})$ que se consiguen en un determinado capilar. Una mayor eficacia vendrá condicionada por el tiempo de migración de las especies y de la anchura de pico, relacionados según la ecuación:

Ecuación $6.4 \quad N=16\left(\frac{t_{m}}{w}\right)^{2}$

Donde $t_{m}$ es el tiempo de migración de las especies y $w$ es la anchura del pico de la base. Donde a partir de esa ecuación es posible determinar que cuanto más estrecho sea un pico y mayor tiempo de migración tenga, mayor será la eficacia de la separación.

\section{- Resolución $\left(\mathbf{R}_{s}\right)$}

Es el grado de separación de dos componentes de una muestra y se puede calcular a través de la siguiente expresión:

Ecuación 6.5 $\quad R_{s}=\Delta t=2 \frac{t_{2}-t_{1}}{w_{1}+w_{2}}$

Donde $\Delta t$ es la diferencia entre los tiempos de migración de las especies, w es el valor medio de los picos $t_{2}-t_{1}$ tiempos de migración de las especies 1 y $2, w_{1}+$ $w_{2}$ es el ancho del pico de las especies 1 y 2 . De acuerdo con esta expresión mientras más estrechos sean los picos y mayor sea la diferencia entre los tiempos de migración, mayor será la resolución ${ }^{8}$.

\subsubsection{Electroforesis en microdispositivos}

Los microchips de electroforesis capilar han sido fabricados en vidrio y cuarzo, debido a su transparencia y a que su EOF es muy similar al obtenido en los capilares de sílice de los sistemas de electroforesis capilar convencional. En los 
últimos años se han empezado a usar materiales poliméricos de precio más reducido en comparación con el vidrio y el cuarzo, como: el polimetilmetacrilato $(\mathrm{PMMA})^{9-11},(\mathrm{PDMS})^{12-15}$, policarbonato $(\mathrm{PC})^{16,17}$, polietilentereftalato $(\mathrm{PET})^{18,19}$ o poliéster ${ }^{20}$. Estos materiales se han venido usando en los últimos años debido a sus propiedades químicas y mecánicas, su bajo coste y su facilidad de manejo y fabricación. De todos estos polímeros, el PMMA y el PDMS son, probablemente, los más empleados en la fabricación de microdispositivos analíticos. Comúnmente, para la fabricación de microchips en materiales como el PDMS, vidrio pírex y cuarzo se usa la técnica de fotolitografía clásica, empleada en la industria microelectrónica ${ }^{21}$. En la bibliografía es posible encontrar diversas publicaciones que hacen referencia a diferentes métodos de fabricación de los microchips en materiales poliméricos ${ }^{22-23}$. Para los microdispositivos utilizados en el este capitulo se utilizaron los polímeros utilizados en la flexografía como se detalló en el capítulo 2 y los trabajos publicados. Desde su aparición se han desarrollado distintos diseños de microchips ${ }^{24,25}$, pero el más utilizado y sencillo es el que se muestra en la figura 6.3. Éste consiste en dos canales en forma de cruz, uno de separación y otro de inyección. Al final de cada extremo se sitúa un depósito para: la disolución reguladora (A), la detección (B), la disolución del analito, ya sean patrones o muestra (de ahora en adelante se hará referencia siempre a muestra) (C) y desecho (D). A su vez, existen dos diseños para el canal de inyección. Según el volumen de inyección, podemos tener una "cruz" o una doble " $T$ ".

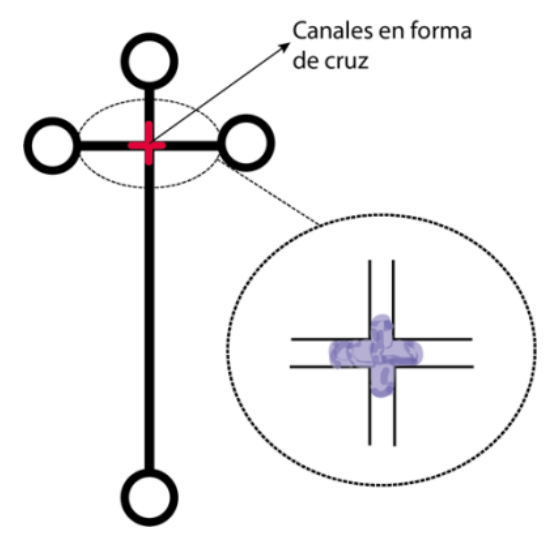

Figura. 6.3. Esquema del diseño típico de un microchip de electroforesis capilar. 


\subsubsection{Trigo y la roya de la hoja}

Triticum aestivum, conocido como trigo blando, es uno de los cereales más cultivados en el mundo. En Argentina, es uno los cultivos más importantes, con una superficie sembrada promedio de alrededor de 6,8 millones de hectáreas y una producción anual que varía entre los 19,9 millones de toneladas ${ }^{26}$. A nivel genómico, Triticum aestivum, es una especie constituida por tres genomas homólogos con secuencias de $\mathrm{ADN}$ repetitivo ${ }^{27,28}$. Por otro lado, la roya de la hoja es una de las enfermedades más importantes de este cultivo, cuyo agente causal es el hongo biotrofo Puccinia triticina, produce una disminución del rendimiento del $5-10 \%{ }^{29}$. Además de afectar al rendimiento, existe una importante disminución del área verde fotosintética (en particular de la hoja bandera, última hoja previa a la espiga) y además consume una cantidad importante de agua y fotosintatos, afectando así la calidad del grano ${ }^{30}$.

En Argentina esta enfermedad se propaga a través de urediniosporas (forma asexual del hongo). Las urediniosporas, al caer en las láminas de las hojas, en condiciones de humedad y temperatura óptimas germinan con un tubo germinativo que forma los apresorios y penetra por las estomas. Después el micelio se disemina por los espacios intercelulares del mesófilo de la hoja y esporula a los 12-15 días formando pústulas de uredosporos que son capaces de reiniciar de nuevo el proceso de infección en la planta e inclusive a grandes distancias llevados por el viento ${ }^{31}$ Figura 6.4.

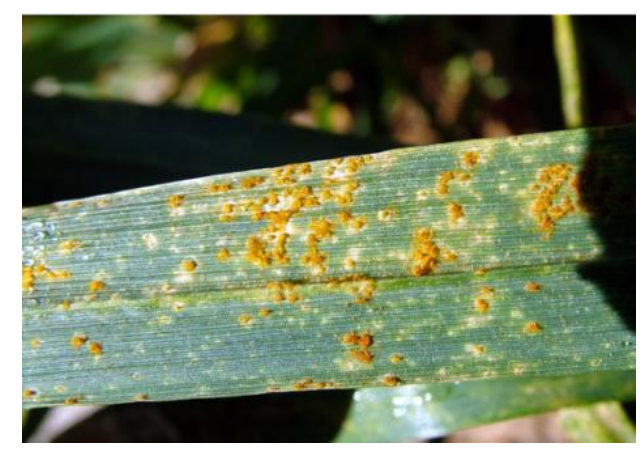

Figura. 6.4. Roya de la hoja - Puccinia recondita. Daño en hoja de trigo (Louisiana State University AgCenter Archive, Louisiana State University AgCenter, Bugwood.org) 


\subsubsection{Mecanismos genéticos de resistencia de la planta}

Se han identificado genes que confieren resistencia a determinadas razas del patógeno que se denominan raza-específicos ${ }^{32}$. Varios experimentos realizados sobre herencia de la virulencia en el patógeno y de la resistencia en el hospedante, permitieron conocer un determinismo genético con algunos tipos de enfermedades, estableciendo una teoría de la relación gen a gen. Esta teoría propone que la "Respuesta Hipersensible" (HR), solamente se manifiesta cuando el huésped posee al menos un gen de resistencia y el patógeno tiene el correspondiente alelo de avirulencia. Por lo tanto, otra combinación resultará en una reacción de susceptibilidad $^{33}$. La relación gen a gen se pudo confirmar en la interacción del trigo y la roya de la hoja en estudios genéticos ${ }^{34}$.

En trigo se han reportado alrededor de 80 loci que poseen genes de resistencia a roya de la hoja, o Lrs, por el inglés "leaf rust" 35 . Actualmente hay dos tipos de genes $L r$ en función del estadio en el cual comienza a expresarse la resistencia. Los genes de plántula o resistencia en todos los estadios (ASR, all stage resistance) en el cual la resistencia inicia en la primera hoja y continua durante todo el ciclo de vida de la planta, y los genes de resistencia en planta adulta (APR, adult plant resistance) en el que la expresión de la resistencia puede empezar en cualquier estadío posterior al de plántula, pero alcanzan su máxima expresión en la hoja bandera $^{36}$. Por lo general se ha visto que los genes $L r$ otorgan resistencia razaespecífica y expresan la respuesta hipersensible ${ }^{35}$ figura 6.5 . 


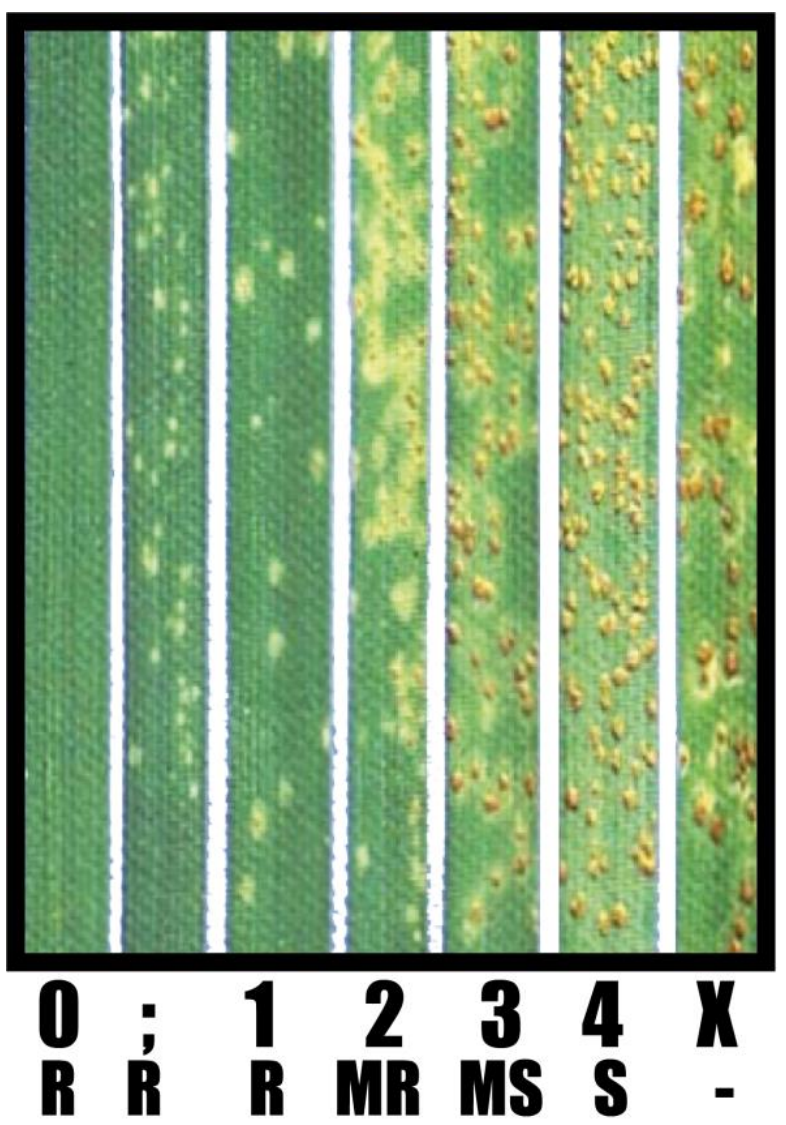

Figura. 6.5. Escala de Mains \& Jackson, donde se describen los grados de resistencia o susceptibilidad de acuerdo al tipo de respuesta del huésped. R: Resistente; MR: Moderadamente Resistente; MS: Moderadamente Suceptible; S: Suceptible ${ }^{35}$.

Hasta el momento se han clonado tres genes Lrs raza-específicos de plántula: el $L r 10^{37}$, el $L r 21^{38}$ y el $L r 1^{39}$ y tres $L r$ de resistencia de expresión en planta adulta; dos de amplio espectro: el $\operatorname{Lr} 34^{40}$ y el $\operatorname{Lr} 67^{41}$ y uno de resistencia especifica: el $L r 22^{42}$. Los genes de resistencia raza-específica usados en variedades comerciales confieren inicialmente buenos niveles de resistencia. Sin embargo, cuando el gen que otorga la resistencia es utilizado extensivamente por largos períodos de tiempo, aumenta la selección de nuevas razas del patógeno con la capacidad de infectar al cultivo. Consecuentemente, este tipo de resistencias es poco durables y su utilización en programas de mejoramiento requiere de una constante evaluación de nuevas variantes génicas resistentes. Sin embargo, existen algunas variedades de trigo portadoras de resistencia durable a roya como Sinvalocho MA, Buck Manantial, Buck Poncho y El Gaucho FA ${ }^{43}$, que se comportan como resistentes 
por largos períodos de tiempo aún luego de alcanzar una gran difusión ${ }^{44}$. En todas ellas se han reconocido genes de expresión en planta adulta, permitiendo suponer una correlación positiva entre la presencia de estos y una posible durabilidad de la resistencia.

La utilización de genes de resistencia representa una de las formas más económicas para el control de las enfermedades en plantas y de menor impacto ambiental, ya que elimina la necesidad de utilización de funguicidas. Evita además un recambio acelerado de variedades como se observa en los últimos años, donde la durabilidad promedio de la mayoría de las variedades comerciales es de alrededor de 3 años. En los últimos años la introducción de germoplasma de origen mejicano y más recientemente de origen francés, ambos con altos potenciales de rendimiento, pero con características sanitarias regulares, han determinado un uso creciente de paquetes tecnológicos que involucran el uso de agroquímicos con el consiguiente impacto económico-ambiental. La identificación de los genes responsables de la resistencia durable y el clonado de los mismos para hacerlos disponibles para su introducción mediante ingeniería genética y para el estudio de las bases moleculares de la resistencia a enfermedades, significarían un importante aporte en el logro de una agricultura sustentable, con el consiguiente beneficio económico social ${ }^{45-50}$.

\subsubsection{Marcadores moleculares}

El desarrollo de nuevas técnicas de biología molecular permite una caracterización precisa del material genético de los organismos vivos. La disponibilidad de marcadores de ADN como los RFLPs, RAPDs, microsatétlites y AFLPs (CaetanoAnolles and Gresshoff 1997), entre otros ${ }^{51-59}$, ha avanzado rápidamente en los últimos años permitiendo la construcción de mapas de ligamiento de notable grado de saturación, clonado posicional de genes, selección asistida y también la caracterización genómica o fingerprinting para determinar el grado de parentesco entre individuos de una población ${ }^{60,61,63,64}$. En particular, el uso de marcadores de ADN ligados a genes de resistencia en plántula y fundamentalmente en planta adulta facilita los trabajos de selección en poblaciones segregantes provenientes de cruzamientos con variedades portadoras de resistencia durable. Por su gran disponibilidad, bajo costo, gran reproducibilidad, codominancia y alto grado de 
polimorfismo, los microsatelites o SSRs son los marcadores más utilizados en trigo (http://wheat.pw.usda.gov/GG2/index.shtml). Básicamente, los SSRs se basan en la amplificación por PCR de fragmentos de ADN utilizando cebadores o "primers" específicos que flanquean arreglos de mono-di-tri-tetra o pentanucleótidos en tándem con altos niveles de variación basados en diferencias en el número de unidades repetidas en cada locus ${ }^{65}$.

El cultivar Sinvalocho MA (SV), se obtuvo por el cruzamiento Klein Sin Rival x 38 MA y ha sido usado como una variedad local diferencial en estudios de la roya de la hoja por más de 50 años en Argentina ${ }^{43,45}$. En estudios genéticos realizados en esta variedad de resistencia durable, se han identificado un alelo o un gen estrechamente vinculado al locus $L r 3$ en el cromosoma 6B y dos genes de resistencia en planta adulta $L r S V 1$ y $L r S V 2$ localizados en los cromosomas 2DS y $3 \mathrm{BS}$, respectivamente, y marcadores de $\mathrm{ADN}$ asociados ${ }^{66}$. En campo, las líneas que llevan los genes LrSV1 o LrSV2 reducen el número de pústulas a 60-65\%, respectivamente, y a $55 \%$ cuando ambos están presentes ${ }^{66}$, sugiriendo que son factores importantes en la durabilidad de la resistencia observada en este cultivar. Además, se demostró que para la expresión del gen $L r S V 2$ es necesaria la presencia de por lo menos una dosis de otro gen, ubicado en el cromosoma 4BL, cercano o idéntico al $\operatorname{Lr} 12 / \mathrm{Lr} 31^{67}$. y que se denominó provisoriamente $\operatorname{LrcSV} 2$. Ambos genes se comportan como dominantes con efectos complementarios, de forma similar a lo que ocurre con los genes de resistencia en plántula $L r 27$ y $L r 31$.

Con respecto al gen $\operatorname{LrcSV} 2$, utilizando una población de 100 RILs (Líneas Recombinantes Homocigotas) del cruzamiento de Sinvalocho por la variedad susceptible Purple Straw, se había construido un mapa genético del 4BL con 16 microsatélites delimitando un intervalo de $3.1 \mathrm{cM}$ entre dos clusters de 3 marcadores flanqueantes (gwm149, gwm251 y gwm375 proximales y cfd22, cfd39 y barc163 distales) ${ }^{68,69}$. Luego se hallaron nuevos marcadores ligados, dos de los cuales (FSs34 y FSs35) fueron diseñados a partir de secuencias de cóntigo del cromosoma 4BL utilizando la sintenia con Brachypodium distachyon. La incorporación de estos al mapa genético permitió reducir el intervalo blanco a 1cM entre los marcadores FSs34 (proximal) y gpw4388 (distal) y detectar un marcador cosegregante con el gen; el microsatelite wmc692 ${ }^{70}$. Para obtener una mejor resolución del mapa es necesario incrementar el número de individuos segregantes 
estudiados por lo tanto es necesario analizar una población F2 con los marcadores flanqueantes del gen. El objetivo de este trabajo que se encuentra desarrollado en este capítulo es el desarrollo y diseño de microcanales para electroforesis de ADN, fabricados en PDMS que permitan analizar un alto número de individuos segregantes en menor tiempo y con reducción del costo de materiales. La electroforesis se realizará utilizando un campo eléctrico de acuerdo con las moléculas estudiadas. A modo de ejemplo, se utilizarán marcadores moleculares de tipo microsatelites asociados a genes de resistencia a roya de la hoja de trigo.

\subsection{Materiales y métodos.}

\subsubsection{Material Vegetal.}

El cultivar argentino de trigo (Triticum aestivum) Sinvalocho MA (SV) con resistencia duradera a roya de la hoja lleva el gen de resistencia $\operatorname{LrcSV} 2$ que proporciona resistencia en planta adulta a la raza Castelar02-Gama1R (Ca02-G1R) de Puccinia triticina. El cultivar Purple Straw (P) es susceptible a esta raza. Se utilizó una población segregante de 388 F2s del cruce $\mathrm{SV} \times \mathrm{P}$. Las plantas fueron cultivadas en el invernadero a temperaturas entre 15 y $25{ }^{\circ} \mathrm{C}$ en recipientes de un litro con 5 plantas por maceta.

\subsubsection{Aislamiento de ADN}

El ADN se aisló del tejido de la hoja. Brevemente, $300 \mathrm{mg}$ de tejido foliar deshidratado se trituraron mecánicamente con el Tissue Lyser (Quiagen) y se añadieron $0.8 \mathrm{ml}$ de tampón de extracción (Tris-HCl 100 mM pH 7.5, NaCl 700 $\mathrm{mM}$, EDTA $50 \mathrm{mM} \mathrm{pH} \mathrm{8)} \mathrm{a} 65^{\circ} \mathrm{C}$. Después de la incorporación de $100 \mu \mathrm{l}$ de CTAB al $10 \%$ y $100 \mu \mathrm{l}$ de SDS al 20\%, las muestras se incubaron con agitación suave a $65^{\circ} \mathrm{C}$ durante $60 \mathrm{~min}$. Una vez a temperatura ambiente, se agregaron 900 $\mu l$ de cloroformo / alcohol isoamílico (24: 1) y, después de 5 min de mezcla suave por inversión, se centrifugó durante $10 \mathrm{~min}$ a $14000 \mathrm{rpm}$. La fase acuosa superior se incubó con $5 \mu \mathrm{l}$ de RNasa $(10 \mu \mathrm{g} / \mu \mathrm{l})$ durante 60 min a $37^{\circ} \mathrm{C}$. Después de un segundo cloroformo /en la extracción con alcohol isoamílico, se añadieron $510 \mu \mathrm{l}$ de isopropanol frío a la fase acuosa y se centrifugó durante 10 min a 14000 rpm. 
El sedimento se lavó con $1 \mathrm{ml}$ de etanol al 70\%. y se re suspendió en $50 \mu 1$ de $\mathrm{H}_{2} \mathrm{O}$. La cantidad de ADN purificado se estimó por la absorbancia a $260 \mathrm{~nm}$ usando un espectrofotómetro (ND-1000, NanoDrop®).

\subsubsection{Amplificación de marcadores de ADN por PCR.}

Las amplificaciones por PCR se realizaron con $50 \mathrm{ng}$ de ADN como plantilla en reacciones de $20 \mu \mathrm{l}$ con $1,5 \mathrm{mM}$ de $\mathrm{MgCl} 2$, DNTP $0,16 \mu \mathrm{M}, 0,08 \mu \mathrm{M}$ de cada cebador y 0,032 unidades/ $\mu 1$ de la ADN polimerasa Taq (Invitrogen) en su correspondiente tampón (10x, sin $\mathrm{MgCl} 2)$. El ciclo térmico consistió en siete ciclos de 30 sa $94{ }^{\circ} \mathrm{C}, 30$ sa 62 (reduciendo $1^{\circ} \mathrm{C}$ por ciclo) y 30 sa $72{ }^{\circ} \mathrm{C} ; 31$ de ciclos 30 sa $94^{\circ} \mathrm{C}, 30$ sa $55^{\circ} \mathrm{C}$ y 30 sa $72{ }^{\circ} \mathrm{C} ; 11$ ciclos de 30 sa $94^{\circ} \mathrm{C}, 30$ sa $56^{\circ} \mathrm{C}$ y 30 sa $72^{\circ} \mathrm{C}$. Las secuencias del cebador fueron las descritas: gpw $4388^{71}$.

\subsubsection{Diseño de los microdispositivos para la electroforesis.}

Se diseñaron 3 dispositivos de microfluídica, utilizando Layout editor como paquete informático para el diseño;

i) dos canales en forma de cruz, uno de separación y otro de inyección. Al final de cada extremo se sitúa un depósito para: la disolución reguladora (A), la detección (B), la disolución del analito (C) y desecho (D). (Figura 6.6i).

ii) dos vidrios porta objetos enfrentados, colocando en los bordes un espaciador de 0,4 $\mathrm{mm}$ de espesor y en el extremo superior microcanales para colocar las muestras. Los microcanales fueron fabricados de acuerdo con la metodología descrita en el capítulo II. Posteriormente, para fijarlos y evitar el corrimiento del gel durante el llenado se colocaron ganchos en los bordes que sujeten los vidrios. (Figura 6.6ii). iii) un molde maestro que contenía 10 canales y cada canal con su respectivo agujero para cargar las muestras, fabricado también con la metodología descrita en el capítulo II y cuyas dimensiones se pueden visualizar en la Figura 6.6iii. 

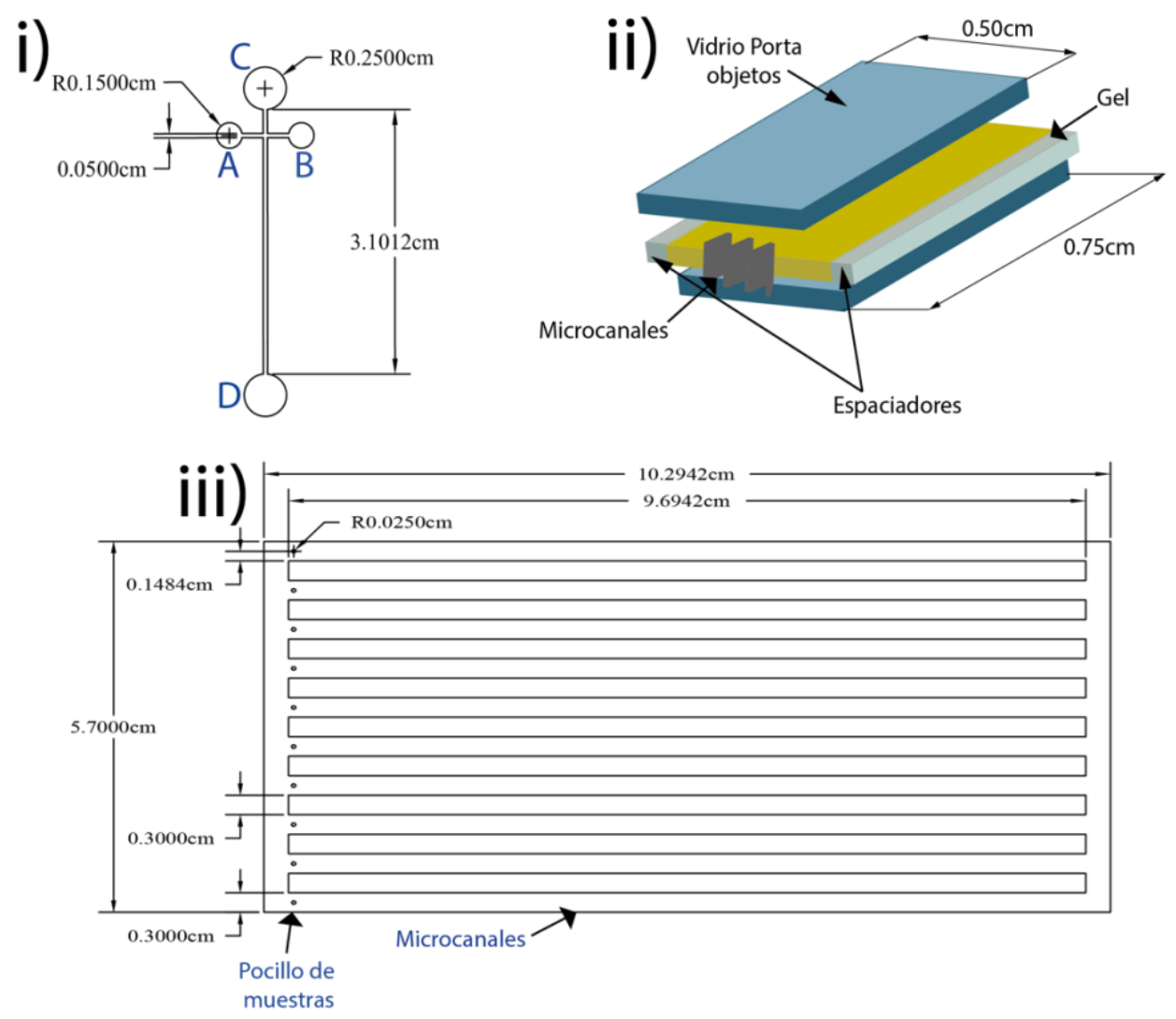

Figura. 6.6. Dispositivos utilizados para la electroforesis. i). Diseño en forma de cruz donde A es la entrada de las muestras, B y C sitios donde se colocan los electrodos para introducir las muestras en los canales y $\mathrm{C}$ es la salida o el desecho. (Los electrodos también son colocados en A y D para poder aplicar un diferencial de potencial dependiendo el caso). ii) Dispositivo ensamblando con vidrios cubre objetos donde el gel de acrilamida queda contenido. iii) Diseño del dispositivo de los nueve microcanales con dimensiones escaladas y con pocillos para las muestras.

\subsubsection{Fabricación de los dispositivos en PDMS.}

La fabricación de los dispositivos i) y iii) se realizó utilizando la metodología desarrollada y descrita en el capitulo II. Brevemente, el proceso de fabricación del dispositivo de microfluidos PDMS consta de tres pasos principales: (1) fabricación del molde maestro flexográfico de fotopolímero (Fmold), (2) fabricación de un molde macho de resina epóxica reutilizable (ERmold) utilizando el Fmold mediante copia de la réplica y (3) transferencia del ERmold en PDMS. El Molde maestro flexográfico de fotopolímero (Fmold): El fotopolímero Flexcel NX y la 
capa TIL utilizadas en la fabricación de los moldes fueron suministrados por Eastman Kodak24 $4^{72}$. Los pasos de fabricación del Fmold se han descrito en un trabajo anterior ${ }^{73}$. Brevemente la red de microcanales se diseñó con un paquete informático y el diseño fue transferido al TIL con una fuente de láser infrarrojo de 2400 ppi. En el siguiente paso, se expuso la placa de fotopolímero a la luz UVA a 0,45 J en el reverso y luego en el anverso se expuso a luz UVA a $19 \mathrm{~J}$ durante 360 s, después se eliminó el TIL. Se utilizaron diferentes períodos de exposición a los rayos UVA en el reverso para controlar la altura de los microcanales. Posteriormente, la placa de fotopolímero se lavó con disolvente PROSOL N-1 (suministrado por Eastman Kodak) a $360 \mathrm{~mm} \cdot \mathrm{min}^{-1}$ y se secó en estufa durante 30 min a $50^{\circ} \mathrm{C}$. Finalmente, la placa de fotopolímero se expuso a luz UVC a $10 \mathrm{~J}$ durante 17 min y luz UVA a $4 \mathrm{~J}$ durante 2 min en la parte frontal. Este molde fue codificado como Fmold. Antes de su uso, el Fmold se colocó en una estufa a100 ${ }^{\circ} \mathrm{C}$ por $12 \mathrm{~h}$ y luego se trató en una cámara de vacío por 1 ha $25^{\circ} \mathrm{C}$, seguido de un proceso de limpieza en solución de etanol al $70 \%$ en baño ultrasónico por 7 min, secado a $40{ }^{\circ} \mathrm{C}$ por 10 min y con nitrógeno. El molde de resina epóxica (ERmold): disponible comercialmente y un agente de curado (Cristal-Tack, Novarchem Argentina) se mezclaron con agitación manual durante 3 minutos en una proporción en peso de 2:1 y se trataron con un sonicador (TESTLAB Ultrasonic Cleaner) durante $7 \mathrm{~min}$ para eliminar las burbujas de aire. Luego, la mezcla se vertió sobre el molde Fmold y se curó a temperatura ambiente durante 72 h. Después del curado, el molde de resina epóxica se despegó del molde Fmold para formar el molde macho, este molde se conoce como ERmold. El PDMS se mezcló con el agente de curado en una proporción en peso de 10:1 (Sylgard 184 Silicone Elastomer Kit), como anteriormente descrito por Peñaherrera et al. ${ }^{26}$ Luego, la mezcla se colocó al vacío durante 30 min para eliminar las burbujas de aire, se vertió en el Ermold y se curó en una estufa a $40{ }^{\circ} \mathrm{C}$ durante la noche. Después del curado, la réplica de PDMS se despegó del molde y se perforaron los orificios para las entradas y salidas de los canales de $1 \mathrm{~mm}$ de diámetro. (Integra Miltex®Ted Pella, Inc). Finalmente, la réplica se unió de forma irreversible a una oblea de vidrio después de la exposición a un generador de alta frecuencia (BD-10AS, Chicago) durante $120 \mathrm{~s}$. 


\subsection{6 i) Ensamblaje del dispositivo en PDMS en forma de cruz.}

El dispositivo en forma de cruz (i) consiste en un canal fabricado en PDMS y unido a un sustrato de vidrio de dimensiones $38 \mathrm{~mm}$ x $13 \mathrm{~mm}$, que actúa además como cierre de los microcanales para hacer pasar disoluciones a través de los microcanales. Sobre el PDMS, se encuentran los electrodos. Antes de realizar la electroforesis en los microdispositivos, fue necesario llevar a cabo un acondicionamiento de los microcanales. Este proceso constituye uno de los pasos más importantes y críticos a la hora de conseguir señales reproducibles. Éste ha consistido en hacer pasar a través de los canales del microchip una disolución de $\mathrm{NaOH} 0.1 \mathrm{M}$, durante 20 min. A continuación, se procede al lavado con $\mathrm{H}_{2} \mathrm{O}$, durante 15 min. y finalmente se hace pasar la disolución de trabajo (Agarosa+TBE) durante 15 min. Los microchips de vidrio se han acondicionado con puntas de pipeta a la salida. Se añadió gel de agarosa $2 \%$ en tampón TBE 1 X ((0,89 mM Tris, 0,89 mM Ácido Bórico y 20 mM EDTA pH 8.0). El gel de agarosa se introdujo hacia el canal de separación justo hasta que el gel llegó a la unión en T, luego se llenaron todos los depósitos con tampón de electroforesis (1X TBE) y el chip se enfrió a temperatura ambiente. El gel de agarosa gelificó a temperatura ambiente y el chip quedó listo para usar.

- Electroforesis

La separación de los fragmentos se realizó utilizando una fuente de poder Biorad 300 controlada manualmente que proporcionó los voltajes necesarios para la inyección y separación de muestras. En este trabajo, se sembraron aproximadamente 5-10 $\mu \mathrm{L}$ de muestra con buffer de carga $(10 \mathrm{mM} \mathrm{NaOH}, 0.05 \%$ Azul de Bromofenol, $0.05 \%$ Xylene Cyanol y 95\% (v/v) Formamida desionizada). Al aplicar un campo eléctrico, de $200-400 \mathrm{~V} \mathrm{~cm}^{-1}$, entre los depósitos A y B (figura 6.6i), la muestra migró a través del canal de muestra y, por lo tanto, llenó el área T del microchip. Después de un tiempo de inyección predeterminado ( $1 \mathrm{~min}$ ), la separación electroforética comenzó aplicando un potencial entre los depósitos $\mathrm{C}$ y D (figura 6.6a), por $4 \mathrm{~min}$. Los resultados fueron visualizados en un transiluminador Labnet. 


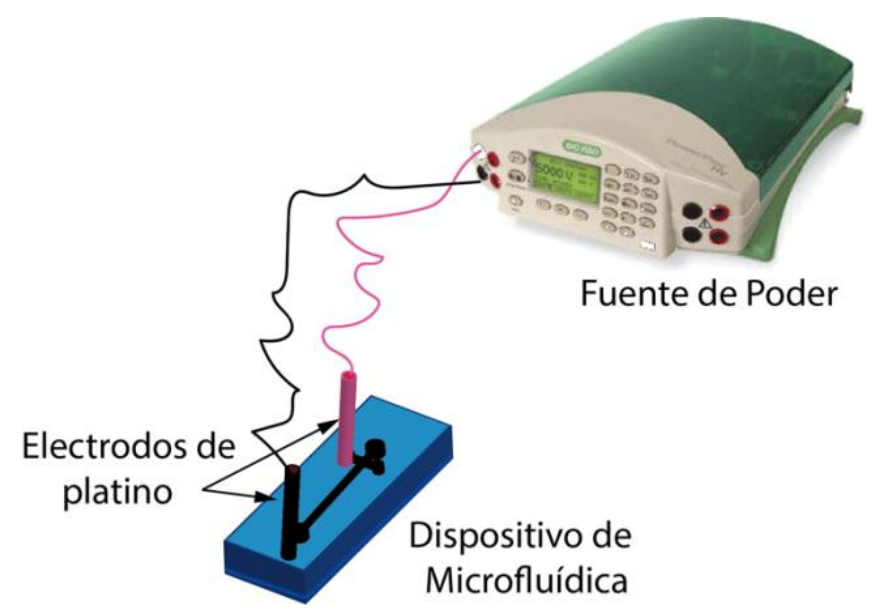

Figura. 6.7. Esquema de electroforesis en el (i) dispositivo de microfluídica en forma de cruz.

\subsection{7 ii) Ensamblaje del dispositivo en vidrios.}

Antes del ensamblando del dispositivo, Uno de los portaobjetos de vidrio se trató con una solución de 9,50 $\mu 1$ de alcohol, 0,5 $\mu 1$ de ácido acético y 0,3 $\mu 1$ de Bind (PlusOne Bind- Silane. Amersham Biosciences), y se lavó posteriormente 3 veces con $10 \mathrm{ml}$ de alcohol, en intervalos de 3 minutos. El otro portaobjeto se trató con $40 \mu \mathrm{l}$ de Gel Save (AppliChem). Biosciences), y se lavó posteriormente 3 veces con $1 \mathrm{ml}$ de alcohol, en intervalos de 3 minutos. El armado del dispositivo consistió en colocar las caras tratadas de forma enfrentada, colocando en los bordes un espaciador de $0,4 \mathrm{~mm}$ de espesor y en la parte superior el porta muestras. Se colocaron ganchos en los bordes para fijarlos. Entre los vidrios se coloco una solución de acrilamida 5\% Acri:bis (19:1), urea $7 \mathrm{M}$ en buffer TBE 1X (0,89 mM Tris, 0,89 mM Ácido Bórico y $20 \mathrm{mM}$ EDTA pH 8.0) a la que se agregaron los catalizadores Temed ( $1 \mu \mathrm{l} / \mathrm{ml}$ de gel) y Persulfato de amonio $25 \%$ en agua $\left(1 \mu 1 . \mathrm{ml}^{-}\right.$ ${ }^{1}$ de gel). A los productos de amplificación se les agregó $10 \mu 1$ de buffer de carga (10 mM NaOH, 0.05\% Azul de Bromofenol, $0.05 \%$ Xylene Cyanol y 95\% (v/v) Formamida desionizada) y se desnaturalizó a $95^{\circ} \mathrm{C}$ por 5 minutos. Luego se los colocó rápidamente en hielo. Para la resolución de los productos de amplificación, se sembraron 1-5 $\mu 1$ de la muestra y la electroforesis se realizó con buffer TBE 0.5 $\mathrm{X}$ durante aproximadamente 45 minutos a 60 Watts constantes dentro de una cuba 
electroforética Bio-Rad, como se puede ver en la figura 6.8). Se incluyó un marcador de peso molecular (25 bp Invitrogen) y la visualización de la corrida electroforética se realizó mediante tinción con Nitrato de Plata $\left(\mathrm{AgNO}_{3}\right)$ e Hidróxido de Sodio $(\mathrm{NaOH})$.

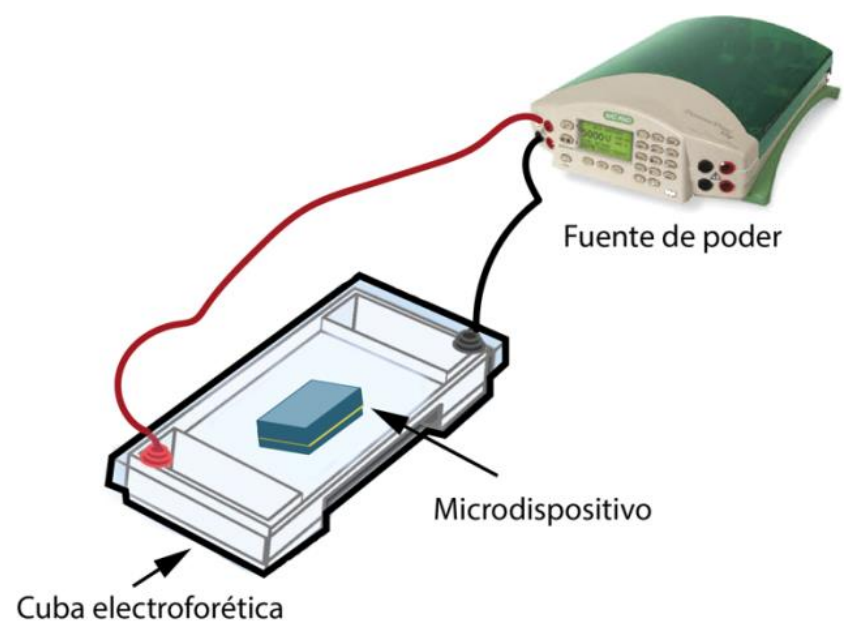

Figura. 6.8. Esquema de electroforesis en el dispositivo de microfluídica utilizando el ensamblaje de vidrios porta objetos (ii).

\subsubsection{Visualización de productos de PCR.}

Después del ciclo de PCR se añadió un volumen de tampón de carga $(\mathrm{NaOH} 10$ $\mathrm{mM}$, azul de bromofenol al $0,05 \%$, cianol de xileno al $0,05 \%$ y formamida desionizada al 95\%) y después de 5 min de incubación a $95{ }^{\circ} \mathrm{C}$, se cargaron $7 \mu 1$ en poliacrilamida desnaturalizante al $5 \%$. los geles se sometieron a electroforesis en tampón TBE $0,5 \times$ durante 90 min a $60 \mathrm{~W}$. Los fragmentos separados se tiñeron con plata de la siguiente manera: incubación de 5 min en ácido acético al 0,05\% etanol al 10\%, incubación de $10 \mathrm{~min}$ en 1,5 g / 1 de AgNO3 más 1,5 ml / 1 de formaldehído, $15 \mathrm{~s}$ de lavado en agua bidestilada e incubación en $15 \mathrm{~g} / 1 \mathrm{de} \mathrm{NaOH}$ más $2 \mathrm{ml} / 1$ de formaldehído hasta que los productos de PCR fueron visibles. La tinción se detuvo con ácido acético al 0,05\% y etanol al 10\%. Para los ensayos del ii) dispositivo de vidrio sección 6.2.8. 


\subsection{Resultados y Discusión.}

\subsubsection{Fabricación de los dispositivos para electroforesis.}

Con el desarrollo de los dispositivos se logró avanzar hacia el concepto de miniaturizar las electroforesis que se realizaban en geles de poliacrilamida vertical de $45 \mathrm{~cm}$ por $32 \mathrm{~cm}$. A lo largo de este trabajo se han orientado gran parte de los esfuerzos a intentar diseñar y fabricar un verdadero dispositivo de microfluídica que permita realizar electroforesis. Para ello, se ha profundizado en el diseño y desarrollo de dispositivos. Así, uno de los primeros dispositivos diseñados y utilizados fue el dispositivo de PDMS en forma de cruz (i) ya que es uno de los más utilizados en la literatura y en varias aplicaciones ${ }^{75-77}$. La electroforesis en el dispositivo de PDMS en forma de cruz fue factible, pero el proceso para obtener los resultados de varias muestras fue muy lento, debido al proceso de lavado y acondicionamiento del dispositivo entre cada muestra a ser analizada. Por lo tanto, con la idea de paralelizar el análisis y la obtención de los resultados se utilizó el dispositivo (ii). Los resultados obtenidos después de la amplificación, la electroforesis, y la tinción de los marcadores, ligados a la resistencia a roya ${ }^{66,60}$ se muestran en la figura 6.9. El proceso resultó mucho más rápido que en el dispositivo (i) anteriormente descrito. En cuanto a la paralelización de las muestras, mostró la posibilidad de analizar dos muestras. En la Figura 6.9a, se muestra el dispositivo después de la electroforesis y de la tinción con Nitrato de Plata $\left(\mathrm{AgNO}_{3}\right)$ e Hidróxido de Sodio $(\mathrm{NaOH})$, donde se pueden visualizar dos muestras: los individuos parentales Sinvalocho (SV) y Purplestraw (P). Se observan los fragmentos y la diferencia en sus tamaños en el gel. Esta diferencia en el tamaño de los fragmentos se debe al polimorfismo de tamaño de este marcador molecular entre las líneas parentales del cruzamiento. Estos fragmentos permiten identificar si los individuos poseen el alelo de SV o de $\mathrm{P}$ del marcador ligado al gen de interés. 


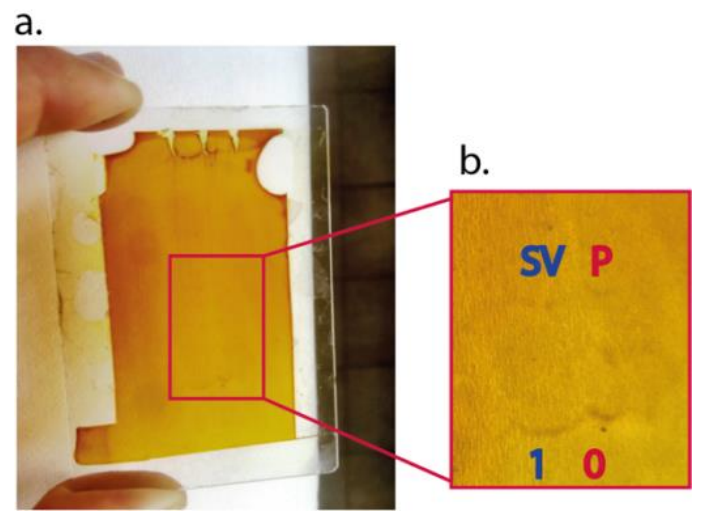

Figura. 6.9. Visualización del polimorfismo del marcador gpw4388 por electroforesis en gel de poliacrilamida desnaturalizante 5\%, en las líneas parentales SV (Sinvalocho) y P (Purplestraw).

Uno de los principales objetivos de las técnicas de separación es la disminución de los tiempos de análisis, analizando varios individuos en paralelo. Por esa razón se diseñó un nuevo dispositivo (iii) con nueve canales, con entradas independientes, como se muestra en la Figura 6.10. El nuevo dispositivo integra dos características: primero, la integración de un microcanal con unas dimensiones de $10 \mathrm{~cm}$ x $5 \mathrm{~cm}$ no reportada en la literatura para electroforesis en microcanales y segundo, cada canal posee una entrada independiente para cada muestra, donde se haría la electroforesis en gel de poliacrilamida como se describió anteriormente. Este dispositivo permitiría, mejorar la separación ${ }^{8}$ al poseer un canal independiente de diámetro menor y uniforme para la migración por el efecto de la electroforesis en un capilar. Además, incrementaría la eficacia por poseer más platos teóricos, debido a la longitud del canal ${ }^{8}$. Finalmente, como se mencionó previamente el dispositivo también permite el análisis de hasta 9 muestras en forma simultánea. El diseño e implementación del dispositivo permitiría escalar e incrementar el número de análisis. 


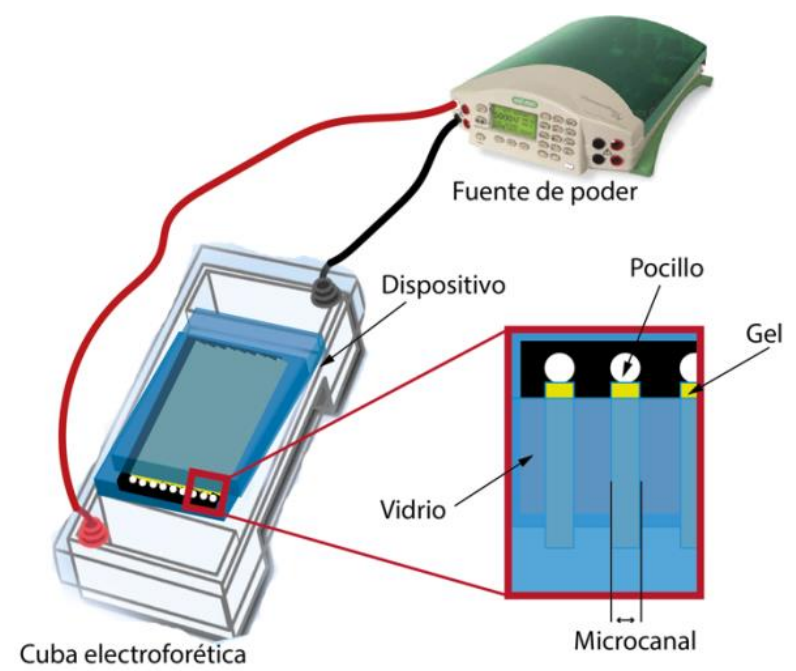

Figura. 6.10. Esquema propuesto para electroforesis en el dispositivo (iii) con canales de microfluídica y el ensamblaje de vidrios con gel de acrilamida independiente.

\subsection{Conclusiones.}

Es posible la miniaturización de diferentes partes de la instrumentación analítica, sin perder su funcionalidad, así se han desarrollado tres modelos de electroforesis capilar con detección. La simplificación y el uso de microdispositivos es posible gracias al desarrollo de diferentes configuraciones propuestas. En este trabajo se han presentado modelos para electroforesis de forma fácil y rápida ahorrando tiempo y costos en materiales adicionales al montaje de electroforesis convencionales en geles de acrilamida. Así se han desarrollado la primera generación de dispositivos de microfluídica y que es necesario continuar optimizando el proceso para buscar marcadores asociados a genes de resistencia a la roya de la hoja del trigo. Uno de los marcadores flanqueantes GPW4388 fue probado con el dispositivo (ii) y se podría utilizar para genotipar la población segregante utilizando menor cantidad de recursos. Y finalmente fue posible identificar otros recombinantes dentro del intervalo genético. 


\subsection{Referencias.}

1. A. Tiselius, A new apparatus for electrophoretic analysis of colloidal mixtures, Trans. Faraday Soc., 1937, 33, 524-531

2. C. C. Blanco, Electroforesis capilar, Universidad de Almería, Servicio de publicaciones Universidad de Almería, 1998.

3. S. Hjertén, Free zone electrophoresis, Chromatogr. Rev., 1967, 9, 122-219

4. R. Virtenen, Zone electrophoresis in a narrow-bore tube employing potentiometric detection. Theoretical and experimental study, Acta Polytech. Scand., 1974, 123, 1-67

5. F. Mikkers, F. Everaerts, T. Verheggen, Concentration Distributions in Free Zone Electrophoresis, J. Chromatogr., 1979, 169, 1-10

6. J.W. Jorgenson, K.D. Lukacs, Zone electrophoresis in open-tubular glass capillaries, Anal. Chem., 1981, 53, 1298-1302

7. J.W. Jorgenson, K.D. Lukacs, Capillary zone electrophoresis, Science, 1983, 22, 266- 272.

8. Fernández La Villa A., Nueva generación de sistemas microfluídicos de electroforesis portátiles y automáticos con detección electroquímica para análisis agroalimentario y clínico. 2013 Oviedo España. Tesis doctoral.

9. M. J. Schöning, M. Jacobs, A. Muck, D.-T. Knobbe, J. Wang, M. Chatrathi, S. Spillmann, Amperometric PDMS/glass capillary electrophoresis based biosensor microchip for catechol and dopamine detection, Sens. Actuators. B, 2005, 108, 688-694.

10. J. Wang, M. Pumera, M. P. Chatrathi, A. Rodriguez, S. Spillman, R. S. Martin, S. M. Lunte, Thick-Film Electrochemical Detectors for Poly(dimethylsiloxane)based Microchip Capillary Electrophoresis, Electroanalysis, 2002, 14, 1251-1255.

11. M. W.Li, B. H. Huynh, M. K. Hulvey, S. M. Lunte, R. S. Martin, Design and

Characterization of Poly(dimethylsiloxane)-Based Valves for Interfacing Continuous-Flow Sampling to Microchip Electrophoresis, Anal. Chem. 2006, 78, 1042-1051

12. M. Castaño-Álvarez, A. Fernández-la-Villa, M. Fernández-Abedul, A. CostaGarcía, MCE-electrochemical detection for following interactions of ssDNA and dsDNA with methylene blue Electrophoresis, 2009, 30, 1943-1948. 
13 Y. Liu, D. Ganser, A. Schneider, R. Liu, P. Grodzinski, N. Kroutchinina, Microfabricated Polycarbonate CE Devices for DNA Analysis, Anal. Chem., 2001, 73, 4196-4201.

14. Y. Wang, H. Chen, Q. He, S.A. Soper, A high-performance polycarbonate electrophoresis microchip with integrated three-electrode system for end-channel

amperometric detection, Electrophoresis, 2008, 29, 1881-1888.

15. X. Bai, C. Roussel, H. Jensen, H. H. Girault, Polyelectrolyte-modified short microchannel for cation separation, Electrophoresis, 2004, 25, 931-935

16. A.-L, Liu, F.-Y. He, Y.-H. Xia, Plastified poly (ethylene terephthalate) (PET)toner microfluidic chip by direct-printing integrated with electrochemical detection for pharmaceutical analysis, Talanta 2006, 68,1303-1308.

17. W. K. T. Coltro, J. A. F. da Silva., H. D. T. da Silva, E. M. Richter, R. Burlan, L. Angnes, C. L. do Lago, L. H. Mazo, E. Carrillo, Electrophoresis microchip fabricated by a directprinting process with end-channel amperometric detection, Electrophoresis, 2004, 25, 3832-3839.

18. C.S. Henry, M. Zhong, S.M. Lunte, M. Kim, H. Bau, J.J. Santiago, Ceramic microchips for capillary electrophoresis/electrochemistry, Anal. Commun., 1999, 36, 305-311.

19. N.E. Hebert, B. Synder, R.L. McCreery, W.G. Kuhr, S.A. Brazill, Performance of Pyrolyzed Photoresist Carbon Films in a Microchip Capillary Electrophoresis Device with Sinusoidal Voltammetric Detection, Anal. Chem., 2003, 75, 42654271.

20. G.R.M. Duarte, W.K.T. Coltro, J.C. Borba, C.W. Price, J.P. Landers, E. Carrilho, Disposable polyester-toner electrophoresis microchips for DNA analysis, Analyst, 2012, 137, 2692-2698.

21. B. Ziaie, A. Baldi, M. Lei, Y. Gu, R. A. Siegel, Hard and soft micromachining for BioMEMS: review of techniques and examples of applications in microfluidics and drug delivery., Adv. Drug Deliver. Rev., 2004, 56, 145-172.

22 M.-S. Kim, S.I. Cho, K.-N. Lee, Y-K. Kim, Fabrication of microchip electrophoresis devices and effects of channel surface properties on separation efficiency, Sens. Actuators B, 2005, 107, 818-824.

23. H. Fan, Z. Chen, L. Zhang, P.Yang, G-Chen, Fabrication and performance of Poly (methyl methacrylate) microfluidic chips with fiber cores, J. Chromatogr. A, 2008, 1179, 224-228.

24. A.J. Gawron, R.S. Martin, S.M. Lunte, Microchip electrophoretic separation systems for biomedical and pharmaceutical analysis, Eur. J. Pharm. Sci., 2001, 14, $1-12$. 
25 U. Bilitewski, M. Genrich, S. Kadow, G. Mersal, Biochemical analysis with microfluidic systems, Anal. Bioanal. Chem., 2003, 377, 556-569.

26. Bolsa de Cereales. Informe producción de cereales. 2010.

27. Bennett MD, Smith JB (1976) Nuclear DNA amounts in angiosperm. Philos Trans R Soc Lond Ser Biol Sci 274:227-274.

28. Gill KS, Gill BS, Endo TR, and Taylor T (1996b) Identification and highdensity mapping of gene rich regions in chromosome group 1 of wheat. Genetics 144: 1883-1891.)

29. Rodriguez Amieva PJ, tessi JL, Frecha JH y Vallega J (1961) Estimación de los daños producidos en la Argentina por las royas del tallo y de la hoja del trigo durante el periodo 1949-1958. Robigo 12:18-22.

30. Macagno LF, Pizarro JB, Cordone GE (1993) Dirección Nacional de Planificación. Publicación Miscelánea N4. INTA. Pág. 15-28.

31. Annone J, García R, Botta G, Ivancovich A (2001) Pérdidas de rendimiento ocasionadas por la "Roya de la Hoja" y la "Mancha Amarilla" del trigo: estimaciones en el norte de la Provincia de Buenos Aires. Revista de Tecnología agropecuaria Vol VI, Núm 16.

32. Hooker AL (1985) Corn and sorghum rusts. In: Roelfs A, Bushnell W (eds) The Cereal Rust. Academic Press, New York, pp 207-236.

33. Favret EA (1971) The host-pathogen system and its genetic relationship. Barley Genetics, Vol. II, 457:71.

34. Samborski DJ and Dyck PL (1968). Inheritance of virulence in wheat leaf rust on the standard differential wheat varieties. Can J Genet Cytol 10:24-32.

35. McIntosh RA, Welllings CR and Park RF (1995) Wheat rusts: an atlas of resistance genes. Ed. By Mc Intosh RA and Wellings CR and Park RF. Kluwer Academic publishers.

36. Samborski DJ (1985) Wheat leaf rust. In: Roelfs A, Bushnell W (eds) The cereal rusts. Academic Press, pp 39-59.

37. Feulliet C, Travella S, Stein N, Albar L, Nublat A, Keller B (2003) Molecular cloning of a new receptor like-kinase gene encoded at the Lr10 disease resistance locus of wheat. Plant J 11:45-52.

38. Huang L., Brooks SA, Li W, Fellers JP, Gill BS, Trick HN and Gill BS (2003) Map-Based Cloning of Leaf Rust Resistance Gene Lr21 From the Large and Poliploid Genome of Bread Wheat. Genetics 164: 655-664.

39. Cloutier S, McCallum BD, Loutre C., Banks TW, Wicker T, Feulliet C, Keller B, Jordan MC (2007). Leaf rust resistance gene 
Lr1, isolated from bread wheat (Triticum aestivum L.) is a member of the large psr567 gene family. Plant Mol Biol.

40. Krattinger SG, Lagudah ES, Spielmeyer W, Singh RP, Huerta-Espino J, McFadden H, Bossolini E, Selter LL, and Keller B (2009) A putative ABC transporter confers durable resistance to multiple fungal pathogens in wheat. Science 623: 1360-1363.

41. Moore JW, Herrera-Foessel S, Lan C, Schnippenkoetter W, Ayliffe M, HuertaEspino J, Lillemo M, Viccars L, Milne R, Periyannan S, Kong X, Spielmeyer W, Talbot M, Bariana H, Patrick JW, Dodds P, Singh R and Lagudah E. (2015) A recently evolved hexose transporter variant confers resistance to multiple pathogens in wheat. Nature Genetics, Advance On Line Publication.

42. Thind, A., Wicker, T., Šimková, H. et al. Rapid cloning of genes in hexaploid wheat using cultivar-specific long-range chromosome assembly. Nat Biotechnol 35, 793-796 (2017). https://doi.org/10.1038/nbt.3877

43. Favret EA, Saione HA, Franzone PM (1983) New approaches in breeding for disease resistance. Cereal breeding and production Symp. Argentina Special Report 718. Oregon State University.

44. Johnson R (1981) Durable resistance: definition of, genetic control, and attainment in plant breeding. Phytopathology 71:567-568.

45. Sacco F, Favret EA, Suarez EY, Solari RM, Saione HA (1995) Spontaneous genetic variation for leaf rust reaction in Sinvalocho MA wheat. J Phytopathol (Berl.) 143:251-255.

46. Haggag MEA, Samborski DJ and Dyck PL (1973) Genetics of pathogenicity in three races of leaf rust on four wheat varieties. Can J Genet Cytol 15:73:82.

47. Suárez EY, Favret EA (1984) Reaction to leaf rust of "Sinvalocho" wheat gene in hemizygous condition. Z PXanzenzuchtg 92:289-294.

48. Sacco F, Tranquilli G, Gorgoschidse L., Suarez EY (1992) Aminopeptidase B7: a centromere marker for chromosome 6B of wheat. Genome 35:261-263.

49. Diéguez MJ, Altieri E, Ingala LR, Perera E, Sacco F, Naranjo T (2006) Physical and genetic mapping of AFLPs and the leaf rust resistance Lr3 gene on chromosome 6BL of wheat. Theor Appl Genet 112(2):251-257.

50. Favret EA, Cenoz HP (1963) Análisis genético de una mutante resistente a la roya del tallo, obtenida en trigo. Robigo 14:18-20.

51. Röder MS, Korzum V, Wendehake K, Plashke J, Tixier MH, Leroy P, Ganal MW (1998) A microsatellite map of wheat. Genetics 149:2007-2023.

52. Song QJ, Shi JR, Singh S, Fickus W, Costa JM, Lewis J, Gill BS, Ward R and Cregan PB (2005) Development and mapping of microsatellite (SSR) markers in wheat. Theoretical and Applied Genetics 110:550-560. 
53. Somers DJ and Isaac P (2004) SSRs from the Wheat Microsatellite Consortium. wheat.pw.usda.gov/SSR/WMC.

54. Liu S, Zhang X, Pumphrey MO, Stack RW, Gill BS, Anderson JA (2006) Complex microcolinearity among wheat, rice, and barley revealed by fine mapping of the genomic region harboring a major QTL for resistance to Fusarium head blight in wheat. Functional \& Integrative Genomics 6: 83-89.

55. Xue S, Zhang Z, Lin F, Kong Z, Cao Y, Li C., Yi H, Mei M., Zhu H, Wu J, $\mathrm{Xu} \mathrm{H}$, Zhao D, Tian D, Zhang D and Ma Z (2008) A high-density intervarietal map of the wheat genome enriched with markers derived from expressed sequence tags. Theoretical and Applied Genetics 117: 181-189.

56. Hayden MJ, Stephenson P, Logojan AM, Khatkar D, Rogers C., Elsden J, Koebner MD, Snape JW and Sharpe PJ (2006) Development and genetic mapping of sequence-tagged microsatellite (STMs) in bread wheat (Triticum Aestivum L.). Theoretical and Applied Genetics 113: 1271-1281.

57. Vos P, Hogers R, Bleeker M., Reijans M, Van de Lee T, Hornes M, Friters A, Pot J, Paleman J, Kuiper M, Zabeau M (1995) AFLP: a new technique for DNA fingerprinting. Nucleic Acids Res 23:4407-4441.

58. Zhang W, Chao S, Manthey F, Chicaiza O, Brevis J. C., Echenique V, Dubcovsky J (2008) QTL analysis of pasta quality using a composite microsatellite and SNP map of durum wheat. Theoretical and Applied Genetics 117:1361-1377.

59. Zhang LiYi, DongCheng Liu, XiaoLi Guo, WenLong Yang, JiaZhu Sun, DaoWen Wang, Pierre Sourdille and AiMin Zhang (2011) Investigation of genetic diversity and population structure of common wheat cultivars in northern China using DArT markers. BMC Genetics 12:42 doi:10.1186/1471-2156-12-42.

60. Diéguez M. J, Pergolesi MF, Velasquez S M, Ingala L., López M, Darino M, Paux E, Feuillet C., Sacco F (2014) Fine mapping of LrSV2, a race-specific adult plant leaf rust resistance gene on wheat chromosome 3BS.Theoretical and Applied Genetics 127: 1133-1141.

61. Sacco F, Su.rez EY, Naranjo T (1998) Mapping of the leaf rust resistance gene Lr3 on chromosome 6B of Sinvalocho MA wheat. Genome 41:686-690.

62. Hart, A.C., Kramer, H., Zipursky, S.L. (1993). Extracellular domain of the boss transmembrane ligand acts as an antagonist of the sev receptor. Nature 361(6414): 732--736.

63. Martin G.B Chromosome landing. Trends Genet. 1995; 11: 63-68.

64. M S Röder, V Korzun, K Wendehake, J Plaschke, M H Tixier, P Leroy, M

W Ganal. A microsatellite map of wheat. Genetics. 1998 Aug; 149(4): 2007-2023. 
65. Morgante M. and Olivieri AM (1993) PCR-amplified microsatellites as markers in plant genetics. Plant J 3:175-182.

66. Ingala L., López M., Darino M, Pergolesi MF, Diéguez MJ, Sacco F (2012) Genetic analysis of leaf rust resistance genes and associated markers in the durable resistant wheat cultivar Sinvalocho MA. Theoretical and Applied Genetic DOI 10.1007/s00122-

012-1788-8.

67. Singh RP, Park RF, McIntosh RA (1999) Genetic relationship between the adult plant resistance gene Lr31 for seedling resistance to leaf rust in common wheat. Plant Pathol 48:567-573.

68. Singh S, Bowden R (2011) Molecular Mapping of adult-plant racespecific leaf rust resistance gene Lr12 in bread wheat. Mol Breed 28:137-142.

69. Petignat C (2010) Mapeo de marcadores moleculares y de un gen de resistencia a roya de la hoja de expresión en planta adulta en la región subtelomérica del cromosoma 3BS de Trigo. IGEAF. Tesis de licenciatura para optar el título de Licenciada en Ciencias Biológicas. Facultad de Ciencias Exactas y Naturales. Universidad de Buenos Aires.

70. Diéguez MJ, Petignat C, Ferella L, Fiorentino G, Silva M, Dabove MA, Rosero Yañez GI, López M, Pergolesi MF, Ingala L, Cuyeu AR, Sacco F. Mapping a gene on wheat chromosome 4BL involved in a complementary interaction with adult plant leaf rust resistance gene LrSV2. Theor. Appl Genet (2018) 131(11), 2333-2344 DOI 10.1007/s00122-018-3155-x.

71. Sourdille P, Singh S, Cadalen T, Brown-Guedira GL, Gay G, Qi LL, Gill BS, Dufour P, Murigneux A, Bernard M. (2004) Microsatellite- based deletion bin system for the establishment of geneticphysical map relationships in wheat

(Triticum aestivum L.). Funct Integr Genomics

4:12-25.

72. Kodak, Flexcel NX, 2017. https://www.kodak.com/uploadedFiles/ FlexcelNXCPlatesbrochure.pdf (Accessed 22, February 2018).

73. N. Bourguignon, C. Olmos, M. Sierra-Rodero, A. Peñaherrera, G. Rosero, P. Pineda, K. Vizuete, C. Arroyo, L. Cumbal, C. Lasorsa, M. Pérez, Betiana, Accessible and cost-effective method of PDMS microdevices fabrication using a reusable photopolymer mold, J. Polym. Sci. B 56 (2018) 1433-1442, https://doi.org/10.1002/polb.24726.

74. A. Peñaherrera, C. Payés, M. Sierra-Rodero, M. Vega, G. Rosero, B. Lerner,

G. Helguera, M.S. Pérez, Evaluation of cell culture in microfluidic chips for application in monoclonal antibody production, Microelectron. Eng. 158 (2016) 126-129, https://doi.org/10.1016/j.mee.2016.03.059.

75. J. G. E. Gardeniers, A. Van den Berg, Lab-on-a-chip systems for biomedical and environmental monitoring, Anal. Bioanal. Chem., 2004, 378, 1700-1703. 
76. A.J. Gawron, R.S. Martin, S.M. Lunte, Microchip electrophoretic separation systems for biomedical and pharmaceutical analysis, Eur. J. Pharm. Sci., 2001, 14, $1-12$.

77. U. Bilitewski, M. Genrich, S. Kadow, G. Mersal, Biochemical analysis with microfluidic systems, Anal. Bioanal. Chem., 2003, 377, 556-569.

\subsection{Anexos 1}

Genotipo de los marcadores flanqueantes para LrSV2 en 24 recombiates F2s del cruzo R46 x Si y la oxidacion fenotipica sobre P. triticina en la raza Ca02-G1R con la infección artificial de etapa adulta de su progenie F3.

\begin{tabular}{|c|c|c|c|c|c|c|}
\hline $\begin{array}{c}\text { RIL } 46 \text { X Relmo } \\
\text { Siriri }\end{array}$ & & & & & & \\
\hline $\mathrm{F} 2$ & & & \multirow{2}{*}{\multicolumn{2}{|c|}{$\begin{array}{l}\mathrm{F} 3 \\
\begin{array}{c}\mathrm{Ca} 02 \mathrm{G} 1 \mathrm{R} \text { (flag } \\
\text { leaf) }\end{array} \\
\end{array}$}} & \multirow[b]{3}{*}{ P 3:1 } & \multirow[b]{3}{*}{ P 9:7 } \\
\hline \multirow[t]{2}{*}{ Recombinante } & \multicolumn{2}{|c|}{$\begin{array}{c}\text { LrSV2-flanking markers } \\
\text { (3BS) }\end{array}$} & & & & \\
\hline & cfb3417 & gwm533 & $\mathrm{R}$ & $\mathrm{S}$ & & \\
\hline s3 & $\mathrm{H}$ & 0 & 0 & 18 & $<0,001$ & $<0,001$ \\
\hline s11 & 1 & $\mathrm{H}$ & 0 & 15 & $<0,001$ & $<0,001$ \\
\hline s35 & 0 & $\mathrm{H}$ & 0 & 19 & $<0,001$ & $<0,001$ \\
\hline s65 & $\mathrm{H}$ & 0 & 0 & 17 & $<0,001$ & $<0,001$ \\
\hline s83 & $\mathrm{H}$ & 1 & 0 & 19 & $<0,001$ & $<0,001$ \\
\hline s88 & 0 & $\mathrm{H}$ & 0 & 18 & $<0,001$ & $<0,001$ \\
\hline s104 & 0 & $\mathrm{H}$ & 7 & 9 & $<0,01$ & 0,23 \\
\hline s155 & $\mathrm{H}$ & 1 & 11 & 7 & 0,14 & 0,43 \\
\hline s167 & $\mathrm{H}$ & 1 & 13 & 3 & 0,41 & $<0,05$ \\
\hline s191 & $\mathrm{H}$ & 1 & 15 & 4 & 0,47 & $<0,05$ \\
\hline s240 & $\mathrm{H}$ & 1 & 13 & 7 & 0,21 & 0,28 \\
\hline s263 & $\mathrm{H}$ & 1 & 0 & 17 & $<0,001$ & $<0,001$ \\
\hline s283 & 0 & $\mathrm{H}$ & 0 & 19 & $<0,001$ & $<0,001$ \\
\hline s298 & $\mathrm{H}$ & 1 & 17 & 0 & $<0,01$ & $<0,001$ \\
\hline s299 & $\mathrm{H}$ & 0 & 0 & 18 & $<0,001$ & $<0,001$ \\
\hline s313 & $\mathrm{H}$ & 1 & 13 & 7 & 0,21 & 0,28 \\
\hline s369 & $\mathrm{H}$ & 1 & 20 & 0 & $<0,01$ & $<0,001$ \\
\hline s408 & 0 & $\mathrm{H}$ & 0 & 20 & $<0,001$ & $<0,001$ \\
\hline s411 & $\mathrm{H}$ & 1 & 0 & 18 & $<0,001$ & $<0,001$ \\
\hline s437 & $\mathrm{H}$ & 1 & 19 & 0 & $<0,01$ & $<0,001$ \\
\hline s441 & 1 & $\mathrm{H}$ & 12 & 5 & 0,43 & 0,17 \\
\hline s462 & 0 & $\mathrm{H}$ & 8 & 5 & 0,21 & 0,46 \\
\hline s483 & $\mathrm{H}$ & 0 & 0 & 19 & $<0,001$ & $<0,001$ \\
\hline s509 & $\mathrm{H}$ & 1 & 14 & 5 & 0,53 & 0,09 \\
\hline
\end{tabular}

1: R46 alelo, 0: Si alelo, H: heterocigoto, R: resistante, S: susceptible. p: probabilidad para un valor binomial de prueba de extactitud 


\subsection{Capitulo VII.}

\section{Conclusiones Generales}


En este trabajo de tesis se han explorado las propiedades de la ingeniería de materiales para investigar una novedosa forma de elaborar moldes maestros para la fabricación de dispositivos de microfluídica que podrían ser aplicadas en una variedad de áreas de investigación, donde un aspecto crítico es seleccionar una metodología de construcción de moldes para fabricar microdispositivos PDMS. En el capitulo II se demostró que el ERMold podría considerarse una buena opción para obtener réplicas de PDMS con topologías deseadas. Sorprendentemente, la metodología propuesta aquí permite fabricar moldes reutilizables con alta capacidad de replicación y que contiene estructuras que van de micrones a los milímetros. La funcionalidad y versatilidad de la metodología ha sido demostrada con éxito fabricando varias topologías microfluídicas.

La utilización de una resina epoxi constituye una alternativa de menor costo que la resina SU-8 sobre oblea de silicio que se utiliza tradicionalmente. Consecuentemente, esta tecnología contribuye positivamente a la evolución en el campo de la microfluídica ya que posibilita a los laboratorios de países en vías de desarrollo integrar a la microfluídica a sus estudios sin necesidad de un cuarto limpio (cleanroom). Resulta pertinente mencionar que los resultados del capítulo 2 fueron publicados en la revista científica indexada Sensors and Actuators B: Chemical (https://doi.org/10.1016/j.snb.2019.03.062)

Los resultados del capítulo III demostraron como el estudio de los perfiles de evolución de las corrientes han puesto en evidencia que es posible la fabricación de poros de forma controlada. Se encontró que las condiciones de voltaje, reactivos y temperaturas aplicadas durante el proceso de formación influyen sobre características relevantes de la fabricación, determinándose las condiciones óptimas para una temperatura de $84{ }^{\circ} \mathrm{C}$ y $\mathrm{HCl}$ como agente de frenado. Por el contrario, bajo condiciones de temperatura a $65^{\circ} \mathrm{C}$ no se genera un ataque eficiente de la superficie del silicio y por tanto no es posible obtener poros en esta situación. Finalmente, el análisis de la evolución de las corrientes del proceso para condiciones óptimas de la fabricación permite caracterizar la formación 
macroporos y ofrece un mecanismo altamente funcional para el control de su tamaño.

En general el trabajo ofrece las siguientes posibilidades:

1. Caracterizar el proceso de fabricación de macroporos bajo las condiciones establecidas.

2. Determinar condiciones óptimas de fabricación de macroporos

3. Provee una metodología económica, fácil y versátil para la fabricación de macroporos.

4. Lo anterior da lugar a la extrapolación y adecuación del procedimiento en una metodología que permite la fabricación de nanoporos, generando así una herramienta de utilidad para el desarrollo tecnológico, tanto de la medicina como de la biología.

Estos resultados fueron publicados en la revista Matéria Rio J. (https://doi.org/10.1590/s1517-707620180002.0461.)

En el capítulo IV se logró la integración de un microporo en estado sólido entre un canal de microfluidos multicapa para la detección y el conteo de células. Dos fabricaciones económicas y accesibles fueron presentadas para fabricar los microporos y Microcanales PDMS. Los microporos de diferentes tamaños fueron obtenido por grabado directo bajo la concentración de agente de $50 \%$ en peso de $\mathrm{KOH}$, temperaturas $(40,60,80 \mathrm{C})$ y voltajes $(100,500,1000 \mathrm{mV})$. Se comprobó que el perfil eléctrico depende del voltaje y la temperatura, mientras que la concentración del agente de ataque influye en las características morfológicas superficiales del poro. La caída de presión, esfuerzo cortante, parámetros de viscosidades de fluidos y tasas de flujo en cálculo mediante la simulación los cuales permitieron encontrar las condiciones óptimas para realizar la detección celular evitando el daño o deformación celular. Por otro lado, la fabricación del microporo fue factible sin ser necesarias la litografía y equipos costosos como FIB para la fabricación de los microporos de estado sólido. La integración de multicapa con un solo microporo fue posible para la detección y recuento celular y permitirá el desarrollo de nuevas ideas y trabajos utilizando esta tecnología. Estos resultados fueron publicados en la revista RSC Advances (DOI: 10.1039/c9ra09939e). 
En el capítulo V los resultados confirmaron la utilidad de LOC como un método eficaz para la cuantificación de las dosis de fármacos de: células vivas, muertas, autófagas y apoptóticas. LOC permitió comparar dos tratamientos diferentes para las células del cáncer de mama. El tratamiento metronómico (LDM) reportó una disminución considerable en el porcentaje global de células vivas y un aumento en las células sometidas a PA con respecto a los controles. En conclusión, los dispositivos LOC no solo tienen las ventajas ya conocidas, sino que también son una herramienta poderosa, ya que solo requieren pequeñas cantidades de reactivos y pueden usarse bajo parámetros de cultivo específicos. Los dispositivos LOC podrían considerarse como una tecnología novedosa para ser utilizada como complemento o reemplazo de los estudios tradicionales sobre dosis metronómicas de fármacos con diferentes tratamientos y esquemas. Cabe recalcar que los resultados de esta investigación han sido publicados en un preprint BioRxvi (doi: https://doi.org/10.1101/2020.07.16.188748) y actualmente están ya sumitidos a la revista PLUSONE.

En el desarrollo del Capítulo VI El objetivo fue identificar otros recombinantes dentro del intervalo genético que contiene LrSV2 entre la población F2 de Si $\times$ R46 y el RIL y F2 poblaciones de $\mathrm{SV} \times \mathrm{P}$ mediante el uso de moléculas flanqueantes marcadores. Esto llevó a la identificación y mapeo de un gen complementario que interactúa con LrSV2. Este trabajo destaca la importancia de analizar diferentes cruces para descubrir interacciones genéticas entre genes no ligados. Estos resultados fueron publicados en la revista Theor Appl Genet (https://doi.org/10.1007/s00122-018-3155-x). Además, se desarrolló con éxito la primera generación de dispositivos de microfluídica para marcadores asociados a genes de resistencia a la roya de la hoja del trigo. Y que será necesario continuar optimizando el proceso, demostrando que el trabajo generará futuros trabajos, así como continuidad a las ideas presentadas.

Finalmente, el trabajo presentado permitirá con la nueva tecnología de fabricación, una nueva generación de dispositivos, para una amplia variedad de aplicaciones, 
permitiendo el desarrollo de nuevos trabajos; tesis a bajos costos y fácil implementación de esta tecnología en cualquier laboratorio.

El trabajo de mesada en el laboratorio, así como los experimentos ejecutados han dado como resultado copiosas publicaciones y han proporcionado nuevas ideas que se están desarrollando actualmente y las cuales están próximas a enviar para evaluación. Por todo lo mencionado anteriormente se considera que este trabajo de tesis ha finalizado exitosamente, alcanzando extensamente los objetivos planteados a su inicio. 